\title{
Charakterisierung eines neuen Proteins, Mapl-1 und seine Rolle in der Regulation der Pax6-Funktion
}

\author{
Dissertation \\ zur Erlangung des Doktorgrades \\ der Mathematisch-Naturwisseschaftlichen Fakultäten \\ der Georg-August-Universität zu Göttingen
}

vorgelegt von

Petros Petrou

aus

Famagusta / Zypern

Göttingen, 2001 
D7

Referent: $\quad$ Prof. Dr. Peter Gruss

Korreferent: $\quad$ Dr. Sigrid Hoyer-Fender

Tag der mündlichen Prüfung: 01.11.2001 


\section{Inhaltsverzeichnis}

\section{Einleitung}

1.1 Konservierte Mechanismen der Musterbildung kontrollieren

die Etablierung des embryonalen Bauplans bei Metazoen ............................................

1.2 Entdeckung der Homeo- und Paired-Domäne.........................................................4

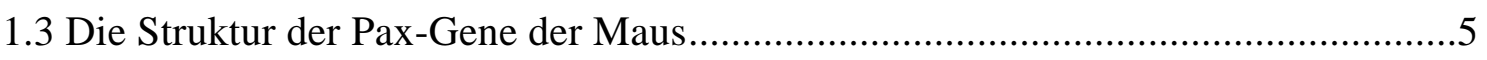

1.4 Pax-Gene und ihre Rolle in der Embryonalentwicklung ......................................

1.5 Pax-6 und seine Rolle in der Embryonalentwicklung ....................................... 8

1.6 Biochemische Eigenschaften der Pax-Proteine .................................................10

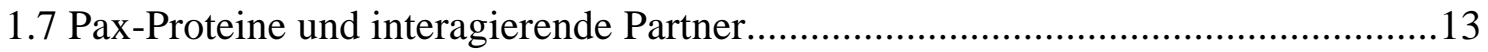

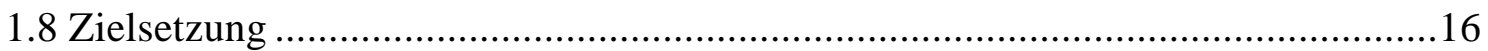

\section{Ergebnisse}

2.1 Mapl-1 als potentieller Pax6-Interaktionspartner .............................................

2.2 Klonierung und Charakterisierung der mapl-1 cDNA.......................................... 18

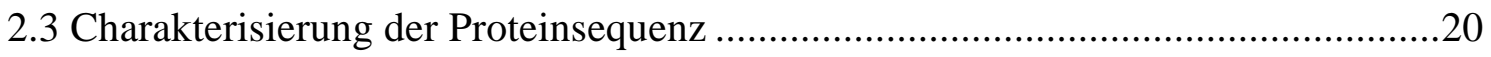

2.4 Chromosomale Kartierung von mapl-1 in der Maus .........................................21

2.5 Mapl-1-ähnliche Proteine in der Maus und anderen Spezies .................................22

2.6 Expressionsmuster von mapl-1 im Vergleich zur Pax-6-Expression

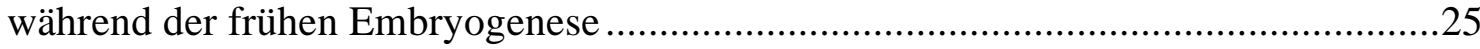

2.7 Expression von mapl-1 folgt der Pax-6-Expression

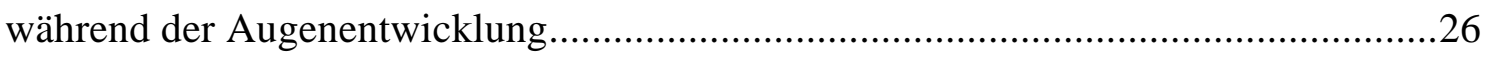

2.8 Expression von Pax-6 und mapl-1 in komplementären Domänen .........................28

2.9 Mapl-1 Expression in fortgeschrittenen Entwicklungsstadien ..............................29

2.10 Weitere mapl-1 Expressionsdomänen........................................................... 31 
2.11 Die Paired-Domäne von Pax-6 als interagierende Region..................................32

2.12 Interaktion zwischen Pax-6 und Mapl-1 in vivo ...................................................34

2.13 Subzelluläre Lokalisation des Mapl-1 Proteins .....................................................35

2.14 Effekt der Mapl-1 Überexpression auf die anderen Filamente des Cytoskeletts ....37

2.15 Die Überexpression von Mapl-1 führt zu erhöhter Stabilität

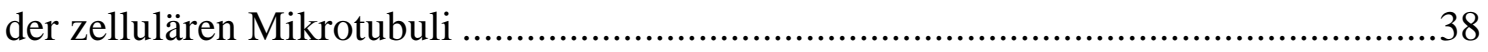

2.16 Mapl-1 bindet direkt an Mikrotubuli in vitro ................................................ 41

2.17 Der Carboxyterminus von Mapl-1 als neue Mikrotubuli-bindende Domäne .........41

2.18 Mapl-1 ist in der Lage, Homodimere zu bilden ...............................................44

2.19 Überexpression von Mapl-1 führt zur Retention von Pax-6,

aber nicht von Pax-2 an zellulären Mikrotubuli........................................................45

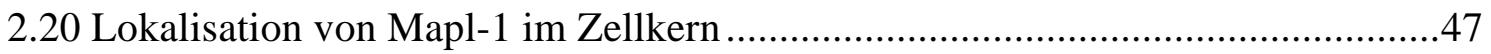

2.21 Regulation der zellulären Lokalisation von Mapl-1

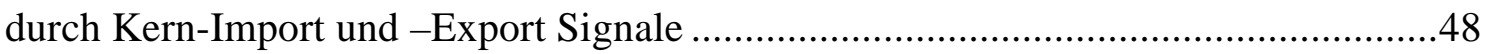

2.22 Herstellung eines polyklonalen Antiserums

und Detektion des endogenen Mapl-1 Proteins .......................................................50

2.23 Der Carboxyterminus von Mapl-1 als Transkriptions-Aktivierungsdomäne...........52

2.24 Mapl-1 konkurriert mit DNA um die Bindung an Pax-6 ...................................53

2.25 Überexpression von Mapl-1 in transgenen Mäusen ..........................................55

2.26 In vivo Elektroporation von Mapl-1 in Mausembryonen ...................................57

\section{Diskussion}

3.1 Protein-Protein Interaktionen als Mechanismus zur Erhöhung der biologischen Diversität von Pax-Proteinen......................................................61

3.2 Mapl-1 definiert eine neue Familie von Proteinen .............................................62

3.3 Mapl-1 und seine Funktion als neues Mikrotubuli-assoziiertes Protein ...................63

3.4 Die Funktion von Mikrotubuli und MAPs im Nervensystem ...............................65

3.5 Regulation der zellulären Lokalisation von Mapl-1 ..........................................66 


\section{Material und Methoden}

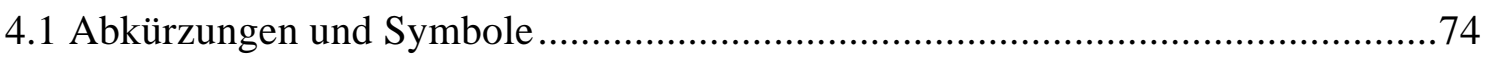

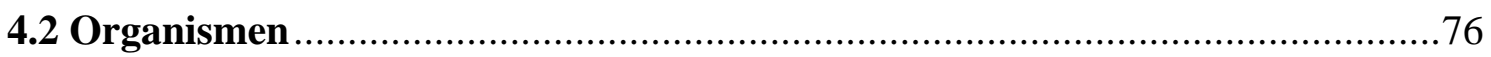

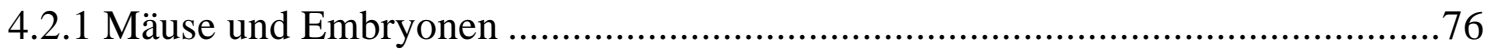

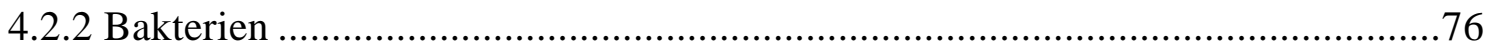

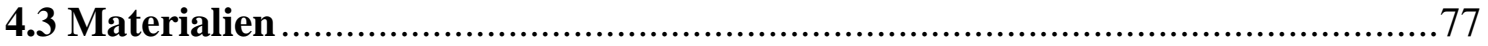

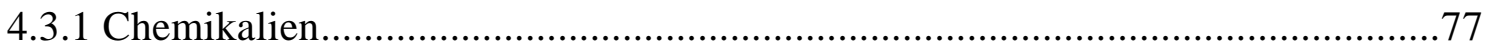

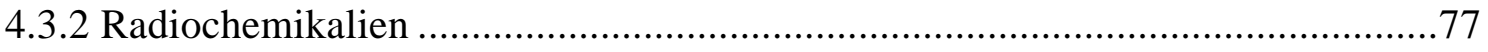

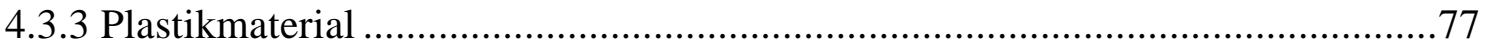

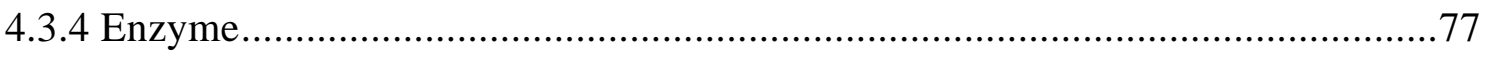

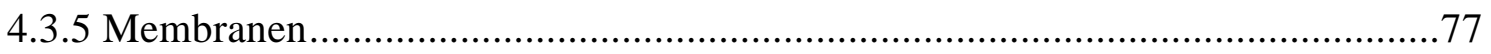

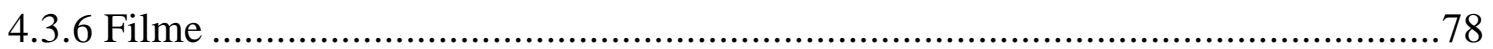

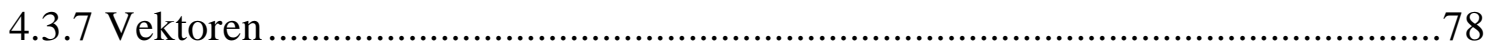

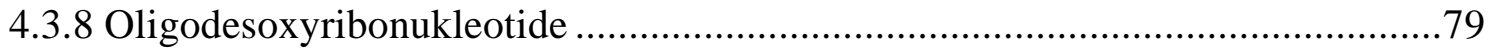

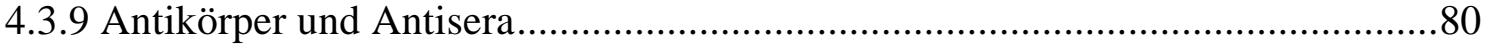

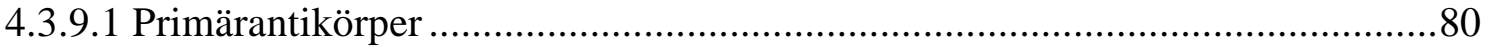

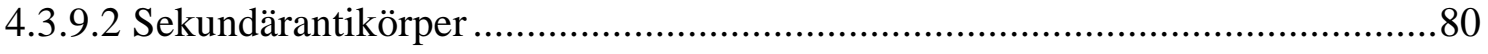

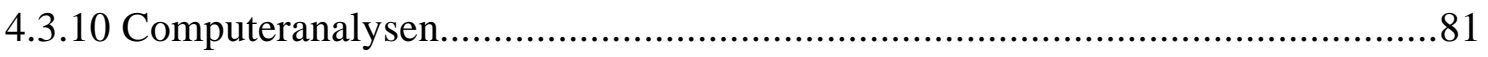

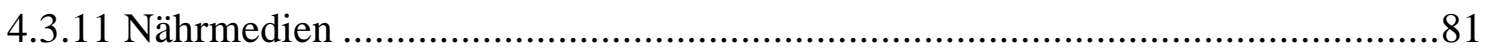

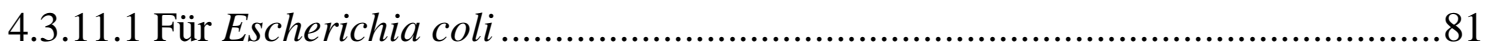

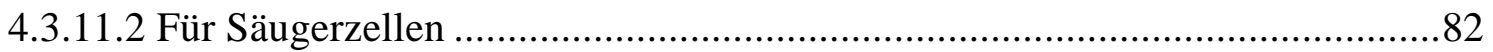

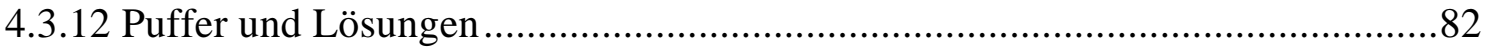

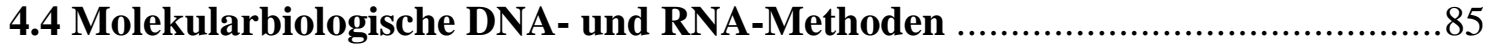

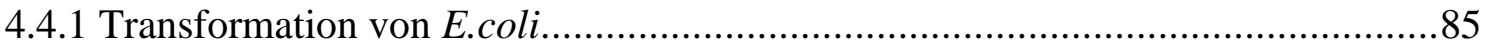

4.4.1.1 Präparation von Bakterien für Elektroporation (Elektrotransformation) ............85

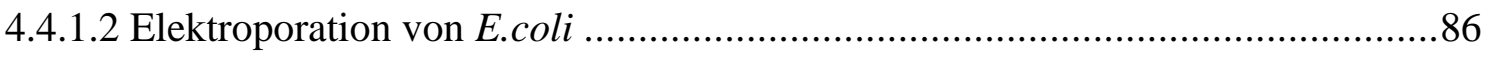


4.4.2 Lagerung von E.coli Stämmen .86

4.4.3 Isolierung von Plasmid-DNA aus E. coli in analytischen Mengen .86

4.4.4 Isolierung von Plasmid-DNA aus E. coli in präparativen Mengen .87

4.4.5 Spaltung von DNA mit Restriktionsendonukleasen ...................................... 87

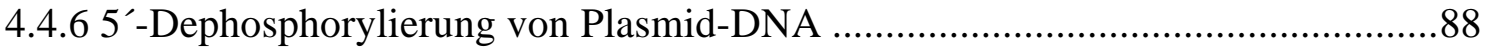

4.4.7 Auffüllen von 5'-überhängenden Enden zur Erzeugung von „blunt’-Enden ........88

4.4.8 Amplifikation von DNA Fragmenten mittels der Polymerase-Ketten-Reaktion...89

4.4.9 Ligation von DNA-Enden zu zirkulären Produkten .89

4.4.10 Markierung von DNA-Fragmenten mit $[\alpha]^{32} \mathrm{P}-\mathrm{dCTP}$. .90

4.4.11 Fällung von DNA mit Ethanol. .90

4.4.12 Phenolextraktion .91

4.4.13 Isolierung und Reinigung von DNA-Fragmenten aus Agarose-Gelen .91

4.4.14 Agarosegelelektrophorese 91

4.4.15 Konzentrationsbestimmung von Nukleinsäuren .92

4.4.16 Sequenzanalyse von DNA. .92

4.4.17 Northern Hybridisierung .92

4.4.18 Genotypisierung durch Southern-Hybridisierung. .94

4.4.19 Durchmusterung von Phagenbibliotheken .95

4.5 Proteinchemische Methoden .98

4.5.1 SDS-Polyacrylamidgelelektrophorese (SDS-PAGE) von Proteinen 98

4.5.2 Transfer von Proteinen auf Membranen („Western-Blot”) 99

4.5.3 Immunochemische Detektion von auf Membranen transferierten Proteinen.......100

4.5.4 Färbung von Proteinen mit „Coomasie Brilliant Blue” ..................................... 100

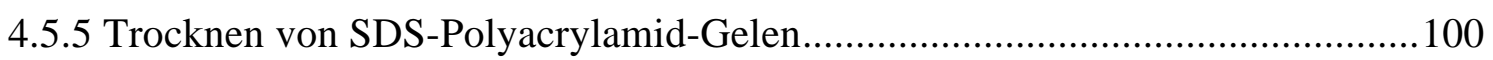

4.5.6 In vitro-Transkription-Translation von klonierter cDNA

in Kaninchen-Retikulocyten-Lysaten 101

4.5.7 Produktion in E.coli und Reinigung von GST und GST-Fusionsproteinen..... 101

4.5.7.1 Produktion der Proteine in analytischen Mengen 101 
4.5.7.2 Produktion der Proteine in präparativen Mengen .......................................... 102

4.5.8 In vitro Protein-Protein-Interaktionstest (GST-,,Pull-down“) ............................. 103

4.5.9 Herstellung eines polyklonalen anti-Mapl-1 Serums...................................... 104

4.5.10 Affinitätsreinigung des polyklonalen Antiserums ....................................... 105

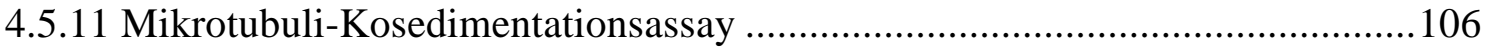

4.5.12 Elektrophoretisches Gelretardationsexperiment (,,Band shift $\left.{ }^{*}\right)$........................106

4.6 Zellbiologische und embryologische Methoden ........................................ 108

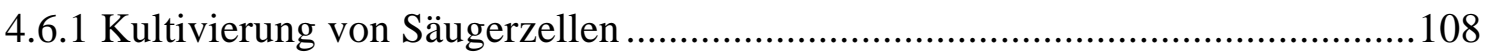

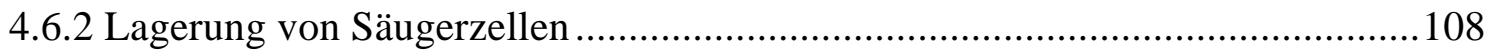

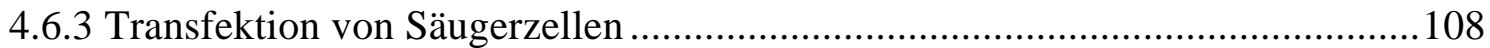

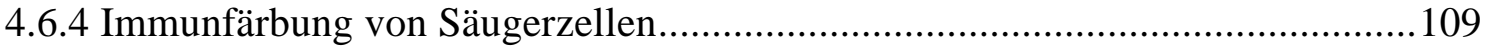

4.6.5 Quantitative Messung von Enzymaktivitäten in transfizierten Zellen.................110

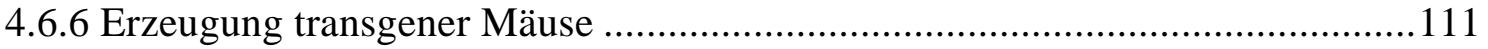

4.6.7 In vivo-Elektroporation von Mausembryonen...............................................111

4.6.8 Anfertigung von Gefrierschnitten und Immunfärbung ..................................111

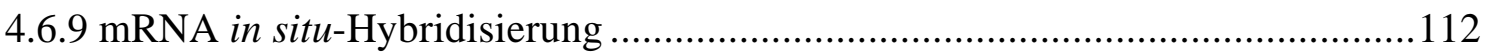

4.6.9.1 In situ-Hybridisierung von Ganzpräparaten (,,whole-mount“) ........................112

4.6.9.2 In situ-Hybridisierung auf Paraffinschnitten ...............................................117

4.6.10 Chromosomale Kartierung mittels

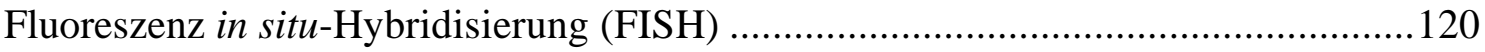

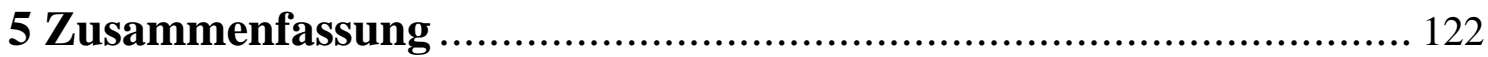

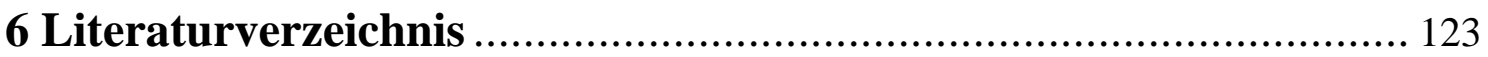

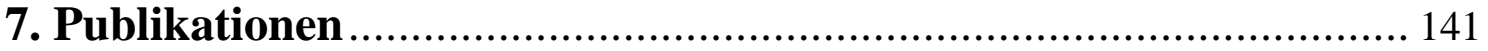

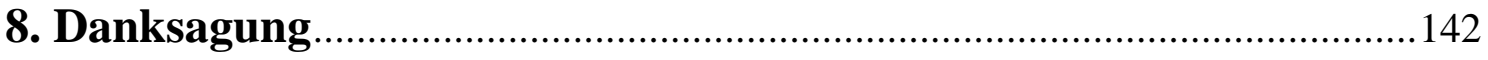

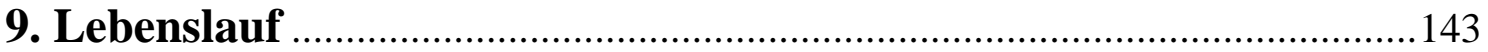




\section{Einleitung}

\subsection{Konservierte Mechanismen der Musterbildung kontrollieren die Etablierung des embryonalen Bauplans bei Metazoen}

Fast alle Metazoen beginnen ihre Entwicklung als befruchtete Eizelle oder Zygote. Während der Embryogenese entsteht aus diesem Einzellstadium eine erstaunliche Vielfalt an Lebensarten und komplizierten Körperbauplänen. Interessanterweise haben Fortschritte auf dem Gebiet der molekularen Entwicklungsbiologie gezeigt, daß Tiere trotz der Unterschiede in ihrer Gestalt und Komplexität vergleichbarer sind als zunächst angenommen wurde. So konnte nach einer Reihe von Untersuchungen demonstriert werden, daß bei allen bilateralsymmetrischen Tieren, einschließlich des Menschen, ein gemeinsamer Mechanismus zur Etablierung der embryonalen anteroposterioren Achse existiert. Verantwortlich dafür sind die Hox-Gene. Sie wurden in der Fruchtfliege Drosophila melanogaster anhand von Mutationen entdeckt, die zu homeotischen Transformationen geführt haben (Kaufman et al., 1980; Lewis, 1978). Die Hox-Gene sind in Genkomplexen angeordnet und kommen bei allen bilateralsymmetrischen Tieren vor. Hox-Gene sind so organisiert, daß auch die Anordnung und Position von homologen Genen zwischen verschiedenen Spezies erhalten geblieben ist. Interessanterweise korreliert die lineare Anordnung der Hox-Gene auf dem Chromosom mit der Reihenfolge ihrer Aktivierung und mit der anterioren Grenze ihrer Expression während der Embryonalentwicklung (Zákány and Duboule, 1999).

Zusätzlich zum Mechanismus der Musterbildung entlang der anteroposterioren Achse, existieren zwischen Vertebraten und Invertebraten weitere Ähnlichkeiten im Bauplan des Körpers, denen gemeinsame konservierte genetische Prozesse zugrunde liegen. So existieren sowohl bei Drosophila als auch bei höheren Säugetieren Organe wie die Augen, die trotz ihrer unterschiedlichen Gestalt ähnliche Funktionen ausüben. Solche Strukturen wurden ursprünglich als analog bezeichnet, da man angenommen hat, daß verschiedene genetische Mechanismen für ihre Spezifizierung verantwortlich sind (Raff and Raff, 1985; von Salvini- 
Plawen and Mayr, 1977; Willmer, 1990). Anhand des heutigen Kenntnisstands jedoch, kann man von homologen Organen sprechen da verwandte Gennetzwerke ihre Entwicklung steuern (zum Überblick, Veraksa et al., 2000).

Es ist also möglich, durch komparative Studien von Tiermodellsystemen Erkentnisse zu gewinnen über die genetischen Mechanismen, welche die frühe Entwicklung des Menschen regulieren. Dies stellt nach der Vollendung der Sequenzierung des menschlichen Genoms (Venter, G. et.al. 2001; Int. Genome Sequencing consort.) die große Herausforderung dar. Zwischen den verschiedenen Tiermodellen ragt besonders die Maus heraus, welche das am besten analysierte und für genetische Manipulationen zugängliche Säugetier ist (Capecchi, 1989).

\subsection{Entdeckung der Homeo- und Paired-Domäne}

Die Entdeckung der Homeo- und Paired-Box geht auf Mutantenanalysen zurück, die in der Fruchtfliege Drosophila melanogaster durchgeführt wurden (Nüsslein-Volhard and Wieschaus, 1980). Dabei wurde nach Mutanten gesucht, bei denen die Etablierung der zwei embryonalen Hauptachsen (anteroposterior und dorsoventral) oder das metamere Segmetierungmuster der Larve beeinträchtigt war. Ziel war es, Gene zu identifizieren, welche die frühe Entwicklung der Fliege steuern. Anhand ihres Phänotyps wurden die Fliegenmutanten als „gap“, ,pair-rule“ oder „,segment polarity“ klassifiziert. Die anschließende Identifizierung und Charakterisierung der Gene, in denen Mutationen zu den beobachteten Phänotypen geführt haben, ergab, daß eine Mehrzahl für Transkriptionsfaktoren kodierten. So wurde zuerst bei den homeotischen Genen des Bithorax- und AntennapediaKomplexes der Fliege, welche die Homologen der Hox-Gene der Vertebraten darstellen, ein gemeinsames Sequenzmotiv, die Homeobox entdeckt (McGinnis et al., 1984; Scott and Weiner, 1984). Es handelt sich um eine hochkonservierte Nukleotidsequenz, die für eine Protein-Domäne von 61 Aminosäuren kodiert, die sequenzspezifische Bindung an DNA vermittelt. Die Homeodomäne setzt sich aus drei $\alpha$-Helices zusammen, die von Schleifen getrennt und um einen hydrophoben Kern gefaltet sind, sowie aus einer flexiblen aminoterminalen Region (Billeter et al., 1990; Philips et al., 1991; Qian et al., 1989; Qian et $a l .$, 1994). Der carboxyterminale Teil der Homeodomäne ähnelt dem Helix-Schleife-HelixMotiv, mit dem viele prokaryotischen Proteine an DNA binden (Laughon and Scott, 1984; 
Pabo and Sauer, 1984). Tatsächlich hat sich aus NMR- und röntgenkrystallographischen Analysen von Homeodomänen aus Drosophila, (Kissinger et al., 1990; Otting et al., 1988; Qian et al., 1993) Hefe (Wolberger et al., 1991) und dem Menschen (Klemm et al., 1994) bestätigt, daß bei der Interaktion zwischen Homeodomäne und DNA die dritte Helix der Homeodomäne in der großen Furche der DNA eingeführt wird, während die aminoterminale Region mit der darrauffolgenden kleinen Furche der DNA Kontakte etabliert. Darüberhinaus ist die dritte Helix der Homeodomäne der Erkennungshelix von prokaryotischen DNAbindenden Proteinen funktionell ähnlich. Ausgehend von der Schlüsselrolle von HomeoboxGenen in der Entwicklung der Fliege und der Konservierung von Entwicklungsprozessen zwischen Invertebraten und Vertebraten, wurde intensiv in anderen Eukaryoten nach Homeobox-Genen gesucht. Heute sind hunderte von Homeobox-Genen in veschiedenen Organismen von der Hefe bis zur Maus und dem Menschen bekannt (Duboule, 1994; Stein et al., 1996).

\subsection{Die Struktur der Pax-Gene der Maus}

Ein zweites Motiv, das ebenfalls zuerst bei Drosophila-Genen entdeckt wurde, ist die PairedBox, die für eine Protein-Domäne von 128 Aminosäuren kodiert. Namensgebend für diese konservierte Domäne war das Segmentierungsgen paired. Erst die Charakterisierung von zwei weiteren Drosophila-Genen aus dem gooseberry-Locus, gooseberry-proximal (gsb-p) und gooseberry-distal ( $g s b-d$ ) (Bopp et al., 1986) zeigte, daß diese Gene zwei mit paired gemeinsame Sequenzmotive enthalten. Es handelt sich einerseits um die Paired-Box und andererseits um eine Homeobox, die in bestimmten Positionen von der Homeobox der Antennapedia- und der Bithorax-Gene abweicht. Zwei weitere Gene der Fliege Pox-meso und Pox-neuro wurden als Paired-Box Gene identifiziert. Im Gegensatz zu paired enthielten diese Gene keine Homeobox (Bopp et al., 1989).

Der Entdeckung der Paired-Box in Drosophila folgte die Suche nach Paired-Box Genen im Genom von anderen Organismen. In der Maus und im Menschen sind heute neun Paired-BoxGene bekannt (Pax-1 bis Pax-9) (zum Überblick, Chalepakis et al., 1993; Dahl et al., 1997; Mansouri et al., 1999; Underhill, 2000; Walther et al., 1991b). Paired-Box Gene wurden ebenfalls aus einer Vielzahl von Genomen anderer Metazoen kloniert wie Nematoden, Arthropoden und Vertebraten. Pax-Gene wurden sogar in primitiveren Metazoen identifiziert wie in Porifera (Schwämme) und Anthozoen (Korallentiere) (Groger et al., 2000; Hoshiyama 
et al., 1998; Miller et al., 2000; Sun et al., 1997). Es handelt sich also um Gene, die sehr früh in der Evolution entstanden sind und die im Tierreich der Vielzeller konserviert sind.

Allen Pax-Proteinen ist die Paired-Domäne gemeinsam, die immer aminoterminal liegt und das längste Strukturmotiv in dieser Genfamilie darstellt. Zusätzlich enthalten einige der PaxGene, ähnlich wie das Gen paired von Drosophila, eine Homeobox. Die in den Paired-BoxGenen enthaltene Homeobox wird als Paired-Typ-Homeobox bezeichnet. Ein weiteres charakteristisches Motiv in dieser Proteinfamilie ist das Oktapeptid, das nicht bei allen PaxProteinen vorkommt und zwischen der Paired- und der Homeodomäne lokalisiert ist. Anhand ihrer genomischen Organisation, ihrer Sequenzähnlichkeit innerhalb der Paired-Domäne, sowie den Ähnlichkeiten und Unterschieden in der Primärstruktur der davon kodierenden Proteinen, wurden die Pax-Gene in vier Klassen eingeteilt (Abb.1). So sind bei Pax-3 und Pax-7 alle drei konservierten Sequenzmotive vorhanden (Paired-Domäne, Oktapeptid, Homeodomäne), bei Pax-4 und Pax-6 fehlt das Oktapeptid, Pax-1 und Pax-9 enthalten keine Homeodomäne, während bei Pax-2, Pax-5 und Pax-8 nur ein Teil der Homeodomäne noch vorhanden ist der die erste $\alpha$-Helix umfaßt (Abb.1).

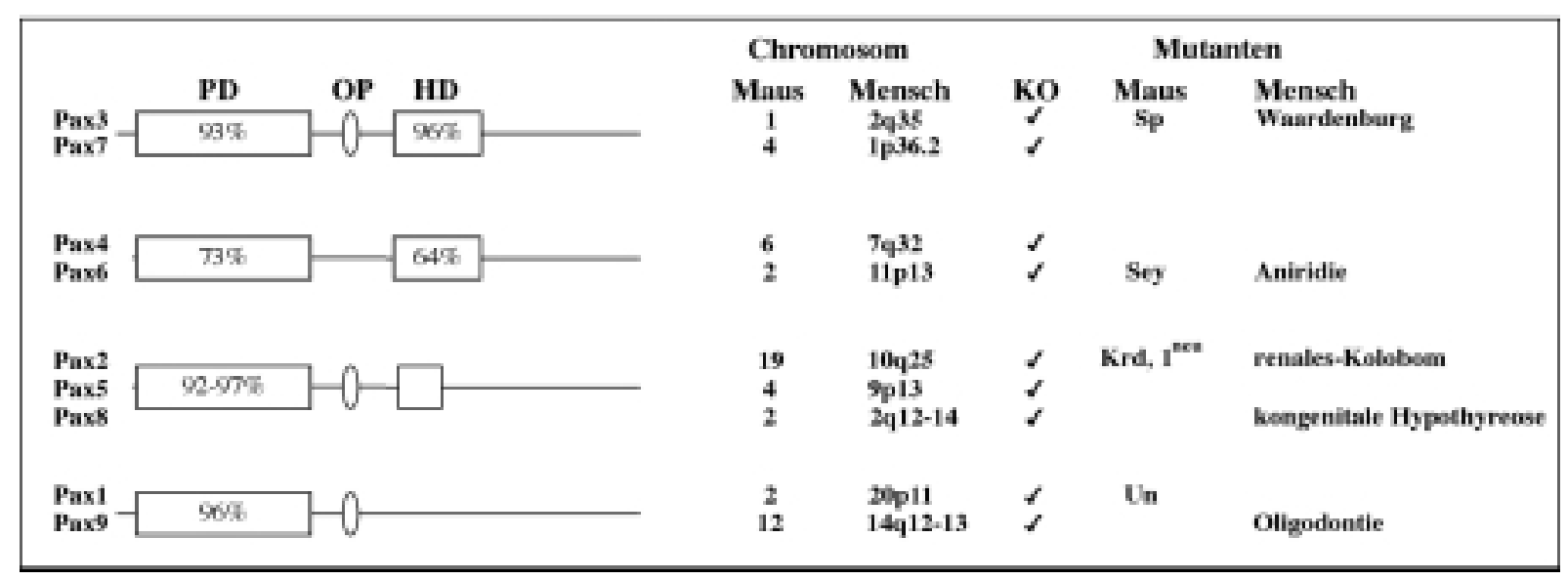

\section{Abbildung 1}

Die Familie der Pax-Gene bei Säugern. Die neun Gene, die zur Pax-Familie gehören werden in vier Unterklassen eingeteilt. Schematisch dargestellt sind die Paired-Domäne (PD), die Paired-Typ-Homeodomäne (HD) sowie das Oktapeptid (OP). Die prozentualen Angaben beziehen sich auf die Aminosäureidentität innerhalb der bestimmten Domäne der Pax-Proteine, die zur gleichen Unterklasse gehören. Angegeben ist die chromosomale Lokalisation der Pax-Gene im Maus- und im menschlichen Genom. Aufgeführt werden natürlich vorkommende Mutationen und Krankheitssyndrome, die in Verbindung zu den Pax-Loci stehen. In der Maus wurden diese phänotypische Effekte durch Geninaktivierungsstudien (KO) bestätigt. 


\subsection{Pax-Gene und ihre Rolle in der Embryonalentwicklung}

Alle Pax-Gene werden während der Embryonalentwicklung in einem spezifischen räumlichen und zeitlichen Muster exprimiert, wobei alle mit Ausnahme von Pax-1 und Pax-9 im sich entwickelnden zentralen Nervensystem aktiv sind (Stoykova and Gruss, 1994). Ihre Expression beginnt zwischen Tag 8 und 9,5 der Embryonalentwicklung. Erste Hinweise auf eine vermutliche Rolle der $P a x$-Gene während der Embryonalentwicklung und der Organogenese lieferte die Korrelation von bekannten Mausmutanten, die einen semidominanten Phänotyp aufwiesen mit molekularen Defekten in Pax-Genloci. Der Undulated (Un)-Phänotyp in der Maus, der durch einen geknickten Schwanz gekennzeichnet ist wurde mit einer heterozygoten Mutation in Pax-1 korreliert. Homozygote Mutanten weisen Skelettanomalien auf, die auf die fehlerhafte Musterbildung des Sklerotoms, in dem Pax-1 exprimiert ist, zurückzuführen sind (Balling et al., 1988). Die Mutation, die für die Ausprägung des $U n$-Phänotyps verantwortlich ist führt $\mathrm{zu}$ einem einzigen Aminosäureaustausch innerhalb der Paired-Domäne von Pax-1, der die DNABindungseigenschaften von Pax-1 erheblich verändert (Chalepakis et al., 1991). Eine Mutation, die zur Verschiebung des Leserasters im menschlichen Pax-2-Gen führt, ist für das Renale-Kolobom-Syndrom verantwortlich, das durch Hypoplasie der Nieren und Kolobom des optischen Nerves gekennzeichnet ist (Sanyanusin et al., 1995); (zum Überblick, Eccles and Schimmenti, 1999). Diese Defekte kommen auch in der Pax $2^{\text {Ineu }}$-Mausmutante vor (Favor et al., 1996). Mutationen im Pax-3-Gen sind die Ursache für den semidominanten SplotchPhänotyp in der Maus und das Waardenburg-Syndrom beim Menschen. Anomalien, die aufgrund einer heterozygoten Mutationen in Pax-3 entstehen sind Defekte im Neuralrohr, Taubheit, Gesichts- und Skelettanomalien sowie Defekte in der Muskulatur der Extremitäten (Auerbach, 1954; Baldwin et al., 1992; Epstein et al., 1991; Franz et al., 1993; Read and Newton, 1997; Russel, 1947; Tassabehji et al., 1992). Hinzukommen Defekte, die auf die anomale Wanderung von Neuralleistenzellen zurückzuführen sind, wie Fehlentwicklung der Spinalganglien, Pigmentierungsanomalien und Herzdefekte (Conway et al., 1997a; Conway et al., 1997b; Tremblay et al., 1995). Über die Rolle von Pax-6 während der Embryonalentwicklung wird im nächsten Abschnitt ausführlicher berichtet.

Die Funktion der restlichen Pax-Gene, für die keine natürlichen Mutanten existieren, wurde mittels Geninaktivierung durch homologe Rekombination in embryonalen Stammzellen untersucht. Dadurch konnte eine essentielle Rolle für Pax-2 in der Nieren-, Augen-, Ohren- 
und Gehirnentwicklung gezeigt werden (Torres et al., 1995). Eine Rolle von Pax-2 wird auch im endokrinen Pankreas vermutet, da die Expression des Gens im Pankreas als auch die Fähigkeit des Proteins den Glukagon-Promotor zu aktivieren, demonstriert wurde (Ritz-Laser et al., 2000). Die Inaktivierung des Pax-4-Gens führte zum Ausbleiben der Insulinproduzierenden $\beta$-Zellen des Pankreas (Sosa-Pineda et al., 1997) während Pax-5 sich als essentielles Gen für die Differenzierung der B-Lymphozyten und für die Musterbildung des Mittelhirns erwiesen hat (Urbánek et al., 1994). Das Fehlen der Pax-7-Genfunktion beeinflusst die Wanderung der Zellen aus dem Kopfteil der Neuralleiste und führt zu Gesichtsanomalien (Mansouri et al., 1996). Pax-8 wurde mit der Entwicklung der Schilddrüse im Zusammenhang gebracht sowohl anhand von Geninaktivierungsstudien (Mansouri et al., 1998), als auch durch die Identifizierung von Mutationen in $P A X-8$ in Fällen von kongenitaler Hypothyreose beim Menschen (Macchia et al., 1998). Schließlich ist Pax-9 notwendig für die Entwicklung von Organen, die aus den Pharyngealtaschen hervorgehen (Peters et al., 1998). Im Einklang mit dem Fehlen der Zähne bei Pax-9 Mausmutanten konnten Mutationen in PAX-9 mit Oligodontie beim Menschen korreliert werden (Stockton et al., 2000).

Die oben aufgeführten Defekte, die auf Mutationen in Pax-Genen zurückzuführen sind, sprechen für eine Schlüsselrole dieser Genfamilie in der Entwicklung und Organogenese bei Säugetieren.

\subsection{Pax-6 und seine Rolle in der Embryonalentwicklung}

Aus der bedeutsamen Familie der Pax-Gene ragt besonders das Pax-6-Gen hervor nicht nur aufgrund seiner Schlüsselfunktion während der Embryonalentwicklung, sondern auch weil es ein Beispiel für die Konservierung von Grundkonzepten der Entwicklung in verschiedenen Spezies darstellt (Gehring and Ikeo, 1999). Die Funktion von Pax-6 während der Embryogenese ist mit der Entwicklung des visuellen Systems eng verknüpft, wobei Pax-6 im Prozeß der Spezifizierung von Augenstrukturen eine Schlüssel- und in der Evolution sehr ursprüngliche Position einnimmt. Diese geht bis hin zum prototypischen Auge bei Planarien zurïck (Pineda et al., 2000). Die Schlüsselrolle von Pax-6 in der Augenentwicklung zeigt sich zunächst anhand der phänotypischen Effekte, die durch Mutationen in diesem Gen ausgelöst werden. Heterozygote Mutationen im Pax-6-Gen führen zur Entstehung des small eye (sey) Phänotyps in der Maus (Hill et al., 1991) und in der Ratte (Matsuo et al., 1993), der durch Mikropthalmie gekennzeichnet ist und zu einer Reihe von okularen Defekten einschließlich 
des Aniridie-Syndroms beim Menschen (Glaser et al., 1992; Jordan et al., 1992). Dabei handelt es sich um eine partielle oder vollständige Abwesenheit der Iris, in Kombination mit Defekten in Kornea, Linse, Retina und optischem Nerv (Hittner, 1989; Nelson et al., 1984; Shaw et al., 1960). Bei homozygoten Sey-Mutanten sowie Pax- $6^{-/}$Mausmutanten (St-Onge et $a l .$, 1997) fehlen komplett Augen und Nase. Der einzelne bekannte Fall beim Menschen, bei dem homozygote Mutationen im PAX-6-Gen aufgetreten sind (Glaser et al., 1994) spiegelte den Phänotyp der homozygoten Sey-Mutanten wieder. Pax-6 homologe Gene wurden aus einer Vielzahl von Organismen isoliert. In Drosophila führen milde Mutationen im Pax-6 Homolog eyeless (ey) zur kleineren Sinnesorganen oder sogar zum Fehlen der Komplexaugen, während schwerwiegende Mutationen im homozygoten Zustand lethal sind (Quiring et al., 1994). Die Ähnlichkeit der Phänotypen zwischen der Fliege und den Säugetieren, die nach Funktionsinsuffizienz des ey-bzw. Pax-6-Gens entstehen, spricht für die Konservierung der Funktion von Pax-6 während der Evolution. Interessanterweise existiert in Drosophila ein zweites Pax-6 homologes Gen, twin of eyeless (toy) (Czerny et al., 1999). Ähnlich wie ey ist toy in Augenstrukturen der Fliege exprimiert. Da Toy homologe Gene nicht in höheren Vertebraten identifiziert werden konnten, geht man von einem Duplikationsereignis von $e y$ aus, das während der Evolution der Insekten stattgefunden hat und bei dem, ey unter der Kontrolle von toy gesetzt wurde. Die Universalität der genetischen Mechanismen sowie die Funktion von Pax-6/ey als „master control gene“ der Augenentwicklung wurde in einer spektakulären Art und Weise demonstriert. Die ektopische Expression von ey in Imaginalscheiben des Kopfes und des Thorax von Drosophila, führte zur Entstehung von Augen in diesen Strukturen (Halder et al., 1995). Zum gleichen Effekt führte die ektopische Expression des Pax-6-Gens der Maus in Drosophila. Die ektopische Ausbildung von Augen in der Fliege konnte ebenfalls mit Pax-6 homologen Genen aus dem Zebrabärbling (Nornes et al., 1998), Ascidien (Glardon et al., 1997) und dem Tintenfisch Loligo opalescens (Tomarev et al., 1997) demonstriert werden. Dies zeigt, daß ein einziges Gen in der Lage ist eine genetische Kaskade zu aktivieren, die zur Entwicklung eines komplexen Organs führt. Diese Eigenschaft von Pax-6 ist auch bei Vertebraten konserviert, wie das Experiment zeigt bei dem die Injektion von Pax-6 mRNA in ein einziges Blastomer in Xenopus laevis zur Ausbildung von ektopischen differenzierten Augen führt (Chow et al., 1999). 
Die Existenz des semidominanten Sey-Phänotyps im heterozygoten Zustand spricht dafür, daß die Gendosis von kritischer Bedeutung für die Pax-6-Funktion ist. Versuche jedoch den heterozygoten Phänotyp durch YAC-Transgene zu retten, in denen der humane Pax-6 Locus enthalten war, haben gezeigt, daß auch eine Überexpression des Gens zu okularen Defekten führen kann, bei denen der resultierte Phänotyp jeweils von der Gendosis abhängig war (Schedl et al., 1996).

Neben der beschriebenen Pax-6 Aktivität bei der Entwicklung des visuellen Systems, spielt Pax-6 im Prosencephalon eine wichtige Rolle. Es ist an der Musterbildung des Neokortex beteiligt (Bishop et al., 2000) und definiert die Grenze zwischen Di- und Mesencephalon. Die ektopische Expression von Pax-6 im Mesencephalon führt zur kaudalen Verschiebung der Abgrenzung zwischen Di- und Mesencephalon (Matsunaga et al., 2000). Im ventralen Neuralrohr ist Pax-6 in der Spezifizierung regionaler neuraler Identität beteiligt (Briscoe, 2000; Ericson, 1997; Goulding et al., 1993) $\mathrm{Pax6}^{-/}$Mäuse weisen zusätzlich Defekte auch in Geweben endodermalen Ursprungs auf. So fehlen in der Abwesenheit von Pax-6 Funktion die Glukagon produzierenden $\alpha$-Zellen der Pankreas. Dabei scheint Pax-6 direkt an der Regulation des Glukagon-Gens beteiligt zu sein (Hussain and Habener, 1999).

\subsection{Biochemische Eigenschaften der Pax-Proteine}

Gemeinsames Strukturmotiv bei allen Pax-Proteinen ist die Paired-Domäne, die erst Jahre nach ihrer Entdeckung durch Studien mit dem Drosophila even skipped Promotor und dem Paired-Protein, als sequenzspezifische DNA-bindende Domäne identifiziert wurde (Treisman et al., 1991). Anschließende Studien haben gezeigt, daß auch andere Pax-Proteine in der Lage waren, mit der Sequenz aus dem even skipped-Promotor sowie mit in vitro identifizierten Erkennungssequenzen für Paired-Domänen, mit vergleichbaren Affinitäten zu interagieren (Czerny et al., 1993). Die Limitierung der einzelnen Pax-Proteine auf ein spezifisches genetisches Programm konnte durch ihre breite Spezifität in der Erkennung von Bindesequenzen durch die Paired-Domäne, nicht erklärt werden. Es hat sich jedoch herausgestellt, daß die DNA-Bindung durch Pax-Proteine viel komplizierter ist als ursprünglich angenommen wurde. So haben Untersuchungen mit Pax-5 gezeigt, daß die Paired-Domäne sich aus einer amino- und einer carboxyterminalen Unterdomäne zusammensetzt, die spezifische Bindungseigenschaften besitzen (Czerny et al., 1993). Die aminoterminale Domäne wird als PAI-Domäne, die carboxyterminale als RED-Domäne 
bezeichnet (PAI+RED=PAIRED) (Jun and Desplan, 1996) (Abb.2). Pax-Proteine unterscheiden sich in ihrer Fähigkeit die RED-Domäne zur DNA-Bindung einzusetzen. Tatsächlich existieren Pax-6, Pax-6(5a), und Pax-8 Isoformen, die mit der DNA ausschließlich durch die RED-Domäne interagieren. Bei diesen Isoformen kommt es durch alternatives Spleißen zur Insertion von zusätzlichen Aminosäuren in der PAI-Domäne, die ihre Bindungsfähigkeit unterbindet (Epstein et al., 1994a, Kozmik et al., 1997). Im Gegensatz zu Pax-6, bei dem sowohl die PAI- als auch die RED-Domäne für die Funktion des Proteins in vivo erforderlich sind, scheint die RED-Domäne des Paired-Proteins von Drosophila nicht für die Interaktion mit DNA erforderlich zu sein. Einerseits ist die RED-Domäne für die in vivo-Funktion des Proteins entbehrlich (Bertuccioli et al., 1996) und andererseits enthalten die in vitro identifizierten Bindestellen für Paired kein Erkennungsmotiv für die RED-Domäne. Der selektive oder kombinatorische Einsatz der zwei Unterdomänen liefert also eine Möglichkeit das Repertoir an Erkennungsstellen für die Paired-Domäne zu erhöhen. Interessanterweise wurde in Drosophila ein Pax-ähnliches Protein identifiziert (Lune/eye gone), das einzigartig innerhalb der Pax-Famillie ist, da es nur die RED-Domäne enthält (Jun et al., 1998). Die DNA-Erkennungssequenz dieses Proteins, das eine Rolle in der Augenentwicklung der Fliege spielt, ist der der Pax-6(5a) Isoform sehr ähnlich.

Wie aus röntgenkrystallographischen Analysen des Drosophila Proteins Paired (Xu et al., 1995) und des menschlichen PAX-6 (Xu et al., 1999) hervorgeht, exstieren auch in der PAIDomäne trotz ähnlicher Faltung funktionelle Unterschiede, die zur Bindungsspezifität beitragen. Aus der Auflösung der Kristallstruktur von PAX-6 konnte gezeigt werden, daß sowohl die PAI- als auch die RED-Domäne mit einem klassischen Helix-Schleife-HelixMotiv an jeweils gegenüberliegende große Furchen der DNA binden (Xu et al., 1999) (Abb.2). Zudem konnte auch ein Beitrag der flexiblen $\beta$-Haarnadelstruktur, welche die „Linker-Region“ zwischen den beiden Unterdomänen darstellt, zur Gesamtbindung der Paired-Domäne beobachtet werden. Die wichtige Rolle der „Linker-Region“ in der DNAErkennung durch die Paired-Domäne läßt sich anhand von Pax-3-Isoformen erkennen, die durch alternatives Spleißen entstehen. Diese Pax-3-Isoformen unterscheiden sich in den Grad der Benutzung der „Linker-Region“ und der RED-Domäne für die DNA-Bindung bei gleichbleibender Bindungsaktivität der PAI-Domäne (Vogan and Gros, 1997; Vogan et al., 1996). 
Pax-3, Pax-7 sowie Pax-4 und Pax-6 besitzen zusätzlich zur Paired-Domäne eine Paired-Typ Homeodomäne als zweites DNA-bindendes Motiv. Es ist also möglich, daß durch die kombinierte Verwendung der Paired- und der Homeodomäne ein höherer Grad der Spezifität in der Erkennung von Zielsequenzen durch die Pax-Proteine erreicht wird. Es wurde gezeigt, daß die Paired-Typ Homeodomäne mit der Paired-Domäne in der Sequenzerkennung in vitro kooperieren kann (Jun and Desplan, 1996). Im Einklang damit konnte in vivo demonstriert werden, daß für die Fähigkeit des Paired-Proteins von Drosophila den mutanten paired Phänotyp zu retten, die Anwesenheit von sowohl der Paired- als auch der Homeodomäne erforderlich ist (Bertuccioli et al., 1996; Miskiewicz et al., 1996). Im Gegensatz dazu ist die Paired-Typ Homeodomäne des Drosophila Pax-6 Homologs eyless (ey) für die in vivo Funktion des Proteins nicht erforderlich, da eine Deletionsvariante von Ey ohne die Homeodomäne in der Lage ist zum einen den mutanten ey Phänoyp zu retten und zum anderen ektopische Augen zu induzieren (Punzo et al., 2001). Diese Daten weisen darauf hin, daß die Paired-Typ Homeodomäne der Pax-Proteine sowohl unabhängig als auch in Kombination mit der Paired-Domäne für die Regulation von Zielgenen eingesetzt wird.

Die Funktion der Pax-Proteine in der Entwicklung von Organen und in der Spezifizierung von Zelltypen während der Embryogenese hängt mit ihrer Fähigkeit zusammen die Expression von untergeordneten Zielgenen zu modulieren. Vorhandene Daten sprechen dafür, daß PaxProteine sowohl eine aktivierende als auch eine reprimierende Wirkung auf die Expression von anderen Genen ausüben. So wurde der Carboxyterminus des Pax-6 Proteins, der reich an den Aminosäuren Prolin, $\underline{S}$ erin und Threonin ist und als PST-Region bezeichnet wird, als transkriptionsaktivierende Domäne identifiziert. Eine Nonsense-Mutation, die zu einer verkürzten PST-Region im menschlichen PAX-6 führt, korrelierte mit Augendefekten und Aniridie (Glaser et al., 1994). Die Aktivität der PST-Region wird möglicherweise mittels Phosphorylierung durch MAP-Kinasen reguliert (Mikkola et al., 1999). In der Regulation von Kristallin-Genen in der Linse fungiert Pax-6 als direkter Aktivator der $\alpha$-Kristallin- zum Überblick, (Cvekl and Piatigorsky, 1996) und gleichzeitig als Repressor der $\beta$-Kristallin-Gene (Duncan et al., 1998). Eine transkriptionsreprimierende Aktivität wurde den Pax-2, Pax-5 und Pax-8 Proteinen zugeordnet, die zur gleichen Unterklasse innerhalb der Familie der PaxProteine gehören. Es wurde gezeigt, daß Pax-2, -5 und -8 die Transkription des Tumorsupressorgens p53 reprimieren können (Stuart et al., 1995). Auch im Pax-3 Protein wurde eine Region vor der Paired-Domäne mit starker transkriptionsinhibitorischer Funktion 
identifiziert (Chalepakis et al., 1994). Während der frühen Pankreasentwicklung, reprimiert Pax-4 die Differenzierung der $\alpha$-Zellen und ermöglicht die Bildung der Insulin produzierenden $\beta$-Zellen (Smith et al., 1999).

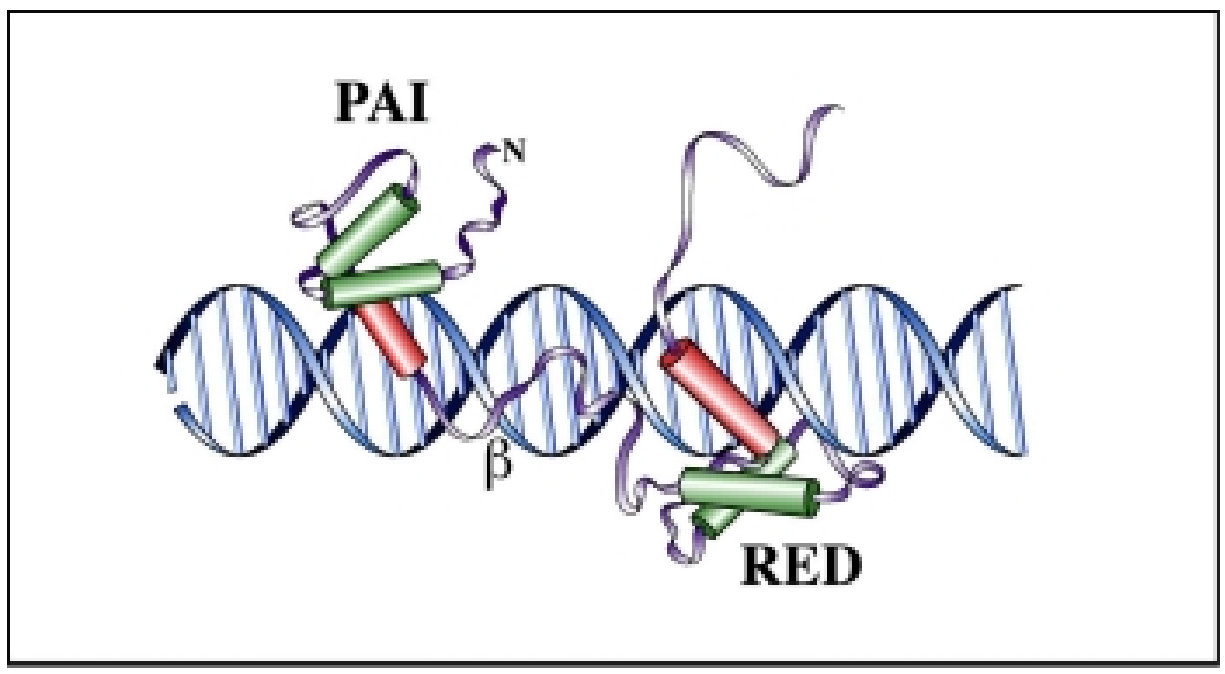

Abbildung 2

Schematische Darstellung der Struktur und des Bindungsmodus der Paired-Domäne an DNA. Die zwei Unterdomänen der Paired-Domäne PAI und RED werden von einer flexiblen $\beta$-Haarnadelstruktur $(\beta)$, die zur Gesamtbindung beiträgt, getrennt. In Rot ist die Erkennungshelix jeder Unterdomäne dargestellt, die in der großen Furche Kontakt zur DNA aufnimmt.

\subsection{Pax-Proteine und interagierende Partner}

Ein zusätzlicher Mechanismus, der neben dem selektiven und kombinatorischen Einsatz der DNA-bindenden Motive, zur Erhöhung der biologischen Diversität der Pax-Proteine beiträgt, ist die Interaktion mit anderen Proteinen. Es wurden mittels „Two-hybrid screens“ oder Immunpräzipitationsexperimente Proteine identifiziert, die mit Pax-Proteinen interagieren und sowohl ihre DNA-Bindungs- als auch ihre Transaktivierungseigenschaften dadurch beeinflussen. Die identifizierten Wechselwirkungen zwischen Pax-Proteinen und anderen Faktoren, zeigten, daß alle strukturelle Motive der Pax-Proteine auch als Protein-ProteinInteraktionsdomänen dienen können. So wurde gezeigt, daß die Fähigkeit von Pax-5 als Repressor zu wirken durch die Interaktion mit Proteinen aus der Familie der Groucho Korepressoren vermittelt wird (Eberhard et al., 2000). Dabei dient bei Pax-5 das Oktapeptid und der Carboxyterminus als interagierende Domänen. Pax-5 ist außerdem in der Lage mit dem TATA-Box bindenden Protein (TBP) und dem Retinoblastoma-Protein ( $\mathrm{Rb}$ ) ein Komplex zu bilden (Eberhard and Busslinger, 1999). An diesen Interaktionen ist die partielle Homeodomäne von Pax-5 direkt beteiligt. Die Wechselwirkung zwischen TBP und Rb wurde 
auch für das Pax-6-Protein demonstriert, bei dem ebenfalls die Homeodomäne als interagierende Region fungierte (Cvekl et al., 1999). Diese Daten sprechen zum einen für direkte Kontakte zwischen Pax-Proteinen und Komponenten der basalen Transkriptionsmaschinerie und zum anderen für eine potentielle zellzyklusabhängige Regulation ihrer Aktivität. Pax-6 ist an Protein-Protein Interaktionen mit zahlreichen anderen Homeo-Transkriptionsfaktoren beteiligt wie Chx-10, Six-3, Lhx-2, En-1, Prep-1, Prox-1 and HoxB1 (Mikkola et al., 2001). Die Komplexbildung zwischen Pax-6 und einigen dieser Proteine führte zur Erhöung der Transkriptionsaktivierung in vitro. Die Homeodomäne von Pax-3 ist an der Interaktion des Proteins mit dem Korepressor HIRA (Magnaghi et al., 1998), mit Proteinen, die zur Familie von Rb gehören (Wiggan et al., 1998) und mit dem Daxx Repressor (Hollenbach et al., 1999) beteiligt. HIRA, das auch mit Histonen interagiert fungiert als Repressor sehr wahrscheinlich durch die Remodulierung des Chromatins. Dies weist auf die Beteiligung von Modifikationen des Chromatins hin, in der durch Pax-Proteine vermittelten Repression. Die Interaktion zwischen Daxx und Pax-3 führt zur Repression der Pax-3 Aktivität. Pax-3 ist außerdem durch die Homeodomäne an Interaktionen mit den Homeoproteinen Mox1 und Mox2 beteiligt, die bei der Entwicklung der Muskulatur der Extremitäten und des Skeletts eine wichtige Rolle spielen (Stamataki et al., 2001). Eine Interaktion mit den gleichen Proteinen konnte auch Pax-1 eingehen. Von Protein-ProteinInteraktionen, in denen die Drosophila Pax-Homologen beteiligt sind wurde ebenfalls berichtet. Eines der ältesten Beispiele ist die Wechselwirkung zwischen Paired (Prd) und dem Homeoprotein Fushi tarazu (Ftz), bei dem zum ersten Mal gezeigt wurde, daß ein Homeoprotein (Ftz) trotz der Abwesenheit der DNA-bindenden Homeodomäne durch die Interaktion mit einem zweiten Homeoprotein (Prd) in der Lage ist Zielgene in vivo zu regulieren (Copeland et al., 1996). Einem unterschiedlichen Zweck dient die Interaktion zwischen Paired und Ppa, einem neuen Protein das zur F-Box Proteinfamilie gehört. Die ektopische Expression von Ppa führt zur Herabsetzung der Proteinmenge von Prd in vivo, wahrscheinllich durch die Ppa vermittelte Degradierung von Prd (Raj et al., 2000).

Bei der Wechselwirkung zwischen Pax- und anderen Proteinen wurde in einigen Fällen die Paired-Domäne als interagierende Domäne identifiziert. Das erste Beispiel einer solchen Wechselwirkung ist die DNA abhängige Interaktion zwischen Pax-5 und Proteinen, die zur Ets-Familie von Transkriptionsfaktoren gehören (Fitzsimmons et al., 1996). Dabei dirigiert an DNA gebundenes Pax-5 die Bindung von Ets-Faktoren an einer benachbarten Stelle in einem 
B-zellspezifischen Promotor. Wie später demonstriert wurde, ist bei diesem Mechanismus die $\beta$-Haarnadelstruktur zwischen der PAI- und RED-Domäne essentiell (Wheat et al., 1999). DNA-abhängige Interaktionen, in denen die Paired-Domäne von Pax-6 beteiligt ist wurden ebenfalls berichtet. So, wird durch die Interaktion zwischen Pax-6 und Sox-2 an benachbarten Stellen des $\delta$-Crystallin Promotors die starke Bindung des Pax-6 Proteins an einer nicht optimalen Bindestelle ermöglicht (Kamachi et al., 2001). Bei der Regulation des GlucagonPromotors wurde die Beteiligung von Pax-6 an einem Komplex mit p300 und Cdx-2 gezeigt, wobei die Interaktion zwischen Pax-6 und Cdx-2 durch die Paired-Domäne von Pax-6 vermittelt wird (Ritz-Laser et al., 1999). Der Aufbau des Komplexes aus den drei Proteinen an den Glucagon Promotor führt zur erhöhter Transkriptionsaktivierung (Hussain and Habener, 1999).

Die Paired-Domäne der Pax-Gene ist auch an DNA-unabhängigen Protein-Protein Interaktionen beteiligt. In der Regel wirken solche Interaktionen inhibitorisch auf die DNABindung durch die Paired-Domäne. Die zur Familie der Helix-Schleife-Helix (HLH) gehörenden Id Proteine sind bekannte Inhibitoren der Zelldifferenzierung indem sie mit anderen bHLH Proteinen interagieren und ihre Bindung an DNA-Zielsequenzen verhindern zum Überblick, (Norton, 2000; Norton et al., 1998). Id-Proteine sind auch in der Lage mit Pax-2, -5 und -8 zu interagieren, wobei sie als Antagonisten der Pax-Aktivität wirken, indem sie die Bindung der Pax-Proteine an Erkennungssequenzen der Paired-Domäne verhindern (Roberts et al., 2001). Inhibitorisch auf die DNA-Bindung der Paired-Domäne von Pax-6 wirken Interaktionen mit Engrailed-1 (En-1) der Wachtel (Plaza et al., 1997) und dem „Microphtalmia transcription factor“ (Mitf) (Planque et al., 2001a). Bei der Interaktion mit Mitf ist spezifisch die carboxyteminale Domäne der Paired-Domäne von Pax-6 beteiligt.

Auch die carboxyterminale PST-Region von Pax-6 konnte bei der Wechselwirkung mit MafProteinen, die zur Familie der bZip-Transkriptionsfaktoren gehören, als Protein-Protein Interaktionsdomäne identifiziert werden (Planque et al., 2001b). Diese Interaktion führt zur Erhöhung der Bindungsfähigkeit von Pax-6 an den Glucagon-Promotor und zur verstärkten Aktivierung.

Während der vergangenen vier Jahren war die Untersuchung von Interaktionen zwischen Paxund anderen Proteinen Gegenstand intensiver Forschung. Ziel ist es, die Pax-Proteine in molekularen Kaskaden einzuordnen und die Regulation ihrer vielseitigen Aktivität zu verstehen. Von den zahlreichen Proteinen, die als Pax-Interaktionspartner identifiziert 
wurden, konnte nur in wenigen Fällen die biologische Bedeutung des gebildeten Proteinkomplexes aufgeklärt werden. Es konnte jedoch gezeigt werden, daß alle strukturelle und funktionelle Regionen der Pax-Proteine zusätzlich zu ihrer Hauptfunktion als DNAbindende- oder Transaktivierungsdomänen eine Oberfläche darstellen, die die Interaktion mit anderen Proteinen ermöglicht.

\subsection{Zielsetzung}

Im Rahmen der vorliegenden Arbeit soll die Interaktion zwischen Pax-6 und einem neu identifizierten Protein, Mapl-1, untersucht werden. Besondere Beachtung verdienen die molekularen und funktionellen Aspekte der Interaktion zwischen den beiden Proteinen, die sowohl in vitro als auch in vivo studiert werden. Es konnten dadurch neue Einblicke in die Regulation der Pax-6 Funktion auf Molekülebene durch interagierende Proteine gewonnen werden. 


\section{Ergebnisse}

\subsection{Mapl-1 als potentieller Pax6-Interaktionspartner}

Grundlage dieser Arbeit war ein in der Hefe durchgeführtes „Two-hybrid screen“, um Proteine zu identifizieren, die mit dem Pax-6 Protein der Maus interagieren (Petrou, 1997). Eines der daraus identifizierten cDNA-Fragmente (Klon TH2.2) repräsentierte ein neues Gen, das hauptsächlich aufgrund seines Expressionsmusters während der Embryogenese zur weiteren Analyse ausgewählt wurde (Abb.3A-B). Die Expression des Gens in allen Strukturen des embryonalen Auges, bei dessen Entwicklung Pax-6 eine Schlüsselrolle spielt, war besonders im Hinblick auf eine biologische Funktion des davon kodierten Proteins als Pax-6-Interaktionspartner interessant. Dem neu identifizierten Gen wurde der Name „MAPlike-1“ (mapl-1) gegeben, aus Gründen, die in den folgenden Abschnitten dieser Arbeit erläutert werden. Ein zweites Gen (mapl-2), das eine sehr hohe Sequenzähnlichkeit zu mapl-1 aufweist, wurde im gleichen „Two-hybrid screen“ identifiziert (Abb.3C). Es handelt sich um ein Gen, das zweimal unabhängig voneinander identifiziert wurde und von den Klonen TH2.16 und TH2.20 repräsentiert wird. Mapl-2 ist ubiquitär exprimiert (Petrou, 1997).

Die Tatsache, daß die gleiche Proteindomäne dreimal unabhängig voneinander als Pax6interagierende Domäne identifiziert wurde, spricht für eine echte Interaktion mit Pax-6 und gegen ein Artefakt der verwendeten Methode. Aufgrund des spezifischeren Expressionsmusters wurde mapl-1 als der bessere Kandidat angesehen, einen Pax6spezifischen Interaktionspartner zu kodieren, und stellt deshalb den Schwerpunkt dieser Arbeit dar. Sehr wahrscheinlich definieren die zwei Gene eine neue Genfamilie, die für strukturähnliche Proteine kodiert. 

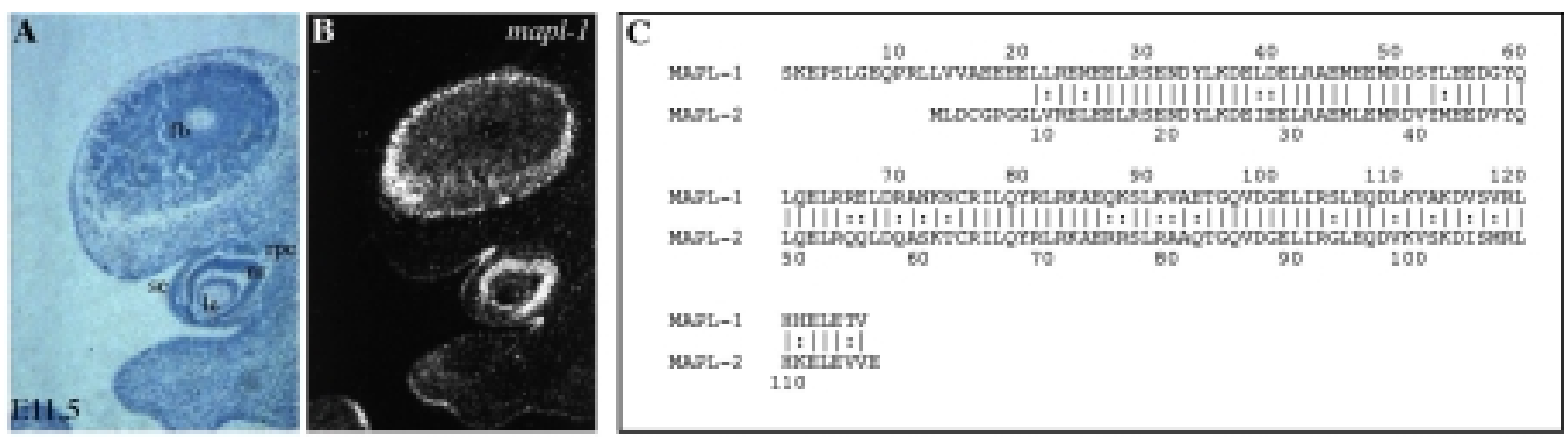

\section{Abbildung 3}

In situ Hybridisierung an $8 \mu \mathrm{m}$-sagittalen Schnitten eines E11,5 Embryos. Dargestellt wird die Expression des mapl-1-Gens in Augenstrukturen. A: Hellfeld-; B: Dunkelfeldaufnahme. C: Vergleich zwischen den Proteindomänen von Mapl-1 und Mapl-2, die als Pax6-Interaktionsdomänen im „Two-hybrid screen“ identifiziert wurden. Auffällig ist die hohe Sequenzidentität zwischen den abgebildeten Domänen der beiden Proteine. Abkürzungen: fb: Vorderhirn; rpe: retinales Pigmentepithel; le: Linsenepithel; nr: Neuroretina; sc: Oberflächenektoderm.

\subsection{Klonierung und Charakterisierung der mapl-1 cDNA}

Um die kodierende Region der mapl-1 cDNA zu vervollständingen, wurde das in Abb.4A rot dargestellte Fragment als Sonde zur Durchmusterung von verschiedenen Phagen-cDNABibliotheken eingesetzt. Es handelt sich um das Fragment, das ursprünglich im „Two-hybrid screen“ identifiziert wurde. Zuerst wurde eine cDNA-Bibliothek durchmustert, die aus RNA von gesamten E10,5 Embryonen, sowohl durch „,random-“ als auch durch „Poly-Apriming"hergestellt wurde (Stratagene). Daraus isolierte Fragmente wurden selbst als Sonden verwendet, um die mapl-1-cDNA Sequenz nach und nach zu verlängern. Schließlich wurde das 3'-Ende der cDNA aus einer „PolyA-primed“ E15,5 cDNA-Bibliothek (Clontech) isoliert. Im Gegensatz zu der zuvor verwendeten Bibliothek sind in einer „PolyA-primed“ cDNAPopulation die 3'-Enden von Genen überrepräsentiert. Es konnte dadurch eine cDNASequenz von 7,1 kb isoliert werden, welche die gesamte kodierende Region des mapl-1-Gens umfaßt (Abb.4A). Die mRNA des Gens weist im Northern-Blot eine Länge von ca. 7,5 kb auf (Abb.4B). Es kann daher davon ausgegangen werden, daß die unten abgebildete Sequenz fast die komplette cDNA-Sequenz des Gens darstellt.

In der isolierten cDNA-Sequenz finden sich die charakteristischen Merkmale von eukaryotischer mRNA. Das ATG, das als Startcodon dient, liegt in der typischen KozakKonsensus-Sequenz A/GCCATGG vor (Kozak, 1986) (in Abb.4A unterstrichen), gefolgt von einem langen offenen Leserahmen (ORF) und dem Stop-Kodon nach 5679 bp kodierender Sequenz. In der $3^{`}$-untranslatierten Region (UTR) findet sich die Sequenz AATAAA (Abb.4A 
Doppelunterstrichen), die das Konsensus-Polyadenylierungssignal darstellt (Proudfoot and Brownlee, 1976).

A.

TGTGCCAGGAGGATCCGAGCGCCGTTGACCTGAGCGAGGGGACACACTCCCCCGGGTCGGCTGAGTGCGGGGGAGGGGACGGCGGGAGCGCAGGGTGCACGCCGGGCGGC GCAGGGGGTCAGT GATGACCGGGCGCGCGGGGAGGCTGCACGCCGCCGCCGCCGCCCGGAGCATCTGCCGCCTGAGCTGCGGATCGCAGCCGCCGCCCGGGCCATGGAGA

CGCTGAACGGCCCCGCGGGCGGCGGCGCCCCGGACACCAAGCCGCAGCCAGCCGGCCAGCATCACCGCCACCACCACCTGCACCCGCTGGCCGAGAGGAGGCGGCTGCAC

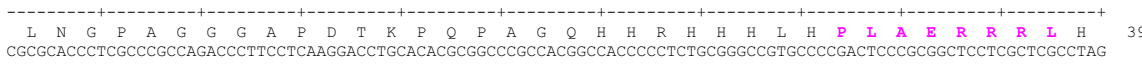

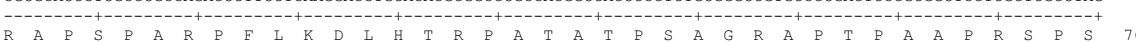
CCTTGCCGGGAAGGCGCCGCCGTCGCCCGGGCCCCCGGCCGCGCCCGGTCGCCTCTCCCGACGCAGCGGTGTAGTCCCCGGCGCGAAGGACAAGCCGCCGCCGGGCGCCG

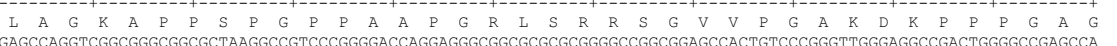
GAGCCAGGTCGGCGGGCGGCGCTAAGGCCGTCCCGGGGACCAGGAGGGCGGCGCGCGCGGGGCGGCGGAGCCACTGTCCCGGGTTGGGAGGCCGACTGGGGCCGAGCC

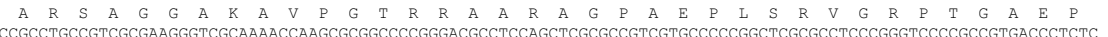

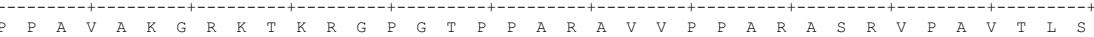
TGTGACCTCGGTGGCTGGCTGTCGTATCAACCACACGGACAGCAGCTCGGATCTCTCCGACTGCGCCTCCGAACCCTTGTCTGATGAGCAGCGCCTACTCCCCGCCGCCA

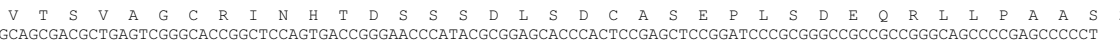
S D A E S G T G S S D R E P I R G A P T P S S G S R G P P P G S P E P P ATCCTGCTCGCGGCGCCCCCTGTCGCCAGTGCCTGTCTCGGGGGCCGAAGCAGCCCAGGCGGGGCCTCCACAGGGTCCCCGGGACCCGGTTCTCAGGAGGATGTTGGGGG

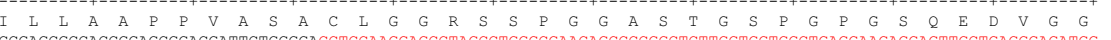

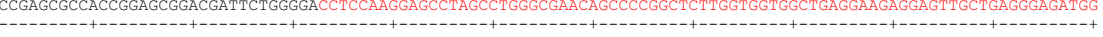

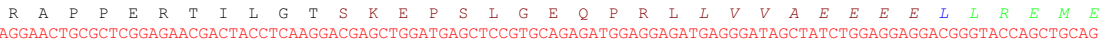

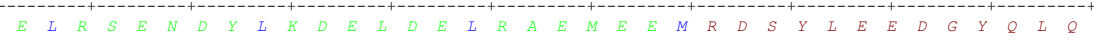
GAGCTCCGGAGAGAGCTGGACCGTGCTAACAAGAACTGCAGAATCCTGCAGTACCGACTCAGGACCGAGCAGAAGAGCCTGAAAGTGGCGGAAACAGGGCAGGTGGA

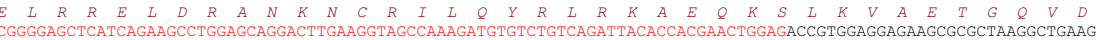

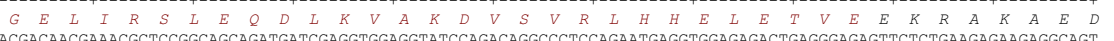
ACGACAACGAAACGCTCCGGCAGCAGATGATCGAGGTGGAGGTATCCAGACAGGCCCTCCAGAATGAGGTGGAGAGACTGAGGGAGAGTTCTCTGAAGAGAAGAGGCAGT $\begin{array}{lllllllllllllllllllllllllllllllllll}D & N & E & T & L & R & Q & Q & M & I & E & V & E & V & S & R & Q & A & L & Q & N & E & V & E & R & L & R & E & S & S & L & K & R & R & G\end{array}$ GATGCGCAAAAAGATGG

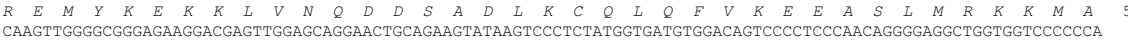

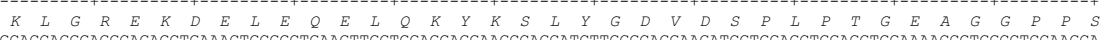
GCACCAGGGAGGCAGAGCIGAAACIGCGGCTGABG GAGATGGAAGACATACGGGTTCAGCATGAACGCGAGGGAACAGGCAGGGACCACGTGCCAAGCACTCCTACCTCACCCTTCGGAGACTCAATGGAGTCCTCCACGGAGC $\begin{array}{lllllllllllllllllllllllllllllllllllll}E & M & E & D & I & R & V & Q & H & E & R & E & G & T & G & R & D & H & V & P & S & T & P & T & S & P & F & G & D & S & M & E & S & S & T & E & L\end{array}$ CCGCCGGCACCTGCAGTTTGTGGAAGAAGAGGCTGAGCTGCTGAGGAGATCCATCTCTGAGATTGAAGATCACAACCGGCAGTTGACCCACGAGCTGAGCAAGTTCAAGT

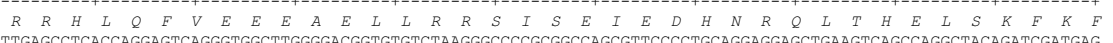

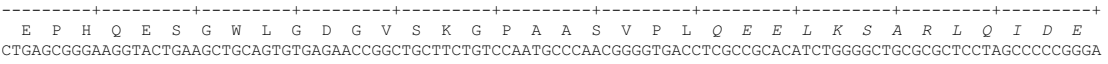

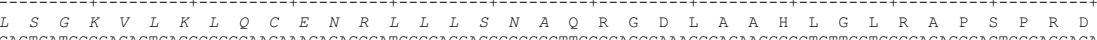
$\underset{\text { TGTTTGAGAAGACCTCGGGCTTCGGAAGCGGAAAGCCGTCGAGGGCTAGTGAGCCATGCCCGGCAGAGCTGCTAAGGGTCCGGGAGGATACCGAGTGCCTGGTGACCATA }}{S}$

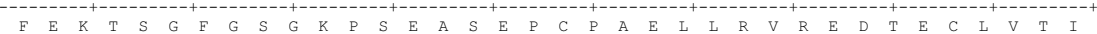
AAGCTGGAGGCTCAGCGGCTTGAGCGGACTGTGGAGCGCCTCATCTCTGATACAGATGGTTTCATCCACGACTCAGGACTGCGGGGCAATGGATTGGCCTCACCTGGAGT

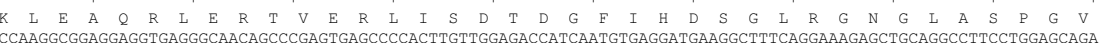
O G G G G E G N S P S E P H L L E T I N V R M K A F R K E L O A F L E O M TGTCCCGGATTGTGGATGGTCTCTCGCCCTTATCCCACCTCACAGAGTCATCCAGCTTCCTCTCCACTGTGACTTCTGTGTCCCGGGACTCCCCCATCGGGACCCTGGGA

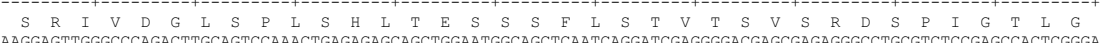

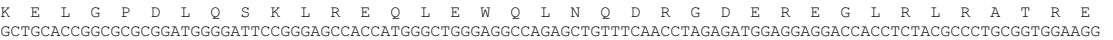

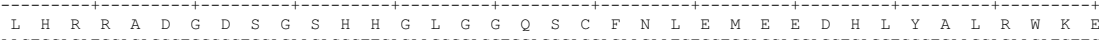
AACTGGAGATGCACAGCCTGGCCCTGCAGAACACCCTTCACAAGCGGACGTGGAGCGACGAGAAGAATCTGCTGCAGCAGGAGCTCAGGTCCCTGAAGCAGAACATCTTC L E M H S L A L CTCTTCTACGTCAAGCTCAGGTGGCTGCTGAAACACTGGCGCCAAGGGAAGCAGATGGAGGAGGGAGGAGAGGATCTGGAGGAGAGCGAACATCCAGAGAATGTGCCTGC

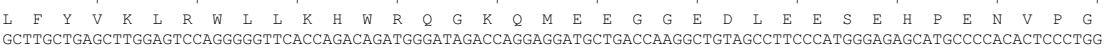

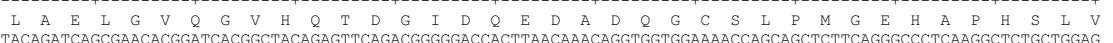
Q I S E H G S R L Q S S D G G P L N K Q V V V E N Q $Q$ G I F R A L K A I L E GACTTCCGTTCGGAGCTGCGCGAAGACGAGCATGCGCGGCTGCGGCTGCAGCAGCAGTACGCCAGCGACAAGGCTGCGTGGGATGTGGAGTGGGCTGTGCTCAAGTGCCC

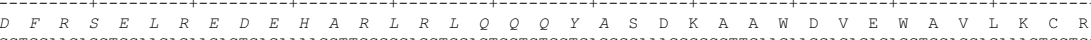
A

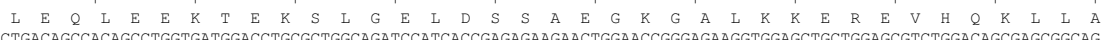
$\underset{\text { GAGTGGGGGCGACAGAAGGAGGAGCTCCTGTGGCGGGTGGAGCAGTTACAGAAAGAGAAAAGTCCCCGGAGAAGCGGCAGTTTCCTCTGCAGCCGAAGGGAAGACGACAC }}{\text { D S }}$

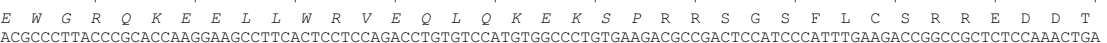

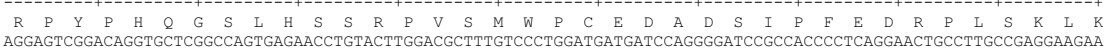




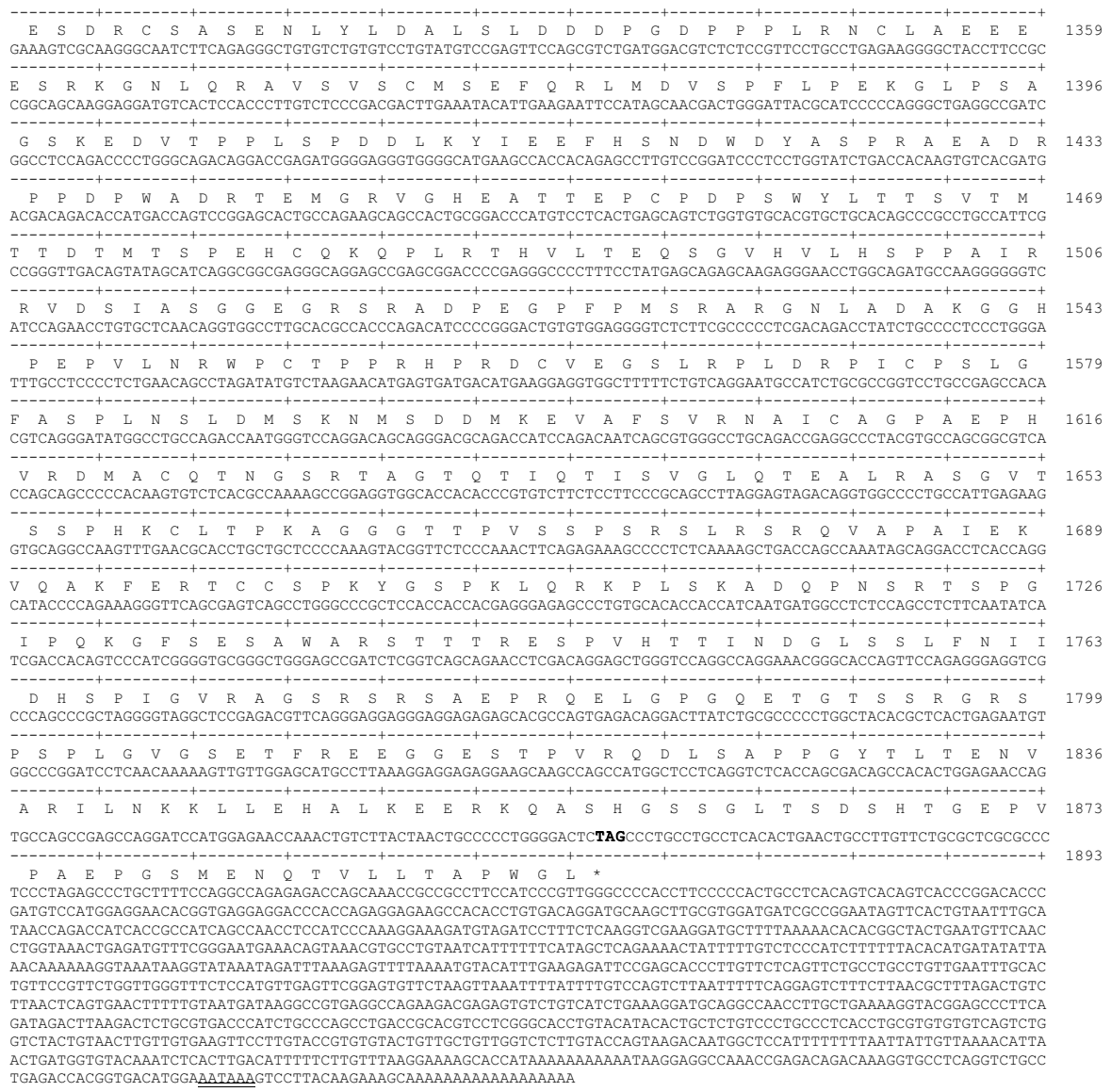

B.

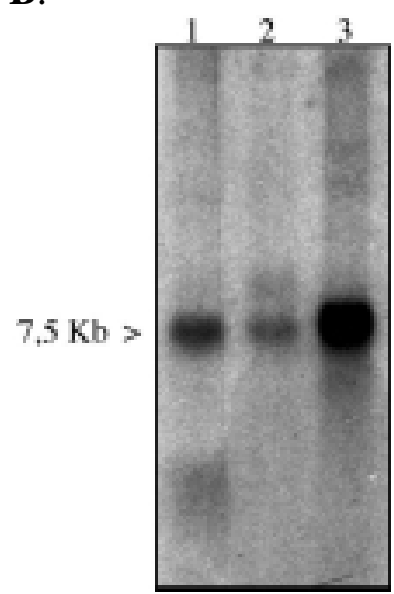

\begin{abstract}
Abb.4
A.:Nukleotid- und daraus abgeleitete Aminosäuresequenz der mapl-1-cDNA. Hervorgehoben sind das ATG-Startkodon sowie das Amber-Terminationskodon. Einfach unterstrichen ist das Kozak-Konsensus-Motiv; Doppelt unterstrichen ist das Polyadenylierungssignal. In violett: putatives nukleäres Lokalisationssignal (NLS); In grün: Leucin-Zipper-Motiv innerhalb der Pax6-Interaktionsdomäne (rot); Die „Coiled-Coil“Domänen sind in kursiver Schrift. B:Northern-Hybridisierung von Gesamt-RNA aus 1: Embryonalen Stammzellen (ES-Zellen); 2: E12,5 Embryonen; 3: Postnatalem Gehirn. Als Sonde wurde die in A rot abgebildete Nukleotidsequenz eingesetzt.
\end{abstract}

\title{
2.3. Charakterisierung der Proteinsequenz
}

Aus den bisher gewonnenen Daten geht hervor, daß mapl-1 mit einem einzigen Transkript von 7,5Kb exprimiert wird und für ein sehr großes Protein von 1893 Aminosäuren kodiert. Da anhand seiner Primärstruktur das Protein nicht eindeutig in bereits bekannte Proteinfamilien eingeordnet werden konnte, wurde mit Hilfe von verschiedenen Computerprogrammen die Aminosäuresequenz analysiert. Aus dieser Analyse konnte zunächst ein Leucin-Zipper-Motiv 
(Abb.4A in grün) innerhalb der Region identifiziert werden, die ursprünglich als Pax6Intraktionsdomäne isoliert wurde. Das Leucin-Zipper-Motiv ist ein bekanntes Protein-Protein Interaktionsmotiv und stellt eine besondere Form der „Coiled-coil“ Struktur dar (Baxevanis and Vinson, 1993). Anhand von konservierten Positionen innerhalb des Leucin-ZipperMotivs konnte Mapl-1 in die Familie der bZIP-Transkriptionsfaktoren eingeordnet werden. Diese Proteine zeichnen sich durch das Vorhandensein eines Leucin-Zipper-Motivs aus, das bei Protein-Protein Interaktionen involviert ist und durch eine basische Sequenz, die sich aminoterminal davon befindet, und sequenzspezifische DNA-Bindung vermittelt. Proteine der bZIP-Familie regulieren als Homo- oder Heterodimere die Expression von untergeordneten Zielgenen (Hurst, 1995). Interessanterweise konnte in der Mapl-1 Aminosäuresequenz keine ähnliche basische Region aminoterminal zum Leucin-Zipper identifiziert werden. Es ließ sich weiterhin ein nukleäres Lokalisationsignal (NLS) (Abb.4A, in violett) am Aminoterminus des Proteins erkennen, einige Aminosäuren nach dem ATG-Startkodon. Mapl-1 zeichnet sich zudem durch vier „Coiled-Coil“-Regionen (Abb. 4A, kohäsiv) aus, von denen sich die längste zwischen Aminosäuren 318-662 erstreckt. „Coiled-Coil“"-Regionen sind bekannte ProteinProtein-Interaktionsdomänen. Damit im Einklang befindet sich auch die Pax-6Interaktionsdomäne von Mapl-1 (Aminosäuren 306-433, Abb.4A in Rot) innerhalb der ersten „Coiled-Coil"“-Region.

\subsection{Chromosomale Kartierung von mapl-1 in der Maus}

Sowohl zahlreiche menschliche Erkrankungen und Syndrome als auch bekannte Mausphänotype korrelieren mit Aberrationen in bestimmten Bereichen von Chromosomen. Dabei handelt es sich meistens um größere Deletionen, die mehr als ein Gen umfassen können, Translokationen oder auch Punktmutationen. Demzufolge kann die chromosomale Lokalisation eines Gens in einigen Fällen Aufschluß über seine mögliche Funktion liefern.

Mittels „Fluoreszenz in situ-Hbridisierung“ (FISH) wurde das mapl-1-Gen im Bereich E2-E3 des Chromosoms 17 der Maus kartiert (Abb. 5A-C). Zwischen mapl-1 und bekannten chromosomalen Aberrationen konnte jedoch anhand dieser Information keine Verbindung hergestellt werden. 

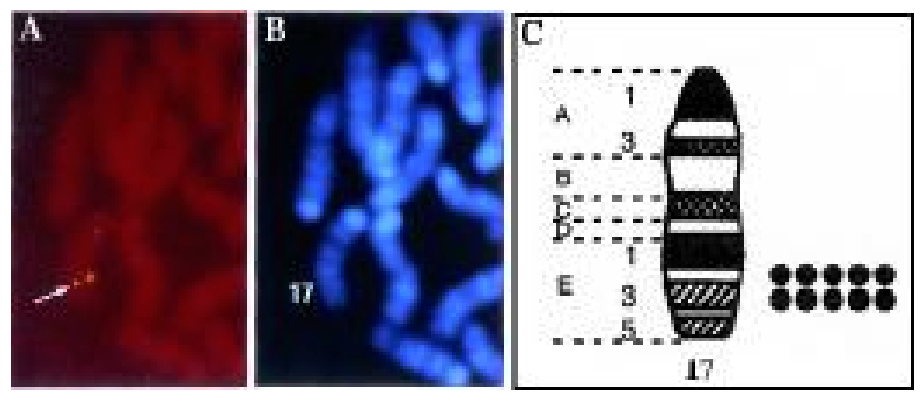

\section{Abbildung 5}

FISH an präparierten Mauschromosomen aus synchronisierten Lymphozyten. A: Das spezifische FISH-Signal ist an einem einzigen Chromosomenpaar lokalisiert, das anhand der DAPI-Bänderung, (B), als das Chromosom 17 identifiziert wurde; C: Schematische Darstellung der FISH-Analyse: jedes detektierte doppelte FISH-Signal wird als Punkt dargestellt. Das mapl-1-Gen befindet sich daher auf Chromosom 17 in der Region E2-E3.

\subsection{Mapl-1-ähnliche Proteine in der Maus und anderen Spezies}

Die Vervollständigung der Sequenzierung des Genoms der Fruchtfliege Drosophila melanogaster, des Menschen sowie Teilen des Mausgenoms, ermöglichte die Identifizierung weiterer Mapl-1-ähnlicher Proteine. Mit Hilfe von BLAST-Sequenzanalysen konnten im Genom des Menschen insgesamt drei Gene als mögliche mapl-1 - orthologe Gene identifiziert werden. Es handelt sich um die Klone KIAA0802 auf Chromosom 18 (p11.2-p11.3) (Nagase et al., 1998b), KIAA0889 auf Chromosom 20 (q11.22-q11.23) (Nagase et al., 1998a) und CAB65989 auf dem Chromosom 6 (q22.31) (Laird, G., 2000: direct submission). Ein Mehrfachvergleich der zur Zeit in der Datenbank vorhandenen Sequenz dieser Proteine mit dem Maus-Mapl-1 wird in Abb.6 dargestellt. Aus diesem Vergleich geht hervor, daß Mapl-1 mit dem humanen KIAA0802-Protein die höchste Sequenzidentität aufweist (82.6\%), sowie die niedrigste mit CAB65989 (22.4\%). KIAA0889 ist zu 36.7\% mit Mapl-1 identisch. Da es sich um Klone handelt, die aus der Sequenzierung des menschlichen Genoms entstanden sind, ist die cDNA-Sequenz dieser Gene nur zum Teil in der Datenbank vorhanden. Aus diesem Grund konnte zwischen den entsprechenden Proteinen ein Sequenzvergleich innerhalb der Region, die als Pax-6-Interaktionsdomäne dient, nicht erstellt werden. 


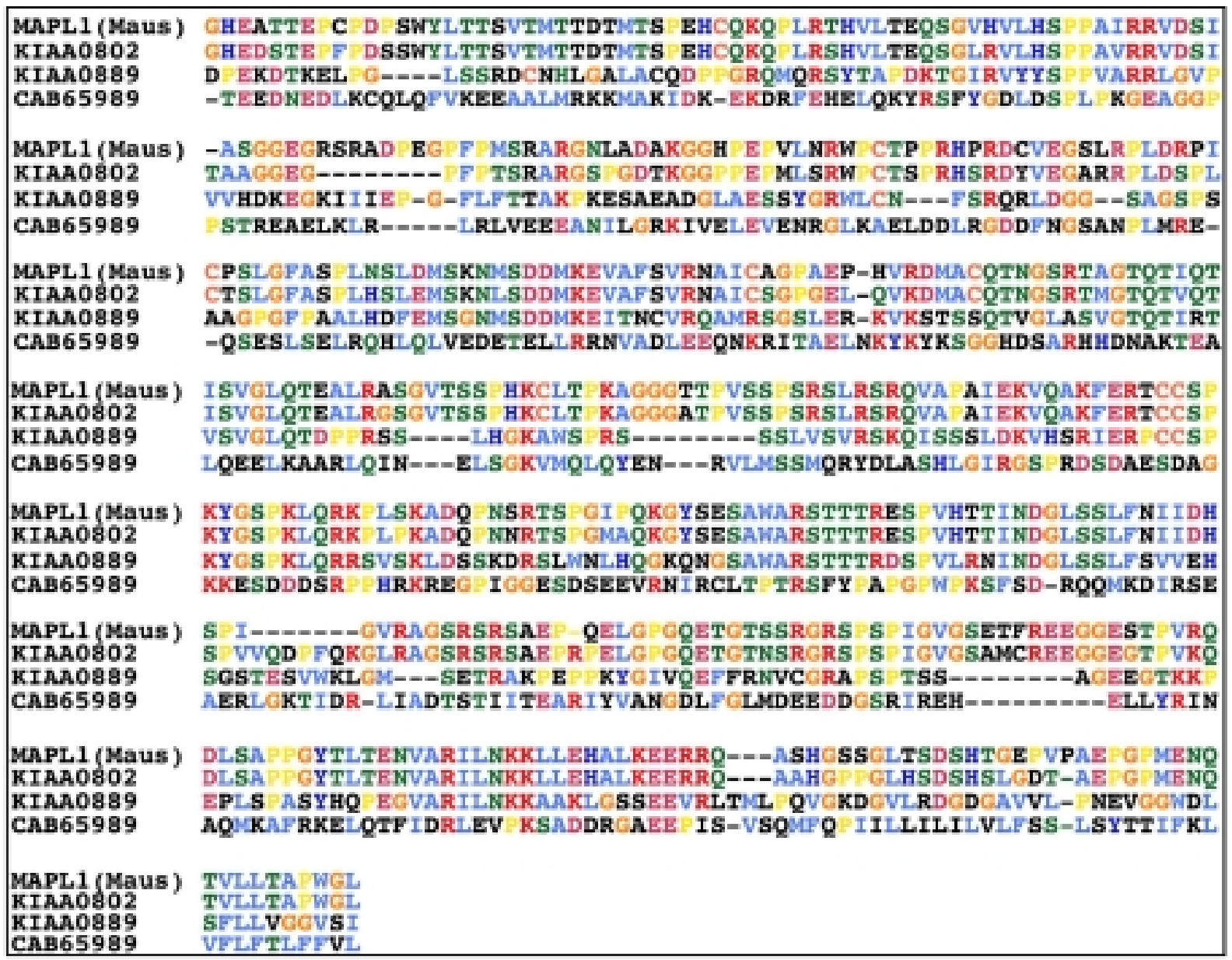

\section{Abbildung 5}

Vergleich der Aminosiuresequenz der Proteine, die im Menschen als Mapl-1-ăhnlich identifiziert wurden mit der Sequenz des Mapl-1 Proteins der Maus. Der dargestellte Vergleich wurde mit Hilfe von CLUSTAL erstellt.

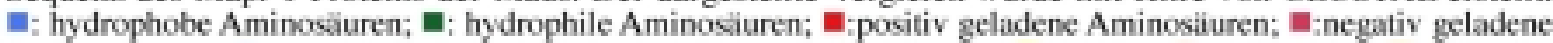
Aminostiuren; $\mathbf{m}$; aromatische, nicht hydrophobe Aminosäuren; 1 ; Prolin; $\mathbf{m}$; Cystein; $\mathbf{m}$; Glycin.

Gemäß den bis jetzt vorhandenen Daten, scheint es im Mausgenom ebenfalls drei Gene zu geben, die zur Mapl-Familie gehören. Zusätzlich zu mapl-1 und mapl-2, die bereits in dieser Arbeit erwähnt wurden, konnte mit Hilfe von BLAST ein drittes Gen identifiziert werden. Es handelt sich um den EST-Klon mit der Nummer BAB31090 (Carninci, 1999), der durch die Sequenzierung des Mausgenoms identifiziert wurde.

Interessanterweise sind Mapl-ähnliche Proteine auch in Invertebraten vorhanden. Es konnte sowohl in der Fruchtfliege Drosophila melanogaster, als auch in der Nematode Caenorhabditis elegans jeweils ein Protein identifiziert werden, das Sequenzähnlichkeit zu Mapl-1 der Maus aufweist. Es handelt sich um das 1833 Aminosäure-lange Protein CG18304 (Adams et al., 2000) von Drosophila und das Protein CAB023023 von C.elegans ( The $c$. elegans sequencing consortium, 1998) das 1577 Aminosäuren lang ist. Die Sequenzidentität zwischen den beiden Proteinen und Mapl-1 erstreckt sich über die gesamte Länge der Proteinsequenz, ist jedoch besonders hoch (40.8\% bei CAB02323 bzw. 32\% bei CG18304) 
innerhalb der Domäne, welche der Pax-Interaktionsdomäne (PID) von Mapl-1 entspricht (Abb.7).

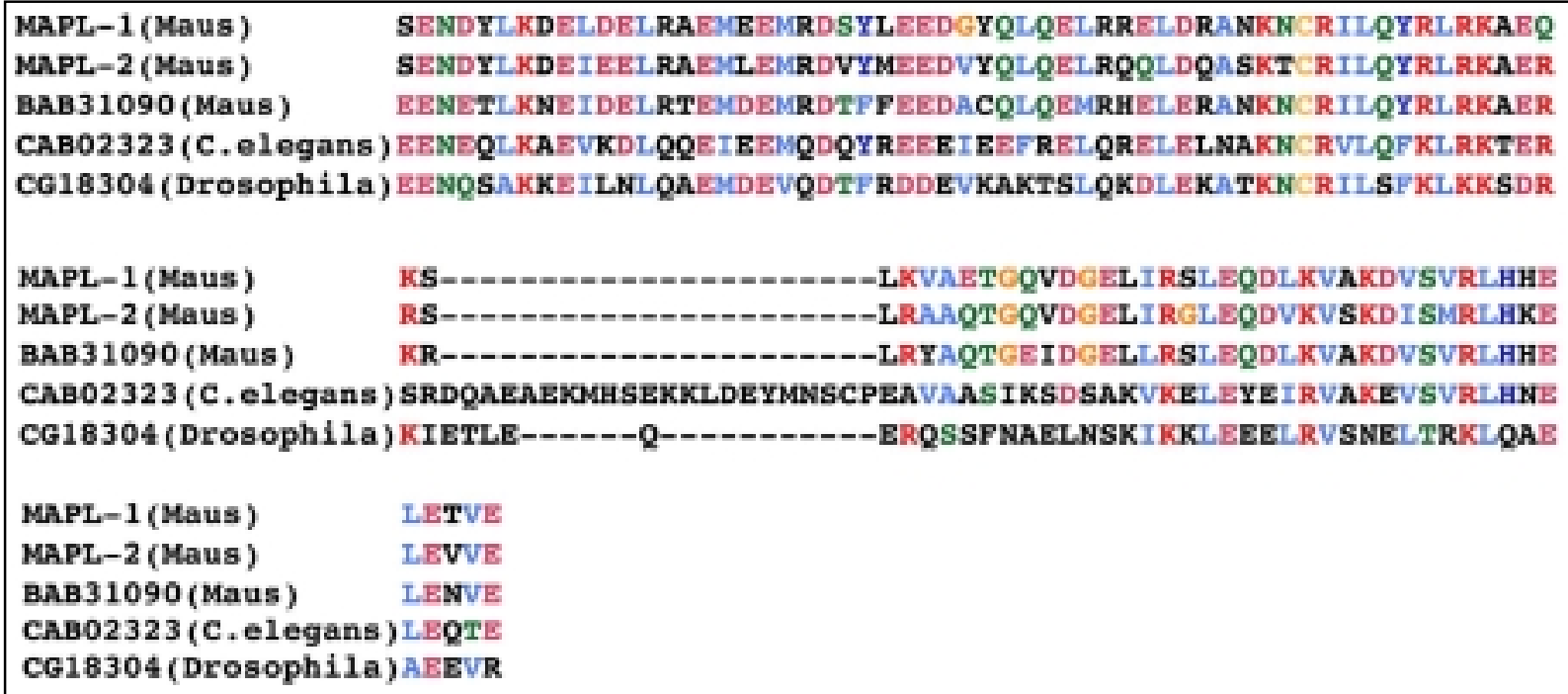

Abbildung 7

Vergleich der Aminosäuresequenz zwischen Mapl-1 und den Proteinen Mapl-2 und BAB31090 der Maus, CAB02323 von C.elegans und CG18304 von Drosophila. Verglichen werden die Proteinbereiche, welche der Pax-Interaktionsdomäne von Mapl-1 entsprechen. Der dargestellte Vergleich wurde mit CLUSTAL erstellt. Es gilt der gleiche Farbcode wie in Abb.6.

Aus den hier dargestellten Sequenzvergleichen geht hervor, daß das als Pax6 Interaktionspartner identifizierte Mapl-1 Protein, das erste Mitglied einer neuen Proteinfamilie darstellt, die in der Maus und im Menschen jeweils drei Proteine umfaßt. Entsprechend der starken Spezieskonservierung des Pax-6 Proteins scheinen auch im Fall von Mapl-1 orthologe Proteine in Drosophila und C.elegans zu existieren. Unter Berücksichtigung der sehr wichtigen und konservierten Funktion von Pax-6 während der Embryogenese in verschiedenen Spezies würde man ebenfalls von einem Protein, das als Pax6 Interaktionspartner dient, eine ähnliche Spezieskonservierung erwarten. Das Vorhandensein von Mapl-1-ähnlichen Genen in Invertebraten kann also im direkten Zusammenhang mit der Funktion von Mapl-1 als Pax-6-interagierendes Protein stehen. Allerdings konnten aus den identifizierten Proteinen keine zusätzlichen Erkentnisse über ihre mögliche Funktion gewonnen werden, da es sich um völlig neue Gene und Proteine handelt, von denen außer der Sequenz keine weiteren Informationen bekannt sind. 


\subsection{Expressionsmuster von mapl-1 im Vergleich zur Pax-6-Expression während der frühen Embryogenese}

Wie in Abschnitt 2.1. erwähnt wurde, weist mapl-1 ein mit Pax6 zum Teil überlappendes Expressionsmuster auf, das mit der möglichen Funktion des Mapl-1-Proteins als Pax-6 Interaktionspartner im Einklang steht. Um den Grad der Überlappung sowie die Unterschiede in der Expression von mapl-1 und Pax6 zu untersuchen, wurde eine detailierte vergleichende Expressionsanalyse in Raum und Zeit während der Embryonalentwicklung durchgeführt. Während der frühen Embryogenese (E8-E10) ist mapl-1 in allen Pax-6-Expressionsdomänen aktiv (Abb.8). Im Gegensatz zu Pax-6, dessen früheste Expression am Tag 8,0 der Mausententwicklung nachgewiesen wird (Walther and Gruss, 1991a), ist mapl-1 bereits im Stadium des Primitvstreifens (E7,5), also früher als Pax-6, im embryonalen Anteil exprimiert (Abb.8E). Wie aus Abb.8 und anhand der Stärke des Hybridisierungssignals ersichtlich ist, scheint mapl-1 deutlich schwächer exprimiert zu sein als Pax-6. Am Tag 8,5 der Embryonalentwicklung ist mapl-1 in den sich vom ventralen Vorderhirn ausstülpenden Augenbläschen, im sich entwickelnden Neuralrohr und im Telencephalon mit Pax-6 koexprimiert (Abb. 8A-C). Der auffälligste Unterschied in der frühen Expression der zwei Gene liegt darin, daß Pax-6 aussschließlich im Telencephalon und Diencephalon aktiv ist und mit seiner posterioren Exressionsdomäne die Grenze zwischen Di- und Mesencephalon definiert, während die Expression von mapl-1 über diese Abgrenzung hinaus, in das Mesencephalon erstreckt (Abb.8I, M vgl. mit 8J, N). Vielmehr scheint mapl-1 im Telencephalon und innerhalb der Pax-6 Expressionsdomäne bis zur posterioren Comissure stärker exprimiert zu sein als im angrenzenden Mesencephalon (Abb.8F, M). Pax-6 und mapl1 sind zusätzlich im Hinterhirn und im olfaktorischen Epithel coexprimiert (Abb.8I-L). Im Neuralrohr ist mapl-1 am Tag 9,5 der Entwicklung, ähnlich wie Pax6 im ventralen Anteil, exprimiert (Abb.8F), während am Tag E10,5 eine zusätzliche starke Expressionsdomäne in der dorsalen Spitze des Neuralrohrs erscheint (Abb.8I, Pfeil). In diesem Stadium können außerdem die mapl-1-Transkripte im ersten Branchialbogen sowie in den unteren Extremitäten nachgewiesen werden, in denen Pax-6 nicht exprimiert wird.

Zusammenfassend läßt sich aus dem frühen Expressionsmuster von mapl-1 schließen, daß mapl-1 früher als Pax6 aktiv ist, bis E10,5 vollständig mit Pax6 in seiner Expression überlappt, aber ein breiteres Expressionsmuster als Pax6 aufweist. 

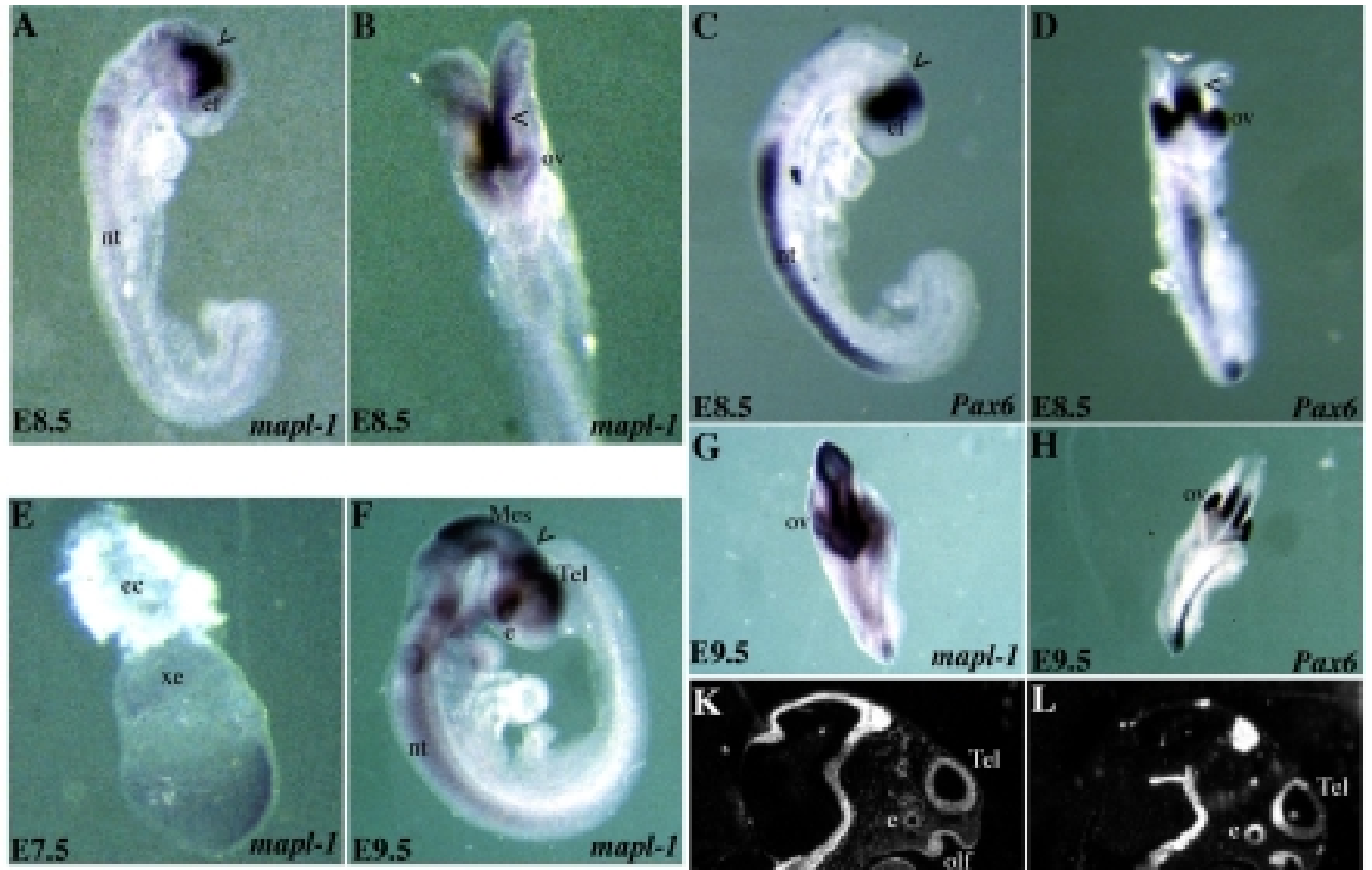

H
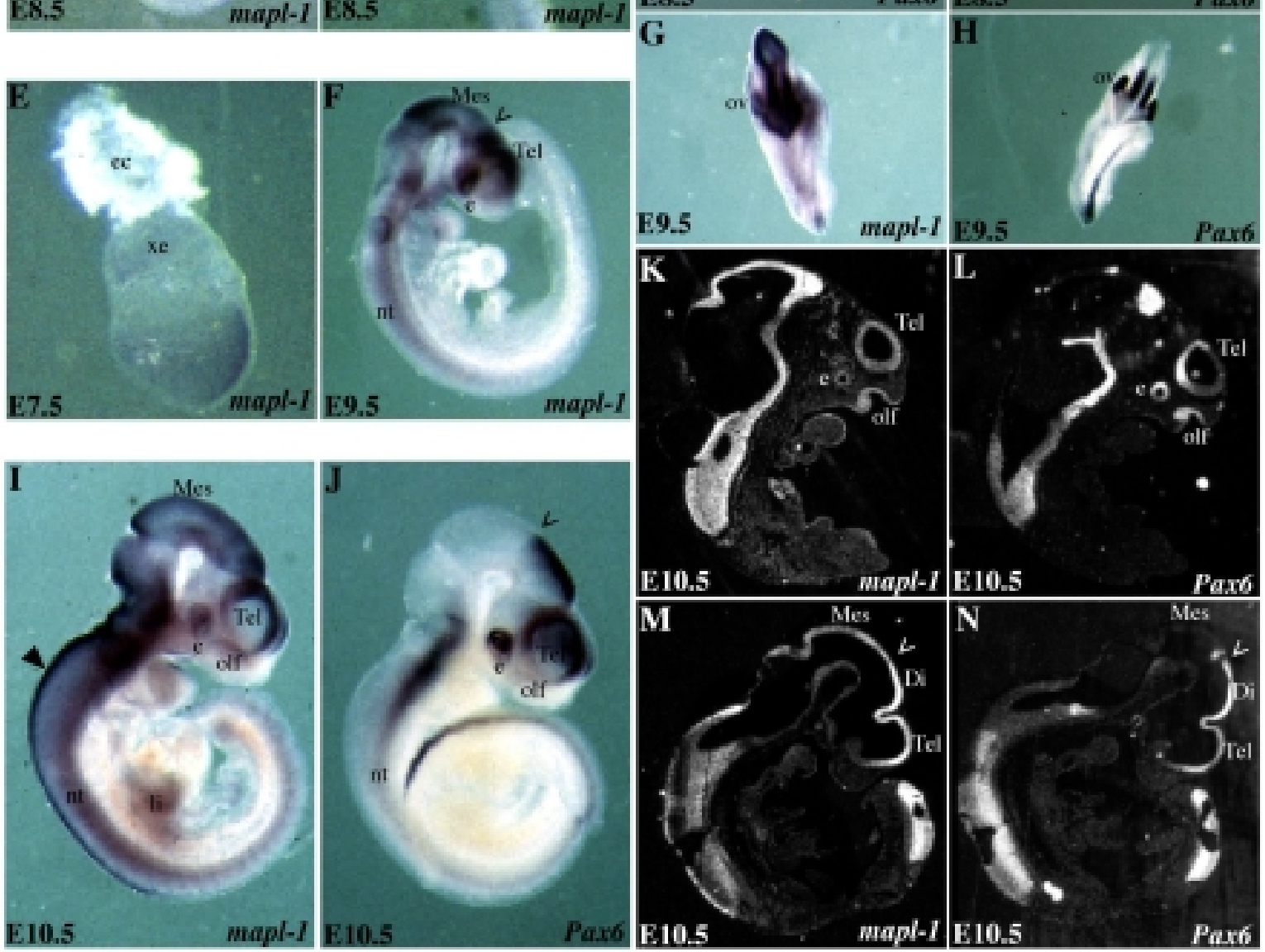

\section{Abbildung 8}

Expressionsmuster von mapl-1 im Vergleich zur Pax-6-Expression. Das Expressionsmuster der zwei Gene weist zwischen E8,5 und E10,5 eine hohe Überlappung auf. A-J: „Whole-mount“-in situ-Hybridisierung; K-N: radioaktive in situ-Hybridisierung an $8 \mu \mathrm{m}$-seriellen sagittalen Schnitten, (K-L), (M-N). Abkürzungen: ef: Augenfeld; nt: Neuralrohr; ov: Augenbläschen; ec: Ektoplacenta; xe: Extraembryonaler Teil des Embryos im Primitivstreifenstadium; Tel: Telencephalon; Mes: Mesencephalon; Di: Diencephalon olf: olfaktorisches Epithel; e: Auge. Offener Pfeil markiert die posteriore Grenze der Pax-6-Expression im Diencephalon; geschlossener Pfeil markiert die starke Expressionsdomäne von mapl-1 im dorsalen Abschnitt des Neuralrohrs, die ab E10,5 auftritt.

\subsection{Expression von mapl-1 folgt der Pax-6-Expression während der Augenentwicklung}

Die biologische Rolle von Pax-6 während der Entwicklung sowohl von Invertebraten als auch Vertebraten ist eng mit der Entstehung von Augenstrukturen in diesen Organismen 
verbunden. Um eine potentielle Rolle von Mapl-1 als Pax-6-Interaktionspartner während der Entstehung von Augenstrukturen zu untersuchcen, wurde die Expression des mapl-1-Gens im Vergleich zur Pax-6-Expression im Verlauf der Augenentwicklung analysiert (Abb.9).

Am E9,5 erreichen die Augenbläschen das Oberflächenektoderm, aus dem die Linse entsteht. Nach dem Kontakt des Augenbläschens und des Ektoderms am E9,5 kommt es zur Verdickung des Ektoderms und zur Ausbildung der Linsenplakode. Wie Pax-6 ist auch mapl1 sowohl in den Augenbläschen als auch im Oberflächenektoderm exprimiert (Abb. 9A vgl. mit D). Am E10,5 hat sich bereits das Linsenbläschen aus dem Oberflächenektoderm abgetrennt, während das Augenbläschen den zweischichtigen Augenbecher bildet. Mapl-1 ist ähnlich wie Pax-6 in diesen Strukturen exprimiert (Abb. 9B vgl. mit E). Am E11,5 ist aus der inneren Schicht des Augenbechers die Neuroretina entstanden, während die äußere Schicht zum Pigmentepithel differenziert. Aus dem Linsenbläschen geht die Linse mit einem äußeren Linsenepithel und den primären Linsenfasern hervor. Sowohl in der Linse als auch in der Neuroretina und dem Pigmentepithel ist mapl-1 mit Pax-6 coexprimiert (Abb.9C vgl. mit F). Aus dem Oberflächenektoderm, das ebenfalls beide Gene exprimiert, wird die Kornea gebildet.

Aus dieser Analyse geht hervor, daß mapl-1 und Pax-6 während des Prozesses der Augenentwicklung in den gleichen Strukturen exprimiert sind. Wie in Abschnitt 2.5 erwähnt und aus Abb.9 ersichtlich ist Pax-6 viel stärker als mapl-1 exprimiert. 


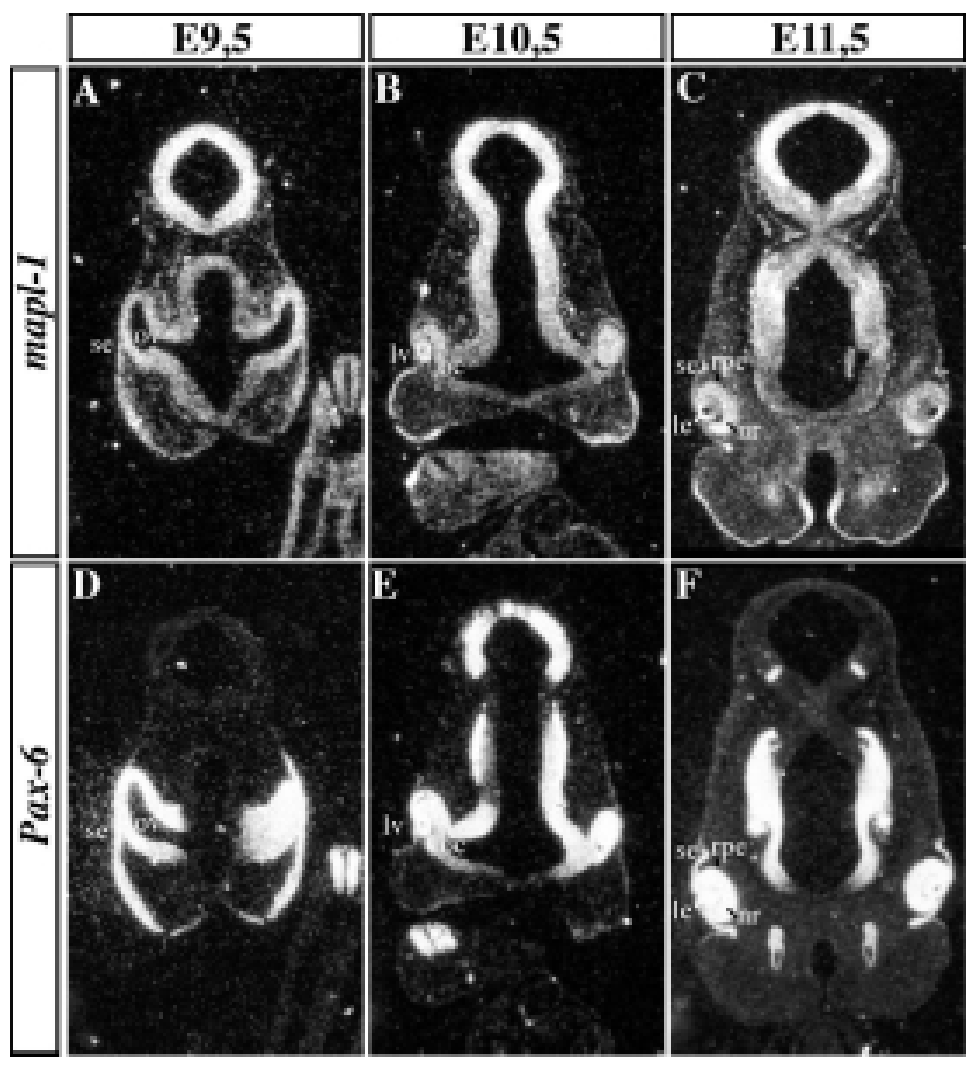

Abbildung 9

Pax-6 und mapl-1 sind in allen Strukturen des sich entwickelnden Auges coexprimiert. Radioaktive in-situHybridisierung an $8 \mu \mathrm{m}$-coronalen Schnitten. A-D, B-E, C-F zeigen im Vergleich serielle Schnitte. Abkürzungen: se: Oberflächenektoderm; ov: Augenbläschen; lv: Linsenbläschen; oc: Augenbecher; nr: Neuroretina; rpe: Pigmentepithel.

\subsection{Expression von Pax-6 und mapl-1 in komplementären Domänen}

Das Expressionsmuster von mapl-1 nach E10,5 kann sowohl als überlappend als auch als komplementär zu dem von Pax-6 bezeichnet werden. Am E11,5 sind im embryonalen Gehirn Regionen erkennbar, in denen sich die Expression von mapl-1 und Pax6 gegenseitig ausschließt (Abb.10). Was als erstes auffällt ist, daß die Expression von mapl-1 im dorsalen Telencephalon nicht mehr mit der von Pax6 überlappt. Während Pax-6 auch nach E10,5 ausschließlich in der Ventrikulärzone des dorsalen Telencephalons aktiv bleibt (Abb.10A vgl mit E, offener Pfeil), ist die Expression von mapl-1 ab E11,5 in den äußeren Schichten begrenzt. Die zwei Gene sind jedoch immer noch im ventralen Telencephalon (Abb.10A vgl. mit E, geschlossener Pfeil) und im Dienzephalon koexprimiert. In mehr posterioren Schnitten (Abb.10B-C, vgl. mit F-G) läßt sich die komplementäre Expression von Pax-6 und mapl-1 in der Struktur, welche die Vorstufe des Choroid Plexus darstellt, nachweisen (offene Pfeile). Während Pax-6-Transkripte in dieser Struktur nicht nachweisbar sind, ist mapl-1 stark 
exprimiert. Umgekehrt ist Pax-6 in den Eminentia thalami und im ventralen Thalamus stark exprimiert, während die Expression von mapl-1 herunterreguliert wird. Mapl-1 scheint im dorsalen Thalamus oberhalb der zona limitans intrathalamica in einer Domäne, in der Pax-6 nicht exprimiert wird, stark aktiv zu sein. Schließlich setzt sich das komplementäre Expressionsmuster dieser beiden Gene auch im Epithalamus fort, in dem Pax-6-, aber nicht mapl-1-Transkripte nachweisbar sind. Weiterhin sind beide Gene im olfaktorischen Epithel aktiv. Mapl-1 ist außerdem ähnlich zu Pax-6 in der Vorstufe der Adenohypophyse „RathkeTasche" exprimiert (Abb.10D vgl. mit H). Im Gegensatz zu Pax-6 ist mapl-1 stark im Trigeminalganglion aktiv.

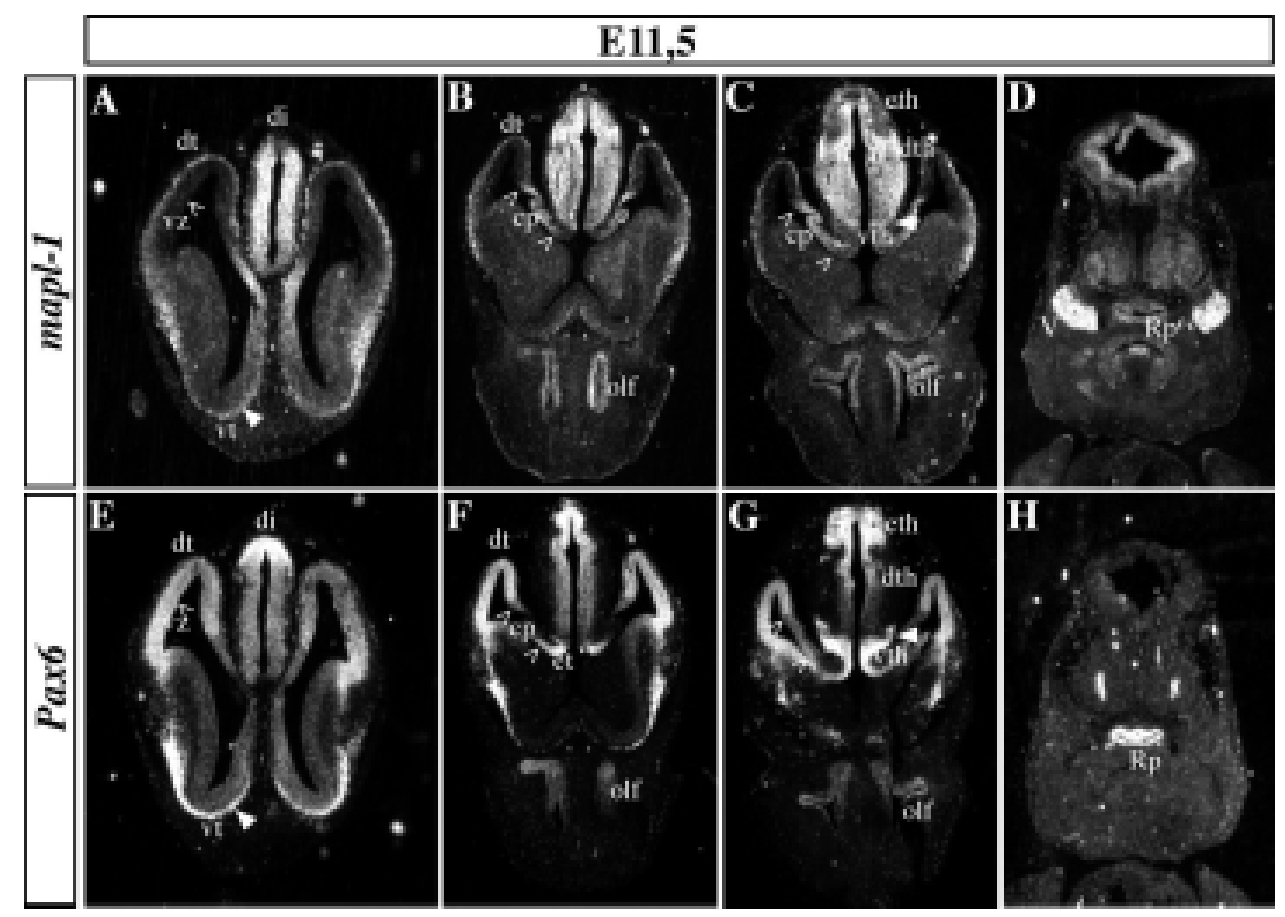

\section{Abbildung 9}

Mapl-1 und Pax6 sind in überlappenden als auch in sich gegenseitig ausschließenden Domänen exprimiert. Radioaktive in-situ-Hybridisierung an $8 \mu \mathrm{m}$-coronalen Schnittten eines E11,5 Embryos. A-E, B-F, C-G bzw. D-H zeigen im Vergleich serielle Schnitte. Die Orientierung in A-D bzw. E-H ist von anterior zu posterior. Abkürzungen: dt: dorsales Telencephalon; vt: ventrales Telencephalon; di: Diencephalon; vz: Ventrikulärzone (in A, E durch offene Pfeile markiert); cp: Vorstufe des choroid Plexus (in B, C, F, G durch offene Pfeile markiert); et: Eminentia thalami; olf: olfaktorisches Epithel; eth: Epithalamus; dth: dorsaler Thalamus; vth: ventraler Thalamus; Rp: „Rathke-Tasche“; V: Trigeminalganglion. Geschlossener Pfeil in C, G markiert die zona limitans intrathalamica.

\subsection{Mapl-1 Expression in fortgeschrittenen Entwicklungsstadien}

Im Verlauf der Embryonalentwicklung wird mapl-1 mit einem immer breiter werdenden Muster exprimiert, auch in Regionen, in denen keine Pax-6 Expression nachweisbar ist. Am E12,5 und E13,5 lassen sich mapl-1 Transkripte in den äußeren Schichten des frontalen 
Cortex nachweisen, angrenzend an die Ventrikulärzone, in der Pax-6 exprimiert wird (Abb.11 A-B vgl. mit E-F). Auch im Thalamus wird die komplementäre Expression von mapl-1 (im dorsalen Thalamus) im Vergleich zu Pax-6 (im ventralen Thalamus) beibehalten. Koexprimiert sind die zwei Gene in der „Rathke-Tasche“, im Neuralrohr, in der Pons und im olfaktorischen Epithel. Zusätzliche Expressionsdomänen von mapl-1 sind die Knorpelanlagen der Wirbel sowie der Intestinalbereich (Abb.11A). Am E13,5 weisen Pax-6 und mapl-1 in der externen Körnerschicht des Cerebellums überlappende Expression auf (Abb.11C, vgl. mit G). Während jedoch Pax-6 im Bereich des Hinterhirns in der Ventrikulärzone exprimiert wird (Abb.11D, offener Pfeil), sind mapl-1 Transkripte in einer ventral davon angrenzenden Domäne nachweisbar (Abb.11H). Auffällige Domäne der Koexpression beider Gene ist in den abgebildeten Schnitten von E14,5 Embryonen der vestibuläre Kern (Abb.11D, vgl. mit $\mathrm{H})$.

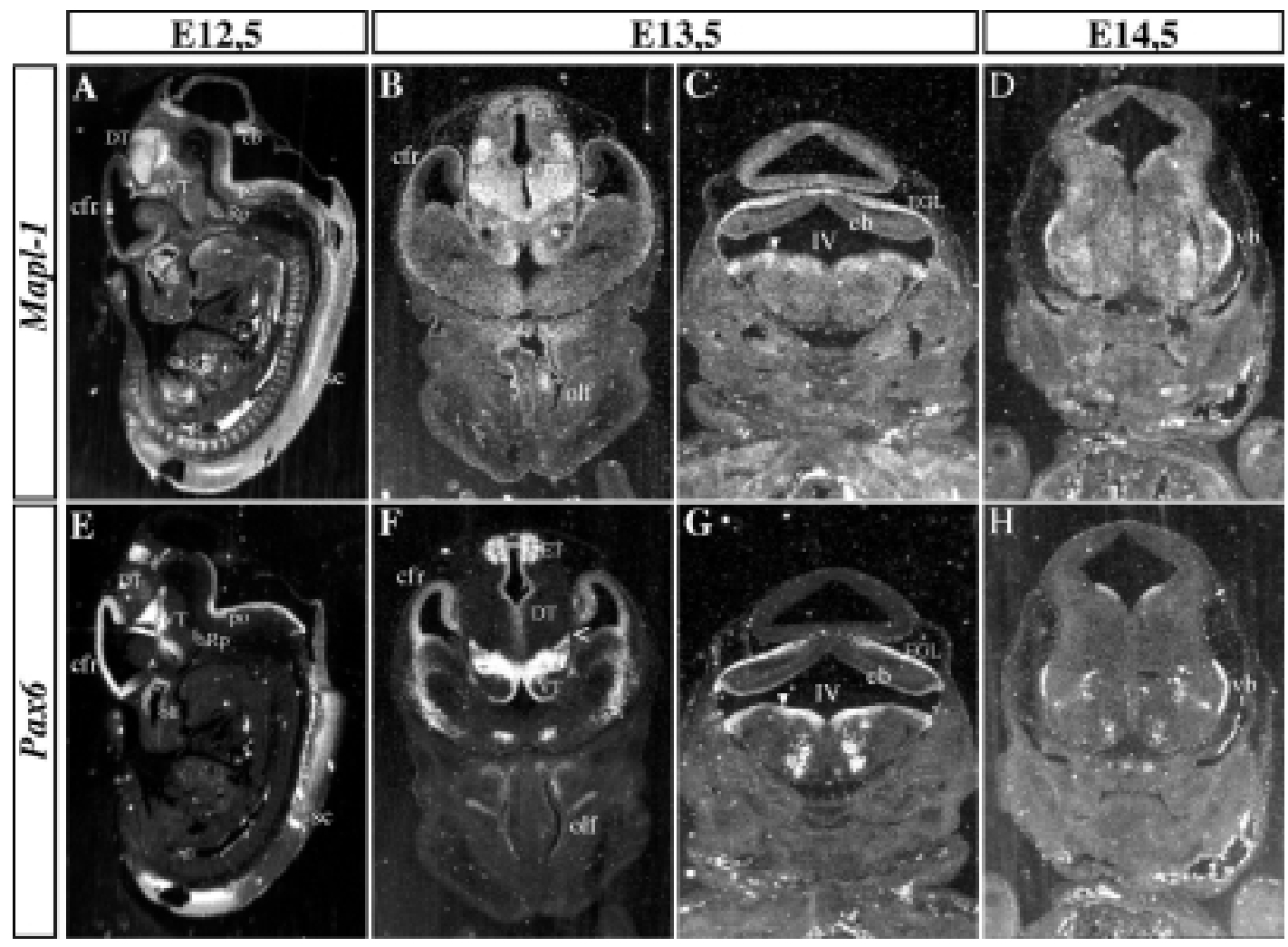

\section{Abbildung 11}

Expression von mapl-1 im Vergleich zur Pax-6 Expression am E12,5, E13,5 und E14,5. Radioaktive in-situHybridisierung an $8 \mu \mathrm{m}$-sagittalen (A, E) bzw. coronalen (B-D, F-H) Schnitten. (A, E), (B-F) (C, G) bzw. (D, H) sind serielle Schnitte im Vergleich. Abkürzungen: cfr: frontaler Cortex; ET: Epithalamus; DT: dorsaler Thalamus; VT: ventraler Thalamus ; cb: Cerebellum; po: Pons; Rp: „Rathke-Tascshe“; sc: Neuralrohr; g: Intestinalbereich; olf: olfaktorisches Epithel; cpv: Knorpelanlage der Wirbel; EGL: externe Körnerschicht des Cerebellums; IV: IV Ventrikel; vb: vestibulärer Kern. B, F: offener Pfeil markiert die zona limitans 
intrathalamica; C, G: geschlossener Pfeil markiert die Ventrikulärzone im Bereich des IV Ventrikels, in der Pax-6 nicht aber mapl-1 exprimiert ist.

\subsection{Weitere mapl-1 Expressionsdomänen}

Die in den vorangegangenen Abschnitten präsentierten Expressionsdaten weisen darauf hin, daß mapl-1 zwischen E8,5 und E10,5 ein zu Pax-6 sehr ähnliches Expressionsmuster aufweist. Ab E11,5 jedoch wird die Expression von mapl-1 immer breiter, so daß mapl-1 zusätzlich zu den mit Pax-6 überlappenden und komplementären Domänen auch in Regionen des Embryos exprimiert wird, die in keinem Zusammenhang mit Pax-6 stehen. So läßt sich eine starke Expression des Gens am E11,5 im Trigeminalganglion und in den Spinalganglien nachweisen (Abb.12A). Mapl-1 Transkripte werden auch in Strukturen endodermalen Ursprungs wie der Lunge (Abb.12F) oder dem Darm (Abb.12G) detektiert. Im sich entwickelnden Telencephalon ist die Expression von mapl-1 mit dem Beginn der Differenzierung der Neuronen von der Ventrikulärzone ausgeschlossen, so daß das Gen ab E11,5 (vgl. Abb.10A-F) nur in den äußeren Schichten des Telencephalons aktiv ist. In späteren Entwicklungsstadien wird diese Expression beibehalten, so daß mapl-1 nur in postmitotischen Neuronen, aber nicht in der Ventrikulärzone exprimiert wird (Abb.12B-C, HI). Im Gehirn von E18,5 Embryonen ist mapl-1 über die gesamte Dicke der kortikalen Platte aktiv, ohne erkennbare Spezifität für bestimmte Schichten des cerebralen Kortex (Abb.12C, H). Erst in postnatalen Stadien läßt sich eine stärkere Expression des Gens im Bereich des somatosensorischen Kortex erkennen (Abb.12D), während mapl-1 im Motorkortex schwächer exprimiert wird. Auch im postnatalen Gehirn sind mapl-1 Transkripte nicht in der Ventrikulärzone nachzuweisen (Abb.12I). Zusätzlich zum cerebralen Kortex ist mapl-1 postnatal im Cerebellum und stark im vestibulären Kern aktiv (Abb.12E). Zudem wird die Expression des Gens im olfaktorischen Neuroepithel im Bulbus olfactorius (OB) und im akzessorischen OB nachgewiesen. Mapl-1 scheint insbesondere spezifisch in den Mitralzellen des OB exprimiert zu sein. 


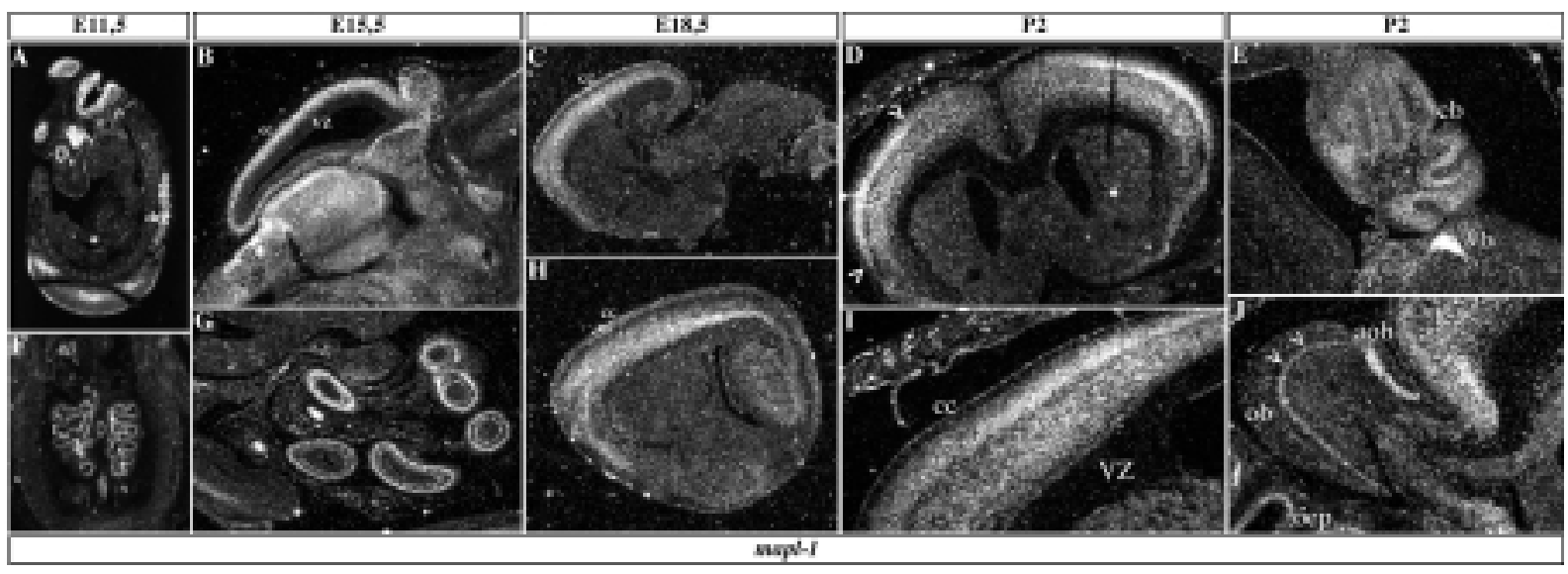

Abbildung 12

Expressionsdomänen von mapl-1, die nicht mit der Pax-6 Expression korrelieren. In-situ-Hybridisierung an $8 \mu \mathrm{m}$ (A, F) bzw. 10 $\mathrm{m}$ (rest) sagittalen (A-C, E, G-J) bzw. coronalen (D, F) Schnitten. Abkürzungen: e: Auge; V: Trigeminalganglion; drg: Spinalganglien; L: Lunge; VZ: Ventrikulärzone; cc: cerebraler Kortex; cb: Cerebellum; vb: vestibulärer Kern; ob: Bulbus olfactorius; aob: akzessorischer Bulbus olfactorius; oep: olfaktorisches Neuroepithel. D, (Pfeile): markieren den Bereich des somatosensorischen Kortex, in denen mapl1 stärker exprimiert wird; $\mathbf{J}$ (Pfeile): markieren die spezifische Expression von mapl-1 in der mitralen Zellschicht des Bulbus olfactorius.

\subsection{Die Paired-Domäne von Pax-6 als interagierende Region}

Um einerseits die in der Hefe nachgewiesene Interaktion zwischen Mapl-1 und Pax-6 in vitro zu bestätigen und andererseits, die an dieser Interaktion beteiligte Domäne von Pax-6 zu identifizieren, wurde das in Abb.13 dargestellte GST-,Pull-down“ durchgeführt. Dabei wurde die Pax-Interaktionsdomäne (PID) von Mapl-1 (Abb.4A) an GST fusioniert (GST-PID), in E.coli produziert und mit in vitro translatierten und radioaktiv markierten Pax-6-Varianten inkubiert. Die in diesem Assay eingesetzten Proteine sind schematisch in Abb.13A dargestellt. Untersucht wurde die Retention der markierten Proteine an das GST bzw. GSTPID. Das Ergebnis dieses Experiments zeigt, daß die Paired Domäne (PD) von Pax-6 direkt an der Interaktion mit Mapl-1 beteiligt ist. Insbesondere ist es die aminoterminale Unterdomäne (PAI) der PD, welche die Interaktion vermittelt, da die Variante der Pax-6 PD, in der eine Insertion von 14 Aminosäuren durch alternatives Spleißen in der aminoterminalen Unterdomäne entsteht, PD(5a), nicht an GST-PID binden kann (Abb.13C). Dies ist von besonderer Bedeutung, da die PD die Haupt-DNA-bindende Domäne von Pax-6 darstellt. 


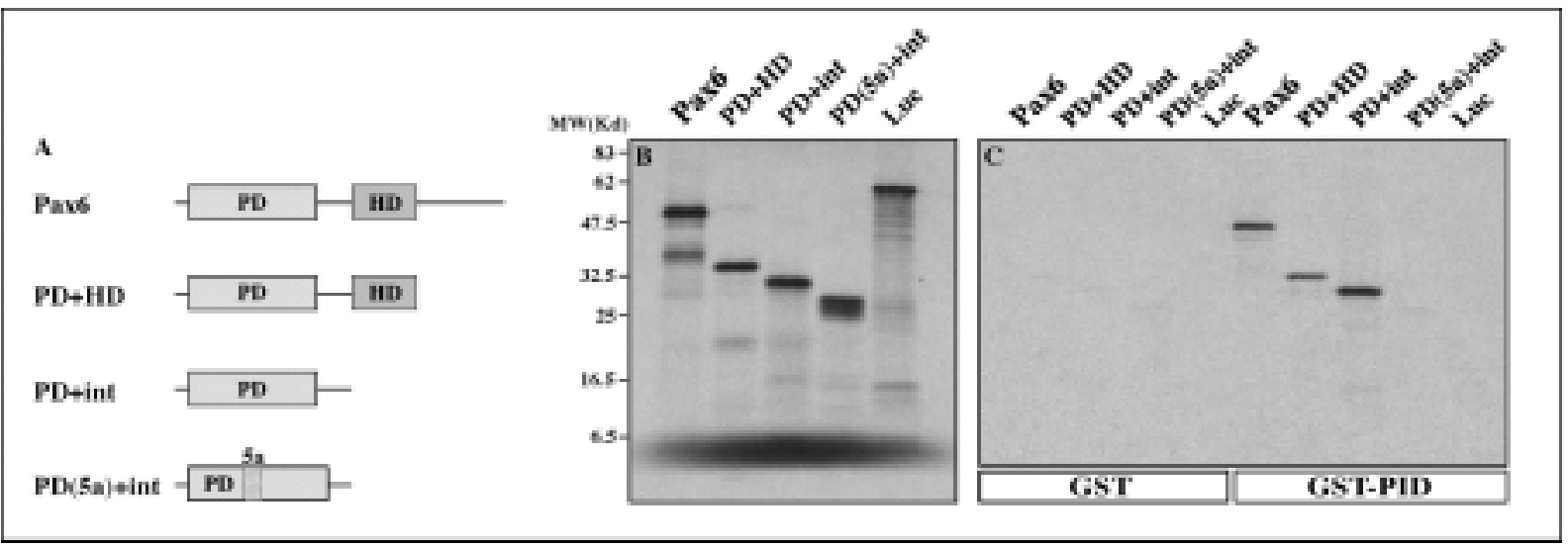

Abbildung 13

Die Pax-6 Paired Domäne ist direkt an der Interaktion zwischen Mapl-1 und Pax-6 beteiligt. A: Schematische Darstellung der Pax6-Varianten, die als in vitro translatierte und mit ${ }^{35} \mathrm{~S}$-Met markierte Proteine (B) in diesem Assay eingesetzt wurden. Pax-6: vollständiges Pax-6-Protein; PD+HD: Pax6-Variante ohne die carboxyterminale Aktivierungsdomäne; PD+int: Pax6-Variante ohne Aktivierungsdomäne und Homöodomäne; PD(5a): Durch alternatives Spleißen entstehende PD-Variante mit 14 Aminosäuren-Insertion innerhalb der aminoterminalen (PAI) Unterdomäne. Luciferase wurde als unspezifisches Kontrollprotein in diesem Assay verwendet. Die in B dargestellte Menge der Proteine entspricht 20\% des tatsächlichen Inputs. C: Retention der markierten Proteine an das GST-PID Fusionsprotein, aber nicht an GST, das als Kontrolle diente. Es erfolgt keine Interaktion mit der PD(5a)+int Variante; dies läßt auf eine direkte Beteiligung der PAI Unterdomäne der PD an der Interaktion mit Mapl-1 schließen. Es findet ebenfalls keine Retention des Kontrollproteins Luciferase statt.

Weiterhin wurde getestet, ob Pax-6 zusätzlich zur isolierten PID auch mit dem vollständigen Mapl-1-Protein eine Interaktion eingehen kann. Dazu wurde ein GST-,,Pulldown“ durchgeführt, bei dem die isolierte PD von Pax-6 an GST fusioniert (GST-Pax6/PD) und zur Retention von entweder der isolierten PID oder dem vollständigen Mapl-1 eingesetzt wurde (Abb.14A). Daraus folgte, daß die Interaktion zwischen Pax-6 und Mapl-1 auch im Kontext des vollständigen Mapl-1 Proteins erfolgen kann und nicht auf die isolierte PID beschränkt ist. Zudem stellt dieses Experiment eine zusätzliche in vitro Bestätigung für die Echtheit der Interaktion zwischen den beiden Proteinen dar.

Mittels eines ähnlichen Assays wurde die minimale Domäne des Mapl-1 Proteins identifiziert, die für die Interaktion mit Pax-6 essentiell ist. Unter Verwendung des GST-Pax6/PD Fusionsproteins und verschiedener Deletionsvarianten des Mapl-1 Proteins innerhalb der PID konnte die für die Interaktion mit Pax-6 erforderliche Domäne des Mapl-1 Proteins auf 68 Aminosäuren reduziert werden. Es handelt sich um die Region zwischen den Aminosäuren 367 und 435 des Proteins (Abb.14B). Interessanterweise ist das Leucin-Zipper-Motiv des Proteins innerhalb dieser minimalen PID nicht enthalten. Dies weist darauf hin, daß das 
Leucin-Zipper Motiv-nicht an der Interaktion mit Pax-6, sondern möglicherweise an einer anderen Art von Protein-Protein Wechselwirkung beteiligt ist.

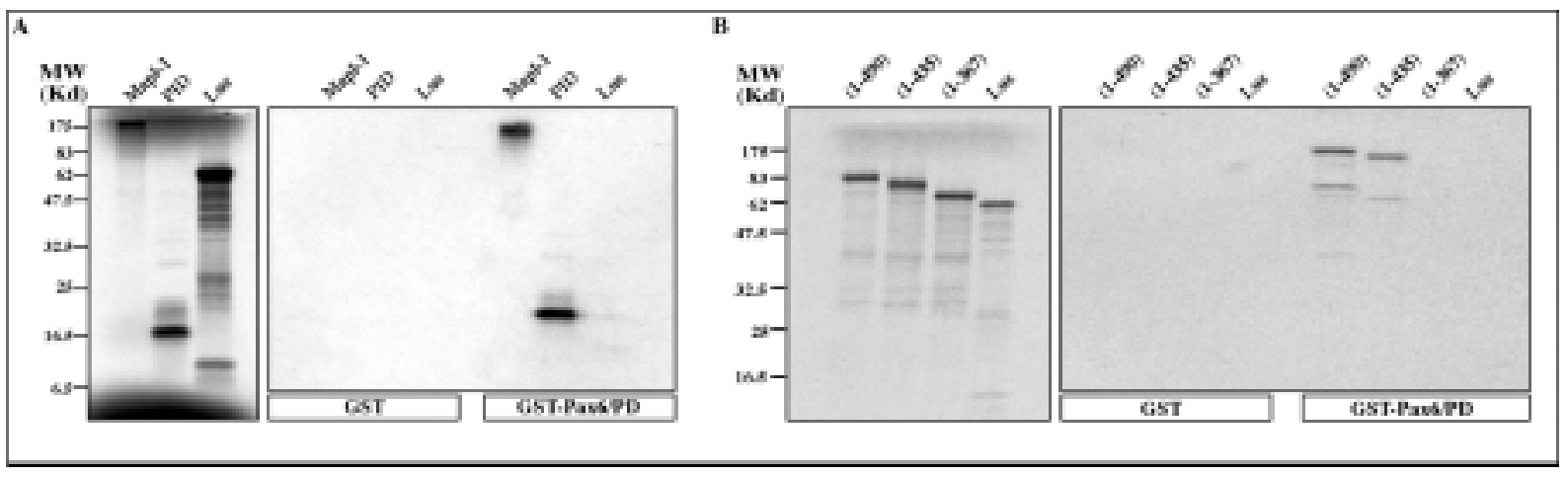

\section{Abbildung 14}

A: Pax-6 ist in der Lage, auch mit dem vollständigen Mapl-1-Protein zu interagieren. GST-,,Pulldown“ unter Verwendung des Fusionsproteins von GST und der PD von Pax6 (GST-Pax6/PD). GST wurde als Kontrolle benutzt. Links: Die bei diesem Assay verwendeten in vitro-translatierten und radioaktiv markierten Proteine, Map1-1: vollständiges Mapl-1 Protein; PID: die isolierte PID; Luc: Luciferase wurde als unspezifisches Kontrollprotein eingesetzt. Die dargestellte Proteinmenge entspricht 20\% des im Assay tatsächlich verwendeten Inputs. Rechts: Sowohl das vollständige Protein wie auch die in der Hefe identifizierte PID sind in der Lage, mit der PD zu interagieren. Es erfolgt keine Retention von Luciferase sowie keine Bindung der markierten Proteine an GST. B: Identifizierung einer minimalen Pax-Interaktionsdomäne. Deletionsvarianten des Mapl-1 Proteins wurden auf ihre Fähigkeit, mit der PD von Pax-6 zu interagieren, getestet. Links: Dargestellte Menge entspricht 20\% der im Assay eingesetzten Proteinmenge. Die Mapl-1 Deletionsvarianten waren an ein multimerisiertes Myc-Epitop am Aminoterminus fusioniert. Die Nummern beziehen sich auf die Aminosäurepositionen des Mapl-1 Proteins. Luciferase wurde als unspezifisches Kontrollprotein verwendet. Rechts: Die Deletionsvarianten 1-490 und 1-435, aber nicht das Protein 1-367 und Luciferase, sind in der Lage, mit der PD von Pax6 zu interagieren. Daraus läßt sich schließen, daß die für die Interaktion erforderliche Proteindomäne zwischen Aminosäuren 367 und 435 von Mapl-1 liegt.

\subsection{Interaktion zwischen Pax-6 und Mapl-1 in vivo}

Nach der Bestätigung der Interaktion der beiden Proteinen in vitro wurde als nächstes getestet, ob Pax-6 und Mapl-1 auch im zellulären Kontext miteinander interagieren können. Dazu wurden COS7-Zellen mit Expressionskonstrukten für die beiden Proteine transfiziert. Mittels Immunpräzipitation und anschließendem Western-Blot konnte ein Komplex zwischen Pax-6 und Mapl-1 in Gesamtextrakten aus den transfizierten Zellen nachgewiesen werden (Abb.15). Daraus kann geschlossen werden, daß die beiden Proteine nicht nur in der Hefezelle und in vitro, sondern auch im Kontext von Säugerzellen eine Interaktion miteinander eingehen können. Dies stellt die dritte unabhängige Methode dar, durch die die Interaktion zwischen Pax-6 und Mapl-1 bestätigt werden konnte. 


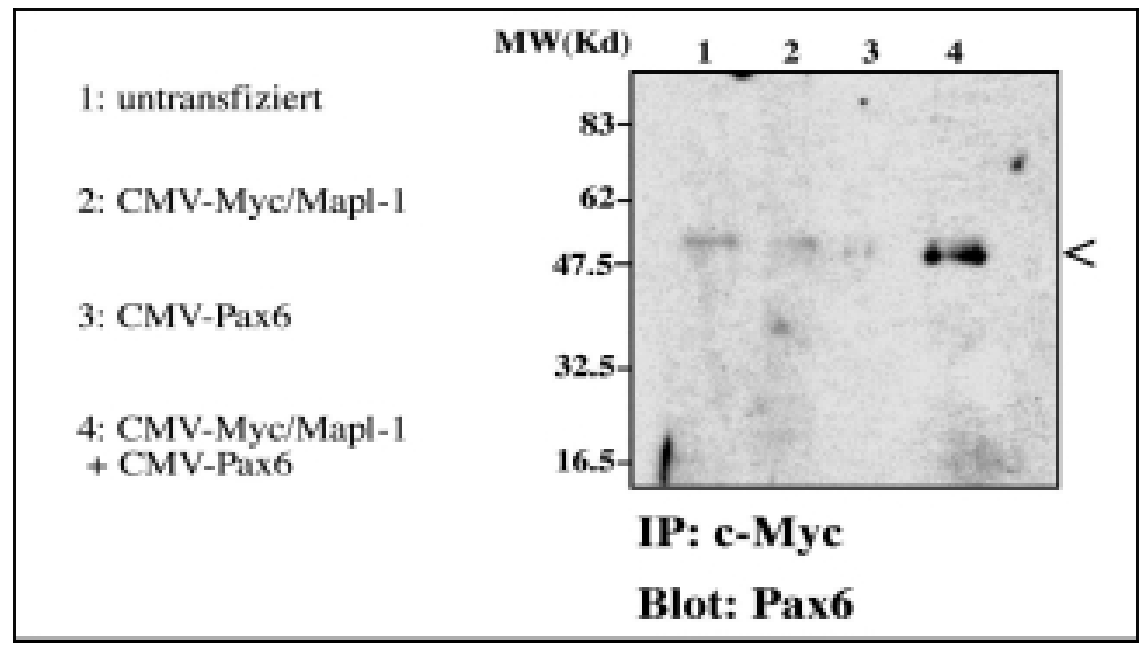

\begin{abstract}
Abbildung 15
Coimmunopräzipitation aus Extrakten von transfizierten COS7-Zellen bestätigt die Anwesenheit eines Komplexes zwischen Pax-6 und Mapl-1. COS7-Zellen wurden mit CMV-Expressionsplasmiden für Pax-6 oder Map1-1 an ein multimerisiertes Myc-Epitop fusioniert, oder mit der Kombination von beiden Plasmiden transfiziert. Proteine wurden aus Gesamtextrakten mit c-Myc Antikörper präzipitiert. Beim anschließenden Western-Blot wurde mit einem polyklonalen Pax-6 Antikörper auf die Anwesenheit des Pax-6-Proteins hin getestet. Die Pax-6-Bande (Pfeil) ist nur in den Extrakten von doppeltransfizierten, aber nicht in denen von einfach oder untransfizierten Zellen nachweisbar. Dies kann nur über die Bindung an Mapl-1 erfolgen.
\end{abstract}

\title{
2.13 Subzelluläre Lokalisation des Mapl-1 Proteins
}

Von entscheidender Bedeutung für die biologische Relevanz einer Wechselwirkung zwischen zwei Proteinen ist die Überlappung der Expression der entsprechenden Gene. Eine weitere Voraussetzung ist die Überlappung ihrer Lokalisation innerhalb der Zellen, in denen beide Proteine produziert werden. In der Primärstruktur des Mapl-1 Proteins konnte mittels des Computerprogramms PSORT ein nukleäres Lokalisationssignal (NLS) identifiziert werden (Abb. 4A), und anhandessen wurde das Protein vom gleichen Programm mit hoher Zuverlässigkeit als Kernprotein klassifiziert. Um dies experimentell zu bestätigen, wurde die kodierende Sequenz der mapl-1 cDNA in einen CMV-Expressionsvektor eingebaut, so daß eine Fusion mit einem multimerisierten c-Myc-Epitop am Aminoterminus des Proteins erfolgt (Myc/Mapl-1). Nach Transfektion von Säugerzellen (COS7) mit dem Expressionsvektor konnte die subzelluläre Lokalisation des Proteins mittels Immunfluoreszenz mit c-MycAntikörpern ermittelt werden. Überraschenderweise wies die Mehrheit der transfizierten Zellen eine Lokalisation des Proteins an Komponenten des Cytoskeletts auf (Abb.16B), während Pax-6 wie erwartet ausschließlich im Zellkern nachgewiesen wurde (Abb.16A). Die gleiche Färbung von Cytoskelett-Filamenten wurde ebenfalls beobachtet, wenn anstelle des Myc-Epitops am Amino-, ein V5-Epitop am Carboxyterminus (Mapl-1/V5) des Proteins 
fusioniert wurde (Abb.16C). Daraus läßt sich schließen, daß die Lokalisation des Proteins am Cytoskelett ausschließlich auf das Mapl-1-Protein zurückzuführen ist und wird von den verwendeten Epitopen nicht beeinflußt.

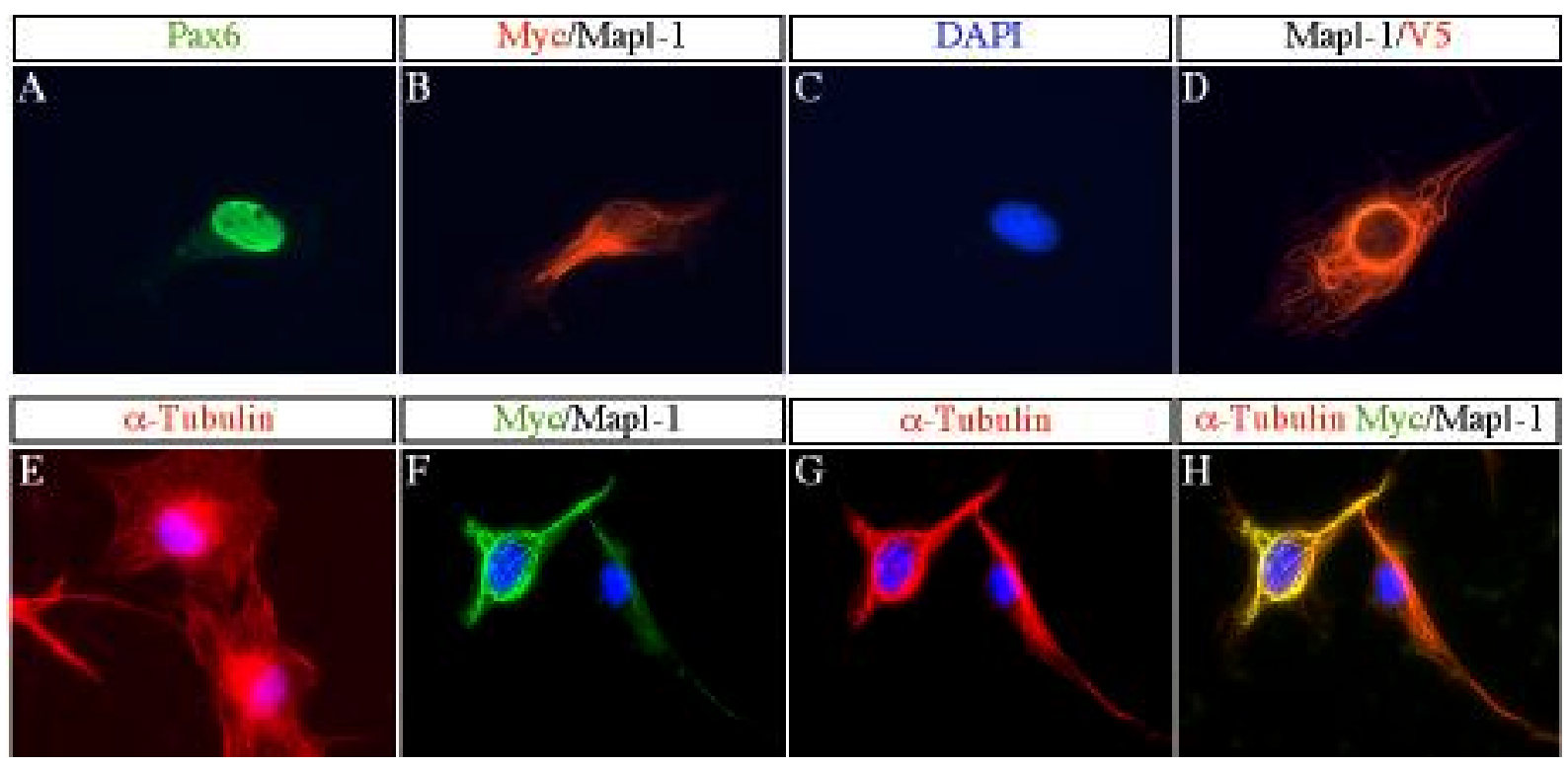

\section{Abbildung 16}

Mapl-1 dekoriert die zellulären Mikrotubuli. Antikörperfärbung an transfizierten COS7-Zellen. Während Pax-6 ausschließlich im Zellkern nachgewiesen wird (A), ist Mapl-1, versehen mit einem aminoterminalen c-MycEpitop, innerhalb der gleichen Zelle an Cytoskelettfilamenten lokalisiert (B). Der Kern der transfizierten Zelle wurde durch Färbung des Chromatins mit DAPI (C) sichtbar gemacht. D: Die Mapl-1-Variante mit einem V5Epitop am Carboxyterminus (Mapl-1/V5) zeigt ähnliche Lokalisation an Komponenten des Cytoskeletts. E: Färbung von Mikrotubuli mit einem $\alpha$-Tubulin-Antikörper (rot) an untransfizierten Zellen. In mit Myc/Mapl-1 transfizierten Zellen (F-H) kommt es zur Kolokalisation des Proteins (grün) mit den zellulären Mikrotubuli (rot). H: Überlagerung der Signale. Zellkerne wurden mit DAPI gefärbt. Für die Aufnahmen wurde ein 60x Objektiv verwendet.

Die Morphologie der von Mapl-1 angefärbten Filamente deutete auf Mikrotubuli hin. Um dies zu bestätigen wurde eine Doppelfärbung durchgeführt, mit einem Antikörper, der spezifisch die $\alpha$-Untereinheit der Mikrotubuli ( $\alpha$-Tubulin) erkennt (Abb.16 F-H). Dadurch konnte bestätigt werden, daß es sich bei den mit Mapl-1 dekorierten Filamenten, tatsächlich um Mikrotubuli handelt. Interessanterweise induzierte die Überexpression von Mapl-1 in COS7Zellen das Zusammenbinden von Mikrotubuli in dicken Bündeln, was zu einer Veränderung der gesamten Zellgestalt führte (Abb.16E vgl. mit F-H). Der gleiche Effekt wurde ebenfalls in den Zelllinien HeLa und NIH313 beobachtet (nicht gezeigt). 


\subsection{Effekt der Mapl-1 Überexpression auf die anderen Filamente des Cytoskeletts}

Das Cytoskelett von eukaryotischen Zellen wird von drei Klassen von Filamenten gebildet: den Mikrofilamenten, die aus Aktin bestehen und einen Durchmesser von ca. 7nm besitzen, den Mikrotubuli, die aus $\alpha$ - und $\beta$-Tubulin Untereinheiten gebildet werden und einen Durchmesser von ca. 30nm haben sowie den Intermediärfilamente (ca. 7-11nm Durchmesser), die verschiedener Art sein und aus unterschiedlichen Proteinen gebildet werden können. Die Organisation dieser Filamente ist stark von den mit ihnen assoziierten Proteinen abhängig. Einige Proteine sind in der Lage, Cytoskelettfilamente miteinander zu vernetzen. Bekannte Beispiele dafür sind die Proteine der Plakin-Familie (Wiche, 1998). Dies spricht dafür, daß die verschiedenen Cytoskelettfilamente nicht als voneinander unabhängige Gerüste, sondern vielmehr als miteinander kooperierende Netzwerke anzusehen sind. Demzufolge wurde getestet, ob Mapl-1 zusätzlich zu den Mikrotubuli auch mit anderen Klassen von Filamenten ko-lokalisieren bzw. ob seine Überexpression in Säugerzellen die Organisation der anderen Komponenten des Cytoskeletts beeinflussen kann. Die Organisation von Mikrofilamenten und zwei Klassen von Intermediärfilamenten (Cytokeratin und Vimentin) wurde in untransfizierten COS7-Zellen und in Zellen, die mit dem Myc/Mapl-1 Expressionsvektor transfiziert wurden, untersucht (Abb.17). Daraus ergab sich, daß Mapl-1 in transfizierten Zellen mit keiner anderen Klasse von Cytoskelettfilamenten außer Mikrotubuli ko-lokalisiert. Es handelt sich also um ein Protein, das spezifisch und ausschließlich mit Mikrotubuli assoziieren kann, während seine Überexpression auf die Organisation der anderen Komponenten des Cytoskeletts keinen offensichtlichen Einfluß hat. 


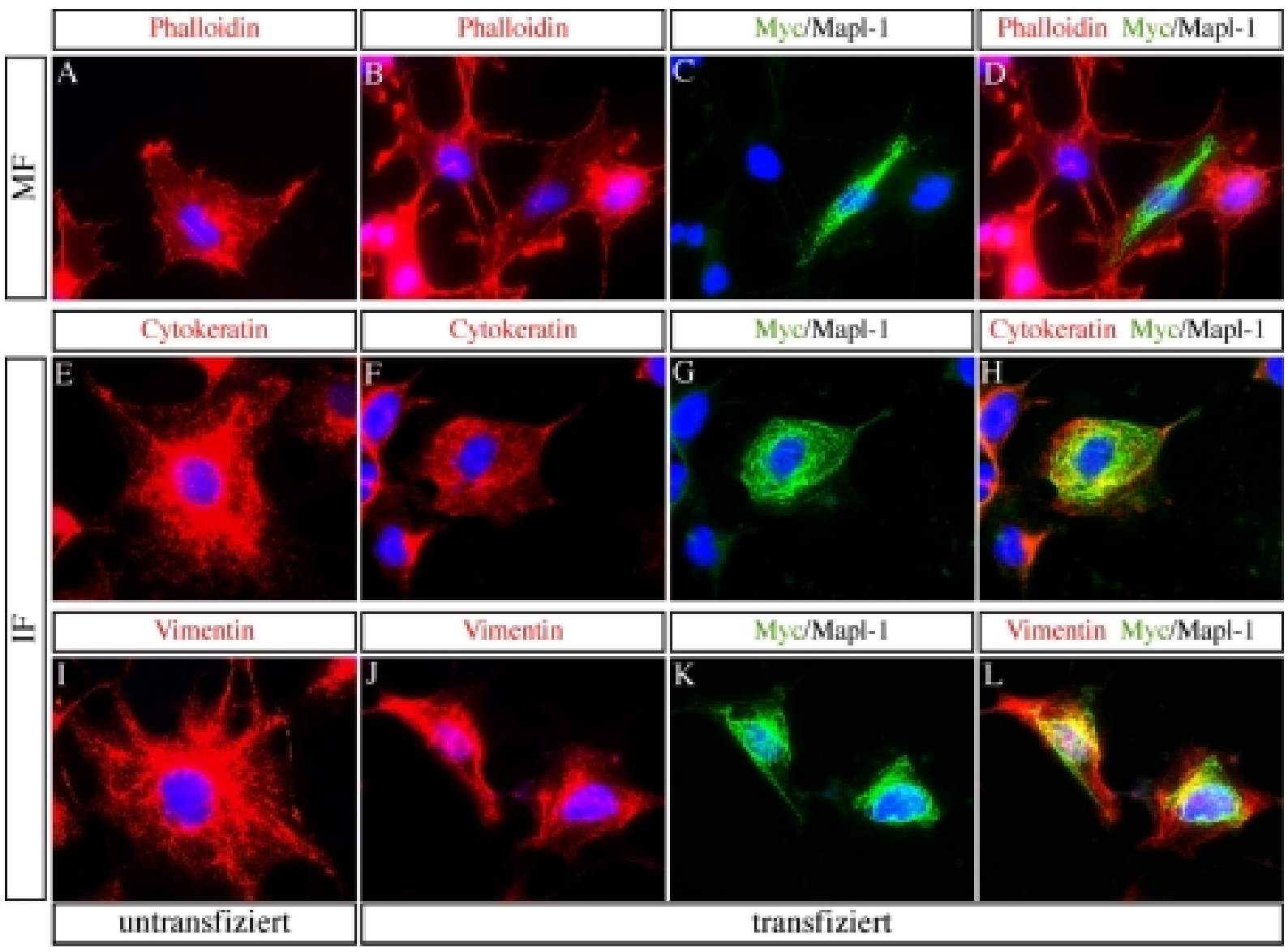

Abbildung 17

Mapl-1 ko-lokalisiert nicht mit den anderen Komponenten des Cytoskeletts und hat keinen Einfluß auf ihre Organisation. A-D: Mikrofilamente (rot) (MF) wurden durch Rhodamin-gekoppeltes Phalloidin in COS7-Zellen sichtbar gemacht; E-H: Intermediärfilamente (Cytokeratin) (rot) gefärbt mit einem Cytokeratin-Antikörper von breiter Spezifität; I-L: Vimentin-Intermediärfilamente (IF) (rot) wurden mittels eines spezifischen Antikörpers in COS7-Zellen nachgewiesen. A, E, I: untransfizierte Zellen; B-C, F-G, J-K: COS7-Zellen transfiziert mit Myc/Mapl-1. Das Myc/Mapl-1 Protein wird mittels eines Myc-Antikörpers in C, G, K (grün) nachgewiesen. D, H, L: Überlagerung der roten und grünen Fluoreszenz. Zellkerne wurden durch Färbung des Chromatins mit DAPI sichtbar gemacht. Für die Aufnahmen wurde ein 60x Objektiv verwendet.

\subsection{Die Überexpression von Mapl-1 führt zu erhöhter Stabilität der zellulären Mikrotubuli}

Mikrotubuli sind sehr dynamische Polymere, deren Organisation sich während des Zellzykluses und während der Entwicklung verändert. Die cytoplasmatischen Mikrotubuli befinden sich in vivo hauptsächlich in zwei Zuständen, im polymerisierenden oder im depolymerisierenden Zustand. Mikrotubuli können stochastisch von einem Zustand in den anderen übergehen, wobei der Übergang vom polymerisierenden in den depolymerisierenden Zustand als „Catastrophe“, das Gegenteil als „Rescue“ bezeichnet wird. Durch dieses Modell der „dynamischen Instabilität“ der Mikrotubuli, können die raschen Veränderungen ihres Polymerisationszustands während des Zellzykluses mechanistisch erklärt werden (Kirschner 
and Mitchison, 1986; Walker et al., 1988). Eine Reihe von Proteinen, die an Mikrotubuli binden können, sind in der Lage, den Übergang zwischen Polymerisation und Depolymerisation zu beeinflussen. Solche Proteine können in zwei Gruppen klassifiziert werden. Proteine wie die MAPs (,Microtubule associated proteins" ${ }^{6}$ ), die einen stabilisierenden Effekt auf die Mikrotubuli ausüben, fördern das Wachstum der Mikrotubuli, indem sie die Polymerisationsrate induzieren und die „Catastrophes“ unterdrücken (Andersen et al., 1994; Gard and Kirschner, 1987; Hirokawa, 1994 Andersen, 1997 \#3252). Den entgegengesetzten Effekt haben destabilisierende Faktoren, welche die Depolymerisation der Mikrotubuli induzieren. Diese Faktoren sind viel später als die MAPs entdeckt worden und stellen eine ständig wachsende Familie von Proteinen dar. Das bekannteste Beispiel ist Stathmin/OP18, dessen Überexpression in Zellen zur Depolymerisierung der Mikrotubuli führt (Belmont and Mitchison, 1996).

Wie in den vorangegangenen Abschnitten beschrieben, assoziiert Mapl-1 in transfizierten Zellen spezifisch mit den Mikrotubuli, wobei die Überexpression des Proteins die Reorganisation der Mikrotubuli in dicken Bündeln zur Folge hat. Dieser Effekt deutet auf eine stabilisierende Wirkung des Mapl-1 Proteins auf die Mikrotubuli hin. Um dies zu überprüfen, wurden mit Myc/Mapl-1 transfizierte COS7-Zellen mit dem Mikrotubulidepolymerisierenden Agens Nocodazol behandelt (Abb.18A). Nach einstündiger Inkubation mit Nocodazol bei einer Konzentration von $4 \mu \mathrm{g} / \mathrm{ml}$ konnte kein polymerisiertes Tubulin in den untransfizierten Zellen nachgewiesen werden (Abb.18A). Allerdings behalten die Mikrotubuli in den Zellen, die mit Myc/Mapl-1 transfiziert wurden ihre filamentöse Morphologie bei und werden vor der depolymerisierenden Wirkung von Nocodazol geschützt (Abb.18A vgl. mit B). Dies spricht für eine stabilisierende Wirkung des Mapl-1 Proteins auf die dynamische Organisation der Mikrotubuli. Der stabilisierende Effekt war vom Expressionsniveau des Proteins abhängig.

Innerhalb einer Zelle lassen sich zwei Populationen von cytoplasmatischen Mikrotubuli unterscheiden. Es handelt sich um die kurzlebigen oder dynamischen und die langlebigen oder stabilen Mikrotubuli (Schulze and Kirschner, 1987). In vielen Zelltypen kommt es bei den stabilen Mikrotubuli zur Akkumulation von verschiedenen posttranslational modifizierten Formen von Tubulin. Die am besten charakterisierte posttranslationale Modifikation, die spezifisch bei Tubulin vorkommt, ist die Detyrosinierung, bei der ein Tyrosinrest am Carboxyterminus von $\alpha$-Tubulin reversibel entfernt wird. Detyrosiniertes Tubulin (Det- 
Tubulin) kommt bevorzugt bei stabilen Mikrotubuli vor, während dynamische Mikrotubuli hauptsächlich tyrosiniertes Tubulin enthalten zum Überblick, (Bulinsky and Gundersen, 1991). Diese modifizierte Form von Tubulin kann von spezifischen Antikörpern erkannt werden und dient als Marker für stabile Mikrotubuli. Je länger die Mikrotubuli innerhalb der Zelle keiner Depolymerisation unterzogen werden, desto höher ist die Wahrscheinlichkeit, daß sie von speziellen Enzymen modifiziert werden und entsprechend höher ist ihr Anteil an Det-Tubulin. Die Detyrosinierung von Tubulin ist jedoch nicht die Ursache für die erhöhte Stabilität der Mikrotubuli (Khawaja et al., 1988; Webster et al., 1990). In Übereinstimmung mit einer stabilisierenden Wirkung von Mapl-1 auf die Mikrotubuli konnte in Zellen, die mit Myc/Mapl-1 transfiziert wurden im Gegensatz zu untransfizierten Zellen ein erhöhter Anteil an Det-Tubulin detektiert werden (Abb.18E-G).

Zusammenfassend sprechen sowohl die schützende Wirkung von Mapl-1 vor Depolymerisation durch Nocodazol, als auch der erhöhte Anteil an Det-Tubulin in den transfizierten Zellen für einen stabilisierenden Effekt der Mapl-1 Überexpression auf den Polymerisationszustand der zellulären Mikrotubuli.
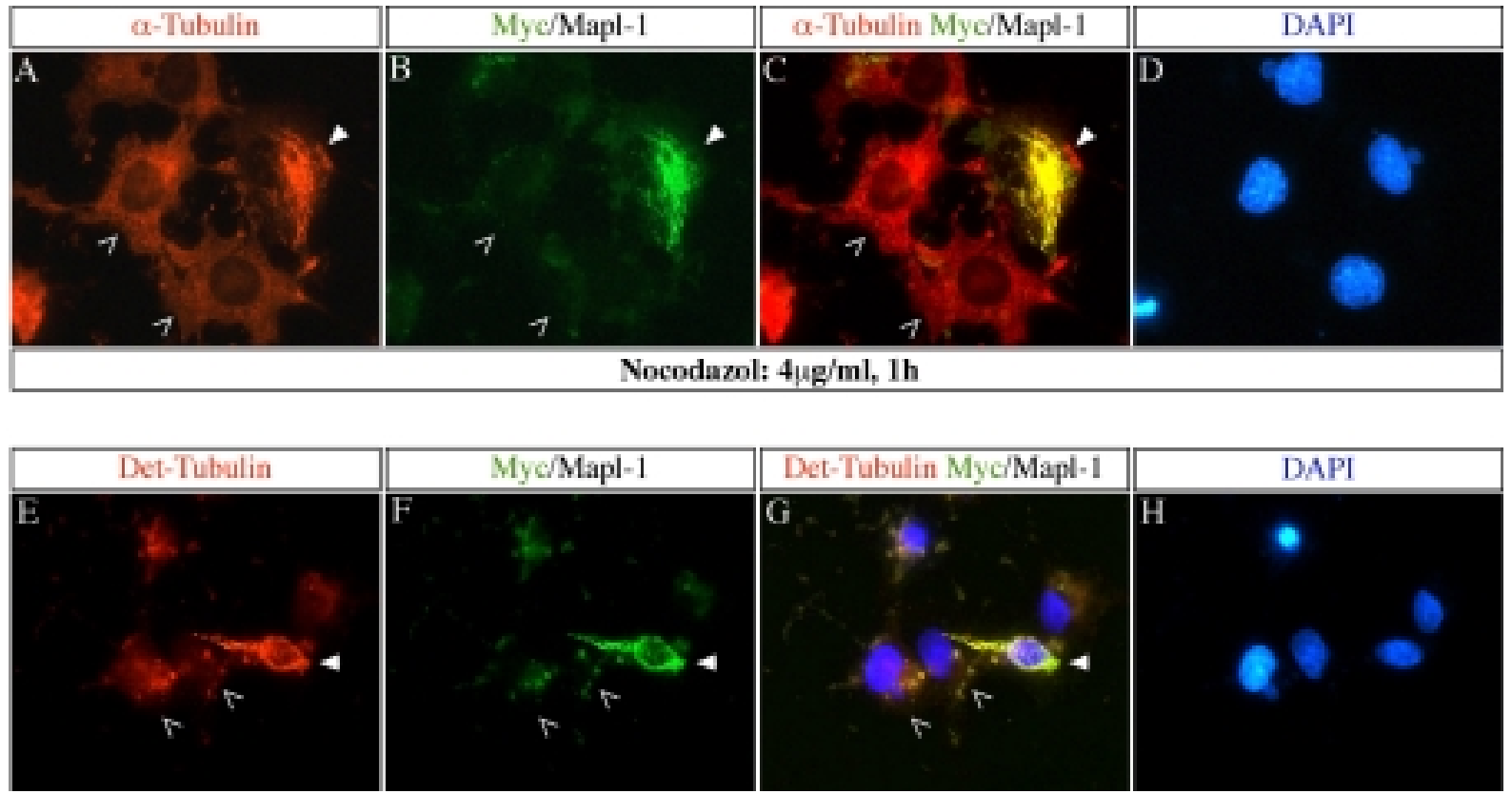

\section{Abbildung 18}

Überexpression von Mapl-1 in COS7-Zellen führt zu erhöhter Stabilität der zellulären Mikrotubuli. A-D: Zellen wurden mit Myc/Mapl-1 transfiziert und wie angegeben mit Nocodazol behandelt. In untransfizierten Zellen (offene Pfeile), ist kein polymerisiertes Tubulin nachweisbar (A). Mit Myc/Mapl-1 transfizierte Zellen (B) (geschlossener Pfeil), behalten zu Mikrotubuli polymerisiertes Tubulin bei. C: Überlagerung der Fluoreszenzen zeigt Kolokalisation von Myc/Mapl-1 (grün) mit Mikrotubuli (rot) .E-G: Erhöhter Anteil von Det-Tubulin, (E) in mit Myc/Mapl-1 transfizierten Zellen (geschlossener Pfeil). Offene Pfeile: untransfizierte Zellen. G: Überlagerung des roten (Det-Tubulin) und des grünen (Myc/Mapl-1) Signals. D, H: Färbung der Zellkerne mit DAPI. Für die abgebildeten Aufnahmen wurde ein 60x Objektiv benutzt. 


\subsection{Mapl-1 bindet direkt an Mikrotubuli in vitro}

Der stabilisierende Effekt der Mapl-1 Überexpression auf die zellulären Mikrotubuli ist gleichzeitig ein indirekter Hinweis darauf, daß das Protein direkt an Mikrotubuli binden kann. Um dies zu überprüfen, wurde Tubulin in vitro und in Anwesenheit von Taxol zu Mikrotubuli polymerisiert und zusammen mit radioaktiv-markiertem Myc/Mapl-1 Protein in einem Kosedimentations-Assay eingesetzt (Abb. 19). Es konnte dadurch gezeigt werden, daß Mapl1 nur in Anwesenheit, aber nicht in Abwesenheit von polymerisiertem Tubulin in der PelletFraktion identifiziert werden kann. Dies bestätigt, daß Mapl-1 direkt mit den Mikrotubuli interagieren kann.

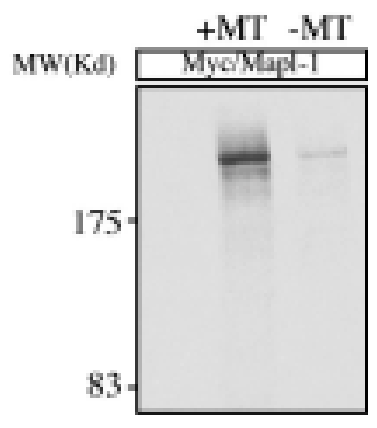

\begin{abstract}
Abbildung 19
Cosedimentation von radioaktiv-markiertem Myc/Mapl-1 Protein mit in vitro polymerisiertem Tubulin. Die Sedimentation des Proteins erfolgt in Anwesenheit (+MT), aber nicht in der Abwesenheit (-MT) von Mikrotubuli.
\end{abstract}

\subsection{Der Carboxyterminus von Mapl-1 als neue Mikrotubuli-bindende Domäne}

Die Wirkung von Mapl-1 auf die Dynamik der Mikrotubuli sowie die direkte Bindung des Proteins an polymerisiertem Tubulin sind den Eigenschaften von bekannten MAPs (Microtubule-associated proteins) sehr ähnlich. Zwischen den verschiedenen MAPs sind die Mikrotubuli-bindenden Domänen sehr konserviert und bestehen aus einem repetitiven Motiv von 18 Aminosäuren (Chapin and Bulinsky, 1992). Diese Mikrotubuli-bindenden Regionen der bekannten MAPs liegen in der Regel am Carboxyterminus des Proteins. Anhand von Sequenzvergleichen konnte jedoch zwischen Mapl-1 und bekannten MAPs keine signifikante Ähnlichkeit identifiziert werden. Weiterhin scheinen innerhalb der Aminosäuresequenz von Mapl-1 keine eindeutigen repetitiven Motive vorhanden zu sein. Um die Region des Mapl-1 Proteins zu identifizieren, die direkt an Mikrotubuli binden kann, wurden 480 Aminosäuren vom Carboxyterminus des Proteins deletiert und die Lokalisation des Proteins in transfizierten COS7-Zellen mittels Immunfluoreszenz untersucht (Abb.20). Es stellte sich heraus, daß die Mapl-1-Variante ohne den Carboxyterminus (Myc/1-1413) nicht mehr in der Lage war, an Mikrotubuli zu binden (Abb.20C). Hierbei behalten die transfizierten Zellen ihre normale Gestalt bei, im Gegensatz zu den mit dem vollständigen Protein transfizierten Zellen 
(Abb.20C vgl. mit B). Die Myc/1-1413 Deletionsvariante wies zusätzlich eine cytoplasmatische Lokalisation auf (Abb.20C). Daraus geht hervor, daß der Carboxyterminus von Mapl-1 für die direkte Interaktion mit Tubulin notwendig ist.

Weiterhin stellte sich die Frage, ob der Carboxyterminus von Mapl-1 nicht nur notwendig sondern auch für die Bindung an Mikrotubuli ausreichend ist. Um dies zu untersuchen, wurden die carboxyterminalen 480 Aminosäuren des Proteins an ein multimerisiertes MycEpitop fusioniert und in COS7-Zellen transfiziert. In den mit Myc/1414-1893 transfizierten Zellen erfolgt sowohl die Bindung der carboxyterminalen Domäne an Mikrotubuli, als auch die Quervernetzung der Mikrotubuli zu Bündeln (Abb.20E). Interessanterweise unterscheidet sich das Muster der vom vollständigen Protein gebündelten Mikrotubuli von den mit der carboxyterminalen Domäne induzierten Bündeln. Während beim vollständigen Mapl-1 die Mikrotubuli-Bündel über die gesamte Zelle verlaufen, werden beim isolierten Carboxyterminus bevorzugt die distalen Mikrotubuli gebunden und vernetzt (Abb.20 vgl. D mit E). Zudem scheint bei den mit Myc/1414-1893 transfizierten Zellen die Zellmorphologie nicht besonders beeinflußt zu sein im Gegensatz zu Zellen, die mit dem kompletten Protein transfiziert wurden. Daraus folgt, daß die carboxyterminale Domäne von Mapl-1 nicht nur notwendig sondern auch für die Bindung und Vernetzung der zellulären Mikrotubuli ausreichend ist.

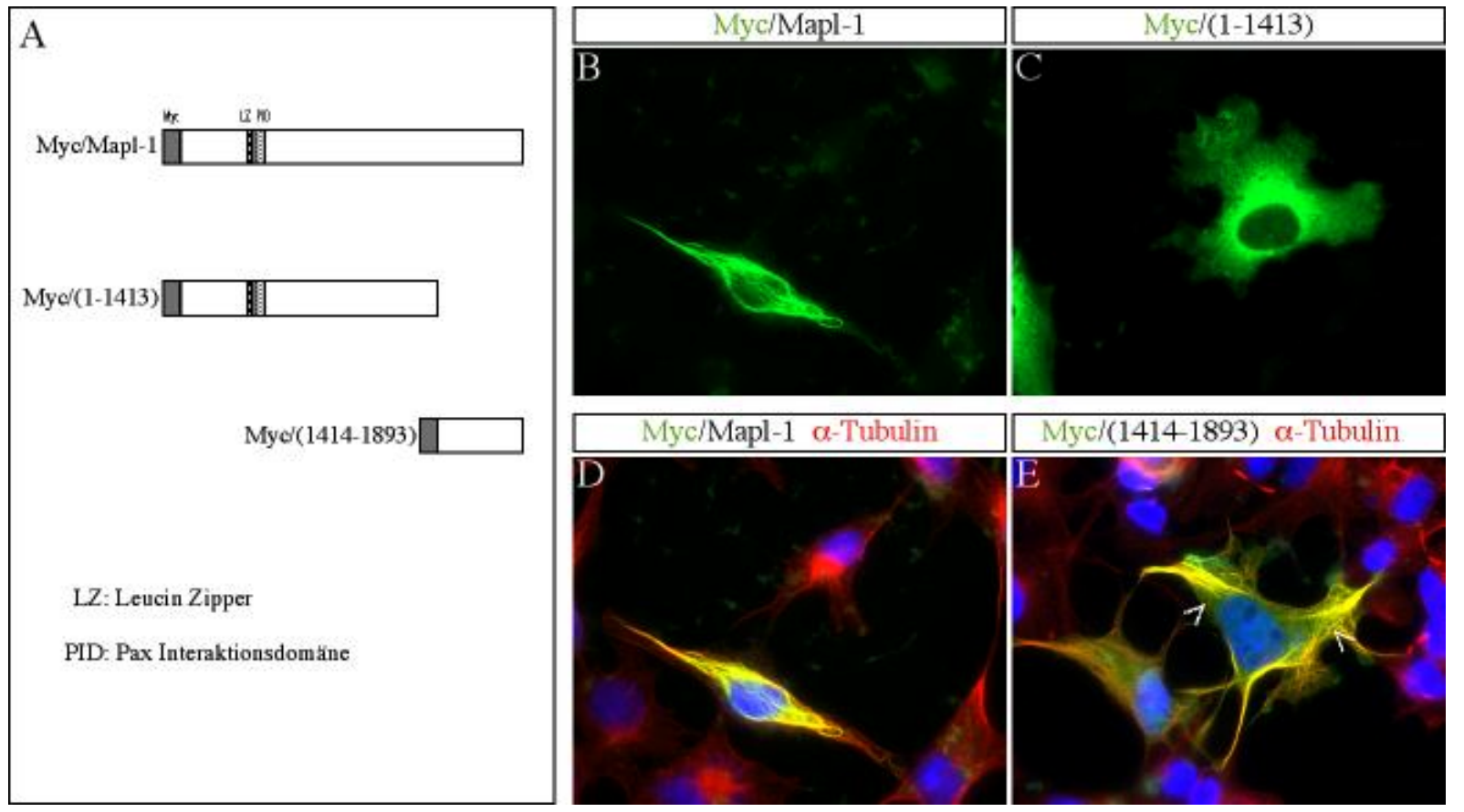

\section{Abbildung 20}

Der Carboxyterminus von Mapl-1 ist sowohl essentiell als auch ausreichend für die Bindung zellulärer Mikrotubuli. A: Schematische Darstellung des kompletten Mapl-1 Proteins (Myc/Mapl-1) sowie der Deletionsvarianten Myc/(1-1413) und Myc/(1414-1893). B-E: Immunfluoreszenz an transfizierten COS7-Zellen. 
C: Die Deletionsvariante Myc/(1-1413) (grün) ist im Gegensatz zum kompletten Protein (B) nicht in der Lage, an Mikrotubuli zu binden. D-E: Doppelfärbung von Myc/Mapl-1 bzw. Myc/(1414-1893) (grün) und $\alpha$-Tubulin (rot). Offene Pfeile in (E) weisen auf die distalen Mikrotubuli hin, die durch den isolierten C-terminus gebunden und gebündelt werden. Abgebildet ist die Überlagerung des roten und grünen Signals. Zellkerne wurden in D-E mit DAPI gefärbt. Für die Aufnahmen wurde ein 60x Objektiv verwendet.

Als nächstes wurde überprüft, ob die isolierte carboxyterminale Region von Mapl-1 auch ausreichend ist, um Mikrotubuli vor Depolymerisation zu schützen. Dazu wurden mit Myc/(1414-1893) transfizierte Zellen unter den gleichen Bedingungen mit Nocodazol behandelt, die auch beim vollständigen Protein angewandt wurden $(4 \mu \mathrm{g} / \mathrm{ml}$, für $1 \mathrm{~h})$ (Abb.21). Während in untransfizierten Zellen nach der Behandlung mit Nocodazol kein polymerisiertes Tubulin nachweisbar ist, werden in den transfizierten Zellen die Mikrotubuli vor der depolymerisierenden Wirkung von Nocodazol geschützt (Abb.21A-C).

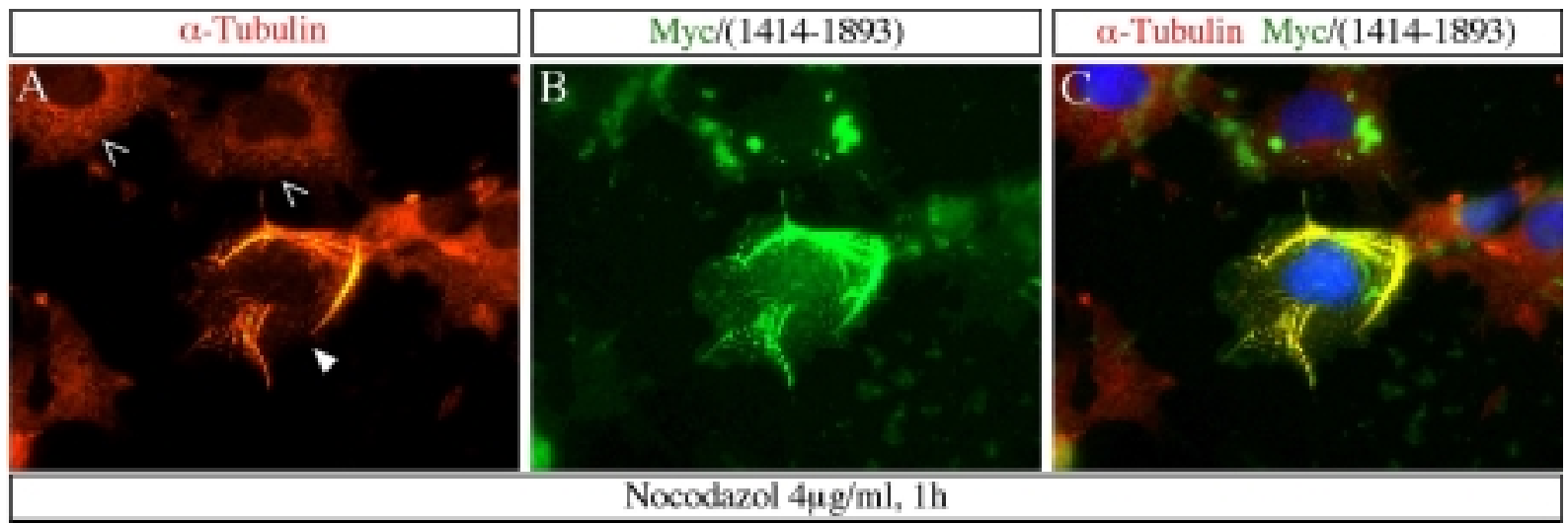

Abbildung 21

Die carboxyterminale Domäne von Mapl-1 ist ausreichend, um Mikrotubuli vor der depolymerisierenden Wirkung von Nocodazol zu schützen. A: Immunfluoreszenz mit $\alpha$-Tubulin-Antikörper. Im Gegensatz zu den untransfizierten Zellen (offene Pfeile) ist in transfizierten Zellen (geschlossener Pfeil) zu Mikrotubuli polymerisiertes Tubulin nachweisbar. B: Der isolierte Carboxyterminus von Mapl-1 (Myc/1414-1893) wird mit c-Myc Antikörper in grün nachgewiesen. C: Überlagerung des roten und grünen Signals. Zellkerne wurden mit DAPI blau gefärbt. Für die Aufnahmen wurde ein 60x Objektiv verwendet.

Anhand der in diesem Abschnitt präsentierten Daten läßt sich die carboxyterminale Region des Mapl-1-Proteins als eine neue „bona fide“Mikrotubuli-bindende Domäne bezeichnen. Diese Region weist keine Sequenzähnlichkeit zu den bekannten Mikrotubuli-bindenden Domänen von MAPs auf und ist sowohl notwendig als auch ausreichend für die Bindung, Vernetzung und Stabilisierung der zellulären Mikrotubuli. 


\subsection{Mapl-1 ist in der Lage, Homodimere zu bilden}

Wie in Abschnitt 2.10 gezeigt wurde, ist das in Mapl-1 vorhandene Leucin-Zipper Motiv nicht direkt an der Interaktion mit Pax-6 beteiligt. Da Proteine, die ein solches Motiv besitzen, unter anderem häufig Homodimere bilden (Alber, 1992), wurde getestet, ob auch Mapl-1 zur Selbstassoziation in der Lage ist. Um dies $\mathrm{zu}$ überprüfen, wurden sukzessive carboxyterminale Deletionen des Proteins hergestellt und an ein multimerisiertes Myc-Epitop am Aminoterminus fusioniert (Abb.22A). Diese Deletionsvarianten waren nicht in der Lage, in einfach transfizierten COS7-Zellen an Mikrotubuli zu binden (Abb.22 B-E). Es wurde daher getestet, ob die konstruierten Deletionsvarianten des Proteins nach Kotransfektion mit dem vollständigen Mapl-1 Protein an Mikrotubuli lokalisieren können. Dies würde die Bildung von Homodimeren indirekt demonstrieren. Aus diesem Experiment ergab sich, daß alle getesteten Deletionsvarianten nach Kotransfektion mit dem kompletten Mapl-1 Protein eine Lokalisation an Mikrotubuli aufwiesen (Abb.22F-I). Dies spricht für die Existenz einer Dimerisierungsdomäne innerhalb der ersten 367 Amminosäuren des Proteins, in denen das Leucin-Zipper-Motiv noch enthalten ist. Interessanterweise zeigt die Myc/(1-367) Deletionsvariante im Vergleich zu den restlichen Deletionsvarianten eine geringere Fähigkeit mit dem vollständigen Protein zu interagieren (Abb.22I vgl. mit F, G, H). Dies könnte darauf zurückzuführen sein, daß die Myc/(1-367) Deletion effizient und aktiv in den Zellkern transportiert wird (Abb.22E). Dieser Prozeß könnte mit der Dimerbildung an den Mikrotubuli in Konkurrenz stehen. Die Deletion (1-367) liegt genau carboxyteminal zum Leucin-Zipper Motiv und enthält nicht die Pax-Interaktionsdomäne von Mapl-1. Dies läßt darauf schließen, daß die Dimerisierungsdomäne des Proteins sich von der Pax-Interaktionsdomäne unterscheidet. 


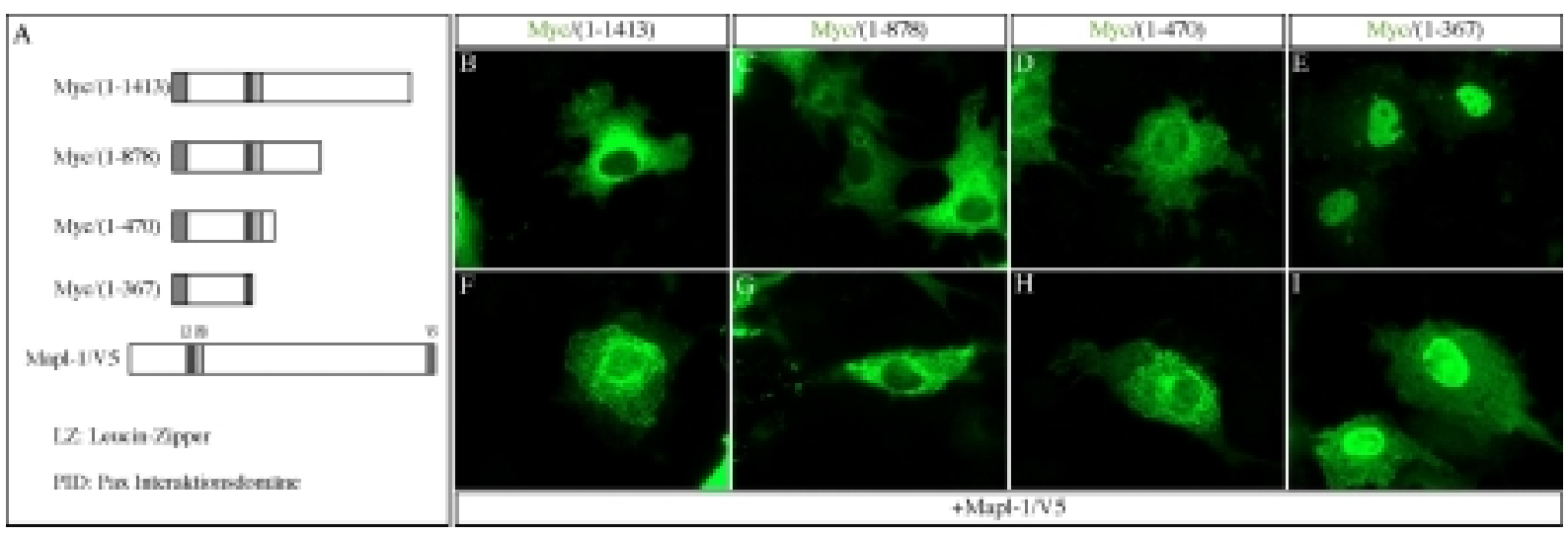

Abbildung 22

Mapl-1 ist in der Lage, Homodimere zu bilden. A: Schematische Darstellung der verwendeten Protein-Varianten von Mapl-1: Myc(1-1413), Myc(1-878), Myc(1-470), Myc(1-367) sind sukzessive carboxyterminale Deletionen des Proteins mit einem multimerisierten Myc-Epitop am Aminoterminus. Mapl-1/V5 ist das komplette Protein mit einem V5 Epitop am Carboxyterminus. B-E: Einfach transfizierte Zellen. In grün wird die jeweilige Deletionsvariante mit einem Myc-Antikörper detektiert. F-I: Immunfluoreszenz an COS7-Zellen, die mit dem jeweiligen Deletionskonstrukt und Mapl-1/V5 kotransfiziert wurden. Um jede mögliche Artefaktquelle, beruhend auf der starken Fluoreszenzemission auszuschließen, wurde nur mit Myc Antikörper gefärbt (grün) und keine Doppelfärbung mit V5 durchgeführt. Im Gegensatz zu den einfach transfizierten Zellen, lokalisieren die Deletionsvarianten von Mapl-1 in kotransfizierten Zellen an Mikrotubuli. Dies weist indirekt die Dimerisierung des Proteins nach. Für die Aufnahmen wurde ein 60x Objektiv verwendet.

\subsection{9 Überexpression von Mapl-1 führt zur Retention von Pax-6, aber nicht von Pax-2 an zellulären Mikrotubuli}

Die zelluläre Lokalisation von Pax-6 und Mapl-1 in transfizierten Zellen steht im Gegensatz zu einer Funktion der beiden Proteine als interagierende Partner in vivo. Während Pax-6 ein Kernprotein ist, ist Mapl-1 hauptsächlich an Mikrotubuli lokalisiert. Aus diesem Grund wurde untersucht, ob die zelluläre Lokalisation eines der beiden Proteine in doppeltransfizierten Zellen verändert wird. Wenn COS7-Zellen mit dem CMV-Pax6 Expressionsvektor transfiziert werden und das Pax-6-Protein mit einem Antikörper nachgewiesen wird, ist es in allen Zellen ausschließlich im Zellkern lokalisiert (Abb.23A). In Zellen jedoch, in denen CMVMyc/Mapl-1 zusätzlich zu CMV-Pax6 transfiziert wurde, kommt es zu einer ektopischen Lokalisation von Pax-6 an Cytoskelettfilamenten (Abb.23C). Da Myc/Mapl-1 und Pax-6 an diesen Filamenten ko-lokalisieren (Abb.23B-C), handelt es sich dabei um Mikrotubuli. Der Effekt der Retention von Pax-6 an den Cytoskellett durch die Interaktion mit Mapl-1 war vom Expressionsniveau des Mapl-1 Proteins abhängig. Zudem kam es in den kotransfizierten Zellen nicht zur vollständigen Retention des Pax-6 Proteins an den zellulären Mikrotubuli, 
vielmehr stellte der Zellkern immer noch das Hauptkompartiment der zellulären Pax-6 Lokalisation dar (Abb.23D). Dieses Experiment demonstriert zum einen die Fähigkeit von Pax-6 und Mapl-1, in vivo miteinander zu interagieren und weist zum anderen auf eine potentielle Konsequenz dieser Interaktion hin, die darin besteht, einen Anteil des zellulären Pax-6 Proteins außerhalb des Zellkerns zu behalten.

Es wurde weiterhin überprüft, ob dieser Effekt spezifisch für Pax-6 ist, indem unter den gleichen Bedingungen CMV-Pax2 zusammen mit CMV-Myc/Mapl-1 in COS7-Zellen kotransfiziert wurde und die Lokalisation des Pax-2-Proteins mittels eines Antikörpers in kotransfizierten Zellen untersucht wurde. Daraus folgte, daß die zelluläre Lokalisation des Pax-2 Proteins durch Mapl-1 nicht beeinflußt wurde, wobei Pax-2 ausschließlich im Zellkern kotransfizierter Zellen nachgewiesen wurde (Abb.23E-F). Im Einklang damit konnte im GST„Pull-down“ (Abb.23G) keine Interaktion zwischen Pax-2 und der Pax-Interaktionsdomäne (PID) von Mapl-1 demonstriert werden. Diese Daten sprechen für eine Spezifität von Mapl-1 für Pax-6 als Interaktionspartner. Die Interaktion zwischen den beiden Proteinen hat in diesem Zellkulturmodell die partielle Retention von Pax-6 im Cytoplasma zur Folge.

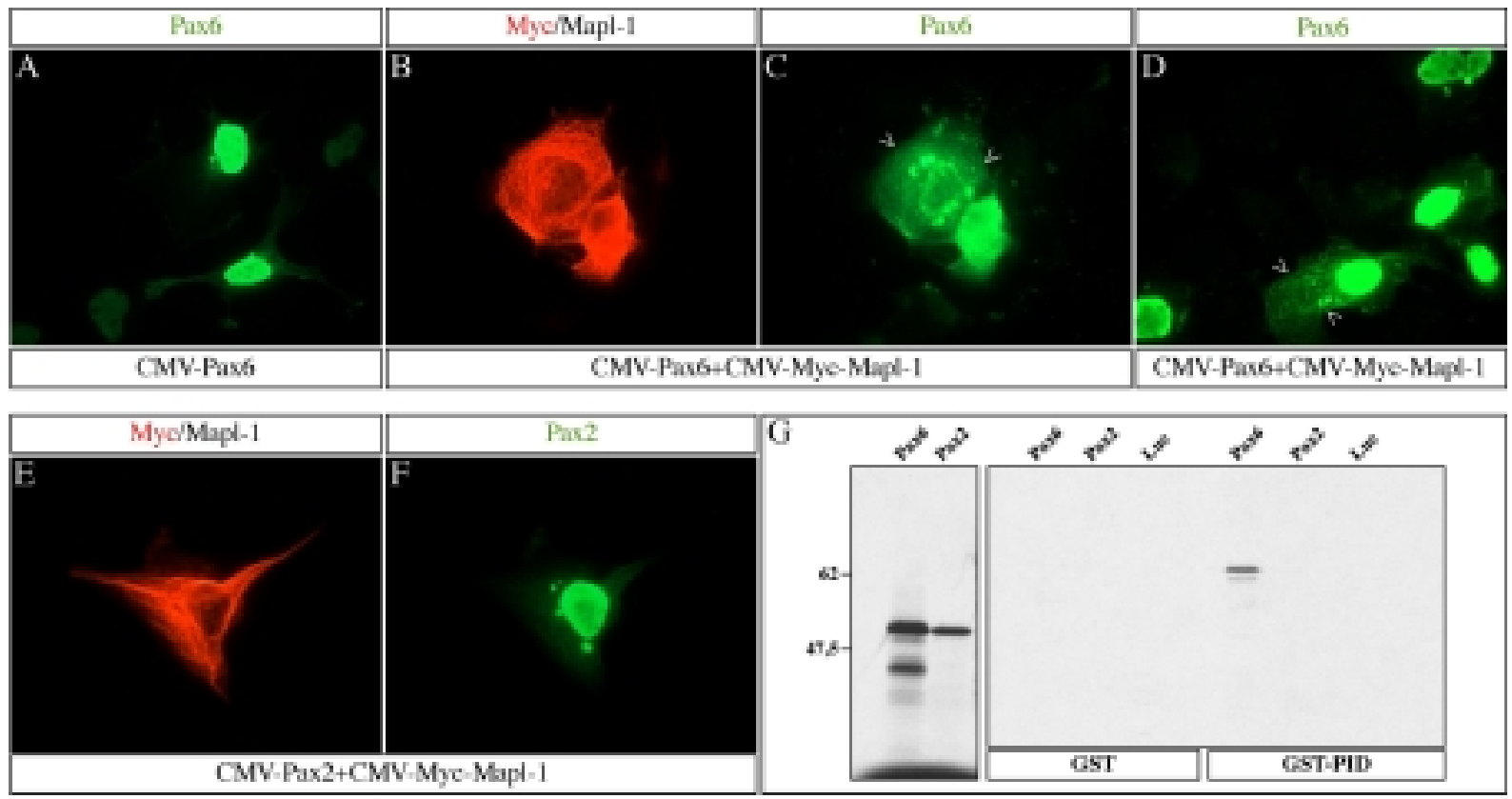

\section{Abbildung 23}

Mapl-1 führt zur Retention von Pax-6 aber nicht von Pax-2 an zellulären Mikrotubuli. A: COS7 Zellen transfiziert mit CMV-Pax6. Das Pax6 Protein (grün) ist ausschließlich im Zellkern lokalisiert. B-C: In kotransfizierten Zellen ist Pax-6 (grün) außerhalb des Zellkerns nachweisbar (C) und ko-localisiert (B) mit Myc/Mapl-1 (rot) an Mikrotubuli. D: Kotransfizierte Zellen in denen nur Pax-6 (grün) aber nicht Myc/Mapl-1 nachgewiesen wurde (um jede mögliche Artefaktquelle auszuschließen). Offene Pfeile in C-D weisen auf die durch die Interaktion mit Mapl-1 bedingten Lokalisation von Pax-6 an Mikrotubuli. E-F: Mit CMV-Pax2 und 
CMV-Myc/Mapl-1 transfizierte COS7 Zellen. Myc/Mapl-1 (rot) beeinflusst nicht die Lokalisation des Pax-2 Proteins (grün). G: GST-,,Pull-down“ bei dem in vitro translatiertes und radioaktiv markiertes Pax-6 bzw. Pax-2 auf eine Interaktion mit der PID von Mapl-1 untersucht wurden. Links: abgebildete Menge der verwendeten Proteine entspricht $20 \%$ der im Assay verwendeten tatsächlichen Menge. Luciferase (Luc) wurde als unspezifisches Kontrollprotein eingesetzt (nicht gezeigt). Rechts: Pax-6 aber nicht Pax-2 ist in der Lage mit der PID von Mapl-1 zu interagieren.

\subsection{Lokalisation von Mapl-1 im Zellkern}

Wie in Abschnitt 2.2 bereits erwähnt wurde besitzt Mapl-1 am Aminoterminus des Proteins ein Kernlokalisationssignal (NLS). Allerdings ist das Protein bei der Transfektion von Myc/Mapl-1 in Säugerzellen bei der Mehrzahl (85\%) der transfizierten Zellen an Mikrotubuli lokalisiert (s. Abschnitt 2.12). Bei etwa 10\% der mit Myc/Mapl-1 transfizierten Zellen jedoch, wurde das Protein nach Färbung mit einem Myc-Antikörper im Zellkern nachgewiesen. Um zu untersuchen, ob es bei dieser Kernlokalisation um das vollständige Protein handelt, wurde eine Variante von Mapl-1 hergestellt, welche die unabhängige Detektion des Amino- und des Carboxyterminus ermöglicht. Diese Variante des Proteins (Myc/Mapl-1/V5) besitzt ein multimerisiertes Myc-Epitop am Aminoterminus, während der Carboxyterminus des Proteins an ein V5-Epitop fusioniert wurde. Nach Transfektion von Myc/Mapl-1/V5 in COS7-Zellen und Doppelfärbung mit Myc und V5 Anikörper stellte sich heraus, daß bei der Mehrheit der transfizierten Zellen, in denen der Aminoterminus (Myc) im Zellkern nachgewiesen wurde, der Carboxyterminus (V5) nicht detektiert werden konnte (Abb.24A-C). Nur in einigen Fällen konnten beide Termini des Proteins im Zellkern nachgewiesen werden (Abb.24D-F). Dies wurde außer in COS7 Zellen auch in anderen Zellinien beobachtet (Hela, Neuro2A; nicht gezeigt). Aus diesen Daten kann geschlossen werden, daß Mapl-1 unter bestimmten Bedingungen in den Zellkern transportiert werden kann. Dies steht in Übereinstimmung mit der Anwesenheit eines Kernlokalisationsignals am Aminoterminus des Proteins. Die aus den Transfektionsexperimenten erhaltenen Ergebnisse sprechen dafür, daß Mapl-1 einerseits als komplettes Protein in den Zellkern transportiert werden kann, andererseits, daß es unter Umständen auch proteolytisch prozessiert wird. Durch die Prozessierung des Proteins könnte ein Produkt erzeugt werden, welches den Aminoterminus des Proteins enthält und in den Zellkern befördert werden kann. Bezüglich der Funktion von Mapl-1 als Pax-6 Interaktionspartner stellt der Zellkern ein zelluläres Kompartiment dar, in dem die Interaktion zwischen den beiden Proteinen in vivo stattfinden kann. 

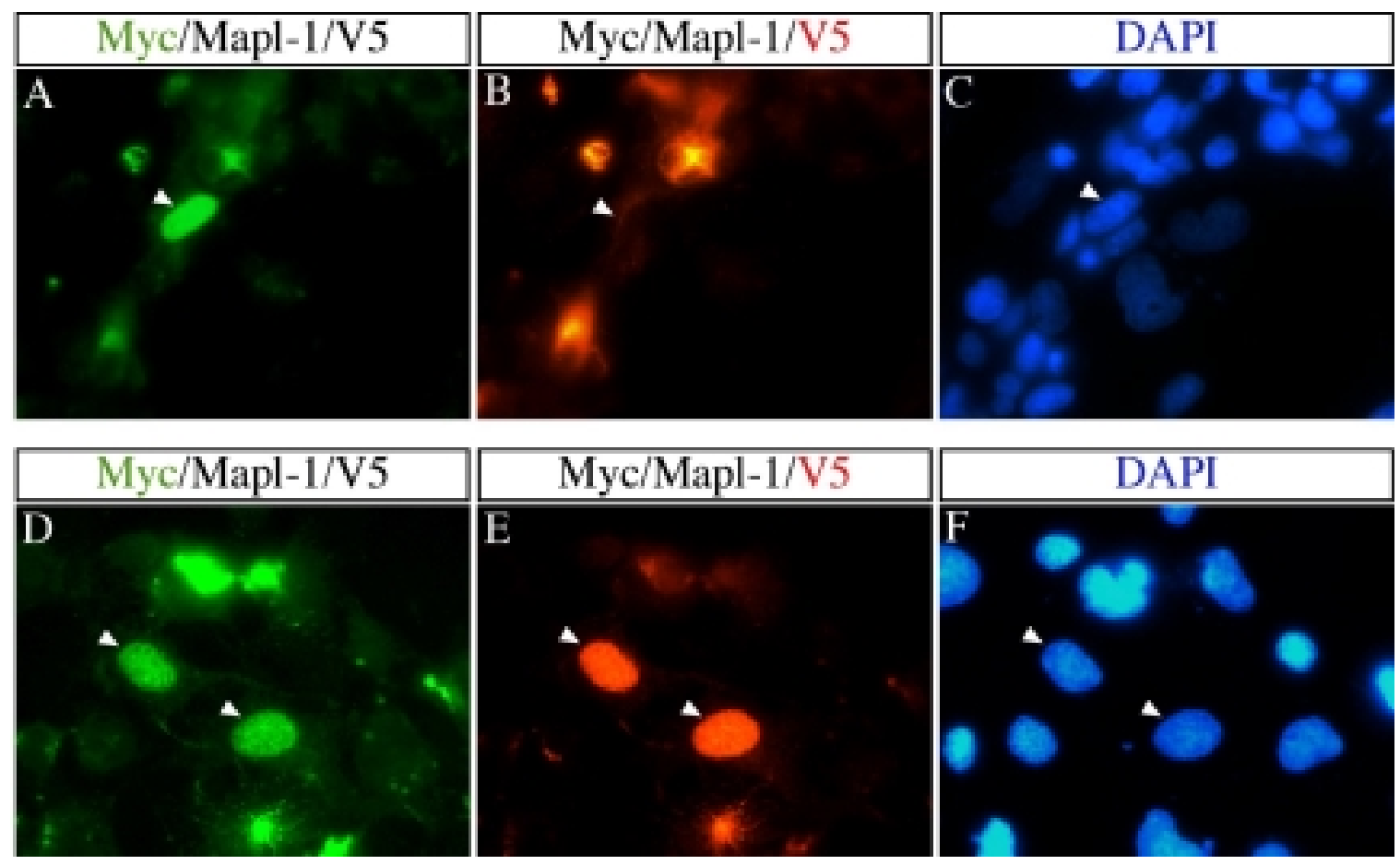

\section{Abbildung 24}

Mapl-1 ist in der Lage in den Zellkern transportiert zu werden. Immunfluoreszenz an COS7 Zellen, die mit der Myc/Mapl-1/V5 Variante des Proteins transfiziert wurden. Mit einem Myc Antikörper (grün) wird der Aminoterminus, mit einem V5 Antikörper (rot) der Carboxyterminus des Proteins nachgewiesen. A-C: transfizierte Zellen, in denen ein aminoterminaler Teil des Proteins in den Zellkern lokalisiert ist (Pfeil). Der Carboxyterminus ist dabei nicht nachweisbar. D-F: Mapl-1 kann als vollständiges Protein in den Zellkern transportiert werden. Sowohl der Amino- als auch der Carboxyterminus werden im Zellkern nachgewiesen (Pfeile). C-F: Färbung der Kerne mit DAPI. Aufnahmen : 60x Objektiv.

\subsection{Regulation der zellulären Lokalisation von Mapl-1 durch Kern-Import und -Export Signale.}

In Abschnitt 2.16 wurden sukzessive carboxyterminale Deletionsvarianten des Mapl-1

Proteins hergestellt. Bei der Untersuchung ihrer zellulären Lokalisation hat es sich ergeben, daß nach Deletion von 1423 Aminosäuren vom Carboxyterminus (Myc/1-470) das Protein immer noch hauptsächlich im Cytosoplasma lokalisiert ist. Die Mapl-1 Variante, die nach einer weiteren Deletion von 103 Aminosäuren entsteht (Myc/1-367), war ausschließlich im Zellkern lokalisiert (Abb.22D vgl. Mit 22E). Dies weist auf die Existenz eines Kernlokalisationssignals (NLS) in den aminoterminalen 367 Aminosäuren des Proteins hin, das den aktiven Transport von Myc/1-367 in den Zellkern bewirkt. Im Einklang damit und wie in Abschnitt 2.3 beschrieben, befindet sich ein putatives NLS am Aminoterminus des Proteins zwischen den Aminosäuren 31-38. Die Tatsache, daß Myc/1-367 ausschließlich nukleär lokalisiert, die Myc/1-470 Variante jedoch hauptsächlich cytoplasmatisch ist, spricht für das Vorhandensein eines Signals zwischen Aminosäuren 360-470, welches die Retention 
des Proteins im Cytoplasma hervorruft. Als möglicher Mechanismus wurde die Existenz eines nukleären Exportsignals (NES) angenommen, das in Konkurrenz mit dem NLS den aktiven Export des Proteins aus dem Zellkern bewirkt. Um dies zu überprüfen, wurden mit Myc/1470 transfizierte COS7-Zellen mit Leptomycin B (LMB) behandelt. LMB ist ein spezifischer Inhibitor des CRM-1 abhängigen nukleären Exportprozesses, der über Leucin-reiche NES vermittelt wird (Fukuda et al., 1997; Kudo et al., 1997). In transfizierten COS7-Zellen ist Myc/1-470 bei der Mehrzahl der Zellen im Cytoplasma lokalisiert (Abb.25A). Bei einigen Zellen scheint diese Mapl-1 Deletionsvariante mit geringer Effizienz auch in den Zellkern transportiert zu werden (Abb.25B). Nach einer vierstündigen Behandlung der transfizierten Zellen mit LMB bei einer Konzentration von 20ng/ml, kommt es bei der Mehrzahl der transfizierten Zellen zur ausschließlichen Lokalisation von Myc/1-470 in den Zellkern. Daraus läßt sich die Existenz eines NES zwischen Aminosäuren 367-470 schließen, das den CRM-1 abhängigen Export des Proteins aus dem Zellkern vermittelt. Anhand der KonsensusSequenz für NES, $\mathrm{LX}_{2-3} \mathrm{LX}_{2-3} \mathrm{LXL}$ (Henderson and Eleftheriou, 2000), wobei X jede beliebige Aminosäure darstellt, konnte innerhalb der Region zwischen Aminosäuren 367-470 das Motif LIRSLEQDLKV (Aminosäuren 409-420) identifiziert werden, das als NES fungieren könnte. In Zellen, die mit den längeren Mapl-1 Varianten (Myc/1-878) und (Myc/1-1413) oder mit dem vollständigen Protein transfiziert wurden, führte die Behandlung mit LMB zu keiner Veränderung ihrer zellulären Lokalisation (nicht gezeigt). Dies könnte auf das Vorhandensein eines zusätzlichen cytoplasmatischen Retentiossignals zwischen den Aminosäuren 470-878 hinweisen, das von LMB nicht inhibiert wird.
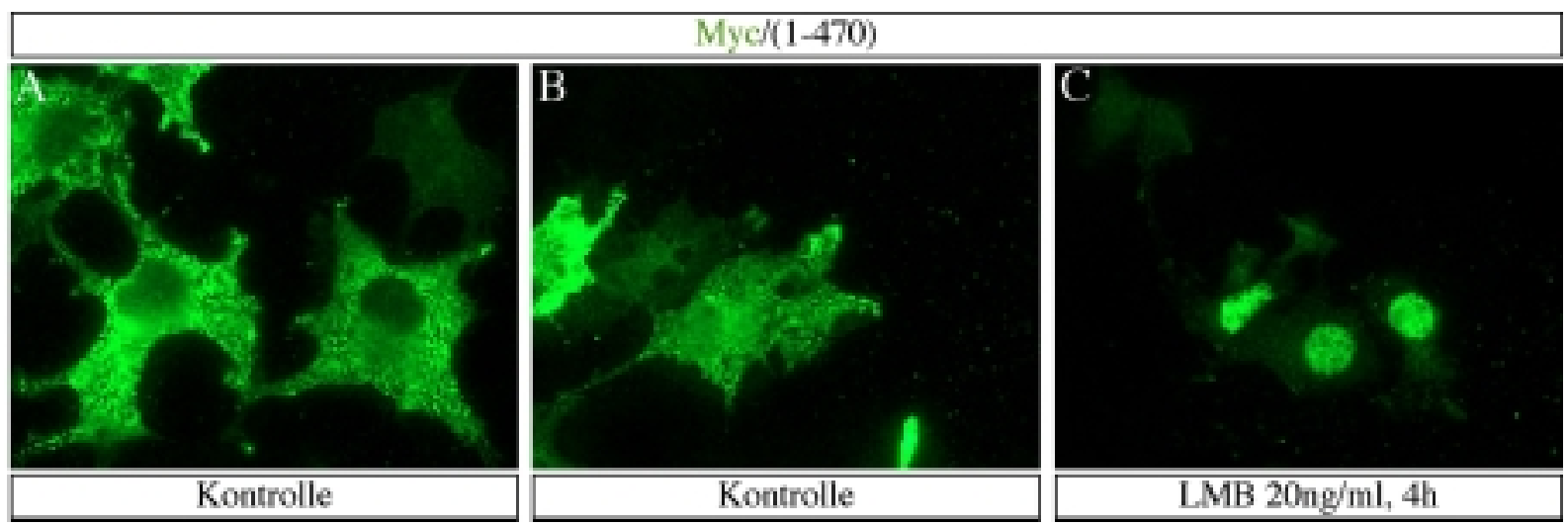

Abbildung 25

Beteiligung des CRM-1 abhängigen Kernexports an der Regulation der zellulären Lokalisation von Mapl-1. COS7-Zellen wurden mit der Deletionsvariante Myc/1-470 transfiziert und die zelluläre Lokalisation des Proteins ohne (A-B) oder nach Behandlung mit LMB (C) mittels Immunfluoreszenz ermittelt. A: Bei der 
Mehrzahl der unbehandelten Zellen ist das Protein im Cytoplasma lokalisiert. B: In einigen Zellen kann Myc/1470 auch schwach im Zellkern nachgewiesen werden. Nach Behandlung mit LMB (C) weist Myc/1-470 bei den meisten transfizierten Zellen ausschließlich eine Lokalisation im Zellkern auf. Für die Aufnahmen wurde ein 60x Objektiv verwendet.

\subsection{Herstellung eines polyklonalen Antiserums und Detektion des endogenen Mapl-1 Proteins}

Um das endogen produzierte Mapl-1 zu detektieren, wurde ein polyklonales Antiserum hergestellt. Die Region zwischen den Aminosäuren 1528-1634 von Mapl-1 wurde für die Immunisierung von Kaninchen ausgewählt. Das wesentliche Kriterium dafür war zum einen der hydrophile Charakter dieser Region und zum anderen die Tatsache, daß der als Epitop verwendete Bereich des Proteins außerhalb der Pax-Interaktionsdomäne liegt. Dadurch wird verhindert, daß die Bindung der Antikörper an das Protein die Interaktion mit Pax-6 unterbindet. Das nach der dritten Immunisierung erhaltene Serum konnte das injizierte Proteinfragment in Western-Blots erkennen (nicht gezeigt). Aufgrund des hohen unspezifischen Hintergunds erwies sich jedoch das hergestellte Antiserum in Immunfluoreszenz-Anwendungen als unbrauchbar (nicht gezeigt). Um die Konzentration der Mapl-1-spezifischen Antikörper zu erhöhen, wurde das Serum einer Affinitätsreinigung unterzogen. Dadurch gelang es, unter Einsatz von relativ großen Mengen des Rohserums die Antikörper zu reinigen und zu konzentrieren, so daß die Detektion des vollständigen Mapl-1 Proteins in transfizierten COS7-Zellen möglich war (Abb.26A). Trotz der Spezifität des Antiserums war das bei der Immunfärbung produzierte Fluoreszenzsignal viel schwächer im Vergleich mit dem, das unter Verwendung des Myc- oder V5-Antikörpers entsteht. Dies weist auf eine nicht optimale Immunisierung und auf eine geringe Konzentration der Mapl-1 spezifischen Antikörper im Serum hin. Das angestrebte Ziel war, das endogene Mapl-1Protein mit Hilfe des hergestellten Antiserums nachzuweisen. Dazu wurde die Zellinie NKR11 verwendet, die aus dem Linsenepithel einer Kataraktenmutanten-Maus stammt (Russell et $a l .$, 1978) und sowohl Pax-6 als auch mapl-1 exprimiert (Abb.26B). In dieser Zellinie ist Pax6, wie erwartet, hauptsächlich im Zellkern lokalisiert (Abb.26C). Für die Detektion des endogenen Mapl-1 war, aufgrund des nicht optimal reagierenden Serums einerseits und der niedrigen Expression des mapl-1-Gens andererseits, die Verwendung eines Amplifizierungssystems notwendig. Zudem hat sich das hergestellte Mapl-1 spezifische Antiserum als empfindlich gegen PFA-Fixierung der Zellen erwiesen, so daß aus diesem 
Grund die Zellen vor der Antikörperfärbung in Methanol fixiert wurden. Unter diesen Bedingungen konnte das endogene Mapl-1 detektiert werden. In Übereinstimmung mit den Ergebnissen der Transfektionsexperimente, konnte Mapl-1 an Cytoskelettfilamenten nachgewiesen werden, die mittels Doppelfärbung mit $\alpha$-Tubulin als Mikrotubuli identifiziert werden konnten (Abb.26D-E). Zusätzlich dazu konnte Mapl-1 in allen Zellen im Kern nachgewiesen werden (Abb.26D, F). Interessanterweise war das Protein nicht diffus im Zellkern verteilt, sondern wies vielmehr eine punktenförmige Verteilung auf (Abb.26D, F). Dies deutet auf eine Lokalisation und möglicherweise auch eine Funktion von Mapl-1 in bestimmten Kompartimenten des Zellkerns hin.
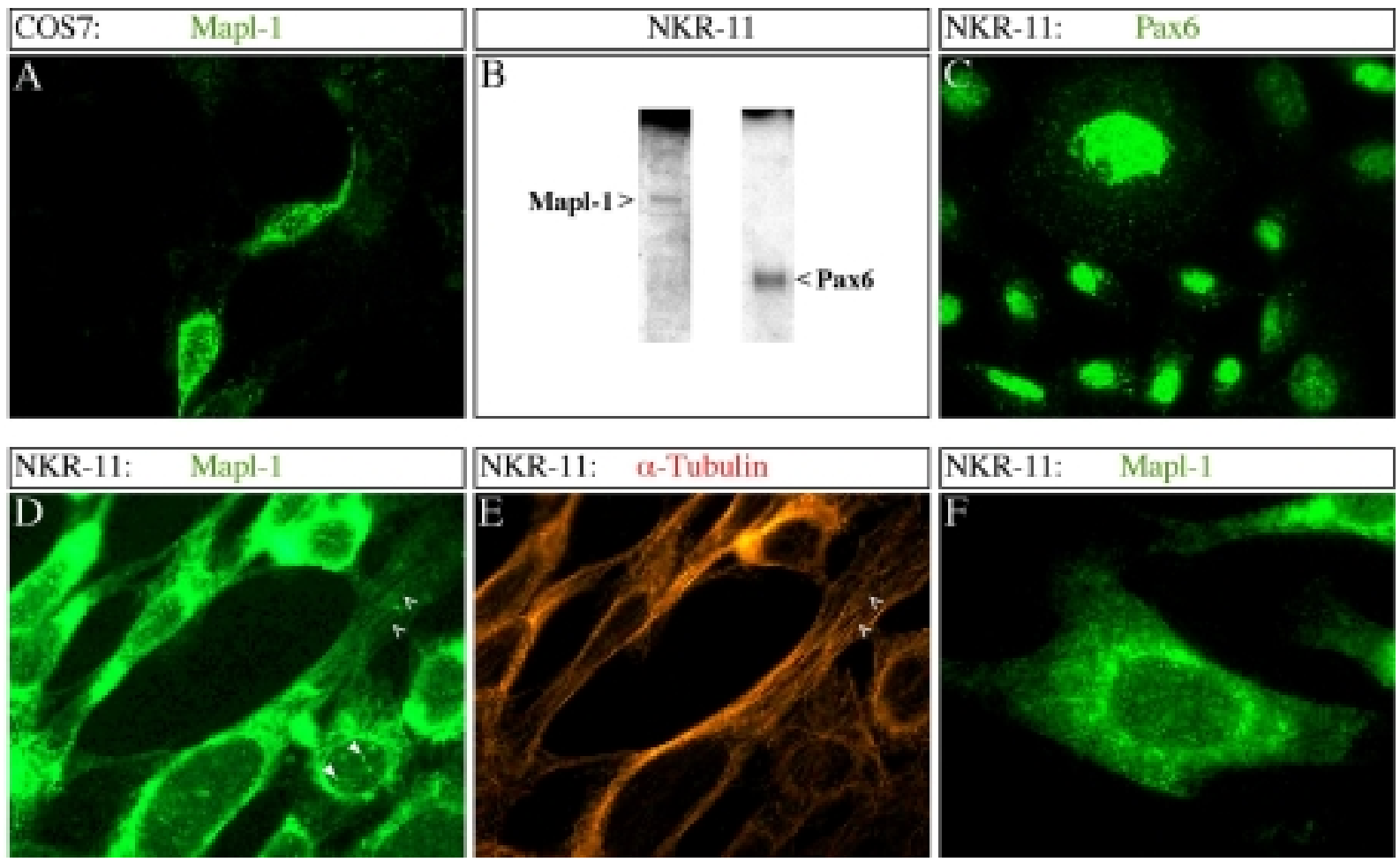

\section{Abbildung 26}

Ermittlung der zellulären Lokalisation von Mapl-1 mit Hilfe eines hergestellten polyklonalen Antiserums. A: Nachweis von Mapl-1 (grün) mit dem spezifischen Antiserum in COS7-Zellen, die mit dem Mapl-1/V5 Expressionsvektor transfiziert wurden. Das Protein wies die typische Assoziation mit Mikrotubuli auf. B. Die Zellinie NKR-11 exprimiert Mapl-1 und Pax-6. Durch Northern-Hybridisierung an Gesamt-RNA aus NKR-11 Zellen konnten die Transkripte für Pax-6 und mapl-1 nachgewiesen werden. C: Lokalisation von endogenem Pax-6 (grün) im Zellkern von NKR-11 Zellen. D: Endogenes Mapl-1 (grün) ist sowohl an Cytoskelettfilamenten (offene Pfeile) als auch in bestimmten Kompartimenten des Zellkerns (geschlossene Pfeile) lokalisiert. E: Färbung mit $\alpha$-Tubulin (rot) identifiziert die Cytoskelettfilamente als Mikrotubuli (geschlossene Pfeile). F: Höhere Vergrößerung (100x Objektiv) von mit Mapl-1 spezifischem Antiserum (grün) gefärbten NKR-11 Zellen. Auffällig ist die punktförmige Färbung in den Zellkern. A, D, E: 60x Objektiv. 


\subsection{Der Carboxyterminus von Mapl-1 als Transkriptions-Aktivierungsdomäne}

Mapl-1 wurde anhand der Primärstruktur des Proteins mit Hilfe der Computerprogramme Pfam und SMART in die Familie der bZIP Transkriptionsfaktoren eingeordnet. Auffällig im Mapl-1 Protein ist der relativ hohe Gehalt an den Aminosäuren Prolin (10,5\%), Serin (11,7\%) und Threonin $(8,4 \%)$ innerhalb der 477 carboxyterminalen Aminosäuren des Proteins. Eine entsprechende Prolin-, Serin- und Threonin-reiche (PST) Region befindet sich ebenfalls im Carboxyterminus des Pax-6 Proteins und wurde als Transkriptions-Aktivierungsdomäne charakterisiert (Czerny and Busslinger, 1995; Glaser et al., 1994). Aus diesem Grund wurde überprüft, ob die carboxyterminale Region von Mapl-1 die Fähigkeit zur Transkriptionsaktivierung besitzt. Dazu wurden die 477 carboxyterminalen Aminosäuren von Mapl-1 an die DNA-bindende Domäne des GAL4-Proteins (GAL4BD) der Hefe fusioniert. In COS7-Zellen wurde dann die Aktivierung des Reportergens Luciferase unter der Kontrolle von 5 Kopien der GAL4 DNA-bindenden Sequenz und des viralen E1b Minimalpromotors quantitativ gemessen. Es zeigte sich, daß die an die GAL4BD fusionierte carboxyterminale Domäne von Mapl-1 im Vergleich zur GAL4BD allein, die Transkription des Reportergens um ca. das Vierfache stimulieren kann (Abb.27). Demnach läßt sich die carboxyterminale Region von Mapl-1 als Transkriptions-Aktivierungsdomäne bezeichnen.

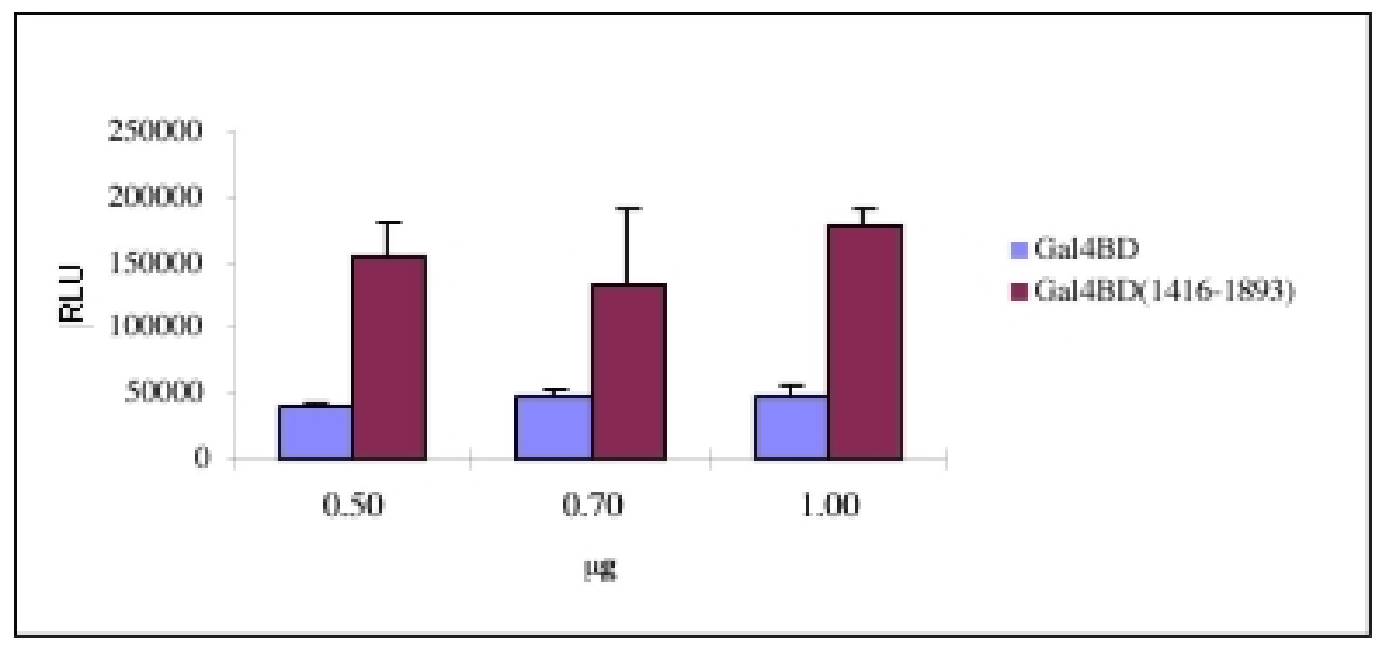

\section{Abbildung 27}

Der Carboxyterminus von Mapl-1 und seine Funktion als Transkriptions-Aktivierungsdomäne. Steigende Menge des Plasmids GAL4BD(1416-1893) (Fusion des Carboxyterminus von Mapl-1 an der GAL4BD) oder GAL4BD (Kontrolle) wurde zusammen mit 0,5 $\mathrm{g}$ des Reporterkonstrukts GAL4(5x)-Luc (Luciferase Reportergen unter der Kontrolle von 5 Kopien der GAL4 Bindesequenz und des viralen E1b-Promotors) in COS7-Zellen

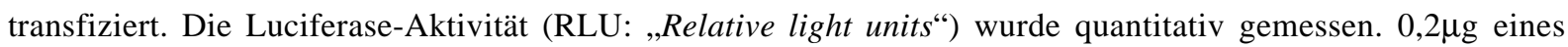
CMV-LacZ Plasmids wurde zur Kontrolle der Transfektionseffizienz eingesetzt. Die dargestellten Werte entsprechen dem Durchschnitt aus drei unabhängigen Transfektionen. 


\subsection{Mapl-1 konkurriert mit DNA um die Bindung an Pax-6}

In Abschnitt 2.10 wurde die Domäne des Pax-6 Proteins kartiert, die direkt an der Interaktion mit Mapl-1 beteiligt ist. Dies führte zur Identifizierung der Paired-Domäne von Pax-6 als Interaktionsdomäne. Da die Paired-Domäne als das Haupt-DNA-bindende Motiv der Pax Proteine gilt, ergab sich die Frage, ob die Paired-Domäne von Pax-6 in der Lage ist, gleichzeitig mit DNA und mit Mapl-1 zu interagieren. Um dies zu überprüfen, wurde mittels GST-,,Pulldown“ die Fähigkeit von Pax-6, mit Mapl-1 zu interagieren, in Anwesenheit der Bindesequenz der Paired-Domäne untersucht. Bei der in diesem Experiment in Form eines Oligonukleotids eingesetzten Bindesequenz, handelt es sich um die optimale Erkennungssequenz der Pax-6 Paired-Domäne (Pax6CON), die durch in vitro Selektion von Bindestellen ermittelt wurde (Epstein et al., 1994b). Ein Oligonukleotid (T7) von gleicher Länge, das eine Region aus dem Bakteriophagen T7 Promotor enthält, wurde als Kontrolle verwendet. Wie im Gelretardationsexperiment (Abb.28B) ersichtlich, bindet Pax-6 am Pax6CON Oligonukleotid sehr effizient, während am T7 Oligonukleotid unter den gleichen Bedingungen keine Bindung nachgewiesen werden konnte. Beim GST-,Pulldown“ wurde dann die Retention von in vitro translatiertem und radioaktiv-markiertem Pax-6 Protein an der Pax-Interaktionsdomäne (PID) von Mapl-1 als Fusion mit GST (GST-PID) untersucht, jeweils in Anwesenheit des Pax6CON- oder des T7 Oligonukleotids in der Bindereaktion. Daraus ergab sich, daß steigende Mengen des T7 Oligonukleotids keinen Einfluß auf die Retention von Pax-6 durch das GST-PID Fusionsprotein hatten. Im Gegensatz dazu wurde mit steigender Konzentration des Pax6CON Oligonukleotids zunehmend weniger Pax-6 am GST-PID Fusionsprotein zurückgehalten (Abb.28A, rechtes Bild). Aus diesem Experiment kann geschlossen werden, daß es in Gegenwart der optimalen Bindesequenz der PairedDomäne zu einer Konkurrenz mit Mapl-1 um die Bindung an das Pax-6-Protein kommt. Durch zunehmende Konzentration der Erkennungssequenz der Paired-Domäne geht diese Kompetition auf Kosten der Interaktion mit Mapl-1. Daraus folgt, daß Pax-6 nicht in der Lage ist, gleichzeitig mit DNA und mit Mapl-1 zu interagieren. Im GST-,,Pulldown“ der Abb.28A wurden alle Komponenten des Assays (Pax-6, GST-PID, und Oligonukleotid) gleichzeitig der Bindereaktion zugesetzt. Im Assay der Abb.28B ließ man zuerst Pax-6 und GST-PID miteinander interagieren, anschließend wurde die entsprechende Menge des Oligonukleotids 
zugesetzt und bis zum Erreichen des Gleichgewichts für zwei weitere Stunden inkubiert. Dabei hatte wiederum die steigende Menge des T7 Oligonukleotids keinen Einfluß auf die Interaktion zwischen Pax-6 und Mapl-1. Durch die zunehmende Menge an Pax6CON Oligonukleotid konnte zwar ein Kompetitionseffekt mit Mapl-1 um die Bindung an Pax-6 erzielt werden, dafür war aber im Vergleich zum Experiment aus Abb.28A eine ca. zehnfach höhere Menge an Pax6CON erforderlich. Dies weist darauf hin, daß durch die Interaktion zwischen der Pax-6 Paired-Domäne und Mapl-1 eine Konformation der Paired-Domäne stabilisiert wird, die nicht mit DNA interagieren kann. Untersucht wurde ebenfalls die Retention von in vitro translatiertem und radioaktiv-markiertem Mapl-1 (Abb.28D) bzw. der isolierten PID von Mapl-1 (Abb.28E) an der Pax-6 Paired-Domäne fusioniert an GST (GSTPax6/PD), in der Anwesenheit des T7 bzw. Pax6CON Oligonukleotids. Auch mit dem vollständigen Protein bzw. der isolierten PID konnte bei zunehmender Menge des Pax6CON Oligonukleotids der gleiche Kompetitionseffekt um die Bindung an Pax-6 beobachtet werden.

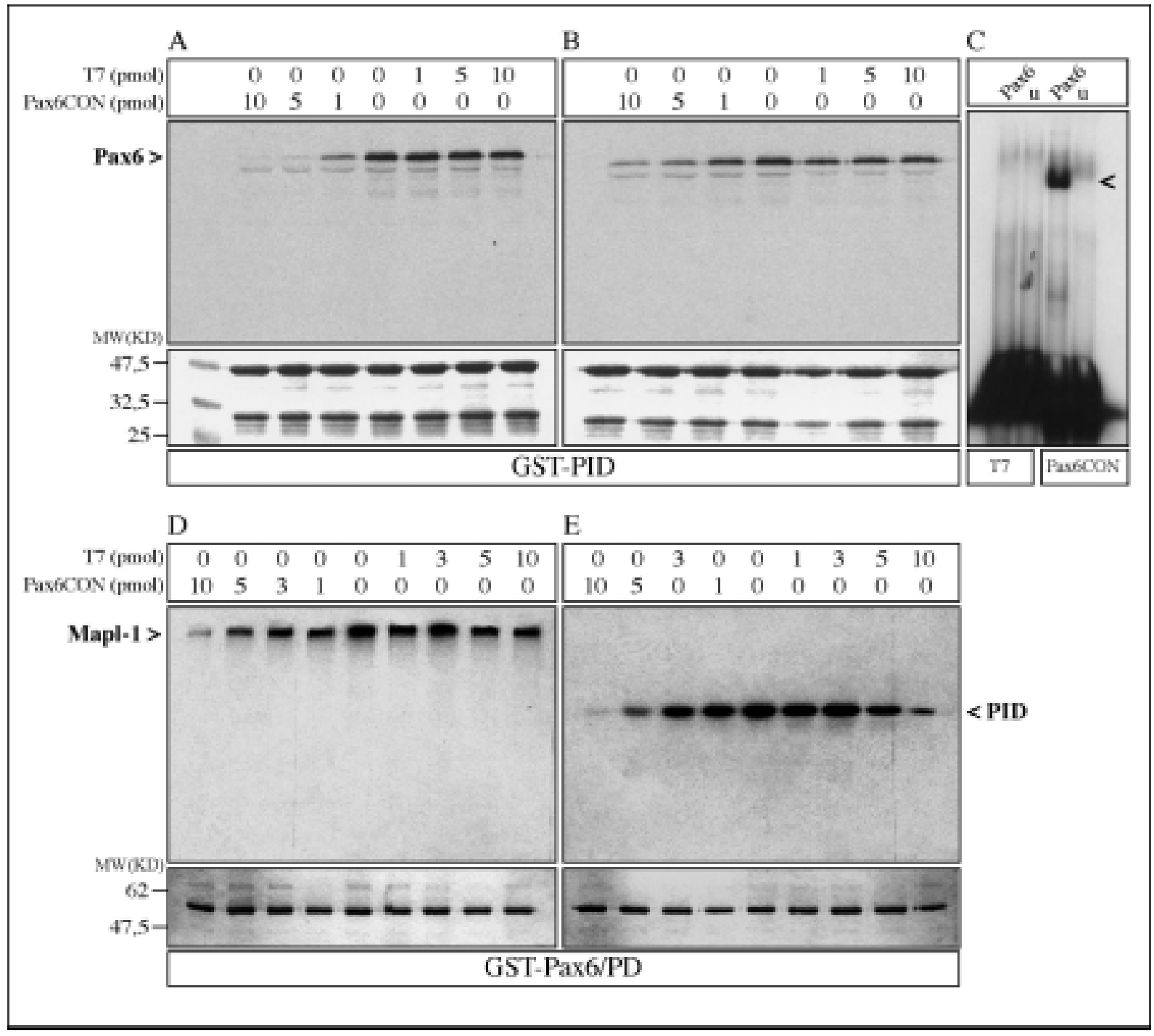




\section{Abbildung 28}

Mapl-1 konkurriert mit DNA um die Bindung an Pax-6. A: GST-,Pulldown“, bei dem die Retention von in vitro translatiertem und radioaktiv-markiertem Pax-6 an das GST-PID Fusionsprotein in Gegenwart der Oligolukleotide Pax6CON (enthält die Konsensus Bindesequenz der Pax-6 Paired-Domäne) und T7 (Kontrolle von gleicher Länge) untersucht wurde. Da durch zunehmende Menge des Pax6CON Oligonukleotids die Interaktion zwischen Pax-6 und Mapl-1 unterbunden wird, kann daraus geschlossen werden, daß die PairedDomäne von Pax-6 nicht gleichzeitig mit DNA und Mapl-1 interagieren kann. B: Parallel zu A durchgeführtes GST-,Pulldown“, bei dem im Gegensatz zu A erst Pax-6 und GST-PID inkubiert wurden und anschließend die Zugabe der entsprechenden Oligonukleotide erfolgte. Es ist dabei mehr Pax6CON Oligonukleotid erforderlich als bei A, um mit der Bindung von Pax-6 an Mapl-1 zu konkurrieren. C: Gelretardationsexperiment, bei dem die Bindung von in vitro translatiertem Pax-6 an die verwendeten Oligonukleotide getestet wurde. Pax- 6 bindet an Pax6CON, aber nicht an das T7 Oligonukleotid. u: Nicht programmiertes Retikulozyten-Lysat (Kontrolle), Pax6: Mit pSP64Pax6 programmiertes Retikulozyten-Lysat. D-E: GST-,Pulldown“, bei dem der Effekt der Oligonukleotide Pax6CON und T7 auf die Interaktion zwischen dem kompletten Mapl-1 Protein (D) bzw. der PID von Mapl-1 (E) an das GST-Pax6/PD Fusionsprotein untersucht wurde. Die Kompetition zwischen Mapl-1 und Pax6CON um die Bindung an Pax-6 konnte dabei ebenfalls bestätigt werden. A, B, D, E: unteres Bild: Durch die Färbung des Gels mit „Coomasie“ wurde nachgewiesen, daß bei allen Ansätzen, die miteinander verglichen wurden, die gleiche Menge an GST-Fusionsprotein eingesetzt wurde.

\subsection{5 Überexpression von Mapl-1 in transgenen Mäusen}

Die Tatsache, daß Mapl-1 mit DNA um die Interaktion mit Pax-6 konkurriert, läßt darauf schließen, daß Mapl-1 die Bindung von Pax-6 an suboptimalen Erkennungssequenzen der Paired-Domäne in vivo verhindern könnte. Darüber hinaus könnte Mapl-1 auf Transkriptionsebene als negativer Regulator der Pax-6 Aktivität fungieren. Gemäß dieser Hypothese würde dann die Erhöhung der Mapl-1-Dosis in Domänen der Pax-6 Expression einen negativen Einfluß auf die Funktion von Pax-6 haben. Um dieses Modell in vivo zu testen, wurde Mapl-1 in transgenen Mäusen überexprimiert. Als Zielregion für die Überexpression des Gens wurde die Linse ausgewählt. Der Grund dafür ist die entscheidende Rolle, die Pax-6 im Oberflächenektoderm und in der Entwicklung der daraus hervorgehenden Linse spielt. Daß die Pax6 Funktion im Oberflächenektoderm für die Induktion der Linse unentbehrlich ist, läßt sich anhand von Transplantations-Experimenten zeigen, die in „Small eye "Rattenembryonen durchgeführt wurden. Es wurde dabei demonstriert, daß die Kombination von Oberflächenektoderm aus homozygoten Mutanten und Augenbläschen aus Wildtyp oder heterozygoten Embryonen nicht zur Linseninduktion führte (Fujiwara et al., 1994). Die somatische Inaktivierung von Pax-6 mittels des Cre/loxP Systems spezifisch im Oberflächenektoderm in der Maus führte ebenfalls zum Ausbleiben der Linseninduktion nach der Spezifizierung des Oberflächenektoderms (Ashery-Padan et al., 2000). Zudem sprechen weitere Hinweise dafür, daß dem semidominanten Pax-6 heterozygoten Phänotyp Defekte im

Oberflächenektoderm zugrunde liegen. Zum einen kommt es bei Pax-6 heterozygoten 
Embryos zur verspäteten Ausbildung der Linsenplakode (van Raamsdonk and Tilghman, 2000), zum anderen, wie mit Hilfe von chimären Embryonen demonstriert wurde, sind Pax-6 heterozygote Zellen nicht in der Lage, zur Ausbildung der Linsenplakode beizutragen und werden davon ausgeschlossen (Collinson et al., 2001). Diese Daten deuten auf die Empfindlichkeit der Linseninduktion in Abhängigkeit der Pax-6-Dosis.

Für die Überexpression von Mapl-1 im Oberflächenektoderm von transgenen Embryonen wurde ein 6,5kb langes genomisches Fragment aus dem Pax-6 Lokus verwendet, das die Expression eines Reportergens ab E9,0 spezifisch in aus dem Oberflächenektoderm hervorgehenden Strukturen (Linse, Kornea) und zusätzlich im Pankreas transgener Mäuse steuert (Williams et al., 1998, Kammandel, et al. 1999). Das genomische Fragment, welches zusätzlich zu den regulatorischen Sequenzen den ersten Pax-6-Promotor (P0) enthält wurde stromaufwärts der Mapl-1 kodierenden cDNA Sequenz kloniert (Abb.29A). Die Verwendung der IRES-gfp Sequenzen stromabwärts der Mapl-1 kodierenden Region erlaubt die gleichzeitige Translation von $g f p$ von einer bicistronischen mRNA. Anhand der $g f p$ Expression konnten richtig exprimierende transgene Tiere in der F1 Generation identifiziert werden (Abb.29B).

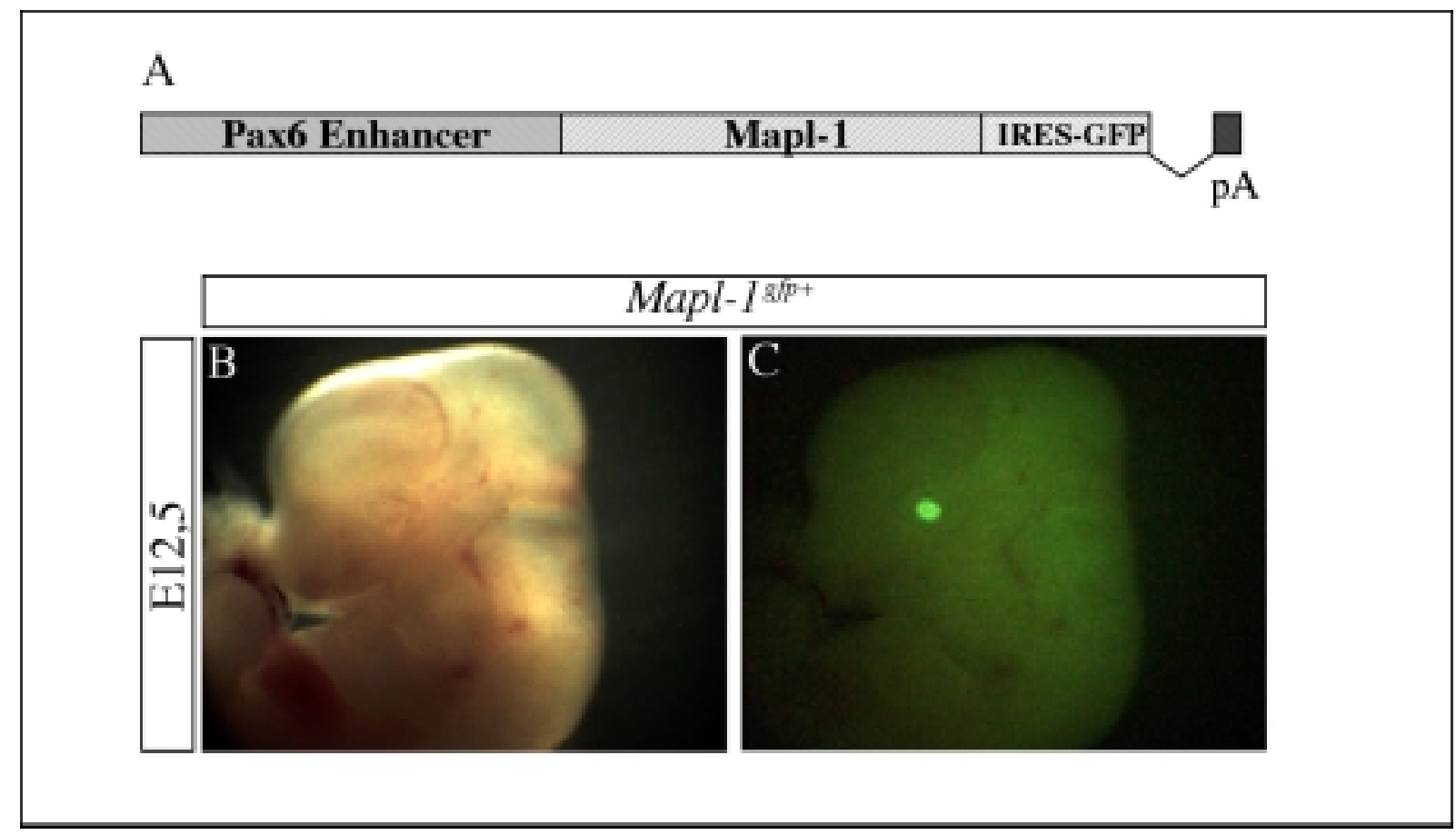

Abbildung 29

Etablierung von transgenen Linien mit Mapl-1 Expression in der Linse. A: Schematische Darstellung des Konstrukts, das bei der Mikroinjektion in befruchtete Eizellen verwendet wurde. Die kodierende Sequenz von Mapl-1 wurde stromaufwärts des Linsen/Pankreas-spezifischen Enhancers aus dem Pax-6 Lokus gesetzt. Die 
Verwendung von IRES- $g f p$ ermöglicht die gleichzeitige Translation von $g f p$, das als Reporter dient, aus der gleichen mRNA. B-C: Transgener Embryo am E12,5, der $g f p$ Expression in der Linse aufweist. B: Hellfeld-; C: Fluoreszenzaufnahme.

Mit diesem Konstrukt wurden 4 Linien etabliert, die das Transgen in der Linse exprimieren, drei davon haben stabil das Transgen an die Nachkommen vererbt und wurden aus diesem Grund weiter analysiert. Die Mapl-1 $1^{g f p+}$ transgenen Tieren konnten sowohl während der Embryonalentwicklung als auch im adulten Stadien anhand der Größe ihrer Augen von Wildtyp-Mäusen des gleichen Wurfes phänotypisch nicht unterschieden werden. Auch nach der Isolierung der Augen aus Mapl-1 ${ }^{g f p+}$ - und Wildtyp-Mäusen konnten keine signifikante Veränderungen in der Größe oder Morphologie der Linse erkannt werden. Dies war in allen drei etablierten Linien der Fall. Offensichtlich führte die Expression von Mapl-1 unter der Kontrolle des Pax-6-Linsenelements zu keiner großen Beeinträchtigung des Programms der Linsenentwicklung, so daß kein morphologisch erkennbarer Phänotyp entstanden ist.

\subsection{In vivo Elektroporation von Mapl-1 in Mausembryonen}

Die postulierte Funktion von Mapl-1 als negativer Regulator der Pax-6 Funktion konnte durch das Funktionsgewinn-Experiment in transgenen Mäusen nicht demonstriert werden. Als alternative Methode um diesem Problem nachzugehen, wurde die in vivo Elektroporation von Embryonen genutzt. Diese Methode wurde zuerst bei Hühnerembryonen verwendet, um in ovo Plasmide in das Embryo zu transfizieren (Muramatsu et al., 1996) und konnte anschließend auch erfolgreich bei Mausembryonen angewandt werden (Itasaki, 1999); zum Überblick, (Schwartz et al., 2001). Wenn Pax-6 in E8,5 Mausembryonen mittels Elektroporation ektopisch exprimiert wird, kann die Expression bestimmter Gene, die dem Pax-6 Gen untergeordnet sind, angeschaltet werden. Otx-2, das im Oberflächenektoderm vor der Entstehung der Linsenplakode exprimiert wird, ist ein solches Gen, dessen Expression durch Pax-6 ektopisch induziert werden kann (G. Bernier persönliche Mittteilung, Abb.30AC). Die Pax-6 abhängige ektopische Induktion von $O t x$-2 in elektroporierten Mausembryonen wurde als Modellsystem eingesetzt, um die vermutliche Rolle von Mapl-1 als negativer Pax-6

Regulator aufzuklären. Ziel war es, bei gleichzeitiger Elektroporation von Expressionskonstrukten für Pax-6 und Mapl-1 die Induktion von Otx-2 in kotransfizierten Zellen negativ zu beeinflussen. Die Detektion der in diesem Assay beteiligten Proteine erfolgte mittels dreifach Antikörperfärbung an Kryoschnitten (Abb.30). In der Mehrzahl der 
durch Elektroporation transfizierten Zellen konnten beide Proteine (Pax-6 und Mapl-1) nachgewiesen werden. In einigen kotransfizierten Zellen konnte trotz der Anwesenheit des Pax-6 Proteins tatsächlich keine Induktion von Otx-2 erzielt werden (Abb.30D-F). Es konnten jedoch kotransfizierte Zellen nachgewiesen werden, in denen trotz der Anwesenheit von Mapl-1 die Aktivierung der Zielgenexpression stattgefunden hat (Abb.30G-I). Mapl-1 selbst war nicht in der Lage, allein die Expression von Otx-2 zu induzieren (nicht gezeigt). Darüber hinaus konnte über dieses Experiment festgestellt werden, daß die ektopische Aktivierung von Otx-2 nicht zu hundert Prozent mit der Expression von Pax-6 korreliert (Abb.30J-L). Offensichtlich ist die Induktion des Zielgens von der Pax-6-Dosis abhängig und findet statt, wenn eine bestimmte Menge an Pax-6 Protein erreicht wird. Dies wird verdeutlicht durch das Vorhandensein von Pax-6-positiven Zellen, in denen Otx-2 nicht induziert wurde (Abb.30JL). Unter den gegebenen Umständen konnte über den postulierten Mechanismus der Mapl-1 Funktion keine eindeutige Aussage gemacht werden. Der Hauptgrund liegt darin, daß bei den kotransfizierten Zellen, in denen Otx-2 nicht aktiviert wurde, nicht eindeutig festgestellt werden konnte, ob einerseits die Interaktion zwischen Pax-6 und Mapl-1 oder andererseits die geringe Pax-6 Dosis für das Ausbleiben der Induktion des Zielgens verantwortlich war. Dem Effekt der Otx-2 Aktivierung bei vergleichbarer Pax-6 Dosis in An- oder Abwesenheit von Mapl-1 konnte mittels Elektroporation und Antikörperfärbung nicht nachgegangen werden, da diese Methode keine quantitativen Aussagen ermöglicht. 

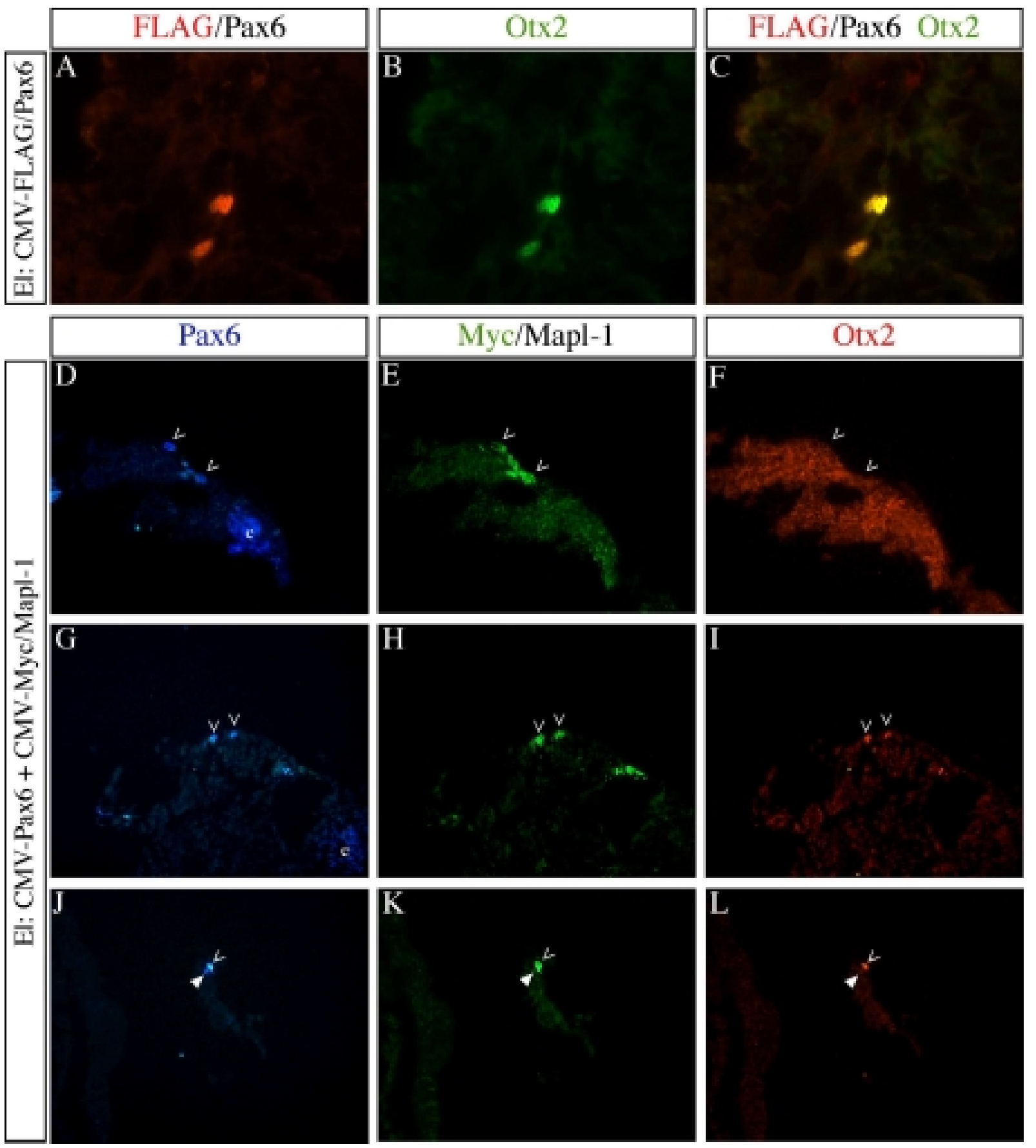

Abbildung 30

Antikörperfärbung an $10 \mu \mathrm{m}$ Kryoschnitten aus in vivo elektroporierten Embryonen. A-B: Pax-6 wurde am Aminoterminus mit einem FLAG Epitop versehen, um das transfizierte vom endogenen Protein unterscheiden zu können. Ektopisch exprimiertes FLAG/Pax-6 (rot) führt zur Induktion von Otx-2 (grün). C: Überlagerung des roten umd grünen Signals. D-L: Bei der Ko-Elektroporation mit Myc/Mapl-1 wurde Pax-6 ohne FLAG-Tag verwendet, da die Anwesenheit des FLAG-Epitops am Aminoterminus von Pax-6 die Interaktion mit Mapl-1 verhindert (nicht gezeigt). D-F: In transfizierten Zellen, die sowohl für Pax-6 (blau) als auch für Myc/Mapl-1 (grün) positiv sind (Pfeile), wird Otx-2 (rot) nicht induziert. G-I: Doppeltransfizierte Zellen, in denen das Otx-2 Zielgen induziert wird. J-L: Abhängigkeit der Otx-2 Aktivierung von der Pax-6 Dosis. Bei hoher Pax-6 Dosis (J, offener Pfeil) kommt es trotz der Anwesenheit von Mapl-1 (K, offener Pfeil) zur Induktion von Otx2 (L, offener 
Pfeil). Bei geringer Pax-6 Expression (J, geschlossener Pfeil) wird das Zielgen nicht aktiviert (L, geschlossener Pfeil). 


\section{Diskussion}

\subsection{Protein-Protein Interaktionen als Mechanismus zur Erhöhung der biologischen Diversität von Pax-Proteinen}

Protein-Protein Interaktionen spielen bei nahezu allen biologischen Prozessen eine bedeutende Rolle. Die physikalische Wechselwirkung zwischen Proteinen stellt einen ökonomischen Modus der Natur dar, durch die Bildung von Komplexen aus bereits vorhandenen Proteinen neue biologische Funktionen und Eigenschaften hervorzubringen. Im Prozeß der Embryonalentwicklung kontrollieren Transkriptionsfaktoren die Abfolge von induktiven Ereignissen, die zur Spezifizierung von Organen oder zu Differenzierung von Zelltypen führen. Solche Transkriptionsfaktoren sind in vielen Fällen strukturell sehr ähnlich, sind aber trotzdem in der Lage, unterschiedliche regulatorische Kaskaden zu steuern. Ein Beispiel für strukturell verwandte Transkriptionsfaktoren, die in verschiedenen Entwicklungsprogrammen eine Rolle spielen, stellt die Familie der Pax-Proteine dar. Wie die biologische Diversität innerhalb der Familie der Pax-Proteine erreicht wird so daß genetische Information räumlich und zeitlich präzise umgesetzt wird, scheint ein komplexes Zusammenspiel von mehreren Faktoren zu sein. Die erste Stufe in der Mannigfaltigkeit bei den Pax-Proteinen wird durch den unterschiedlichen Bindungsmodus an die DNA erreicht. Pax-Proteine können insgesamt bis zu drei Helix-Schleife-Helix-Motive enthalten, die zur DNA-Bindung imstande sind. Trotz der strukturellen und funktionellen Ähnlichkeiten in diesen Domänen unterscheiden sich Pax-Proteine in ihrer Fähigkeit, diese Motive für die Wechselwirkung mit DNA zu kombinieren. Der kombinatorische Einsatz der DNABindungsdomänen der Pax-Proteine in vivo scheint zum einem durch alternatives Spleißen und zum anderen durch Protein-Protein Interaktionen reguliert zu werden. Hierbei wird entweder durch Insertion von zusätzlichen Aminosäuren (alternatives Spleißen) oder durch die Wechselwirkung mit einem anderen Protein erreicht, daß bestimmte Domänen der PaxProteine nicht mehr an DNA binden können. Pax-Interaktionspartner können jedoch nicht nur 
die DNA-Bindung von Pax-Proteinen verhindern, sondern auch eine Bindung an nicht optimale Bindestellen ermöglichen (Kamachi et al., 2001). Ein solcher Mechanismus kann erheblich zur Erhöhung des Repertoirs an natürlichen Bindestellen für die Pax-Proteine beitragen.

Eine höhere Stufe an funktioneller Diversität wird durch die Fähigkeit der Pax-Proteine, sowohl als Aktivatoren wie auch als Repressoren zu wirken, erreicht. Die Fähigkeit der PaxProteine, die Transkription von untergeordneten Genen zu stimulieren oder zu unterdrücken wird in erster Linie durch ihre Primärstruktur bestimmt. Zudem haben Protein-Protein Interaktionen einen entscheidenden Einfluß auf die transkriptionsaktivierenden bzw. -reprimierenden Eigenschaften der Pax-Proteine. So können Pax-Proteine durch die Wechselwirkung mit Korepressoren die Transkription von Genen unterdrücken (Eberhard et al., 2000; Hollenbach et al., 1999; Magnaghi et al., 1998), andererseits führt der Aufbau von größeren Proteinkomplexen an Promotorsequenzen zu erhöhter Aktivierung (Hussain and Habener, 1999).

Die Identifizierung und Charakterisierung von Pax-Interaktionspartnern trägt also erheblich zum Verständnis der molekularen Mechanismen bei, die der Regulation der PaxTranskriptionsfaktoren zugrunde liegen.

\subsection{Mapl-1 definiert eine neue Familie von Proteinen}

In dieser Arbeit wird die Klonierung von einem neuen Gen, mapl-1, und die Charakterisierung der physikalischen Wechselwirkung des davon kodierten Proteins mit dem Pax-6-Protein der Maus beschrieben. Mapl-1 wurde in einem Hefe-,,Two-hybrid-screen“ als potentieller Pax-6 Interaktionspartner identifiziert (Petrou, 1997). Offensichtlich definiert mapl-1 eine neue Familie von Proteinen, da ein zweites Gen (mapl-2), das hohe Sequenzähnlichkeit zu mapl-1 aufweist, aus dem gleichen „Two-hybrid screen“ isoliert wurde. Zusätzlich konnte durch die Suche in Sequenzdatenbanken ein drittes Gen (BAB31090) (Carninci, 1999) im Mausgenom identifiziert werden. Drei mapl-1-ähnliche Gene sind ebenfalls im menschlichen Genom vorhanden. Auch bei Invertebraten lassen sich jeweils ein Gen bei Drosophila und eins bei C. elegans zur Familie der mapl-1-ähnlichen Genen einordnen. Pax-6 gehört zu den wenigen Genen, für die eine stark konservierte Funktion im Laufe der Evolution nachgewiesen wurde. Unter Berücksichtigung der 
Eigenschaft von Mapl-1, mit Pax-6 zu interagieren, könnte die entsprechende Konservierung von mapl-1 bei Invertebraten auf eine bedeutende Funktion des Komplexes zwischen den beiden Proteinen hinweisen, die während der Evolution erhalten blieb. Aus den potentiellen orthologen Genen in anderen Spezies konnten keine zusätzliche Hinweise auf die Funktion von mapl-1 gewonnen werden, da es sich bei allen um uncharakterisierte Klone handelt, die aus Sequenzierungsprojekten entstanden sind. Weder bei Drosophila noch beim Menschen konnten anhand ihrer chromosomalen Lokalisation mapl-1-ähnliche Gene mit vorhandenen Mutanten bzw. menschlichen Erkrankungen in Verbindung gebracht werden. Als einziges Auswahlskriterium für den wahrscheinlicheren Kandidat einen Pax-6 spezifischen Interaktionspartner darzustellen blieb allein das Expressionsmuster der entsprechenden Gene. Während mapl-2 ubiquitär exprimiert ist, wies mapl-1 ein restriktives und Pax-6 ähnliches Expressionsmuster insbesondere während der frühen Entwicklungsstadien auf. Über das Gen BAB31090 der Maus liegen keine Expressionsdaten vor. Aus diesem Grund konzentrierte sich das Interesse im Rahmen dieser Arbeit auf mapl-1.

\subsection{Mapl-1 und seine Funktion als neues Mikrotubuli-assoziiertes Protein}

Mapl-1 übt sehr wahrscheinlich eine doppelte Funktion aus. Zusätzlich zur Funktion des Proteins als Pax-6 Interaktionspartner hat sich Mapl-1 in dieser Arbeit als ein neues Mikrotubuli-assoziiertes Protein (MAP) etabliert. Die Untersuchung der Lokalisation von Mapl-1 in transfizierten Säugerzellen ergab trotz der Anwesenheit eines Kernlokalisationssignals, daß das Protein mit den zellulären Mikrotubuli spezifisch und direkt assoziieren kann. Hierbei induzierte die Überexpression des Proteins in transfizierten Zellen das Zusammenbinden von Mikrotubuli zu dicken Bündeln. Dieser Effekt war vom Expressionsniveau des Proteins abhängig. Die Assoziation des Proteins mit Komponenten des Cytoskeletts sowie ihre Vernetzung in transfizierten Zellen war für Mikrotubuli spezifisch, da die Organisation der anderen Klassen von Cytoskelettfilamenten (Mikrofilamente und Intermediärfilamente) durch das Protein nicht beeinflußt wurde. Es konnte weiterhin demonstriert werden, daß Mapl-1 eine stabilisierende Wirkung auf die Mikrotubuli ausübt. Entscheidend hierbei ist der Beitrag der carboxyterminalen Region von Mapl-1, die für die Assoziation, Vernetzung und Stabilisierung von Mikrotubuli sowohl notwendig als auch ausreichend ist. Einen zusätzlichen Beitrag zur Erhöhung der Stabilität der zellulären 
Mikrotubuli leistet wahrscheinlich die Fähigkeit des Proteins zu dimerisieren. Ob der stabilisierende Effekt von Mapl-1 auf den Polymerisationszustand der zellulären Mikrotubuli durch die Erhöhung der Polymerisations- oder Unterdrückung der Depolymerisationsrate zustande kommt, ist noch offen. Die Bildung von antiparallelen Dimeren gilt als der Mechanismus, durch den ein anderes Mikrotubuli-assoziiertes Protein, (MAP-2), die Mikrotubuli zu Bündeln vernetzt und stabilisiert (Wille et al., 1992a; Wille et al., 1992b). Da die Dimerisierungsdomäne von Mapl-1 am Amino-, während die Mikrotubuli-bindende Domäne am Carboxyterminus des Proteins liegt, könnte die Bildung von antiparallelen Dimeren bei Mapl-1 ebenfalls der molekulare Mechanismus sein, der der Vernetzung der Mikrotubuli zugrunde liegt (Abb.31).

Anhand der in dieser Arbeit präsentierten Daten etabliert sich Mapl-1 als ein neues MAP. Um so interessanter ist die Tatsache, daß die als Mikrotubuli-bindende Domäne identifizierte Region von Mapl-1 keine Sequenzähnlichkeit zu den entsprechenden Domänen der bekannten MAPs aufweist. Demzufolge stellt sie eine neue Mikrotubuli-bindende Domäne dar, die zur Identifizierung von neuen MAPs beitragen kann. Ob es sich bei den restlichen Proteinen der Mapl-Familie ebenfalls um MAPs handelt, muß noch gezeigt werden.

Mikrotubuli sind sehr dynamische Polymere, die während des Zellzyklus rasche Veränderungen in ihrem Polymerisationszustand durchlaufen. Der dynamische Zustand der Mikrotubuli zu jedem Zeitpunkt des Zellzyklus wird durch die Kombination der Aktivitäten von Mikrotubuli-stabilisierenden und -destabilisierenden Proteinen reguliert. Während der Interphase sind die Mikrotubuli lang und stabil, während sie im Laufe der Mitose kurz und dynamisch werden. Dieser Übergang ist auf eine Erhöhung der Depolymerisationsrate der Mikrotubuli auf ca. das Zehnfache zurückzuführen (Saxton et al., 1984; Verde et al., 1992). Für die Ausbildung der Mitosespindel müssen also die zellulären Mikrotubuli depolymerisiert und lokal um die Chromosomen wieder aufgebaut werden. Interessanterweise konnte in Zellen, die mit Mapl-1 Expressionskonstrukten transfiziert wurden, die Ausbildung der Mitosespindel nicht beobachtet werden. Dies spricht dafür, daß aufgrund der stabilisierenden Wirkung von Mapl-1 auf den Polymerisationszustand von Mikrotubuli die für den Übergang in die Mitose erforderliche Depolymerisierung nicht stattfinden konnte. Demzufolge war wahrscheinlich der Übergang des Zellzyklus bei transfizierten Zellen in die Mitose aufgrund der fehlenden Spindel nicht möglich. Dieser Effekt könnte im Zusammenhang mit dem Expressionsmuster von mapl-1 im Telencephalon während der Embryonalentwicklung stehen. 
Ab Tag 11,5-12,0 der Embryogenese ist die Expression von mapl-1 von der Ventrikulärzone des Telencephalons, die eine proliferative Zellschicht darstellt, ausgeschlossen und beschränkt sich nur auf die äußeren Schichten, in denen sich differenzierte post-mitotische Neuronen befinden. Diese Expression von mapl-1 wird bis zu postnatalen Stadien beibehalten und könnte mit einer Funktion des Gens in der Etablierung oder/und Aufrechterhaltung des postmitotischen Charakters der Neuronen im zerebralen Kortex in Verbindung stehen.

\subsection{Die Funktion von Mikrotubuli und MAPs im Nervensystem}

Mikrotubuli und ihre assoziierte Proteine (MAPs) spielen eine sehr wichtige Rolle während der Embryonalentwicklung sowohl im zentralen als auch im peripheren Nervensystem. Sie bestimmen Morphologie und Polarität von Neuronen und nicht zuletzt stellen die Mikrotubuli die intrazellulären Bahnen dar, auf denen der Transport von Organellen in den Axonen stattfindet. Von besonderer Bedeutung ist die Rolle von Mikrotubuli und MAPs bei der Wanderung der Neuronen im zerebralen Kortex. Mutationen in zwei Mikrotubuli-assoziierten Proteinen beim Menschen sind die Ursache für die Lissenzephalie-Erkrankung. Hierbei handelt es sich um eine Mißbildung des Gehirns, die durch das Fehlen der normalen Windungen und durch eine Verdickung des zerebralen Kortex gekennzeichnet ist. Die Ursache für diese Gehirnanomalien ist sehr wahrscheinlich eine ungeordnete Wanderung der Neuronen entlang der kortikalen Platte (Dobyns et al., 1993). Die Gene, in denen Mutationen mit Lissenzephalie in Verbindung gebracht wurden, sind LIS-1 und Doublecortin oder DCX. $L I S-1$ ist ein ubiquitär exprimiertes Gen, das für ein Protein mit 7 WD40 Protein-Protein Interaktionsmotiven kodiert. LIS-1 interagiert mit mehreren verschiedenen Proteinen und ist darüber hinaus an verschiedenen Prozessen beteiligt (zum Überblick, Leventer et al., 2001) Zudem ist LIS1 in der Lage, direkt an Mikrotubuli zu binden und ihre Stabilität zu erhöhen. Seine stabilisierende Funktion auf den Polymerisationszustand der Mikrotubuli erfolgt durch die Inhibierung ihrer Depolymerisation (Sapir et al., 1997).

Im Gegensatz zu LIS1 ist das DCX-Protein ein typisches MAP, da es mit Mikrotubuli kolokalisiert und ihre Polymerisation stimulieren kann. Ähnlich zu Mapl-1 induziert die Überexpression von $D C X$ die Vernetzung der Mikrotubuli zu dicken Bündeln die gegenüber depolymerisierende Agenzien resistent sind (Gleeson et al., 1999). Zudem ist DCX ausschließlich in postmitotischen Neuronen aktiv (Gleeson et al., 1999). Dies stellt eine weitere Gemeinsamkeit mit Mapl-1 dar, das ebenfalls nach E11,0 ausschließlich in 
postmitotischen Neuronen und nicht in der proliferativen Zone aktiv ist. Die wichtige Rolle von DCX als ein MAP bei der Wanderung von Neuronen wird weiterhin durch die Tatsache unterstützt, daß bekannte Mutationen, die Lissenzephalie hervorrufen, innerhalb der Mikrotubuli-bindenden Domäne des Proteins auftreten (Taylor et al., 2000). Diese Mutationen unterbinden die Fähigkeit des Proteins, die Mikrotubuli zu Bündeln zusammenzubinden. Mutationen in DCX und LISI führen zu fast identischen phänotypischen Defekten. Dies spricht für die entscheidende Rolle der MAPs und der Mikrotubuli im Prozeß der neuronalen Wanderung.

Aufgrund der funktionellen Ähnlichkeiten zwischen Mapl-1 und insbesondere DCX und der entsprechend vergleichbaren Genexpression im zerebralen Kortex könnte Mapl-1 in seiner Funktion als MAP ebenfalls in diesem Prozeß eine Rolle spielen. Eine Funktion von Mapl-1 als Motorprotein beim intrazellulären Transport von Organellen scheint unwahrscheinlich, da es keine Sequenzähnlichkeit zu der Familie der Kinesin- oder Dyneinproteine aufweist, die als Motorproteine in diesem Prozeß beteiligt sind. Dagegen spricht ebenfalls die relativ geringe Größe von Mapl-1 (ca. 200Kd) im Vergleich zu den Kinesinen (ca. 500Kd) oder den Dyneinen (1-2 Md) (zum Überblick, Goldstein and Yang, 2000).

\subsection{Regulation der zellulären Lokalisation von Mapl-1}

Der regulierte Import und Export von Proteinen in und aus dem Zellkern stellt eine Möglichkeit dar, ihre Aktivität zu regulieren. Moleküle kleiner als 40-60Kd sind in der Lage, passiv durch die Kernporen zu diffundieren, während der Transport von größeren Molekülen in und aus dem Zellkern aktiv erfolgen muß. Für den aktiven nukleären Transport von Proteinen sind Aminosäuresequenzen verantwortlich, die als nukleäre Lokalisations- (NLS) oder als nukleäre Exportsignale (NES) bezeichnet werden. Beide Sequenzen werden von bestimmten Proteinen erkannt und gebunden, die für den Import oder Export in bzw. aus dem Zellkern sorgen zum Überblick, (Yoneda, 2000). Anhand der Primärstruktur von Mapl-1 konnte ein NLS am Aminoterminus des Proteins identifiziert werden. In der Mehrzahl der transfizierten Säugerzellen war jedoch das Protein im Cytoplasma in Assoziation mit Mikrotubuli lokalisiert, und nur in einigen wenigen Ausnahmen konnte das vollständige Protein im Zellkern nachgewiesen werden. Aufgrund der Größe des Mapl-1 Proteins (ca. 200Kd) handelt es sich dabei um einen aktiven Transport des Proteins in den Zellkern. Auch in NKR-11 Zellen, die endogenes Mapl-1 produzieren, konnte das Protein mit Hilfe eines 
hergestellten Antiserums sowohl im Cytoplasma als auch in bestimmten Kompartimenten des Zellkerns detektiert werden. Offensichtlich wird die zelluläre Lokalisation von Mapl-1 durch die Kombination von Kernimport und cytoplasmatischen Retentionssignalen reguliert. Die Anwesenheit eines funktionellen NES im Mapl-1 konnte anhand der 1-470 Deletionsvariante demonstriert werden. Längere Mapl-1-Varianten sowie das vollständige Protein konnten jedoch durch die Inhibierung des CRM-1 abhängigen Kernexports nicht in den Zellkern befördert werden. Dies weist darauf hin, daß zusätzliche Mechanismen die Retention des Proteins im Cytoplasma bewirken. Es wäre denkbar, daß dies durch die Interaktion mit einem cytoplasmatischen Protein erfolgt. Die Region von Mapl-1, die dafür in Frage käme, liegt zwischen den Aminosäuren 470-878 und enthält einen großen Teil der ersten „Coiled-Coil“Domäne des Proteins, die als Protein-Protein Interaktionsdomäne dienen könnte. Was die Translokation von Mapl-1 vom Cytoskelett in den Zellkern bewirkt, ist noch unklar. Eine vermutete Abhängigkeit dieses Prozesses vom Zellzyklus wurde in synchronisierten Zellpopulationen getestet (Hela- und COS7-Zellen). Es konnte jedoch keine Zellzyklusabhängige Veränderung in der Lokalisation von Mapl-1 in transfizierten Zellen beobachtet werden (nicht gezeigt). Dies könnte jedoch mit der Tatsache zusammenhängen, daß der Zellzyklus in Mapl-1 transfizierten Zellen aufgrund der Eigenschaft des Proteins, die Mikrotubuli zu Bündeln zu vernetzen, nicht normal fortschreitet oder sogar arretiert ist (s. Abschnitt 3.3).

In vielen Fällen sind Proteine, die zwischen Zellkern und Cytoplasma transportiert werden, Komponenten von Kaskaden der Signalübertragung. Nicht zuletzt sind solche Proteine auch Transkriptionsfaktoren. Die zellulären Mikrotubuli sind entscheidende Komponenten der Signalübertragung, indem sie Transkriptionsfaktoren außerhalb des Zellkerns in einem inaktiven Zustand halten. Ein solcher Mechanismus erlaubt die regulierte Translokation von Transkriptionsfaktoren in den Zellkern und darüber hinaus die Umsetzung von genetischer Information als zelluläre Antwort auf die Anwesenheit eines Signals. Eines der am besten untersuchten Beispiele ist die Übertragungskaskade des Hedgehog Signals in Drosophila. In Abwesenheit des Signals wird an den Mikrotubuli ein Komplex aus drei Proteinen aufgebaut, dem Protein Costal2 das mit Kinesin-Proteinen verwandt ist und direkt an Mikrotubuli bindet, einer Proteinkinase (Fused) und dem Transkriptionsfaktor Cubitus interruptus (CI) . CI wird durch seine Wechselwirkung mit Costal2, in Abwesenheit von Hedgehog außerhalb des Zellkerns an den Mikrotubuli festgehalten (Robbins et al., 1997; Sisson et al., 1997). Dabei 
wird CI proteolytisch prozessiert, so daß ein aminoterminales Fragment in den Zellkern transportiert wird und inhibitorisch auf die Expression von Zielgenen wirkt (Aza-Blanc, 1997). Beim Auftreten des Hedgehog-Signals wird die Prozessierung des Transkriptionsfaktors CI durch seine Phosphorylierung verhindert (Chen et al., 1998) so daß CI als vollständiges Protein in den Zellkern transportiert wird und seine Zielgene aktiviert.

Eine weitere Familie von Transkriptionsfaktoren, deren Aktivität in einer ähnlichen Art und Weise reguliert wird, sind die Smad-Proteine. Smads spielen eine Schlüsselrolle in der Signalübertragung von TGF $\beta$. In Anwesenheit des Signals werden Smad-2 und -3 phosphoryliert. Dadurch sind sie in der Lage, mit einem weiteren Protein aus der gleichen Familie (Smad-4) zu dimerisieren, und als Dimere werden sie in den Zellkern transportiert, wo sie regulatorisch auf die Expression von Zielgenen wirken (Derynck et al., 1998; Heldin et al., 1997). Smad-2, -3 und -4 sind in der Lage, in der Abwesenheit von TGF $\beta$ direkt an Mikrotubuli zu binden. Nach der Aktivierung der Signalkaskade durch TGF $\beta$ werden die Smads phosphoryliert, von den Mikrotubuli freigesetzt und in den Zellkern transportiert (Dong, 2000).

Die Translokation von Mapl-1 könnte durch einen vergleichbaren Mechanismus reguliert werden. Auffällig ist, daß Mapl-1 viele Gemeinsamkeiten sowohl mit CI als auch mit SmadProteinen aufweist. Wie CI und Smads könnte auch Mapl-1 als Transkriptionsfaktor fungieren. Dafür spricht zum einen die Klassifizierung des Proteins anhand von konservierten Aminosäuren im Leucin-Zipper-Motiv in die Familie der bZip-Trasnkriptionsfaktoren und zum anderen seine Fähigkeit, die Transkription zu stimulieren, wenn es an einer heterologen DNA-bindenden Domäne fusioniert wurde. Ähnlich zu den Smad-Proteine bindet Mapl-1 direkt an Mikrotubuli und ist in der Lage, Dimere zu bilden. Wie CI wird Mapl-1 proteolytisch prozessiert, wobei vergleichbar mit CI, ein aminoterminales Fragment in den Zellkern transportiert wird. Bei den beiden vorgestellten Transkriptionsfaktoren (CI und Smads) führt die Anwesenheit des extrazellulären Signals zur Phosphorylierung der Proteine. Der Phosphorylierungsschritt ist anscheinend für die Freisetzung der Proteine von den Mikrotubuli notwendig. Bei bekannten Mikrotubuli-assoziierten Proteinen wie MAP2 wurde tatsächlich gezeigt, daß die Phosphorylierung des Proteins durch verschiedenen Kinasen zur erheblichen Herabsetzung der Affinität von MAP2 für Mikrotubuli führt (zum Überblick, Sánchez et al., 2000). In Übereinstimmung damit enthält Mapl-1 mehrere potentielle Phosphorylierungsstellen für verschiedene Kinasen (PKC, Protein Kinase A und MAP- 
Kinasen). Es wäre also denkbar, daß Mapl-1 ein zur Zeit nicht bekanntes extrazelluläres Signal in den Zellkern vermittelt, durch einen Mechanismus, der die Phosphorylierung und die Translokation des Proteins in den Zellkern umfaßt. Im Zellkern könnte Mapl-1 eine Funktion, unter anderem in Form eines Komplexes mit Pax-6, ausüben.

\subsection{Die Funktion von Mapl-1 als Pax-6 Interaktionspartner}

Die zweite interessante Eigenschaft von Mapl-1, die im Rahmen dieser Arbeit eingehend analysiert wurde, ist seine Fähigkeit, mit Pax-6 zu interagieren. Die Wechselwirkung zwischen Pax-6 und Mapl-1 erfolgte über Proteinbereiche, die in der jeweiligen Proteinfamilie konserviert sind. Während bei Pax-6 die Paired-Domäne direkt an der Komplexbildung beteiligt ist, dient bei Mapl-1 eine Region, die die höchste Sequenzidentität zwischen den Proteinen der Maus und denen von Drosophila and C. elegans aufweist, als Pax-Interaktionsdomäne. Demzufolge ist es sehr wahrscheinlich, daß eine Wechselwirkung zwischen einem Pax- und einem Mapl-Protein nicht nur auf Pax-6 und Mapl-1 beschränkt ist. Es könnte sich vielmehr um einen allgemeineren Mechanismus handeln, der auch bei anderen Pax- und Mapl-Proteinen gilt. Die Pax-6(5a) Isoform, die durch alternatives Spleißen entsteht und eine Insertion von 14 Aminosäuren in der aminoterminalen Unterdomäne (PAI) der Paired-Domäne enthält, war nicht in der Lage, mit Mapl-1 zu interagieren. Dies spricht dafür, daß die PAI-Domäne von Pax-6 direkt an der Wechselwirkung mit Mapl-1 beteiligt ist. Es handelt sich hierbei um den ersten Bericht über eine Funktion der PAI-Unterdomäne eines Pax-Proteins als Protein-Protein-Interaktionsmotiv. In Anwesenheit der optimalen Bindesequenz der Pax-6 Paired-Domäne, die in vitro ermittelt wurde (Epstein et al., 1994), war Pax-6 nicht in der Lage, gleichzeitig mit Mapl-1 und DNA zu interagieren. Daraus folgt, daß der Proteinkomplex zwischen Pax-6 und Mapl-1 nicht an Pax-6 Erkennungssequenzen aufgebaut werden kann, bei denen die Bindung der PAI-Unterdomäne den entscheidenden Beitrag leistet. Die Tatsache, daß die Paired-Domäne von Pax-6 nicht gleichzeitig mit DNA und Mapl-1 interagieren kann, läßt sich anhand von früheren Berichten erklären, bei denen eine DNA-abhängige Konformationsänderung der Paired-Domäne beobachtet wurde. Es wurde speziell für die Paired-Domäne von Pax-6 mittels CD-Spektroskopie gezeigt, daß sie im DNA-ungebundenen Zustand relativ strukturlos ist und erst nach der Bindung an die DNA die Konformation einnimmt, die von der Auflösung der Kristallstruktur bekannt ist (Epstein et $a l .$, 1994). Es wäre also möglich, daß Mapl-1 spezifisch mit der ungebundenen Form der 
Paired-Domäne interagiert, während bei der DNA-Bindung die Konformation der PairedDomäne so verändert wird, daß eine Interaktion mit Mapl-1 nicht möglich ist. Die Tatsache, daß im durchgeführten „Two-hybrid screen“ die gleiche Domäne (Pax-Interaktionsdomäne) dreimal unabhängig identifiziert wurde, spricht jedoch für die Existenz einer spezifischen Konformation zumindest bei der PAI-Domäne und gegen die These, daß die Paired-Domäne von Pax-6 im DNA-ungebundenen Zustand strukturlos ist.

Es ergibt sich die Frage, welche die biologische Funktion des Komplexes zwischen Pax-6 und Mapl-1 ist. Anhand der hier präsentierten Daten kann die Interaktion zwischen den zwei Proteinen in zwei verschiedenen zellulären Kompartimenten stattfinden, einerseits im Zellkern und andererseits im Cytoplasma. Dies könnte jeweils einen unterschiedlichen biologischen Effekt haben. Da Pax-6 nicht in der Lage ist, über die PAI-Unterdomäne gleichzeitig mit DNA und Mapl-1 zu interagieren, könnte Mapl-1 im Zellkern eine inhibitorische Wirkung auf die Bindung von Pax-6 an suboptimalen DNA-Bindestellen für die Paired-Domäne ausüben und darüber hinaus als negativer Regulator der Pax-6 Aktivität fungieren. Die Komplexbildung zwischen Pax-6 und Mapl-1 liefert also eine Möglichkeit, die Bindungsseigenschaften von Pax-6 und weiterhin die Regulation von Pax-6-Zielgenen in den Zellen, in denen mapl-1 und Pax-6 koexprimiert werden, zu modulieren. Mapl-1 könnte zudem in Form eines Komplexes mit Pax- 6 bei der Regulation von Pax- 6 Zielgenen, die von der alleinigen Bindung der Homeodomäne von Pax-6 abhängen, eine völlig andere Funktion ausüben. Wie in dieser Arbeit gezeigt wurde, konnte im Mapl-1 Protein eine transkriptionsaktivierende Domäne identifiziert werden, deren Anwesenheit für eine Funktion des Proteins als Transkriptionsfaktor spricht. Da Mapl-1 spezifisch mit der Paired-Domäne von Pax-6 interagiert, wäre es möglich, daß Mapl-1 an Promotorsequenzen an die Pax-6 nur mit der Homeodomäne bindet als Koaktivator dient.

Es konnte in dieser Arbeit gezeigt werden, daß die Kombination der beiden Eigenschaften von Mapl-1, mit Mikrotubuli und Pax-6 zu interagieren, zur Retention des Pax-6 Proteins im Cytoplasma führt. Pax-6 ist im Einklang mit seiner Funktion als Transkriptionsfaktor ein Kern-Protein. Experimentelle Daten weisen jedoch auf die Existenz von cytoplasmatischem Pax-6 auch in vivo hin (V. van Heyningen, persönliche Mitteilung). Diese Lokalisation von Pax-6 außerhalb des Zellkerns kann durch die Interaktion mit einem cytoplasmatischen Protein wie Mapl-1 erklärt werden. Die zelluläre Lokalisation von Transkriptionsfaktoren in vivo kann einer stringenden Regulation unterworfen sein, wie das Beispiel des Homeoproteins 
Otx-2 zeigt. Es konnte für diesen Transkriptionsfaktor demonstriert werden, daß seine zelluläre Lokalisation in der Retina (Zellkern bzw. Cytoplasma) sowohl vom Entwicklungsstadium als auch vom Zelltyp abhängig ist (Baas et al., 2000). Ob die zelluläre Lokalisation von Pax-6 oder Mapl-1 unter einer ähnlichen Kontrolle steht, muß noch gezeigt werden.

Bei der Mehrzal der Pax-Gene führen heterozygote Mutationen zu semidominanten Phänotypen. Dies spricht für die Wichtigkeit der richtigen Gendosis bei der Entwicklung von Strukturen, die von Pax-Genen kontrolliert werden. Die Abhängigkeit der normalen Entwicklung von der richtigen Gendosis gilt insbesondere für Pax-6 und die Augenentwicklung. Sowohl die Inaktivierung des einen Allels als auch die Erhöhung der Kopien des Gens führen zu okularen Defekten (Schedl et al., 1996). Wie eine mit der normalen Entwicklung verträgliche Gendosis in vivo aufrechterhalten wird, ist noch nicht klar. Zwei mögliche Mechanismen, die die molekulare Grundlage für dieses Phänomen darstellen könnten, sind zum einen die Inaktivierung des einen der beiden Allelen (Allelexklusion) in bestimmten Zellen und zum anderen die Existenz eines Interaktionspartners, der auf Proteinebene einen Teil des Proteins in einem inaktiven Zustand behält. Aus Analysen mit Small eye (Sey)-Mausmutanten konnte gezeigt werden, daß der Mechanismus der Allelexklusion nicht zur Erklärung der Augendefekten bei heterozygoten Pax-6-Mutanten herangezogen werden kann, da beide Allele des Gens sowohl in den Zellen des Augenbechers als auch in denen der Linsenplakode aktiv sind (van Raamsdonk and Tilghman, 2000). Das Modell nach dem, die Pax-6-Dosis durch einen interagierenden Proteinpartner reguliert wird scheint demzufolge wahrscheinlicher.

Viele in dieser Arbeit erhaltene Daten sprechen dafür, daß Mapl-1 in der Regulation der Pax6-Dosis eine Rolle spielen könnte. Es ist anzunehmen, daß die Ausprägung des semidominanten Sey-Phänotyps auf die Empfindlichkeit des Oberflächenektoderms auf die reduzierte Pax-6-Dosis zurückzuführen ist (Collinson et al., 2001; van Raamsdonk and Tilghman, 2000). Aus der Analyse der mapl-1-Expression konnte gezeigt werden, daß mapl-1 in allen Strukturen des sich entwickelnden Auges mit Pax-6 koexprimiert ist, auch im Oberflächenektoderm zwischen E9,75 und E10. Während dieses kritischen Zeitfensters kommt es in der Linse von Sey-Embryonen zu einer 50\%igen Reduktion der Zellanzahl, verglichen mit Wildtyp Embryonen. Dies gilt als der ursprüngliche Effekt, dem Sey-Phänotyp zugrundeliegt (van Raamsdonk and Tilghman, 2000). Die vergleichende Expressionsanalyse 
von Pax-6 und mapl-1 hat noch ergeben, daß in Domänen der Koexpression der zwei Gene das Expressionsniveau von mapl-1 deutlich geringer ist als das von Pax-6. Unter der Annahme, daß durch die Wechselwirkung zwischen Pax-6 und Mapl-1 Pax-6 in einem nicht funktionellen Zustand aufrechterhalten wird, könnte die Anwesenheit eines Interaktionspartners in geringerer Menge einen einfachen Mechanismus darstellen, durch den die richtige Dosis an aktivem Protein in bestimmten Strukturen sichergestellt wird. Es konnte zusätzlich eine bemerkennswerte Komplementarität in der Expression von Pax-6 und mapl-1 im sich entwickelnden Diencephalon beobachtet werden, die dafür spricht, daß in bestimmten Regionen des Gehirns die Expression beider Gene in den gleichen Strukturen verhindert wird. Besonders interessant ist die Expression von mapl-1 im sich entwickelnden Telencephalon. Während bis E10,5 beide Gene in der Ventrikulärzone aktiv sind, wird ab E11,5 die Expression von Mapl-1 aus der Ventrikulärzone ausgeschlossen und beschränkt sich auf die postmitotischen Neuronen in den äußeren Schichten des Telencephalons, während Pax-6 weiterhin in proliferierenden Zellen exprimiert wird. Diese Komplementarität und die Dynamik in der Expression von mapl-1 könnte ebenfalls die Notwendigkeit der Regulation der Pax-6 Aktivität in Raum und Zeit widerspiegeln.

Der Versuch, die mapl-1-Dosis spezifisch in der Linse von transgenen Mäusen zu erhöhen, um somit phänotypische Effekte aufgrund einer verminderten Pax-6-Aktivität zu erzielen, führte zu keinen offensichtlichen Augendefekten. Der Grund lag wahrscheinlich darin, daß die Expression des Transgens nicht hoch genug war, um die Dosis an aktivem Pax-6 auf ein Niveau zu reduzieren, der mit jenem der Sey-Mutante vergleichbar ist.

Zwischen E8,0 und E10,5 weist das Expressionsmuster von mapl-1 einen hohen Grad an Überlappung mit dem von Pax-6 auf. Ab E11,5 werden mapl-1-Transkripte auch in Strukturen des Embryos nachgewiesen, in denen Pax-6 nicht aktiv ist. Dies spricht für eine Pax-unabhängige Funktion von Mapl-1. Zudem könnte es sich bei Mapl-1 um einen allgemeineren Pax-Interaktionspartner handeln, dessen Wirkung nicht nur auf Pax-6 beschränkt ist. Für die Spezifität der Wechselwirkung zwischen Pax-6 und Mapl-1 spricht die Tatsache, daß ein zweites Pax-Protein (Pax-2) nicht mit Mapl-1 interagieren konnte. Es konnte jedoch im Hefe-,,Two-hybrid“-Assay eine Interaktion zwischen Pax-3 und der PaxInteraktionsdomäne von Mapl-1 detektiert werden (nicht gezeigt). Mapl-1 ist während der Embryogenese ab E11,0 in Strukturen wie dem Mesencephalon, Trigeminalganglion und Spinalganglien aktiv, die gleichzeitig Pax-3-Expressionsdomänen darstellen. Endgültigen 
aufschluß über eine allgemeinere Wirkung von Mapl-1 auf die Regulation von Pax-Proteinen in vivo sowie endgültigen Aufschluß über seine Funktion während der Emryonalentwicklung wird die Inaktivierung des Gens im Mausgenom verschaffen.

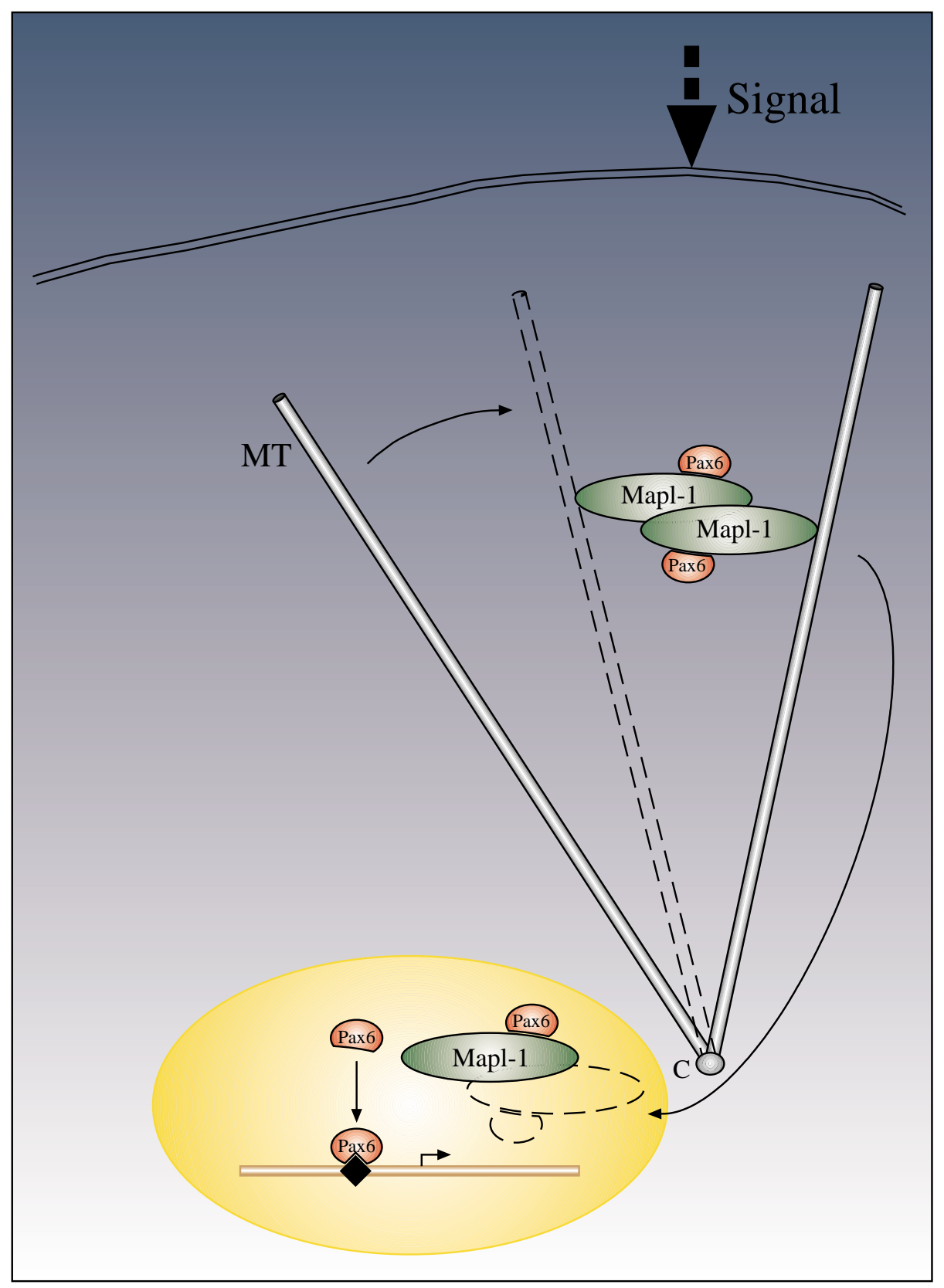

\section{Abbildung 31}

Modell der Funktion von Mapl-1. Mapl-1 interagiert direkt mit den zellulären Mikrotubuli (MT) über die carboxyterminale Domäne und bewirkt ihre Vernetzung zu Bündeln. Dazu trägt die Fähigkeit des Proteins zur Dimerisierung bei. An Mikrotubuli gebundenes Mapl-1 ist durch seine Eigenschaft mit Pax-6 zu interagieren in der Lage, einen Anteil des Pax-6-Proteins im Cytoplasma zurückzuhalten. Mapl-1 kann in den Zellkern transportiert werden, wo es spezifisch mit der ungebundenen Konformation der Paired-Domäne von Pax-6 interagieren kann. Dies verhindert die Bindung von Pax-6 an natürlichen Bindestellen der Paired-Domäne. Die Translokation von Mapl-1 in den Zellkern könnte als Teil einer zellulären Antwort auf die Anwesenheit eines extrazellulären Signals erfolgen. C: Centrosom, ;MT: Mikrotubuli. 


\section{Material und Methoden}

$\begin{array}{ll}\text { 4.1. Abkürzungen und Symbole } \\ \% & \text { Prozent } \\ \text { Amp } & \text { Ampicillin } \\ \text { AP } & \text { Alkalische Phosphatase } \\ \text { AK } & \text { Antikörper(n) } \\ \text { APS } & \text { Ammoniumpersulfat } \\ 3 \text {-AT } & \text { 3-Aminotriazol } \\ \text { ATP } & \text { Adenosintriphosphat } \\ \text { bp } & \text { Basenpaar(e) } \\ \text { c } & \text { centi } \\ { }^{\circ} \text { C } & \text { Grad Celsius } \\ \text { ca. } & \text { circa } \\ \text { Ci } & \text { Curie } \\ \text { CI } & \text { Chlorophorm-Isoamylalkohol } \\ \text { cDNA } & \text { komplementäre DNA } \\ \text { cpm } & \text { radioaktive Zerfälle pro Minute (counts per minute) } \\ \text { CTP } & \text { Cytidintriphosphat } \\ \text { dATP } & \text { Desoxyadenosintriphosphat } \\ \text { dCTP } & \text { Desoxycytidintriphosphat } \\ \text { dGTP } & \text { Desoxyguanosintriphosphat } \\ \text { dTTP } & \text { Desoxythymidintriphosphat } \\ \text { dNTP } & \text { Desoxyukleotidtriphosphat } \\ \text { DAPI } & 4{ }^{\prime}, 6 \text {-Diamino-2'Phenylindol-Dihydrochlorid } \\ \text { DEPC } & \text { Diethylpyrocarbonat } \\ \text { DMSO } & \text { Dimethylsulfoxid } \\ \text { DNA } & \text { Desoxyribonukleinsäure } \\ \text { DTT } & \text { Dithiothreitol } \\ \text { E.coli } & \text { Escherichia coli } \\ \text { EDTA } & \text { Ethylendiamin-N,N,N',N'-tetraessigsäure } \\ \text { EK } & \text { Endkonzentration } \\ \text { et al. } & \text { Und Mitarbeiter } \\ \text { EtOH } & \text { Ethanol } \\ \text { FCS } & \text { Fetales Kälberserum } \\ \text { g } & \text { Gramm, Erdbeschleunigung } \\ \text { GAL4BD } & \text { Gal4-bindende-Domäne } \\ \text { GST } & \text { Glutathion S-Transferase } \\ \text { GTP } & \text { Guanosintriphosphat } \\ & \end{array}$


$\mathrm{h}$

HEPES

His

IPTG

$\mathrm{kb}$

LMB

$\mu$

$\mathrm{M}$

$\mathrm{Mw}$

Met

$\mathrm{MeOH}$

$\min$

MOPS

mRNA

n

$\mathrm{NP}-40$

OD

$\mathrm{p}$

PAGE

Pax, PAX

PBS

PCR

PCI

PEG

PFA

PID

PVP

RNA

RT

s.

SDS

$\sec$

s.o.

s.u.

TCA

TEMED

Tris

$\mathrm{u}$

ÜN

Upm

UTP

vgl

Vol.

$\mathrm{v} / \mathrm{v}$

$\mathrm{w} / \mathrm{v}$

$\mathrm{X}$
Stunde(n)

2-[4-(2-Hydroxyethyl)-1-piperazino]-ethansulfonsäure

L-Histidin

Isopropyl-b-D-thiogalaktosid

Kilobasenpaare (1000bp)

Leptomycin B

mikro

Molarität in mol/l

Molekulargewicht

L-Methionin

Methanol

Minute(n)

3-N-Morpholinopropansulfonsäure

Boten-RNA

nano

Nonidet (non-ionic detergent) P-40

Optische Dichte

pico

Polyacrylamidgelelektrophorese

Paired-Box-Gen aus Maus beziehungsweise Mensch

Phosphat-gepufferte Salzlösung

Polymerase-Ketten-Reaktion

Phenol-Chlorophorm-Isoamylalkohol

Polyethylenglykol

Paraformaldehyd

Pax-Interaktionsdomäne

Polyvinylpyrrolidon

Ribonukleinsäure

Raumtemperatur

siehe

Natriumdodecylsulfat

Sekunde(n)

siehe oben

siehe unten

Trichloressigsäure

$\mathrm{N}, \mathrm{N}, \mathrm{N}^{\prime}, \mathrm{N}^{\prime}$-Tetramethylethylendiamin

Tris (hydroxymethyl)-aminomethan

Einheit(en)

über Nacht

Umdrehungen pro Minute

Uridintriphosphat

vergleiche

Volumen, Volumina

Volumen/Volumen

Gewicht/Volumen

mal 


\subsection{Organismen}

\subsubsection{Mäuse und Embryonen}

NMRI (Weibchen) C57B1/6/xSJL, FVB oder B6D2/F1 (Männchen) wurden vom Zentralinstitut für Versuchstierzucht Hannover bezogen.

Zur Erzeugung von Embryonen, die für RNA in situ-Hybridisierung oder für in vivoElektroporation verwendet wurden, wurden NMRI-Weibchen mit C57B1/6/xSJL- oder B6D2/F1-Männchen verpaart. Der Tag des Vaginalpfropfes wurde als Tag 0,5 der Embryonalentwicklung gezählt.

\subsubsection{Bakterien}

E. coli-Stamm DH5a (Hanahan, 1983): (supE 44 Alac U169 ( $\phi 80$ lacZ $\Delta$ M15) hsdR 17 recA 1 endA 1 gyrA 96 thi-1 relA1), wurde verwendet für die Konstruktion und Propagation von rekombinanten Plasmiden.

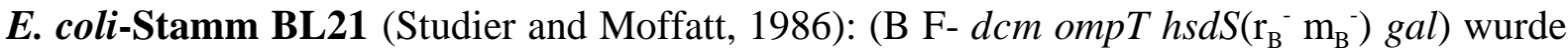
verwendet für die Produktion von GST und GST-Fusionsproteine.

E. coli-Stamm BL21-CodonPlus, (Stratagene) (B F $\mathrm{F}^{-}$ompT hsdS $\left(\mathrm{r}_{\mathrm{B}}{ }^{-} \mathrm{m}_{\mathrm{B}}{ }^{-}\right) d c m^{+} \operatorname{Tet}^{\mathrm{r}}$ gal endA Hte $\left[\arg U\right.$ ileY leuW $\left.\mathrm{Cam}^{\mathrm{r}}\right]$ : wurde ebenfalls verwendet für die Produktion von GST und GST-Fusionsproteine. Dieser Stamm enthält zusätzliche Kopien von bestimmten in E. coli nicht häufig vorkommenden tRNA-Genen und erlaubt somit die effizientere Produktion von heterologen Proteinen in E. coli.

E. coli-Stamm BL21 (DE3) pLysS (Stratagene) (B F ${ }^{-}$omp $T$ hsd $S\left(\mathrm{r}_{\mathrm{B}}{ }^{-} \mathrm{m}_{\mathrm{B}}{ }^{-}\right)$gal $\lambda(\mathrm{DE} 3)[\mathrm{pLys} S$ $\left.\mathrm{Cam}^{r}\right]$ : wurde für die Produktion der Region zwischen den Aminosäuren 1416-1893 von Mapl-1 in Form einer aminoterminalen Fusion mit einer Hexahistidin-Sequenz.

XL1-Blue MRF', (Stratagene) ( $\Delta(m c r A) 183 \Delta$ (mcrCB-hsdSMR-mrr) 173 endA1 supE44 thi-

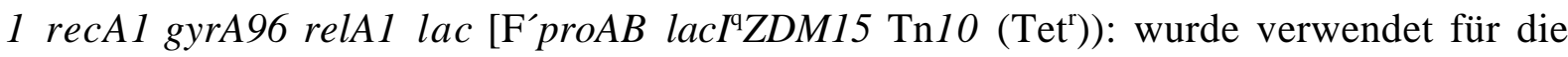
Durchmusterung von Phagen-cDNA-Bibliotheken. 


\subsection{Materialien}

\subsubsection{Chemikalien}

Die verwendeten Chemikalien wurden von den Firmen AMRESCO (Ohio, USA), J.T. Baker (Deventer, Holland), BRL (Bethesda Research Laboratories, Karlsruhe), Difco Laboratories (Detroit, USA), Fluka (Buchs, Schweiz), Merck (Darmstadt), Roth (Karlsruhe), Serva (Heidelberg), und Sigma (München) bezogen. Alle Chemikalien besaßen den Reinheitsgrad „p.a." (zur Analyse).

\subsubsection{Radiochemikalien}

Die verwendeten Radiochemikalien kamen von der Firma Amersham-Buchler (Braunschweig).

\subsubsection{Plastikmaterial}

Plastikmaterial wurde von den Firmen Sarstedt, Eppendorf, Falcon, Greiner und Nunc bezogen.

\subsubsection{Enzyme}

Enzyme wurden von den Firmen SERVA/Promega (Heidelberg), New England Biolabs (Bad Schwalbach), Roche (Mannheim), Gibco-BRL (Karlsruhe), Amersham-Buchler (Braunschweig), Pharmacia Biotech. (Freiburg) Stratagene (La Jolla, Kalifornien, USA) und GeneCraft (Münster) bezogen.

\subsubsection{Membranen}

Für den Transfer von DNA und RNA und Hybridisierungen wurden ungeladene Nylon Membranen der Firma Qiagen (Düsseldorf) verwendet.

Für den elektrophoretischen Transfer von Proteinen wurden Kunststoff-Immobilon PMembranen von der Firma Millipore verwendet. 


\subsubsection{Filme}

Für Farbfotographien wurde der Kunstlichtfilm Kodak, Extrachrome 160T verwendet. Autoradiographische Präparate wurden auf Biomax, MR (Kodak) Filmen exponiert, radioaktive in situ -Hybridisierungen in Kodak NTB-2 Flüssigfilm getaucht.

\subsubsection{Vektoren}

pBluescript II $\mathbf{K S}^{+}$(Stratagene): Diente als allgemeiner Klonierungsvektor. In diesem Vektor wurden cDNA Fragmente kloniert, die aus Phagen-cDNA-Bibliotheken isoliert wurden, zur Sequenzierungszwecken und zur Herstellung von RNA-Sonden für die in situ-Hybridisierung. pSP64-Pax6 (Petrou, 1997): wurde verwendet für die in vitro-Translation des Pax-6-Proteins. Dieser Vektor enthält die Pax-6 kodierende Sequenz unter der Kontrolle des Bakteriophagen SP-6-Promotors.

pSP73-Pax2 (Petrou, 1997): wurde verwendet für die in vitro Translation des Pax-2-Proteins. Dieser Vektor enthält die Pax-2 kodierende Sequenz unter der Kontrolle des Bakteriophagen SP-6-Promotors.

pSP64(5a): wurde verwendet für die in vitro Translation der Variante (5a) der Pax-6 PairedDomäne. Die PD(5a) wurde mittels PCR aus dem Plasmid pPax(5a) (wurde freundlicherweise von Dr. M. Busslinger (IMP, Wien) zur Verfügung gestellt) amplifiziert und in pSP64 (Promega) kloniert.

pGEX-4T-2, pGEX-5X-1 (Pharmacia): wurden verwendet für die Konstruktion von Fusionsproteinen mit GST und für die induzierbare Expression von GST bzw. GSTFusionsproteinen in E.coli.

pRSET-B (Invitrogen): wurde verwendet für die Konstruktion einer Fusion der Mapl-1Region zwischen den Aminosäuren 1528-1634 mit einer Hexahistidin-Sequenz (His-Tag) und die anschließende Produktion des Fusionsproteins in E. coli.

pCS2+MT (Roth et al., 1991): wurde verwendet für die Herstellung, die in vitro Translation und die Expression in Säugerzellen von aminoterminalen Fusionen an ein multimerisiertes (6x) Myc-Epitop.

pcDNA3.1/V5-HisA (Invitrogen): wurde verwendet für die Einführung eines V5-Epitops am Carboxyterminus des Mapl-1-Proteins und für die Expression des Fusionsproteins in Säugerzellen. 
pCMV-Pax6, pCMV-Pax2: Vektoren zur Produktion von Pax-6 bzw. Pax-2 unter der Kontrolle des menschlichen Cytomegalovirus-Promotors in Säugerzellen. (aus der Plasmidsammlung des Labors).

pCMV-Tag2A (Stratagene): wurde verwendet für die Einführung eines FLAG-Epitops an den Aminoterminus von Pax-6 und für die Produktion des Fusionsproteins in Säugerzellen.

pSG424 (Sadowski and Ptashne, 1990): Vektor, der die Konstruktion und anschließende Produktion in Säugerzellen von Fusionen mit der GAL4-bindenden Domäne ermöglicht. Für die Konstruktion der in dieser Arbeit verwendeten GAL4BD(1416-1893) wurde die carboxyterminale Region von Mapl-1 als ein EcorI-XbaI-Fragment in pSG424 (SacI-XbaI) kloniert.

pGAL4(5X)-Luc: Dieser Vektor enthält das Luciferase-Gen (Luc) unter der Kontrolle von 5 GAL4BD-Bindestellen und des viralen E1b-Promotors. Für die Konstruktion dieses Vektors wurde aus dem Plasmid p(GAL4) ${ }_{5}$ E1bCAT (Sadowski and Ptashne, 1990), ein XhoI-EcoRIFragment isoliert, das die GAL4-Bindestellen und den E1b-Promotor enthält und in pGL3Basic (Promega) in NheI-XhoI kloniert.

pCMV-LacZ: wurde als interne Kontrolle bei Transfektionsexperimenten verwendet um die Transfektionseffizienz zu bestimmen (Aus der Plasmidsammlung der Abteilung).

pLSE-Mapl1-IRES/gfp: enthält die kodierende Sequenz von Mapl-1 unter der Kontrolle des Linsen/Pankreas spezifischen regulatorischen Elements aus dem Pax-6 Lokus. Dieser Vektor enthält zusätzlich die IRES/GFP Sequenzen und ermöglicht die unabhängige Translation des gfp-Reportergens. Zur Konstruktion dieses Vektors wurde die kodierende Sequenz von Mapl1 als NotI/XbaI-Fragment in den pIRES/gfp-Vektor (NotI/NruI) (Ashery-Padan et al., 2000) kloniert. Das regulatorische Element wurde aus dem Plasmid pGNA-LE (Kammandel et al., 1999) als 6,5Kb langes SpeI/NotI-Fragment isoliert und in StuI/NotI stromaufwärts der Mapl1 cDNA kloniert. Für die Mikroinjektion in befruchteten Eizellen wurde ein SpeI/NheIFragment aus diesem Vektor isoliert.

pcdc2-gfp (Zernicka-Goetz et al., 1997): Aus diesem Vektor wurde ein 0,8Kb langes EcoRIFragment als Sonde verwendet für die Genotypisierung von Mapl-1 ${ }^{\text {gfp+ }}$ Mäusen und Embryonen.

\subsubsection{Oligodesoxyribonukleotide}

Die verwendeten Oligodesoxyribonukleotide wurden von der Firma NAPS (Göttingen) bezogen. 
Pax6CON, (Epstein et al., 1994):

(sense): 5' TGGAATTCAGGAAAAATTTTCACGCTTGAGTTCACAGCTCGAGTA 3'

(antisense): 5’ TACTCGAGCTGTGAACTCAAGCGTGAAAATTTTTCCTGAATTCCA 3’

T7 :

(sense): 5' GGAGCTCCAATTCGCCCTATAGTGAGTCGTATTACGCGCGCTCAC 3'

(antisense): 5’ GTGAGCGCGCGTAATACGACTCACTATAGGGCGAATTGG 3’

\subsubsection{Antikörper und Antisera}

Die folgenden Antikörper wurden in der vorliegenden Arbeit für die Immunfärbungen bzw. Western Blots verwendet. Angegeben werden die Bezugsquellen und die verwendeten Verdünnungen.

\subsubsection{Primärantikörper}

Polyklonale Antikörper

Anti-Mapl-1 (s. 4.5.9, 1:20), Anti-Pax-6 (Babco, 1:500)

Der Anti-Otx-2 Antikörper (1:50) wurde freundlicherweise von Dr. F. Vaccarino (Yale) zur Verfügung gestellt.

Der verwendete anti-c-Myc-Antikörper aus Huhn (1:1000) wurde von MoBiTec bezogen.

Monoklonale Antikörper

Anti-Pax-6 (1:50, DSHB*), anti- $\alpha$-Tubulin (1:2000, Sigma), anti-cMyc(9E10) (1:1000, Santa Cruz), anti-V5 (1:1000, Invitrogen), anti-FLAG(M2) (1:1000, Sigma).

anti-Vimentin (1:20), anti-Det-Tubulin (1:20) und anti-Cytokeratin (1:20) wurden freundlicherweise von Prof. Mary Osborn (MPI für Biophys. Chem., Göttingen) zur Verfügung gestellt.

*DSHB: Developmental Studies Hybridoma Bank der Universität Iowa (Iowa City, IA52242)

\subsubsection{Sekundärantikörper}

Die verwendeten Fluorophorkonjugierten Antikörpern aus der Alexa-Serie wurden von der Firma Molecular-Probes/MoBiTec bezogen. Sie wurden bei Immunfärbungen in einer Verdünnung 1:500 eingesetzt.

Blaue Emission: Alexa-350-konjugiert, Ziege-anti-Maus IgG

Grüne Emission: Alexa-488-konjugiert: Ziege-anti-Maus IgG, Ziege-anti-Kaninchen IgG $(\mathrm{H}+\mathrm{L})$, Ziege-anti-Huhn IgG $(\mathrm{H}+\mathrm{L})$. 
Rote Emission: Alexa-568-konjugiert: Ziege-anti-Maus IgG, Ziege-anti-Kaninchen IgG.

Für die Detektion von Proteinen in Western-Blots wurde ein Immunglobulin-PeroxidaseKonjugat (Dianova) verwendet.

\subsubsection{Computeranalysen}

Für DNA-Sequenzvergleiche, Identifizierung von offenen Leserahmen Vergleiche und Charakterisierungen von Aminosäuresequenzen wurden folgende Computerprogramme verwendet:

„GCG-Sequence Analysis Package” (Wisconsin), BLAST (Altschul et al., 1990), CLUSTAL (Thompson et al., 1994), SMART (Schultz et al., 2000; Schultz et al., 1998), Pfam (Bateman et al., 2000) and PSORT (Nakai and Kanehisa, 1992).

\subsubsection{Nährmedien}

\subsubsection{Für Escherichia coli}

LB (Luria-Bertani)-Medium: 0,5\% (w/v) Bacto-Yeast-Extrakt, 1\% (w/v) Bacto-Trypton, $1 \%$ (w/v) $\mathrm{NaCl}$. Der $\mathrm{pH}$ wurde mit $1 \mathrm{M} \mathrm{NaOH}$ auf 7,0 eingestellt. Das Medium wurde autoklaviert.

Nährböden enthielten zusätzlich 1,5\% (w/v) Agar.

LB-Ampicillin-Nährböden: Dem LB-Medium mit 1,5\% (w/v) Agar wurde nach dem Autoklavieren und Abkühlen (auf ca $50^{\circ} \mathrm{C}$ ) Ampicillin mit einer EK von $100 \mu \mathrm{g} / \mathrm{ml}$ zugegeben.

dYT-G Medium: 1,6\% (w/v) Bacto-Trypton, $1 \%(w / v)$ Bacto-Yeast-Extrakt, 0,5\% (w/v) $\mathrm{NaCl}$. Der $\mathrm{pH}$ wurde mit $1 \mathrm{M} \mathrm{NaOH}$ auf 7,0 eingestellt. Nach dem Autoklavieren wurde sterilfiltrierte Glukose mit einer EK von $2 \%$ (w/v) zugesetzt.

SOB-Medium: 0,5\% (w/v) Bacto-Yeast-Extrakt, 2,5 mM KCl, 0,05\% (w/v) NaCl, 2\% (w/v) Bacto-Trypton. Nach dem Autoklavieren wurden steriles $\mathrm{MgCl}_{2}$, und $\mathrm{MgSO}_{4}$ mit einer EK von $10 \mathrm{mM}$ zugegeben.

SOC-Medium: SOB-Medium, dem nach dem Autoklavieren zusätzlich noch sterilfiltrierte Glukose mit einer EK von $20 \mathrm{mM}$ zugegeben wurde 
NZY-Medium: 0,5\% (w/v) NaCl, 0,2\% (w/v) Magnesiumsulfat, 0,5\% (w/v) Bacto-YeastExtrakt, 0,1\% (w/v) Kaseinhydrolysat. Der $\mathrm{pH}$ wurde mit $1 \mathrm{M} \mathrm{NaOH}$ auf 7,5 eingestellt. Das Medium wurde autoklaviert. Nährböden enthielten zusätzlich 1,5\% (w/v) Agar.

TOP-Agarose: 0,7\% (w/v) Agarose, in NZY-Medium. Das Medium wurde autoklaviert. Kurz vor dem Gebrauch wurde die TOP-Agarose geschmolzen und in einem $50^{\circ} \mathrm{C}$-Wasserbad gestellt.

\subsubsection{Für Säugerzellen}

Alle in dieser Arbeit verwendeten Zellinien wurden in DMEM-Medium mit 4,5mg/ml Glukose (GIBCO, BRL), kultiviert in dem 10\% Hitze-inaktiviertes (30min, $56^{\circ} \mathrm{C}$ ) FCS, und 2mM L-Glutamin (GIBCO, BRL) zugesetzt wurden.

\subsubsection{Puffer und Lösungen}

Alle nachfolgend beschriebene Puffer und Lösungen wurden mit Millipore-H20 angesetzt. Acrylamid-Lösung: 29,2\% (w/v) Acrylamid, 0,8\% (w/v) Methylenbisacrylamid, in H2O gelöst und filtriert.

Ampicillin: Das Natriumsalz wurde zu einer EK von $50 \mathrm{mg} / \mathrm{ml}$ in $\mathrm{H} 20$ gelöst, sterilfiltriert und bei $-20^{\circ} \mathrm{C}$ gelagert.

Acetylierungs-Mix: 0,1M Triethanolamin, 0,05M Essigsäureanhydrid. Die Lösung wurde frisch in Wasser angesetzt.

APS-Lösung:10\%(w/w) Ammoniumpersulfat in H20 kurz vor Gebrauch angesetzt.

ATP/GTP/CTP-Mix: ATP-, GTP und CTP-Lithiumsalz wurden in DEPC-Wasser zu einer Konzentration von $10 \mathrm{mM}$ gelöst und in Aliquots bei $-20^{\circ} \mathrm{C}$ gelagert.

Chlorophorm/Isoamylalkohol (CI): Mischung aus Chlorophorm und Isoamylalkohol im Mengenverhältnis 24:1.

Coomasie-Lösung: „Coomasie Brilliant Blue R250” wurde mit einer EK von 0,25\% (w/v) in einer Lösung aus Methanol/Wasser/Essigsäure (4,5:4,5:1 v/v) gelöst. Die Lösung wurde anschließend filtriert.

50\% (w/v) Dextransulfat-Stocklösung: Dextransulfat (Sigma) wurde in DEPC-Wasser mit einer EK von 50\% (w/v) gelöst. Das Lösen des Dextransulfats in Wasser erfolgte ÜN, da die Lösung sehr viskös ist. Die Lösung wurde in Aliquots bei $-20^{\circ} \mathrm{C}$ gelagert. 
DNAseI: DNAseI (Roche) wurde mit einer EK von $10 \mathrm{mg} / \mathrm{ml}$ in $10 \mathrm{mM}$ Tris/HCl pH7,5, $20 \%$ Glycerol gelöst und in Aliquots bei $-20^{\circ} \mathrm{C}$ gelagert.

1M DTT: DTT wurde mit einer EK von $1 \mathrm{M}$ in Wasser gelöst und in kleine Aliquots bei $20^{\circ} \mathrm{C}$ gelagert. Es wurde in den verwendeten Puffern immer frisch zugesetzt.

0,5M EDTA-Lösung: $186,12 \mathrm{~g} \mathrm{Na} 2$ EDTA. $2 \mathrm{H}_{2} \mathrm{O}$ wurden in $800 \mathrm{ml} \mathrm{H} 20$ kräftig gemischt und der $\mathrm{pH}-$ Wert wurde durch die Zugabe von $\mathrm{NaOH}-\mathrm{Plätzchen} \mathrm{auf} \mathrm{pH8,0} \mathrm{eingestellt.} \mathrm{Die} \mathrm{Lösung}$ wurde auf 11 mit Wasser aufgefüllt und autoklaviert.

Ethidiumbromidlösung: Ethidiumbromid wurde mit einer EK von $10 \mathrm{mg} / \mathrm{ml}$ in Wasser für mehrere Stunden unter Rühren gelöst. Es wurde im Dunkeln bei $4^{\circ} \mathrm{C}$ gelagert.

5xFormalydehyd-Laufpuffer: 0,1M MOPS, pH7,0, 40mM Natriumacetat, 5mM EDTA, pH8,0. Der Puffer wurde im Dunkeln bei RT gelagert.

Giemsa-Färbelösung: 20ml der Giemsa-Stocklösung und 10ml eines 0,2M Natriumphosphatpuffers pH6,0 wurden in 500ml H2O verdünnt. Die Lösung wurde vor Benutzung filtriert.

Giemsa-Stocklösung: 0,8\% (w/v) Giemsa (Sigma), 50\% (v/v) Glycerol, 50\% (v/v) Methanol. Die Lösung wurde ÜN bei $37^{\circ} \mathrm{C}$ unter Rühren gelöst.

100mM IPTG-Lösung: 0,5g IPTG wurden in 20ml H2O gelöst, sterilfiltriert und in Aliquots bei $-20^{\circ} \mathrm{C}$ gelagert.

6xLadepuffer: 0,25\% (w/v) Bromphenolblau, 0,25\% (w/v) Xylencyanol FF, 30\% (v/v) Glycerol. Die Lösung wurde in $\mathrm{H} 2 \mathrm{O}$ angesetzt.

2xLaemmli-Auftragspuffer: 0,1M Tris/ $\mathrm{HCl}$ pH8, 0, 2\% (w/v) $\beta$-Mercaptoethanol, $20 \%$ (v/v) Glycerin, 2\% (w/v) SDS, 0,002\% (w/v) Bromphenolblau.

Lysozym-Lösung: Lysozym wurde mit einer EK von $10 \mathrm{mg} / \mathrm{ml}$ in $50 \mathrm{mM}$ Tris/HCl pH8,0 gelöst und in $1 \mathrm{ml}$ Aliquots bei $-20^{\circ} \mathrm{C}$ gelagert.

Mowiol-Einbettmedium: 9,6g Mowiol, 24g Glycerol in 24ml Wasser wurden unter Rühren ca. 1 h gelöst. Dazu wurden $48 \mathrm{ml}$ 0,2M Tris/ $\mathrm{HCl}$ pH8,5 zugegeben und bei $50^{\circ} \mathrm{C}$ gelöst. Nach kurzer Zentrifugation (1000g) um ungelöste Substanzen zu entfernen wurde die Lösung aliquotiert und bei $-20^{\circ} \mathrm{C}$ gelagert.

MTBS-Puffer: $1 \%$ (v/v) Triton X-100, 1\% (v/v) Tween-20, 10mM DTT in PBS. DTT wurde kurz vor Gebrauch zugesetzt.

$1 \mathrm{M}$ Natrium-Phosphatpuffer: $1 \mathrm{M}$ Lösungen der beiden Komponenten $\left(\mathrm{Na}_{2} \mathrm{HPO} 4\right.$ und $\mathrm{NaH}_{2} \mathrm{PO} 4$ ) wurden zusammengegeben bis der gewünschte $\mathrm{pH}-$ Wert erreicht wurde. 
NTE-Puffer: $0,5 \mathrm{M} \mathrm{NaCl}, 10 \mathrm{mM}$ Tris/HCl pH7,5, 5mM EDTA pH8,0. Die Lösung wurde in Wasser angesetzt, autoklaviert und auf $37^{\circ} \mathrm{C}$ vor Gebrauch erwärmt.

PAGE-Puffer: 0,19M Glycin, 25mM Tris-Base, 0,1\%(w/v) SDS

PBS: $140 \mathrm{mM} \mathrm{NaCl}, 10 \mathrm{mM} \mathrm{KCl}, 6,4 \mathrm{mM} \mathrm{Na}_{2} \mathrm{HPO}_{4}, 2 \mathrm{mM} \mathrm{KH} \mathrm{PO}_{4}$

PBS-Tween-Puffer: PBS-Puffer mit zusätzlich 0,5\% (v/v) Tween 20

4\% Paraformaldehyd (PFA)/PBS: $10 \mathrm{~g}$ PFA wurden in 250ml PBS auf $60^{\circ} \mathrm{C}$ erhitzt und die Lösung mit 3-4 Tropfen $2 \mathrm{M} \mathrm{NaOH}$ geklärt. Die Lösung wurde bei $-20^{\circ} \mathrm{C}$ gelagert und eiskalt verwendet.

Phagen-Lysepuffer: 100mM Tris/HCl, pH7,5, 5mM EDTA, 0,5\%(w/v) SDS, 200mM NaCl, in Wasser gelöst. Dazu wurde Proteinase K mie einer EK von $0,4 \mu \mathrm{g} / \mu \mathrm{l}$ frisch zugesetzt.

Phenol: Mit TE gesättigtes Phenol pH 8,0 wurde von der Firma AMRESCO bezogen.

Phenol/Chlorophorm/Isoamylalkohol (PCI): Mischung aus Phenol, Chlorophorm und Isoamylalkohol im Mengenverhältnis 25:24:1 (AMRESCO).

40\% (w/v) PEG (6000): PEG (6000) wurde mit einer EK von 40\%(w/v) in Wasser gelöst, autoklaviert und bei RT gelagert.

Poly-L-Lysin-Stocklösung: Poly-L-Lysin (Sigma) wurde mit einer EK von 10mg/ml in Wasser verdünnt und in $20 \mu \mathrm{l}$ Aliquots bei $-20^{\circ} \mathrm{C}$ gelagert. Bei der Anwendung wurden die Aliquots in $2 \mathrm{ml}$ Wasser verdünnt und sterilfiltriert.

Ponceau-Rot-Lösung: 0,25\% (w/v) Ponceau S, 40\% (v/v) Methanol, 15\% (v/v) Essigsäure Nach dem Lösen des Ponceau S wurde die Lösung filtriert.

Proteinase K: Proteinase K (Roche) wurde mit einer EK von 10mg/ml in H20 gelöst und in kleinen Aliquots bei $-20^{\circ} \mathrm{C}$ gelagert.

Proteinase K-Mix: 20mM Tris/HCl pH7,5, 1mM EDTA pH8,0, 20 $\mu \mathrm{g} / \mathrm{ml}$ Proteinase K. Die Lösung wurde frisch angesetzt.

RNase A: RNase A (Boheringer, Mannheim) wurde in 10mM Tris/HCl pH7,5, $15 \mathrm{mM} \mathrm{NaCl}$ gelöst (EK $10 \mathrm{mg} / \mathrm{ml})$. Anschließend wurde die Lösung, zur Inaktivierung von DNasen, für 15 min bei $95^{\circ} \mathrm{C}$ inkubiert und langsam auf RT abgekühlt. Die Lagerung erfolgte bei $-20^{\circ} \mathrm{C}$.

1XSSC: 0,15M NaCl, 0,015M NaCitrat, pH 7,0.

SM-Puffer: $100 \mathrm{mM} \mathrm{NaCl}, 10 \mathrm{mM}$ Magnesiumsulfat, 50mM Tris/HCl, pH7,5, 0,01\% (w/v) Gelatine.

10X TBE: 0,89M Tris-Borat, 0,89M Borsäure, 25mM EDTA pH8,0.

TBS-Puffer: 20mM Tris/HCl, pH7,5, 150mM NaCl. 
TE: 10mM Tris/HCl, pH7,5, 1mM EDTA pH8,0

Transferpuffer: 20mM Tris-Base, 150mM Glycin, 20\% (v/v) Methanol

\subsection{Molekularbiologische DNA- und RNA-Methoden}

Die Zusammensetzung von Puffer und Lösungen, die nachfolgend nur mit Namen erwähnt werden, findet sich in Abschnitt 4.3.11 (Puffer und Lösungen).

Alle molekularbioligischen Standardmethoden, die nachfolgend nicht aufgeführt sind, wurden nach der Beschreibung von (Sambroock et al., 1989) oder (Ausubel et al., 1987) durchgeführt.

\subsubsection{Transformation von E.coli}

\subsubsection{Präparation von Bakterien für Elektroporation (Elektrotransformation)}

E.coli DH5a oder BL21 wurden auf eine LB-Platte ausgestrichen und ÜN bei $37^{\circ} \mathrm{C}$ inkubiert. Von dieser Platte wurde eine einzelne Kolonie in 100ml LB-Medium suspendiert und ÜN bei $37^{\circ} \mathrm{C}$, unter Schütteln, (250 Upm) inkubiert. Von dieser Kultur wurden 2,5ml Bakteriensuspension in 500ml LB-Medium verdünnt und bis $\mathrm{zu}$ einer $\mathrm{OD}_{600}$ von 0,5 (entspricht 4-7 x107 lebender Zellen/ml) bei $37^{\circ} \mathrm{C}$ unter Schütteln (250 Upm) kultiviert. Die Bakteriensuspension wurde in vorgekühlten Zentrifugationsbechern überführt und die Bakterien wurden durch Zentrifugation geerntet $\left(20 \mathrm{~min}, 3000 \mathrm{Upm}, 4^{\circ} \mathrm{C}\right)$. Die pelletierten Bakterien wurden mit 500ml eiskaltem Wasser gewaschen, pelletiert (20min $3000 \mathrm{Upm}, 4^{\circ} \mathrm{C}$ ) und erneut mit 500ml eiskaltem Wasser gewaschen. Die Bakteriensuspension wurde in 40ml eiskalter 10\% (v/v) Glycerol-Lösung resuspendiert und in ein 50ml Röhrchen (Falcon) überführt. Die Bakterien wurden erneut durch Zentrifugation geerntet (20min 3000 Upm, $4^{\circ} \mathrm{C}$ ), das Volumen des Pellets wurde abgeschätzt und im gleichen Volumen $10 \%(\mathrm{v} / \mathrm{v})$ Glycerol resuspendiert wurde. Die entstandene Suspension wurde in 50ml Aliquots in, auf $80^{\circ} \mathrm{C}$ vorgekühlte Eppendorf-Gefäße aufgeteilt und bis zum Gebrauch bei $-80^{\circ} \mathrm{C}$ gelagert.

Es wurde während der ganzen Prozedur bei $4^{\circ} \mathrm{C}$ oder auf Eis gearbeitet. Alle Lösungen waren zuvor autoklaviert und kaltgestellt worden. 


\subsubsection{Elektroporation von E.coli (Dower et al., 1988)}

Zur Transformation von E.coli durch Elektroporation wurden kompetente Bakterien (s.o.) (50 $\mu \mathrm{l})$ auf Eis aufgetaut, mit der zu transformierenden DNA gemischt und in einer sterilen Elektroporationsküvette überführt. Es wurde in der Regel $1 \mu$ der Ligationsansätzen oder 1ng von bereits zirkullär geschlossener Plasmid-DNA für die Elektroporation verwendet.

Die Elektroporation erfolgte unter folgenden Bedingungen:

Kapazität: $25 \mathrm{mF}$

Spannung: $2,5 \mathrm{KV}$

Widerstand: $200 \Omega$

für 3,8 -4,6 sec (BIORAD Gene Pulser)

Nach der Elektroporation wurden die Bakterien in 1ml SOC-Medium suspendiert und 45min unter leichtem Schütteln bei $37^{\circ} \mathrm{C}$ inkubiert. Es wurde anschließend entweder der komplette Transformationsansatz (im Falle von Ligationen) oder ein Teil davon (im Falle von PlasmidDNA) auf LB-Platten mit Ampicillin ausplattiert. Die Inkubation der Platten erfolgte ÜN bei $37^{\circ} \mathrm{C}$.

Bakterien des E. coli-Stammes BL21-CodonPlus wurden nach den Angaben des Herstellers transformiert.

\subsubsection{Lagerung von E.coli Stämmen}

Zur dauerhaften Lagerung einzelner Zellklone wurden Zellen einer frischen Kultur mit 15$20 \%$ sterilem Glycerol versetzt und bei $-80^{\circ} \mathrm{C}$ eingefroren und aufbewahrt.

\subsubsection{Isolierung von Plasmid-DNA aus $E$. coli in analytischen Mengen (Holmes and Quigley, 1981)}

Die Mini-Präparation von Plasmid-DNA aus E.coli -Zellen erfolgte nach der „rapid boiling”Methode. Die mit dem entsprechendem Plasmid transformierten Klone wurden in $2 \mathrm{ml}$ LBMedium mit Ampicillin $(100 \mu \mathrm{g} / \mathrm{ml})$ suspendiert und ÜN bei $37^{\circ} \mathrm{C}$ rotiert. Die Zellen aus einer 1,5ml Aliquot dieser Kultur wurden durch Zentrifugation (3000 Upm, 5min, RT) geerntet und in $120 \mathrm{ml}$ STET-Puffer resuspendiert. Der Bakteriensuspension wurden 10 $\mu 1$ LysozymLösung zugesetzt, $1 \mathrm{~min}$ bei RT inkubiert und 2,5min bei $90^{\circ} \mathrm{C}$ gekocht. Um Zelltrümmern zu entfernen, wurden die lysierten Bakterien zentrifugiert (13000 Upm, 30min, $4^{\circ} \mathrm{C}$ ), der plasmidhaltige Überstand in ein neues Gefäß überführt, das $230 \mu 1$ TE-Puffer, $34 \mu 13 \mathrm{M}$ 
Natriumacetat-Lösung, $130 \mu \mathrm{l}$ Phenol und $130 \mu \mathrm{l} \mathrm{CI}$ enthielt und für eine Minute gründlich gemischt. Die Phasentrennung erfolgte anschließend durch Zentrifugation (13000 Upm, $15 \mathrm{~min}, 4^{\circ} \mathrm{C}$ ), die wäßrige Phase wurde in ein neues Gefäß überführt, mit $250 \mu 1 \mathrm{CI}$ extrahiert und erneut zentrifugiert (13000 Upm, $\left.15 \mathrm{~min}, 4^{\circ} \mathrm{C}\right)$. Die wäßrige Phase wurde erneut in ein neues Gefäß überführt und die Plasmid-DNA durch Zugabe von $850 \mu 196 \%$ (v/v) EtOH und 10minütige Inkubation bei RT gefällt. Durch Zentrifugation (13000 Upm, 15min, $4^{\circ} \mathrm{C}$ ) wurde die DNA pelletiert, mit 500 $\mu 1$ 70\% EtOH gewaschen und erneut zentrifugiert. Das Pellet wurde luftgetrocknet und in $50 \mu 1$ TE-Puffer resuspendiert. $5 \mu 1$ der somit isolierten PlasmidDNA wurden für einen analytischen Restriktionsverdau eingesetzt. Hierzu wurden 5U des entsprechenden Restriktionsenzyms und $1 \mu \mathrm{l}$ RNase A in einem Gesamtvolumen von $20 \mu \mathrm{l}$ eingesetzt

Zuweilen erfolgte die Minipräparation von DNA aus E.coli mit dem „QIAprep Spin Miniprep Kit (250),, von Qiagen nach den Angaben des Herstellers.

\subsubsection{Isolierung von Plasmid-DNA aus $E$. coli in präparativen Mengen}

Die Isolierung von Plasmid-DNA aus E.coli im präparativen Maßstab erfolgte nach dem Prinzip der alkalischen Lyse (Birnboim and Doly, 1979), mit Hilfe des „Plasmid Maxi Kits” von Qiagen (Düsseldorf), das nach den Angaben des Herstellers verwendet wurde. Dazu wurden 100ml Bakterienkulturen in LB-Medium mit Ampicillin $(100 \mu \mathrm{g} / \mathrm{ml})$ herangezogen und die Aufreinigung der Plasmid-DNA erfolgte mittels einer Anionen-Austauscher-Säule.

\subsubsection{Spaltung von DNA mit Restriktionsendonukleasen}

DNA wurde mit Restriktionsendonukleasen unter den vom jeweiligen Hersteller des Enzyms empfohlenen Temperatur- und Pufferbedingungen gespalten. Restriktionsverdaus mit mehreren Enzymen konnten gleichzeitig erfolgen, wenn die Enzyme dieselben Reaktionsbedingungen erfordeten. Im Falle von Enzymen die nicht dieselben optimalen Bedingungen benötigten und demzufolge nicht gleichzeitig für ein Verdau eingesetzt werden konnten, wurde zuerst mit dem einen Enzym verdaut, dann erfolgte eine PCI Extraktion mit anschließender EtOH-Fällung, bevor mit dem anderen Enzym geschnitten werden konnte. Bei analytischen Verdaus wurden bis zu $5 \mu$ g DNA in $20 \mu \mathrm{l}$ Gesamtvolumen eingesetzt. Die Ansätze wurden im allgemeinen 60min inkubiert. Bei präparativen Verdaus wurde je nach 
Bedarf mehr DNA und entsprechend mehr Enzym eingesetzt; zudem wurde die Inkubationszeit mit dem Enzym, wenn eine vollständige Spaltung der Plasmid-DNA gewünscht war, unter Umständen verlängert.

Im Falle von partiellen Verdaus wurden verschiedene Verdünnungen des Enzyms im Reaktionspuffer hergestellt und in der Reaktion eigesetzt. Zudem wurde die Inkubationszeit verkürzt. Damit wurden die optimalen Bedingungen ermittelt bei denen eine partielle Spaltung durch das Enzym erfolgte.

\subsubsection{5'-Dephosphorylierung von Plasmid-DNA}

Vektoren, die zu Klonierungszwecken nur mit einem einzigen Enzym geschnitten wurden, wurden zur Verhinderung der Rezirkularisierung des einfachen Vektors während der Ligationsreaktion mit alkalischer Phosphatase (Boehringer) behandelt. Das Enzym entfernt aus den von der Restriktionsendonuklease erzeugten Enden die 5'-Phosphatgruppe. Somit ist die Ligase nicht mehr in der Lage, die Vektorstränge wieder kovalent zu schließen. Eine kovalente Verknüpfing ist daher nur mit dem Insert möglich, da es intakte 5'Phosphatgruppen besitzt.

Nach dem Restriktionsverdau $(20 \mu \mathrm{l})$ wurden $5 \mu \mathrm{l} 1 \mathrm{M}$ Tris/HCl pH8,0 und $1 \mu \mathrm{l}$ Alkalische Phosphatase $(1 \mathrm{u} / \mu \mathrm{l})$ zugegeben und das Volumen wurde auf $100 \mu \mathrm{l}$ mit $\mathrm{H} 2 \mathrm{O}$ eingestellt. Die Inkubation erfolgte bei $37^{\circ} \mathrm{C}$ für $30 \mathrm{~min}$. Die Reaktion wurde durch Zugabe von EDTA mit einer EK von 12,5mM gestoppt. Es folgte eine Extraktion mit $80 \mu \mathrm{l}$ CI und nach Zentrifugation (13000 Upm, $15 \mathrm{~min}, 4^{\circ} \mathrm{C}$ ) wurde die DNA aus der wässrigen Phase mit $300 \mu 1$ $96 \%(\mathrm{v} / \mathrm{v}) \mathrm{EtOH}$ und $10 \mu 13 \mathrm{M}$ Natriumacetat und 10minütige Inkubation bei RT gefällt. Anschließend wurde die DNA mit 70\% (v/v) EtOH gewaschen, luftgetrocknet und in $20 \mu 1$ H20 resuspendiert.

\subsubsection{Auffüllen von 5'-überhängenden Enden zur Erzeugung von ,blunt’-Enden}

In den Fällen, in denen der Einbau von Insert-Fragmenten in Klonierungs- oder Expressionsvektoren nicht über kompatible Enden erfolgen konnte, wurden 5'-überhängende Enden mit dem Klenow-Fragment der DNA-Polymerase I von E.coli aufgefüllt. Dabei entstehen „,blunt”-Enden, die dann durch die Ligase kovalent verknüpft werden können. In diesen Fällen wurde zunächst in einem Gesamtvolumen von $20 \mu 1$ mit einem Enzym 
geschnitten, das 5'-Überhänge erzeugt. Anschließend wurden $1 \mu 10,5 \mathrm{mM}$ dNTPStammlösung $(\mathrm{N}=\mathrm{A}, \mathrm{G}, \mathrm{C}, \mathrm{T})$ und $1 \mu \mathrm{l}$ Klenow $(2 \mathrm{u} / \mu \mathrm{l})$ (Boehringer) dazugegeben, gemischt und bei $30^{\circ} \mathrm{C}$ für $30 \mathrm{~min}$ inkubiert. Das Enzym wurde anschließend durch die Zugabe von $1 \mu 1$ 0,5M EDTA, und durch Hitze $\left(10 \mathrm{~min}, 75^{\circ} \mathrm{C}\right)$ inaktiviert.

\subsubsection{Amplifikation von DNA Fragmenten mittels der Polymerase-Ketten-Reaktion (PCR) (Mullis and Faloona, 1987; Saiki, et al., 1988)}

Die PCR ermöglicht die exponentielle in vitro Amplifikation eines spezifischen DNA-Bereiches der von zwei entgegengestzt orientierten Oligonukleotidprimern flankiert ist.

Die PCR wurde in dieser Arbeit hauptsächlich zur Klonierungszwecken eingesetzt. Ein Standard-PCR-Ansatz enthielte in einem Gesamtvolumen von $25 \mu 1$ folgende Komponenten:

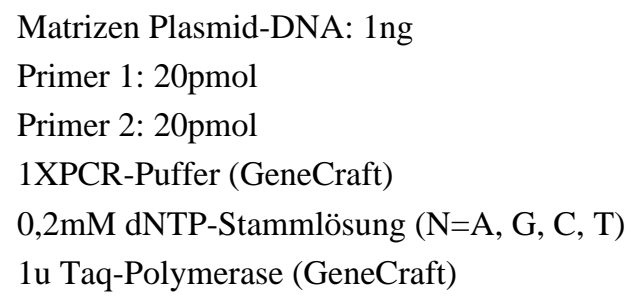

Die Reaktion wurde in einem Peltier Thermal Cycler PTC-2000 (MJ-Research) mit Heizverschluss unter folgenden Bedingungen durchgeführt: zuerst 1min und dann bei jedem Zyklus 20sec bei $94^{\circ} \mathrm{C}$ zur Denaturierung, das Annealing erfolgte für 30sec und die Elongation bei $72^{\circ} \mathrm{C}$. In der Regel wurden 25 Zyklen durchgeführt. Die AnnealingTemperatur sowie die Dauer des Elongationsschrittes wurden empirisch berechnet. Die Annealing-Temperatur wurde nach der Formel $2\left(\mathrm{n}_{\mathrm{A}}+\mathrm{n}_{\mathrm{T}}\right)+2\left(\mathrm{n}_{\mathrm{G}}+\mathrm{n}_{\mathrm{C}}\right)$, während die Dauer des Elongationsschrittes nach der Regel $(1 \mathrm{~min} / \mathrm{kb})$ berechnet wurde.

\subsubsection{Ligation von DNA-Enden zu zirkulären Produkten}

Bei der Ligation von zwei DNA-Fragmenten zu einem zirkulären Produkt wurde das kleinere Insert-Fragment in einem 3-5 fach molaren Überschuß zum Vektorfragment eingesetzt.

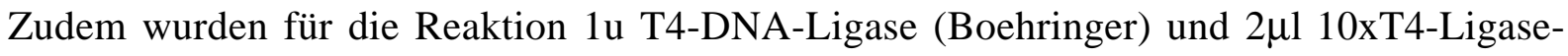
Puffer mit $10 \mathrm{mM}$ ATP in einem Gesamtvolumen von $20 \mu 1$ verwendet. Die Inkubation erfolgte in der Regel ÜN bei $14^{\circ} \mathrm{C}$. Ligationsansätze wurden meistens direkt, ohne nachfolgende Behandlung zur Transformation eingesetzt. In einigen Fällen wurden die Ligationsansätze zuvor in $\mathrm{H} 2 \mathrm{O}$ mit Hilfe von semipermeablen Membranen (Millipore) 
entsalzen, damit ein größeres Volumen zur Elektrotransformation von E.coli eingesetzt werden konnte.

\subsubsection{Markierung von DNA-Fragmenten mit $[\alpha]^{32}$ P-dCTP (Feinberg and Vogelstein, 1983)}

DNA Fragmente die als Sonden für Hybridisierungen eingesetzt wurden, wurden zuerst durch

Restriktionsverdau erzeugt, aus Agarosegelen isoliert und mit $[\alpha]^{32} \mathrm{P}-\mathrm{dCTP}$ markiert. Dies erfolgte mit dem „Multiprime DNA Labeling Kit“ der Firma Amersham. Dazu wurden randomisierte Hexanukleotide an das durch Hitze denaturierte Fragment gebunden und durch das Klenow Enzym in 3'-Richtung matrizenabhängig verlängert. Der Klenow Polymerase wird dabei zusätzlich zu den normalen Nukleotiden (dATP, dGTP, dTTP), $[\alpha]^{32} \mathrm{P}$-dCTP angeboten, das in den synthetisierten Strang eingebaut wird. Es wurde 20-30ng DNA in ein Volumen von $11,5 \mu$ l eingesetzt, die durch Inkubation bei $95^{\circ} \mathrm{C}$ für $3 \mathrm{~min}$ denaturiert wurde. Zur denaturierten DNA wurde in exakter Reihenfolge folgendes zugegeben:

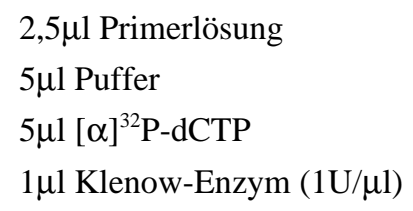

Der Ansatz wurde für mindestens $1 \mathrm{~h}$ bei $37^{\circ} \mathrm{C}$ inkubiert.

Aufreinigung der markierten Sonde

Nicht eingebaute Nukleotide wurden über eine „ProbeQuant ${ }^{\mathrm{TM}} \mathrm{G}-50$ Microcolumn“ (Pharmacia) nach den Angaben des Herstellers entfernt. Das Ausmaß der Markierung wurde bestimmt indem $1 \mu 1$ des Durchflusses im Szintillationszähler (Beckman, LS 1701) gemessen wurde. Die markierten Sonden wurde vor dem Einsatz in Hybridisierungen für $5 \mathrm{~min}$ bei $95^{\circ} \mathrm{C}$ denaturiert.

\subsubsection{Fällung von DNA mit Ethanol}

Die Fällung von DNA mit EtOH diente einerseits der Reinigung und andererseits der Konzentrierung der DNA. Dies geschiet durch die Erhöhung der Konzentration an monovalenten Ionen und den Entzug der Hydrathülle der DNA durch EtOH.

Zur Fällung wurde zu der DNA-haltigen Lösung 1/10 Vol. 3M Natriumacetat-Lösung gegeben, 3 Vol. 96\% (v/v) EtOH zugesetzt und für 10min bei RT inkubiert. Die gefällte DNA wurde durch Zentrifugation pelletiert (13000 Upm, 15min, $\left.4^{\circ} \mathrm{C}\right)$ und mit $70 \%$ (v/v) EtOH 
gewaschen, luftgetrocknet und in einem geeigneten Volumen Wasser oder TE-Puffer resuspendiert.

\subsubsection{Phenolextraktion}

Durch das Versetzen einer DNA-Lösung mit Phenol geht die Mehrzahl der Proteine sowie anderer hydrophobe Substanzen in die organische Phase über, während die DNA, frei von diesen Kontaminationen, in der wäßrigen Phase verbleibt.

Der DNA-Lösung wurde 1 Vol. Phenol zugesetzt, gründlich gemischt und zur Phasentrennung $5 \mathrm{~min}$ bei $4^{\circ} \mathrm{C}$ zentrifugiert. Die wäßrige Phase wurde auf die gleiche Weise einmal mit PC und einmal mit CI extrahiert. Im Anschluß an diesen Extraktionsschritten wurde die DNA mit EtOH gefällt.

\subsubsection{Isolierung und Reinigung von DNA-Fragmenten aus Agarose-Gelen}

Für die Isolierung von DNA-Fragmenten nach ihrer elektrophoretischen Trennung in Agarose-Gelen wurde das „Qiaex II Gel Extraction Kit (150)”(Qiagen), nach den Angaben des Herstellers, verwendet. Diese Reinigungsmethode (Vogelstein and Gillespie, 1979) beruht auf der Bindung von DNA an Glaspartikel bei hohen Konzentrationen chaotroper Salze.

Die damit aufgereinigten Fragmenten wurden direkt entweder in Ligationsreaktionen oder zur Herstellung radioaktiv markierter Sonden eingesetzt.

\subsubsection{Agarosegelelektrophorese}

Die Auftrennung von DNA für analytische und präparative Zwecke wurde in Agarosegelen mit 0,5xTBE als Laufpuffer durchgeführt.

Der aufzutrennenden Fragmentgröße entsprechend, wurden 0,5-1,5\%ige Agarosegele (Gibco BRL) mit etwa $5 \mu \mathrm{g} / \mathrm{ml}$ Ethidiumbromid verwendet. Die DNA-Proben wurden nach Zugabe von 1/6 Vol. 6xLadepuffer bei einer konstanten elektrischen Feldstärke von 5-10V/cm elektrophoresiert und im UV-Durchlicht $(258 \mathrm{~nm})$ durch Fluoreszenz sichtbar gemacht. Präparative Gele wurden langwelligem UV-Licht (366 nm) ausgesetzt um die Bildung von Thymidin-Dimeren und die Entstehung von Strangbrüchen zu vermeiden. 


\subsubsection{Konzentrationsbestimmung von Nukleinsäuren}

Die Bestimmung der DNA-und RNA-Konzentration erfolgte photometrisch. Dabei macht man sich die Absorption von UV-Licht durch die Purin- und Pyrimidin-Basen der DNA und RNA zunutze, die bei 260nm ihr Maximum hat. Für die Messung wurde zunächst die DNA-bzw. RNA-Lösung mit Wasser 1:200 verdünnt. Die Absorption wurde in einer Quarzküvette (Schichtdicke: 1 cm) bei 260, 280 und 320nm gemessen. Wasser bildete den Leerwert.

Es gilt:

Für doppelsträngige DNA: $1 \mathrm{OD}_{260}=50 \mu \mathrm{g} \mathrm{DNA} / \mathrm{ml}$

Für RNA: $1 \mathrm{OD}_{260}=40 \mu \mathrm{g} \mathrm{RNA} / \mathrm{ml}$

\subsubsection{Sequenzanalyse von DNA}

Die Sequenzierung von cDNA-Fragmenten in den verschiedenen Vektoren, die in dieser Arbeit verwendet wurden, wurde mit dem „Dye Terminator cycle sequencing Kit” von Applied Biosystems durchgeführt. Die Auftrennung und anschließende Auswertung erfolgte auf ein denaturierendem 4,5\%igem, 0,2 mm dicken Polyacrylamid-Gel mit dem „DNASequencer 377" von Applied Biosystems.

Verwendet wurden vektorspezifische Primer, die das Insert flankierten oder aber insertspezifische Primer. Als Matrize diente doppelsträngige Plasmid-DNA.

\subsubsection{Northern Hybridisierung}

\section{$\underline{\text { RNA-Isolierung }}$}

Die Isolierung von gesamter RNA aus Embryonen bzw. kultivierten Zellen erfolgte mit dem TRIZOL Reagenz (GIBCO BRL) nach den Angaben des Herstellers. Embryonen wurden zuvor mit einem Homogenisator zerkleinert, während Zellen direkt auf der Schale mit dem Reagenz lysiert wurden. Die somit präparierte RNA wurde in Wasser gelöst und ihr Konzentration photometrisch bestimmt.

Präparation von Formaldehyd Gelen

RNA-Moleküle wurden in einem Formaldehyd Gel nach ihrer Grösse aufgetrennt. Dazu wurde 1g Agarose in 75ml Wasser unter Hitze gelöst, kurz abgekühlt, 20ml 5xFormaldehydLaufpuffer und 5,4ml 37\% (v/v) Formaldehyd wurden zugegeben und in eine geeignete Kammer gegossen. 
$10-15 \mu \mathrm{g}$ Gesamt-RNA in ein Volumen von 4,5 $\mu$ l wurden in ein Gesamtvolumen von $20 \mu 1$ in $10 \mu \mathrm{l}$ deionisiertem Formamid, 3,5 $4137 \%$ (v/v) Formaldehyd, und $2 \mu 15 x$ Formaldehyd Laufpuffer verdünnt und für $10 \mathrm{~min}$ bei $70^{\circ} \mathrm{C}$ denaturiert. Die RNA wurde direkt auf das Gel aufgetragen ohne zuvor mit Farbmarker versetzt zu werden. Als Grössenstandart diente ein Gemisch aus E.coli-und Maus-Gesamt RNA (5 $\mu$ g). Dabei macht man sich der Tatsache zunutze, daß die ribosomalen RNA Moleküle die einen großen Anteil der Gesamt-RNA ausmachen bei Prokaryoten und Eukaryoten verschieden groß sind. Während bei Prokaryoten die $16 \mathrm{~S}$ und die 23S die Haupt-ribosomalen RNAs darstellen, sind es bei Säugern die 18S und 28S ribosomale RNA Moleküle. Da diese, als prominente Banden im Formaldehyd Gel erscheinen und von bekannter Grösse sind können sie als Marker eingesetzt werden.

Die aufgetragene RNA wurde bei einer konstanten Feldstärke, 5V/cm, in 1xFormaldehyd Laufpuffer elektrophoresiert. Um starken Veränderungen des $\mathrm{pH}$ Werts an den beiden Elektroden zu vermeiden, die das Laufverhalten der RNA beeinflussen könnten wurde der Laufpuffer mit einer peristaltischen Pumpe rezirkularisiert.

Färben des Gels

Am Ende des Laufs wurde das Gel aus der Kammer entnommen und für ca. 30min in Wasser geschüttelt um das Formaldehyd zu entfernen. Dabei wurde das Wasser mehrmals gewechselt. Um die aufgetragene RNA sichtbar zu machen wurde das Gel in einer $5 \mu \mathrm{g} / \mathrm{ml}$ Ethidiumbromid Lösung für 20min eingetaucht. Um den Überschuß an Ethidiumbromid zu entfernen wurde mit Wasser 2x10min gewaschen. Das Gel wurde im UV-Durchlicht (258nm) mit Längenmaß photographiert.

\section{Blotten}

Der Transfer der RNA auf eine ungeladene Nylon Membran (Blot) erfolgte mit 20xSSC. Dabei wurde das Gel auf eine Glasplatte auf ein Whattmanpapier gelegt, dessen Enden in ein Reservoir mit 20xSSC eingetaucht waren. Auf des Gel wurde möglichst luftblasenfrei die Nylon Membran gelegt, die zuvor 1min in Wasser und 3min in 2xSSC getränkt wurde. Eine weitere Lage Whattmanpapier wurde auf die Membran gelegt und darauf ein Stapel von Papierhandtücher. Um den für den Transfer erforderlichen Sog zu erzeugen wurde das Papierstapel mit einem Gewicht von ca. 200g belastet. Der Transfer an die Membran erfolgte ÜN. Am darauffolgenden Tag wurde die transferierte RNA durch backen bei $80^{\circ} \mathrm{C}$ für $1 \mathrm{~h}$ und unter UV-Licht $\left(0,3 \mathrm{~J} / \mathrm{cm}^{2}\right)$ kovalent an die Membran gebunden.

Hybridisierung 
Die Membran wurde kurz mit Wasser angefeuchtet und in vorgewärmte Prähybridisierungslösung für mindestens $1 \mathrm{~h}$ bei $65^{\circ} \mathrm{C}$ unter Rotieren inkubiert. Zur Hybridisierung wurde die mit $[\alpha]^{32} \mathrm{P}$-markierte DNA-Sonde für $5 \mathrm{~min}$ bei $95^{\circ} \mathrm{C}$ denaturiert, in frische vorgewärmte Prähybridisierungslösung verdünnt und zu der Membran gegeben. Hybridisiert wurde $\ddot{\mathrm{NN}}$ bei $65^{\circ} \mathrm{C}$.

\author{
Prähybridisierungslösung \\ $7 \%(\mathrm{w} / \mathrm{v})$ SDS \\ $0,5 \mathrm{M}$ Natrium-Phosphatpuffer, $\mathrm{pH} 7,2$
}

Waschen

Am darauffolgenden Tag wurde die Membran wie folgt gewaschen:

$$
\begin{aligned}
& 2 x \text { für jeweils } 30 \mathrm{~min} \text { in } 2 x \mathrm{xSC}, 0,5 \%(\mathrm{w} / \mathrm{v}) \text { SDS } \\
& 2 \mathrm{x} \text { für jeweils } 20 \mathrm{~min} \text { in } 0,5 \mathrm{xSSC}, 0,5 \%(\mathrm{w} / \mathrm{v}) \mathrm{SDS} \\
& 2 \mathrm{x} \text { für jeweils } 15 \mathrm{~min} \text { in } 0,1 \mathrm{xSSC}, 0,1 \%(\mathrm{w} / \mathrm{v}) \mathrm{SDS}
\end{aligned}
$$

Nach dem letzten Waschschritt wurde die Membran kurz getrocknet und einem Film bei $80^{\circ} \mathrm{C}$ ÜN exponiert. Anhand der Intensität des Signals wurde die weitere Expositionsdauer bestimmt.

Auswertung

Um die Länge der hybridisierten RNA zu bestimmen wurde die Wanderungsstrecke der Markerbanden im Gel in $\mathrm{cm}$ gegen ihre Länge in $\mathrm{kb}$ aufgetragen. Dabei ist die Wanderungsstrecke umgekehrt proportional zur Grösse der Fragmente. Anhand der daraus resultierenden Gerade läßt sich die Grösse des hybridisierten RNA Moleküls bestimmen.

\title{
4.4.18 Genotypisierung durch Southern-Hybridisierung
}

DNA aus Embryonen bzw. Mäusen wurde aus Chorionhülle- bzw. Schwanzbiopsien isoliert. Dazu wurde das Gewebe in $500 \mu 1$ Lysispuffer dem $10 \mu 1$ Proteinase K-Lösung zugesetzt wurden ÜN bei $56^{\circ} \mathrm{C}$ unter Schütteln verdaut. Nach Zentrifugation (13000rpm, 10min) wurde der Überstand in ein neues Gefäß überführt und nach Zugabe von $700 \mu$ Isopropanol und Zentrifugation bei 13000rpm, 2min, wurde die genomische DNA gefällt. Die präzipitierte DNA wurde zweimal mit 70\% EtOH gewaschen, kurz luftgetrocknet und in $100 \mu 1$ Wasser ÜN resuspendiert. Zur Genotypisierung von Mapl-1 ${ }^{\mathrm{gfp}+}-$ Mäusen und Embryonen wurden $25 \mu 1$ der isolierten genomischen DNA mit EcoRI in einem Gesamtvolumen von 50 $\mu 1$, ÜN verdaut. Anschließend wurden die erzeugten Fragmenten über ein Agarosegel elektrophoretisch getrennt bei einer konstanten Spannung von $30 \mathrm{~V}$. 


Lysis-Puffer
$100 \mathrm{mM} \mathrm{NaCl}$
$10 \mathrm{mM}$ Tris/HCl, pH8,0
$25 \mathrm{mM}$ EDTA
$0,5 \%(\mathrm{w} / \mathrm{v}) \mathrm{SDS}$

Für den Transfer der DNA-Fragmente auf eine Nylon ungeladene Membran wurde das Gel wie folgt behandelt:

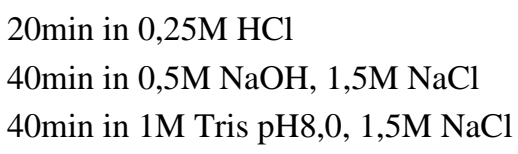

Zwischen den oben angegebenen Lösungen wurde kurz mit Wasser gewaschen. Der Transfer der DNA-Fragmente auf die Membran (Blotten), die Hybridisierung sowiwe die anschließenden Waschschritten erfolgten wie in Abschnitt 4.4.17 beschrieben.

\subsubsection{Durchmusterung von Phagenbibliotheken}

\section{Präparation von Wirtsbakterien}

E.coli Bakterien des Stammes der jeweils für die zu durchmusternde Bank geeignet sind, wurden auf eine LB-Platte ausgestrichen und ÜN bei $37^{\circ} \mathrm{C}$ inkubiert. Eine einzelne Kolonie wurde in LB-Medium suspendiert dem zusätzlich 0,2\%(w/v) Maltose, und 100mM Magnesiumsulfat zugesetzt wurde und bei $37^{\circ} \mathrm{C}$ unter Schütteln (250rpm) inkubiert bis die Kultur eine $\mathrm{OD}_{600}$ von 0,6 - 1,0 erreicht hat. Die Bakterien wurden durch Zentrifugation (3000rpm, 10min) geerntet und in $10 \mathrm{mM}$ Magnesiumsulfat $\mathrm{zu}$ einer $\mathrm{OD}_{600}$ von 0,5 resuspendiert. $300 \mu \mathrm{l}$ (für $10 \mathrm{~cm}$ Platten) oder $700 \mu \mathrm{l}$ (für $15 \mathrm{~cm}$ Platten) der präparierten Bakterien wurden mit Phagen infiziert und bei $37^{\circ} \mathrm{C}$ für $15 \mathrm{~min}$ leicht geschüttelt. Die infizierten Bakterien wurden mit 3ml (10cm Platten) bzw 6ml (15cm Platten) TOP-Agarose übergoßen, gemischt und auf NZY Platten verteilt. Die Platten wurden ÜN bei $37^{\circ} \mathrm{C}$ inkubiert. Dabei entsteht ein Bakterienrasen durch das die rekombinante Phagen als sichtbare Plaques erscheinen, die zerstörte Bakterien darstellen.

Titerbestimmung und Ausplattieren

Für die erfolgreiche Identifizierung von bestimmten cDNA oder genomischen Sequenzen ist es entscheidend, daß eine genügend hohe Anzahl an rekombinanten Phagen durchmustert wird. Dazu wurde vor dem Ausplattieren der Titer der Bank bestimmt. Aus einem bei $-80^{\circ} \mathrm{C}$ gefrorenen Stock wurden Splitter mit einer Pipettenspitze entnommen und in ein Eppendorf-Gefäß überführt. Es wurde eine Verdünnungsreihe in SM-Puffer angesetzt und 
anhand der Anzahl der gebildeten Plaques ließ sich die Zahl der infizierenden Phagen pro $\mu 1$, pfu (,plaque forming units“/ $\mu 1)$ errechnen.

\section{Durchmusterung}

Das Ausplattieren der Phagenbibliothek erfolgte auf Platten mit den Dimensionen 243 x 243 x 18mm, (Nunc) mit NZY als Nährboden. Es wurden wie oben beschrieben ca. 200000 pfu/Platte, mit 3ml Bakterien inkubiert, mit 30ml TOP-Agarose vermischt und auf die Platte verteilt Insgesamt wurden ca. $1 \times 10^{6} \mathrm{pfu}$ ausplattiert und $\mathrm{U} N$ bei $37^{\circ} \mathrm{C}$ inkubiert. Am darauffolgenden Tag wurden Replikas von den Platten entnommen indem ungeladene Nylonmembranen (Qiagen) auf die TOP-Agarose - Schicht gelegt wurden und mit einer Injektionsnadel durch das Nährboden mit wasserfester Tinte assymetrisch markiert wurden. Um das Kleben von TOP-Agarose an der Membranen zu verhindern wurden die Platten zuvor bei $4^{\circ} \mathrm{C}$ gestellt. Es wurden zwei Replikas von jeder Platte entnommen. Um die Phagen-DNA für die Hybridisierung vorzubereiten wurden die Membranen mit der DNA-Seite nach oben nacheinader durch folgende Lösungen überführt.

$1,5 \mathrm{M} \mathrm{NaCl}, 0,5 \mathrm{M} \mathrm{NaOH}$ für $2 \mathrm{~min}$ zum Denaturieren

$1,5 \mathrm{M} \mathrm{NaCl}, 0,5 \mathrm{M}$ Tris / $\mathrm{HCl} \mathrm{pH} 8,0$ für 5min zum Neutralisieren

Nach kurzem Einlegen (30sec) in 0,2M Tris / HCl pH7,5, 2xSSC wurde die Phagen-DNA durch Backen bei $80^{\circ} \mathrm{C}$ und anschließende UV-Bestrahlung $\left(0,3 \mathrm{~J} / \mathrm{cm}^{2}, 302 \mathrm{~nm}\right)$ kovalent an die Membran gebunden. Die Hybridisierung der Membranen mit der $[\alpha]^{32} \mathrm{P}$-markierter DNA-Sonde sowie die darauffolgende Waschschritte und Filmexponierung ist im Abschnitt beschrieben.

\section{Isolierung rekombinanter Phagenklone}

Die mit der DNA-Sonde hybridisierten Phagen konnten anhand der Schwärzung der Filme identifiziert werden. Es wurden die Phagenklone isoliert die auf beiden Replikas Hybridisierung mit der DNA-Sonde aufwiesen. Der entwickelte Film bei dem die Markierungen der zugehörigen Membran sowie die Lage des zu isolierenden Phagenklons deutlich gekennzeichnet wurde, wurde unter der Agarplatte gelegt und anhand der Markierungen orientiert. Die Isolierung der Phagen erfolgte mit einer Pipettenspitze durch das

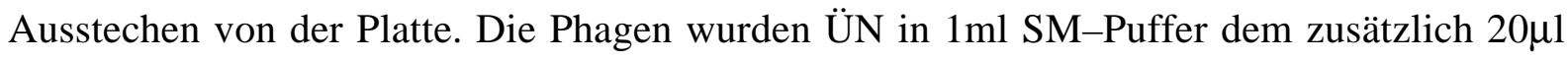
Chlorophorm zugesetzt wurde bei $4^{\circ} \mathrm{C}$ unter Schütteln eluiert. In der Regel konnten in der ersten Hybridisierungsrunde keine einzelne Klone isoliert werden; aus diesem Grunde wurde 
das gleiche „screening“-Verfahren wiederholt bis einzelne Plaques isoliert werden konnten. Dies war meistens in der dritten Selektionsrunde möglich.

Anlegen eines hohen Titers (HT-Stock) und Präparation von Phagen-DNA

Für die Präparation von DNA aus Phagen wurden Stocks mit hohem Titer angelegt. Dabei wurden vereinzelte Phagenklone auf $10 \mathrm{~cm}$ Platten verteilt, so daß eine vollständige Lyse der Wirtsbakterien erfolgte. Die Phagen wurden ÜN unter Scütteln mit 4ml SM/50 $\mu 1$ Chlorophorm bei $4^{\circ} \mathrm{C}$ in der Platte eluiert. Am nächsten Tag wurde der Überstand (ca. 1,5ml) in ein Falcon Gefäß überführt und bei $4^{\circ} \mathrm{C}$ aufbewahrt.

Die Präparation der Phagen-DNA erfolgte aus einer Flüssigkultur. Dazu wurden 50 $\mu 1$ der präparierten Bakterien (s.o) mit $1 \mu \mathrm{l}$ aus dem HT-Stock infiziert und in 20ml NZY Medium mit zugesetztem 0,2\%(w/v) Maltose, 10mM Magnesiumsulfat, überführt. Die Kultur wurde bei $37^{\circ} \mathrm{C}$ geschüttelt (250rpm) bis eine Lyse der Bakterien erfolgte. Die besten Ergebnisse wurden erzielt wenn eine Lyse der Bakterien nach ca. 6-7 Stunden eintratt. Die Kultur wurde

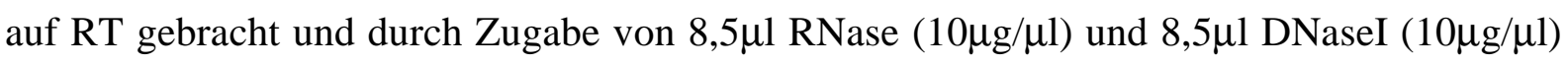
und 30minütige Inkubation unter leichtem Schütteln wurde in der Kultur freigesetzte bakterielle DNA und RNA verdaut. Bakterientrümmer wurden durch Zentrifugation 20min 12000rpm (SA600 Rotor) pelletiert. Der Überstand wurde in ein neues Gefäß überführt, dem wurde $1 / 4$ Volumen $5 \mathrm{M} \mathrm{NaCl}$ zugegeben, leicht gemischt und erneut zentrifugiert. Der Überstand wurde entnommen und nach Zugabe von 1/3 Volumen 40\% PEG (6000)-Lösung auf Eis für $1 \mathrm{~h}$ inkubiert. Durch Zentrifugation bei $10000 \mathrm{rpm}, 15 \mathrm{~min}$ wurden die Phagenpartikel pelletiert und der Überstand verworfen. Das Pellet wurde in $700 \mu 1$ Phagen-Lysepuffer resuspendiert in ein Eppendorf-Gefäß überführt und für $45 \mathrm{~min}$ bei $50^{\circ} \mathrm{C}$ inkubiert. Die Phagen-DNA wurde anaschließend 2x mit 700 $\mu 1$ PCI und mit CI extrahiert. Die DNA wurde aus der wässrigen Phase durch Zugabe von $800 \mu 1$ Isopropanol/0,8M Ammoniumacetat, 5minütige Inkubation auf Eis und Zentrifugation präzipitiert, mit $1 \mathrm{ml} 70 \%$ EtOH gewaschen und in $500 \mu \mathrm{l}$ TE-Puffer mit RNaseA mit einer EK von $(100 \mu \mathrm{g} / \mathrm{ml})$ resuspendiert. Mit RNase A wurde für $30 \mathrm{~min}$ bei $37^{\circ} \mathrm{C}$ verdaut erneut mit PCI extrahiert und mit Isopropanol präzipitiert. Nach dem Waschen mit 70\% EtOH wurde schließlich die DNA in 50 $\mu 1$ TE-Puffer aufgenommen. Um die Qualität der präparierten DNA sowie um die Länge des enthaltenen Fragments zu überprüfen wurden $5 \mu 1$ der Phagen DNA mit einem geeigneten Restriktionsenzym geschnitten. Vor dem Auftragen auf das Gel wurden die COS-Enden des linearen Phagen-DNA-Moleküls durch Erhitzen bei $50^{\circ} \mathrm{C}$ für $5 \mathrm{~min}$ dissoziiert. Für die 
weiteren Manipulationen wurde das DNA Fragment aus dem Phagen in ein Plasmid (pBS $\mathrm{KSII}^{+}$) kloniert. Dazu wurde die Phagen-DNA mit einem geeigneten Restriktionsenzym geschnitten und ohne das Fragment über ein Agarosegel zu isolieren direkt in das Plasmid ligiert.

\subsection{Proteinchemische Methoden}

\subsubsection{SDS-Polyacrylamidgelelektrophorese (SDS-PAGE) von Proteinen}

Proteine wurden unter denaturierenden Bedingungen in diskontinuierlichen SDSPolyacrylamid-Gelen, nach der Methode von (Laemmli, 1970), mit PAGE-Puffer als Laufpuffer aufgetrennt. Die Gele wurden zwischen zwei Platten mit den Dimensionen $6 \times 11 \times 0,1 \mathrm{~cm}$ gegossen. Es wurde mit dem Trenngel begonnen, das ca. zwei drittel des gesamten Geles ausmachte. Dieses wurde, um eine gerade Oberkante zu bekommen sofort nach dem Gießen und vor seiner Polymerisation mit Isopropanol überschichtet. Nach abgeschlossener Polymerisation wurde das Isopropanol abgegossen, die Oberkante des Trenngels mit Wasser gespült und mit einem Filterpapier getrocknet. Anschließend wurde das Sammelgel darüber gegossen und mit dem taschenbildenden Kamm versehen. Nachdem das Sammelgel auspolymerisiert war, wurde das Gel in eine dafür geeignete Apparatur eingespannt.

Die Proben wurden mit Laemmli-Auftragspuffer im Verhältnis eins zu eins versetzt und 5min bei $95^{\circ} \mathrm{C}$ denaturiert, bevor sie auf das Gel aufgetragen wurden. Die Elektrophorese erfolgte bei einer konstanten Strommstärke von 30mA.

Das Prinzip der diskontinuierlichen PAGE beruht auf dem unterschiedlichen Ladungszustand von Glycin, das im PAGE-Puffer enthalten ist, im Sammel- und im Trenngel. Im Sammelgel ist Glycin aufgrund des pH-Wertes $(6,8)$ elektrisch neutral; die SDS-Proteinkomplexe stellen die Leitionen dar. Sie bilden die Lauffront und sammeln sich dort. Im Trenngel ist Glycin wegen des höheren $\mathrm{pH}$-Wertes $(8,9)$ negativ geladen, es ist das Leition. Die SDSProteinkomplexe trennen sich dahinter nach ihrer Größe auf.

Nach der Elektrophorese wurden die Gele entweder mit „Coomasie-Brilliant-Blue” gefärbt, getrocknet, oder zum Transfer der Proteine auf eine Kunststoffmembran verwendet. 
Bei den in dieser Arbeit durchgeführten SDS-PAGE wurden 12\%ige (w/v) Acrylamid-Gele verwendet. Als Größenstandard wurde eine Mischung aus verschiedenen vorgefärbten Proteinen (New England Biolabs) benutzt.

\begin{tabular}{|c|c|c|c|c|}
\hline \multicolumn{3}{|c|}{ Trenngel: $12 \mathrm{ml} \mathrm{12 \%} \mathrm{(w/v)} \mathrm{Acrylamid}$} & \multicolumn{2}{|c|}{ Sammelgel: $10 \mathrm{ml}, 5 \%(\mathrm{w} / \mathrm{v})$ Acrylamid } \\
\hline Acrylamid-Lösung: & 4,8 & $\mathrm{ml}$ & Acrylamid-Lösung: & 1,7 \\
\hline H2O: & 3,55 & $\mathrm{ml}$ & $\mathrm{H} 2 \mathrm{O}$ & 4,7 \\
\hline 1,5M Tris/HCl, pH8,9: & 3,35 & $\mathrm{ml}$ & 0,5M Tris/HCl, pH6,8: & 3,4 \\
\hline $10 \%(\mathrm{w} / \mathrm{v}) \mathrm{SDS}:$ & 133,5 & $\mu 1$ & $10 \%(w / v)$ SDS: & 99 \\
\hline APS-Lösung: & 187 & $\mu \mathrm{l}$ & APS-Lösung: & 149 \\
\hline TEMED: & 13,5 & $\mu \mathrm{l}$ & TEMED: & 10 \\
\hline
\end{tabular}

Die Polymerisation sowohl des Trenngels wie auch die des Sammelgels wurde durch die Zugabe von APS-Lösung und TEMED ausgelöst.

\subsubsection{Transfer von Proteinen auf Membranen (,Western-Blot”)}

Der Transfer von Proteinen aus SDS-Polyacrylamidgelen auf Kunststoffmembranen (Immobilon P, Millipore) (Towbin et al., 1979) wurde nach dem „Semi-dry”-Verfahren (Kyhse-Anderson, 1984) durchgeführt, durch Strommfluß senkrecht zur Gelebene. Auf drei mit Transferpuffer getränkte Lagen Filterpapier wurde die Membran, das Gel (nur das Trenngel) und drei weitere Lagen Filterpapier, die ebenfalls mit Transferpuffer getränkt wurden gelegt. Entscheidend für den effizienten Transfer der Proteine auf die Membran ist die Hydrophobizität der Membran, die dadurch erhöht wurde, indem sie vor dem Aufbau des Blots in Methanol getaucht wurde. Dieser Stapel wurde zwischen zwei Graphitelektroden gepreßt.

Es ergab sich folgender Aufbau:

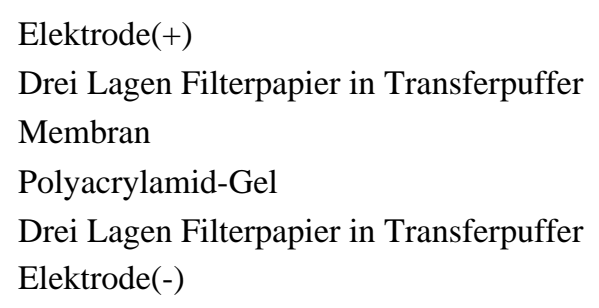

Für den elektrophoretischen Transfer der Proteine wurde das Gerät „TRANS-BLOT 50 SEMI-DRY TRANSFER CELL , der Firma BIORAD verwendet. Es wurde bei $0,8 \mathrm{~mA} / \mathrm{cm} 2$ Gelfläche, 1,5h lang geblottet. Nach dem Transfer wurden die Proteine reversibel mit Ponceau-Rot gefärbt, um die Effizienz des Transfers zu kontrollieren. Die Membran wurde bis zur vollständigen Entfärbung mit PBS-Tween-Puffer gewaschen. 


\subsubsection{Immunochemische Detektion von auf Membranen transferierten Proteinen (Blake et al., 1984)}

Die Membran wurde nach dem „Western-Blot” zunächst eine Stunde in Blockierungslösung geschwenkt, um unspezifische Antikörper-Bindungsstellen abzusättigen. Danach wurde das in Blockierungslösung verdünnte Antiserum zugegeben und auf einem Schütteltisch ÜN bei $4^{\circ} \mathrm{C}$ inkubiert.

Die Membran wurde danach je 10min in Waschpuffer A, Waschpuffer B und wieder in Waschpuffer A bei RT gewaschen. Die Markierung der gebundenen primären AK erfolgte durch einstündiges Schwenken in, in Blockierungslösung verdünnter, sekundären Immunoglobulin-Peroxidase-Konjugat. Die Membran wurde wie beschrieben ein weiteres Mal gewaschen. Die Detektion der gebundenen AK erfolgte durch Chemolumineszenz mit dem „SuperSignal West“ von PIERCE nach Angaben des Herstellers.

$\begin{array}{lll}\text { Waschpuffer A } & \text { Waschpuffer B } & \text { Blockierungslösung } \\ 10 \mathrm{mM} \mathrm{Tris} / \mathrm{HCl} \mathrm{pH} 7,5 & 0,2 \%(\mathrm{w} / \mathrm{v}) \mathrm{SDS} & 5 \%(\mathrm{w} / \mathrm{v}) \text { Magermilchpulver } \\ 0,9 \%(\mathrm{w} / \mathrm{v}) \mathrm{NaCl} & 0,9 \%(\mathrm{w} / \mathrm{v}) \mathrm{NaCl} & \text { in Waschpuffer A } \\ 0,05 \%(\mathrm{v} / \mathrm{v}) \text { Tween-20 } & 0,5 \%(\mathrm{v} / \mathrm{v}) \text { Triton X-100 } & \end{array}$

\subsubsection{Färbung von Proteinen mit „Coomasie Brilliant Blue”}

Nach der SDS-PAGE wurde das Gel in Coomasie-Lösung getaucht und mindestens eine Stunde inkubiert. Dabei kann das Gel mit Methanol/Essigsäure fixiert und gleichzeitig mit „Coomasie Brilliant Blue" gefärbt werden. Anschließend wurde das Gel in einer Lösung aus Methanol/Wasser/Essigsäure- 4,5:4,5:1 (v/v) bis zur vollständigen Entfärbung geschwenkt, wobei die Lösung mehrmals gewechselt wurde. Dabei diffundiert der Farbstoff aus dem Gel, während er an den Proteinen haften bleibt, die dadurch als sichtbare Banden erscheinen. Nach vollständiger Entfärbung wurden die Gele getrocknet.

\subsubsection{Trocknen von SDS-Polyacrylamid-Gelen}

SDS-Polyacrylamid-Gele, in denen $[\alpha]^{35}$-S-markierte Proteine aufgetrennt wurden, wurden vor der Exponierung auf einem Film getrocknet. Ebenfalls getrocknet wurden mit „Coomasie“ gefärbte Gele in den Fällen in denen ihre Aufbewahrung gewünscht war.

Dazu wurden die Gele erst in einer Methanol/Wasser/Essigsäure (20:70:10 v/v)-Lösung fixiert, solange bis der Bromphenolblau-Indikator, der im Laemmli-Puffer enthalten ist, Gelb 
wurde, anschließend auf zwei Lagen Filterpapier gelegt, mit Haushaltsfolie überdeckt und in einem Geltrockner (Biorad) bei $80^{\circ} \mathrm{C}$ unter Vakuum getrocknet.

\subsubsection{In vitro-Transkription-Translation von klonierter cDNA in Kaninchen- Retikulocyten-Lysaten}

Für die Produktion und die gleichzeitige Markierung von Proteinen in vitro wurde das „TNT SP6 Coupled Reticulocyte Lysate System" nach den Angaben des Herstellers (Promega) verwendet. Dazu wurden die entsprechenden cDNA Fragmente in Vektoren kloniert so daß sie unter der Kontrolle des Bakteriophagen SP6 Promotors geraten. Verwendet wurde $1 \mu \mathrm{g}$ des Vektors, in zirkulärgeschlossener Form der als Matrize diente. Bei diesem System produziert eine SP6-RNA-Polymerase den ,sense”-RNA-Strang, der anschließend durch das System zu Protein translatiert wird. Die Proteine können durch den Einbau von $[\alpha]{ }^{35} S$-Met (Amersham) markiert werden. Nach Ablauf der Reaktion wurde $1 \mu 1$ der Reaktion mittels SDS-PAGE auf die Produktion eines Proteins mit dem erwarteten Molekulargewicht hin analysiert. Das Gel wurde nach der Elektrophorese getrocknet und einem Film für 1h bis ÜN exponiert.

\subsubsection{Produktion in E.coli und Reinigung von GST und GST-Fusionsproteinen (Smith and Johnson, 1988)}

Für die Expression von GST und GST-Fusionsproteinen in E.coli wurden die Expressionsvektoren der Reihe pGEX (Pharmacia) verwendet. Diese Vektoren ermöglichen die Konstruktion einer Fusion mit GST und die Expression des konstruierten Fusionsgens in E.coli unter der Kontrolle eines chemisch induzierbaren Promotors (tac-Promotor). Dazu wurden die oben aufgeführten Expressionsvektoren in den Protease-deffizienten E.coli BL21oder den verbesserten BL21 CodonPlus-Stamm transformiert.

\subsubsection{Produktion der Proteine in analytischen Mengen}

Proteine wurden in analytischen Mengen produziert, um rekombinante Klone zu identifizieren, die ein Fusionsprotein mit dem erwarteten Molekulargewicht produzieren. Dazu wurden einzelne Transformanten, in 3ml dYT-G-Medium mit Ampicillin $(100 \mu \mathrm{g} / \mathrm{ml})$ suspendiert und ÜN bei $37^{\circ} \mathrm{C}$ rotiert. Am nächsten Tag wurden aus jeder Vorkultur zwei $3 \mathrm{ml}-$ Kulturen in dYT-G-Medium mit Ampicillin $(100 \mu \mathrm{g} / \mathrm{ml})$ angesetzt und bis zu einer $\mathrm{OD}_{600}$ von 
0,6-0,8 wachsen gelassen. Die Expression des Fusionsproteins wurde durch die Zugabe von IPTG-Lösung mit einer EK von 1mM induziert. Dabei wurde jeweils eine der zwei Kulturen jedes rekombinanten Klons mit IPTG induziert. In der zweiten Kultur, die als Kontrolle diente, wurde die Protein-Expression nicht induziert. Die Kulturen wurden für zwei weitere Stunden bei $37^{\circ} \mathrm{C}$ inkubiert. Eppendorf-Gefäße wurden mit $1,5 \mathrm{ml}$ der Bakteriensuspension gefüllt, die Bakterien wurden durch Zentrifugation (4000Upm, 5min, $4^{\circ} \mathrm{C}$ ) geerntet und in $300 \mu 1$ eiskaltem PBS resuspendiert. 10 $\mu 1$ dieser Bakteriensuspension wurden dann entnommen mit $10 \mu \mathrm{l} 2 \mathrm{xLaemmli}$-Auftragspuffer versetzt und $5 \mathrm{~min}$ bei $95^{\circ} \mathrm{C}$ erhitzt. Nach kurzer Zentrifugation wurden die Proben auf einem Polyacrylamid-Gel aufgetrennt und durch Färbung mit „Coomasie“ sichtbar gemacht. Dabei sollte bei den Ansätzen, in denen die Expression des Proteins induziert wurde, eine prominente Bande erscheinen, die in den Kontrollansätzen nicht auftreten sollte.

\subsubsection{Produktion der Proteine in präparativen Mengen}

Für die Präparation von GST und GST-Fusionsproteinen wurde aus einer frisch ausgestrichenen LB-Ampicillin-Platte eine einzelne Kolonie in 50ml dYT-G-Medium mit Ampicillin $(100 \mu \mathrm{g} / \mathrm{ml})$ suspendiert und ÜN unter Schüteln $(250 \mathrm{Upm})$ bei $37^{\circ} \mathrm{C}$ inkubiert. Am darauffolgenden Morgen wurde die Kultur in 200ml dYT-G-Medium mit Ampicillin $(100 \mu \mathrm{g} / \mathrm{ml})$ 1:10 verdünnt und für ca. eine weitere Stunde, bis zu einer $\mathrm{OD}_{600}$ von 0,6-0,8, unter Schütteln $(250 \mathrm{Upm})$ bei $37^{\circ} \mathrm{C}$ inkubiert. Die Protein-Expression wurde durch die Zugabe von IPTG-Lösung mit einer EK von 1mM induziert und die Kulturen wurden für drei weitere Stunden inkubiert. Die Bakterien wurden dann durch Zentrifugation (4000Upm, $10 \mathrm{~min}, 4^{\circ} \mathrm{C}$ ) geerntet und in $10 \mathrm{ml}$ eiskaltem MTPBS-Puffer resuspendiert. Durch Sonifizieren (3x30sec, Branson Cell Disruptor) auf Eis wurden die Bakterien aufgeschlossen. Zelltrümer und unlysierte Bakterien wurden durch Zentrifugation (12000Upm, 15min, $4^{\circ} \mathrm{C}$ ) entfernt und der Überstand mit der zuvor equilibrierten Glutathion-Sepharose-Matrix inkubiert (s.u.).

Equilibrierung der Glutathion-Sepharose-Matrix und Kopplung von GST und GSTFusionsproteinen

Verwendet wurde Glutathion-Sepharose 4B nach den Angaben des Herstellers (Pharmacia). $133 \mu 1$ der ursprünglichen Matrix-Suspension wurden entnommen, durch Zentrifugation (2000Upm, 5min, $4^{\circ} \mathrm{C}$ ) pelletiert und der Überstand wurde verworfen. Die Matrix wurde mit 
$1 \mathrm{ml}$ MTPBS-Puffer bei $4^{\circ} \mathrm{C}$ für 30min unter langsamem Rotieren inkubiert, erneut zentrifugiert (2000Upm, $\left.5 \mathrm{~min}, 4^{\circ} \mathrm{C}\right)$ und in $100 \mu 1$ MTPBS-Puffer resuspendiert.

Protein extrakte aus Bakterien (s. o) wurden mit der equilibrierten Matrix für $30 \mathrm{~min}$ bei $4^{\circ} \mathrm{C}$ rotiert. Während dieser Inkubationszeit bindet GST bzw. das GST-Fusionsprotein an das, an die Matrix gekoppelte, Glutathion. Die Matrix wurde anschließend durch Zentrifugation (2000Upm, 5min, $4^{\circ} \mathrm{C}$ ) pelletiert und dreimal mit 1ml MTPBS-Puffer gewaschen (15min Inkubation bei $4^{\circ} \mathrm{C}$, Zentrifugation-2000Upm, 5min, $4^{\circ} \mathrm{C}$, Verwerfen des Überstands). Nach

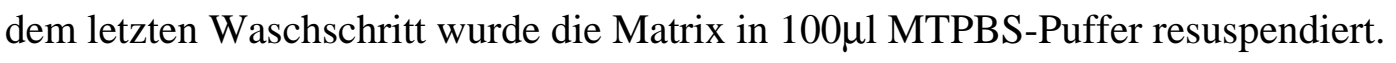

\subsubsection{In vitro Protein-Protein-Interaktionstest (GST-,,Pull-down“6)}

In diesem Test wurden die an die Matrix gekoppelten GST bzw. das GST-Fusionsprotein (s.o.) mit Proteinen inkubiert, die mit $[\alpha]^{35}$-S-Met markiert worden waren. Im Falle einer Interaktion zwischen dem immobilisierten und dem markierten Protein sollte nach einer Inkubation, mehrfachem Waschen der Matrix, SDS-PAGE, Trocknen des Gels und Autoradiographie eine Bande, die dem markierten Protein entspricht, erkennbar sein.

Dabei wurden $5 \mu 1$ der in Kaninchen-Retikulocyten-Lysaten translatierten, mit $[\alpha]^{35}$-S-Met markierten Proteine in $200 \mu l$ Bindungspuffer verdünnt, dem zusätzlich $3 \mu 1$ normales Kaninchenserum zugesetzt wurden. Dazu wurden 30 $\mu 1$ der mit GST oder GST-Fusion beladenen Glutathion-Sepharose-Matrix (s.o.) zugesetzt und ÜN bei $4^{\circ} \mathrm{C}$ unter langsamem Rotieren inkubiert. Anschließend wurde die Matrix bei RT viermal mit $1 \mathrm{ml}$ eiskaltem RIPAPuffer gewaschen (Zentrifugation 2000Upm, 5min, RT, Verwerfen des Überstands, 15min Inkubation). Nach dem letzten Waschschritt wurde die Matrix in 10 $\mu 1$ 2xLaemmliAuftragspuffer resuspendiert, $5 \mathrm{~min}$ bei $95^{\circ} \mathrm{C}$ erhitzt und zentrifugiert. Der Überstand wurde in einem SDS-Polyacrylamid Gel analysiert. Um die Menge und Reinheit der an der Matrix immobilisierten Proteine (GST bzw GST-Fusion) zu testen, wurde das Gel mit Coomasie gefärbt, während die Bindung der $[\alpha]^{35}$-S-Met-markierten Proteine an GST oder GST-Fusion durch Trocknen des Gels und anschließende Autoradiographie nachgewiesen wurde.

$\begin{array}{ll}\text { Bindungspuffer } & \underline{\text { RIPA - Puffer }} \\ \text { 20mM HEPES/KOH pH7,9 } & 10 \mathrm{mM} \mathrm{Tris/HCl} \mathrm{pH7,5} \\ 50 \mathrm{mM} \mathrm{KCl} & 150 \mathrm{mM} \mathrm{NaCl} \\ 2,5 \mathrm{mM} \mathrm{MgCl} 2 & 1 \mathrm{mM} \mathrm{EDTA} \mathrm{pH8,0} \\ 10 \%(\mathrm{v} / \mathrm{v}) \text { Glycerin } & 0,2 \%(\mathrm{v} / \mathrm{v}) \mathrm{NP}-40 \\ 1 \mathrm{mM} \mathrm{DTT} & \end{array}$




\subsubsection{Herstellung eines polyklonalen anti-Mapl-1 Serums}

Konstruktion einer Fusion mit einer Hexahistidin-Sequenz

Die Region des Mapl-1 Proteins zwischen den Aminosäuren 1528-1634 wurde aufgrund seines hydrophilen Charakters als Epitop ausgewählt für die Herstellung von polyklonalen Antikörpern. Dazu wurde die entsprechende cDNA-Sequenz miitels PCR amplifiziert und in den Vektor pRSETB (Invitrogen) alsl BamHI/HindIII-Fragment kloniert. Somit entsteht eine Fusion von 6 Histidinresten am Aminoterminus des Peptids. Die Richtigkeit des Leserahmens wurde durch Sequenzierung bestätigt.

Produktion des Peptids in Bakterien

Das hergestellte Fusionsprotein wurde in den E. coli-Stamm BL21 (DE3) pLysS transformiert, der die induzierbare Produktion des Fusionsproteins von einem T7-Promotor ermöglicht. Für eine analytische Präparation des Fusionsproteins in Bakterien, um die Effizienz der Produktion zu testen, wurden Transformanten in $3 \mathrm{ml} \mathrm{dYT} \mathrm{mit} \mathrm{zugesetztem}$ Ampicillin $(50 \mu \mathrm{g} / \mathrm{ml})$ und Chloramphenicol $(35 \mu \mathrm{g} / \mathrm{ml})$ wurden bei $37^{\circ} \mathrm{C}$ bis zu einer $\mathrm{OD}_{600}$ von 0,4-0,6 kultiviert. Die Induktion der Proteinproduktion erfolgte durch die Zugabe von IPTG-Lösung mit einer EK von 1mM. Die Kulturen wurden für zwei weiteren Stunden bei $37^{\circ} \mathrm{C}$ unter Schütteln inkubiert. Anschließend wurden die Bakterien durch Zentrifugation geerntet (13000rpm, 1min), der Überstand wurde verworfen und das Pellet in 300 $\mu$ l eiskaltem PBS resuspendiert. 10 $\mu \mathrm{l}$ der Bakteriensuspension wurde mit 10 $\mu 1$ 2Xlaemmli-Auftragspuffer versetzt und einer SDS-PAGE unterworfen. Durch des Färbung des Gels mit „Coomasie“ konnte das produzierte Peptid sichtbar gemacht werden. Um eine für die Immunisierung von Kaninchen genügende Menge des Peptids zu erhalten wurde eine analytische Präparation durchgeführt. Dazu wurde eine Übernachtkultur zu einer $\mathrm{OD}_{600}$ von 0,2 in $200 \mathrm{ml} \mathrm{dYT}$ verdünnt und bis zu einer $\mathrm{OD}_{600}$ von 0,8 wachsen gelassen. Anschließend erfolgte die Induktion der Proteinproduktion mit 1mM IPTG. Es wurde für drei weiteren Stunden kultiviert.

Aufreinigung des Peptids

Die Anwesenheit der Hexahistidin-Sequenz ermöglicht die Aufreinigung des Peptids über Affinitätschromatographie an immobilisierten Metallionen (IMAC). Für die Aufreinigung des Peptids (1528-1634) wurde eine mit Ni ${ }^{2+}$-Ionen beladene Säule eingesetzt (ProBond ${ }^{\mathrm{TM}}$-Resin, Invitrogen). Die Aufreinigung erfolgte bei denaturierenden Bedingungen. Die Bakterien wurden durch Zentrifugation (4000rpm, 10min) geerntet, in 10ml Guanidinium-Lysispuffer 
resuspendiert, in ein 15ml Falcon-Gefäß überführt und unter langsamen Schütteln für 10min bei RT inkubiert. Durch Sonifizieren (2x5sec und 1x10sec, Branson Cell Disruptor) auf Eis wurden die Bakterien aufgeschlossen. Zelltrümer sowie unlysierte Bakterien wurden durch Zentrifugation (4000rpm, $15 \mathrm{~min}, 4^{\circ} \mathrm{C}$ ) entfernt und der Überstand auf eine präparierte Säule bei $4{ }^{\circ} \mathrm{C}$ aufgetragen. (Eine Kunststoffsäule wurde mit $1 \mathrm{ml}$ der Matrix (ProBond ${ }^{\mathrm{TM}}-$ Resin, Invitrogen) gefüllt, mit $5 \mathrm{ml}$ Wasser gewaschen und mit $5 \mathrm{ml}$ Bindungspuffer äquilibriert). Die gesamte Prozedur erfolgte bei $4^{\circ} \mathrm{C}$. Nach dem Durchlauf wurde die Matrix 2x mit $5 \mathrm{ml}$ Bindungspuffer gewaschen, anschließend mit 5ml Waschpuffer A und 5ml Waschpuffer B. Die Elution erfolgte durch die Zugabe von $5 \mathrm{ml}$ Elutionspuffer in $1 \mathrm{ml}$ Schritten wobei das Eluat jeweils gesammelt wurde. $15 \mu \mathrm{l}$ von jeder Fraktion wurden mit $15 \mu 12 x$ LaemmliAuftragspuffer versetzt und mittels analytischer SDS-PAGE und Färbung mit „Coomasie“ wurde untersucht in welcher Fraktion das aufgereinigte Protein enthalten ist. Die restliche Proteinmenge aus der entsprechenden Fraktion wurde einer SDS-PAGE unterzogen, das Gel wurde mit „Coomasie“ gefärbt und die Proteinbande aus dem Gel ausgeschnitten und in drei vergleichbaren Stücken aufgeteilt. Die Polyacrylamid-Stücken wurden zur Immunisierung von Kaninchen eingesetzt.

$\begin{array}{ll}\text { Guanidinium Lysispuffer } & \text { Bindungspuffer } \\ 6 \mathrm{M} \text { Guanidiniumhydrochlorid } & 8 \mathrm{M} \mathrm{Harnstoff} \\ 20 \mathrm{mM} \mathrm{Na} \text {-Phosphatpuffer } \mathrm{pH} 7,8 & 20 \mathrm{mM} \mathrm{Na} \text {-Phosphatpuffer } \mathrm{pH} 7,8 \\ 500 \mathrm{mM} \mathrm{NaCl} & 500 \mathrm{mM} \mathrm{NaCl}\end{array}$

Waschpuffer A

20mM Na-Phosphatpuffer pH6,0 $500 \mathrm{mM} \mathrm{NaCl}$
Waschpuffer B

20mM Na-Phosphatpuffer pH5,3 $500 \mathrm{mM} \mathrm{NaCl}$
Elutionspuffer

20mM Na-Phosphatpuffer $\mathrm{pH} 4,0$

$500 \mathrm{mM} \mathrm{NaCl}$

$8 \mathrm{M}$ Harnstoff

Die Immunisierung von Kaninchen und die Blutabnahme wurde von der Firma EUROGENTEC (Herstal, Belgien) durchgeführt.

\subsubsection{Affinitätsreinigung des polyklonalen Antiserums}

Um die Mapl-1 spezifischen Antikörper zu konzentrieren und aufzureinigen wurde das Serum aus der letzten Immunisierung einer Affinitätsreinigung unterzogen. Als Substrat wurde die Proteinregion (1528-1634) verwendet. Um eventuell gegen die Hexahistidin-Sequenz produzierte Antikörper zu entfernen wurde das Peptid 1528-1634 in den Vektor pGEX4T-2 kloniert und als Fusion mit GST in Bakterien produziert. Die Produktion, und Aufreinigung

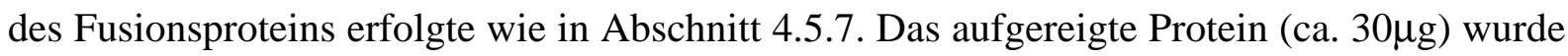


einer SDS-PAGE unterzogen und anschließend auf eine Kunststoffmembran (Immobilon P, Millipore) transferiert (s. Abschnitt 4.5.2). Nach dem Färben der Membran mit Ponceau-RotLösung wurde der Teil der Membran der die Proteinbande enthält ausgeschnitten und in Blockierungslösung für 30min bei RT geschwenkt. Das Membranstück wurde mit $5 \mathrm{ml}$ des Rohserums ÜN bei $4{ }^{\circ} \mathrm{C}$ unter leichtem Schütteln inkubiert. Am darauffolgenden Tag wurde die Membran 3x für 5min bei RT in TBS gewaschen. Die Elution der gebundenen Antikörper erfolgte durch die Zugabe von $300 \mu$ l eiskaltem und frisch eingesetztem Elutionspuffer auf die Membran und eine Inkubation von $5 \mathrm{~min}$ bei RT. Die Lösung wurde vorsichtig von der Membran entfernt und mit $300 \mu \mathrm{l}$ eiskaltem $1 \mathrm{M}$ Tris/ $\mathrm{HCl}$ pH8,0 in ein Eppendorf-Gefäß gemischt. Der Elutionsschritt wurde einmal wiederholt. Die antikörperhaltige Lösung wurde aliquotiert und bei $-20^{\circ} \mathrm{C}$ gelagert.

$\begin{array}{ll}\text { Blockierungslösung } & \text { Elutionspuffer } \\ \text { 5\% (w/v) Magermilchpulver } & 0,2 \mathrm{M} \mathrm{Glycin} / \mathrm{HCl} \mathrm{pH} 2,5 \\ \text { in TBS } & \end{array}$

\subsubsection{Mikrotubuli-Kosedimentationsassay}

Das Experiment wurde mit dem „Microtubule Associated protein (MAP) Spin-Down Assay

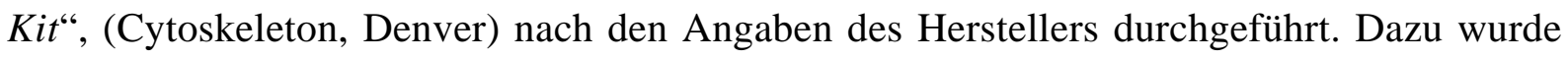
Tubulin in Anwesenheit von Taxol nach den Angaben des Herstellers in vitro zu Mikrotubuli polymerisiert. Mapl-1 als Fusion mit einem Aminoterminalen Myc-Epitop wurde vom Vektor pCS2+MT in vitro produziert und in einer $25 \mu 1$ Reaktion mit ${ }^{35} \mathrm{~S}$-Met markiert (s. 4.5.6). Um Proteinpräzipitate zu entfernen wurde das hergestellte Protein zentrifugiert (100000g, 30min, $4^{\circ} \mathrm{C}$, Beckman Ultrazentrifuge). Jeweils $10 \mu \mathrm{l}$ des Überstands wurden mit bzw. ohne Mikrotubuli mit einer EK von 2nM in Bindungspuffer für 20min bei RT inkubiert. Nach Zentrifugation $(100000 \mathrm{~g}, 40 \mathrm{~min}, \mathrm{RT})$ wurde der Überstand entfernt und die Pellet-Fraktion nach den Angaben des Herstellers gewaschen und mittels SDS-PAGE analysiert.

\subsubsection{Elektrophoretisches Gelretardationsexperiment (,,Band shift $\left.{ }^{\circ}\right)$}

Durch dieses Experiment wird die Bindung von Proteinen an doppelsträngige Oligonukleotide über eine Veränderung der elektrophoretischen Mobilität der Oligonukleotide in einem nativen Polyacrylamidgel nachgewiesen.

Herstellung des Proteins 
Das verwendete Protein (Pax-6) wurde mittels in vitro Translation vom Plasmid pSP64Pax-6 in Abwesenheit von radioaktivem Met hergestellt (s. 4.5.6).

Annealing und Markierung der Oligonukleotide mit $[\gamma]^{32} \mathrm{P}-\mathrm{dATP}$

Zur Bildung des doppelsträngigen Oligonukleotids wurden jeweils 5pmol des „Sense“ und „Antisense“ Oligolukleotids in 50 $\mu$ l Annealingpuffer in kochendes Wasser zugegeben und langsam abkühlen lassen.

\author{
$\underline{\text { Annealingpuffer }}$ \\ $10 \mathrm{mM}$ Tris/HCl \\ $50 \mathrm{mM} \mathrm{NaCl}$ \\ $0,1 \mathrm{mM}$ EDTA
}

Das doppelsträngige Oligonukleotid wurde wie folgt mit Polynukleotidkinase (PNK) mit $[\gamma]^{32} \mathrm{P}-\mathrm{dATP}$ endmarkiert:

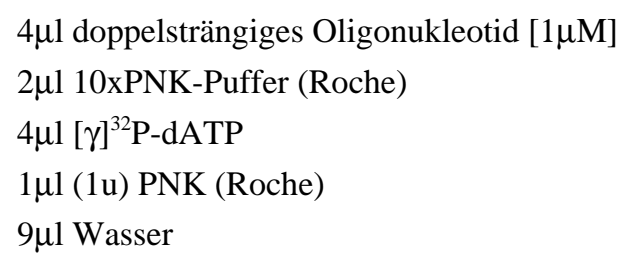

Die Reaktion wurde bei $37^{\circ} \mathrm{C}$ für $3 \mathrm{~h}$ inkubiert.

Bindungsreaktion

Die Bindung des Proteins an das markierte Oligonukleotid erfolgte in einem Volumen von $20 \mu \mathrm{l}$ im Bindungspuffer dem zusätzlich $1 \mu \mathrm{g}$ Poly dI-dC (Roche), $1 \mu \mathrm{g}$ Lachssperma DNA, als unspezifische Kompetitor-DNA. Es wurden 0,4pmol des markierten Oligonukleotids und $1 \mu 1$ des hergestellten Proteins eingesetzt. Zur Bindung wurden die Ansätze auf Eis für 15min inkubiert. Anschließend wurden die Bindungsreaktionen auf ein 6\%iges Polyacrylamidgel ohne mit Auftragpuffer versetzt zu werden aufgetragen.

\author{
Bindungspuffer \\ 25mM Hepes/KOH, pH7,9 \\ $100 \mathrm{mM} \mathrm{KCl}$ \\ $12,5 \mathrm{mM} \mathrm{MgCl}{ }_{2}$ \\ $20 \%$ (v/v) Glycerol \\ $0,1 \%(\mathrm{v} / \mathrm{v}) \mathrm{NP}-40$ \\ $1 \mathrm{mM}$ DTT \\ 6\% natives Polyacrylamidgel \\ $15 \mathrm{ml}$ Acrylamid-Lösung \\ 1,875ml 10xTBE \\ in $75 \mathrm{ml}$ Wasser
}


Die Polymerisierung des Gels wurde durch die Zugabe von 187,5 $\mu 1$ 20\%APS-Lösung und $120 \mu 1$ TEMED begonnen. Als Laufpuffer diente 0,5xTBE. Elektrophoresiert wurde bei 150V für ca. 3 h.

Trocknen und Exponierung des Gels

Nach Ablauf der Elektrophorese wurde das Gel mit einem Whatmanpapier abgezogen und getrocknet. Die Exponierung eines Röntgenfilms erfolgte ÜN.

\subsection{Zellbiologische und embryologische Methoden}

\subsubsection{Kultivierung von Säugerzellen}

Die in dieser Arbeit verwendeten Zellinien wurden bei $37^{\circ} \mathrm{C} / 5 \% \mathrm{CO}_{2}$ im Brutschrank kultiviert. Alle 3-4 Tage wurden die Zellen passagiert. Dazu wurde das Medium entfernt und die Zellen mit 10ml PBS (10cm-Schale) gewaschen. Durch die Zugabe von $3 \mathrm{ml}(10 \mathrm{~cm}-$ Schale) einer Trypsin/EDTA-Lösung (GIBCO, BRL) und ca. 3-minütige Inkubation bei $37^{\circ} \mathrm{C}$ wurden die Zellen vom Untergrund abgelöst. Zu den Zellen wurden 7ml Medium zugegeben, die Zellsuspension wurde in ein Falcon-Gefäß überführt und die Zellen durch Zentrifugation (1000rpm, 5min) pelletiert. Die Zellen wurden anschließend in Medium aufgenommen und mit einer geeigneten Dichte wieder ausgesät.

\subsubsection{Lagerung von Säugerzellen}

Zur dauerhaften Lagerung von Säugerzellen wurden die Zellen nach Ablösung vom Untergrund und Zentrifugation (s. 4.6.1) in Medium resuspendiert. Die Zellsuspension ca. $4 \times 10^{6}$ Zellen/ml wurden 1:1 in 2x Einfriermedium verdünnt und in 1ml Kryoröhrchen abgefüllt. Nach ÜN Inkubation bei $-80^{\circ} \mathrm{C}$ wurden die Zellen in flüssigen Stickstoff gelagert.

2XEinfriermedium (12ml)
2ml DMSO
2ml FCS
$8 \mathrm{ml}$ Medium

\subsubsection{Transfektion von Säugerzellen}

Zellen wurden in einer Dichte von $2 \times 10^{5}$ in $2 \mathrm{ml}$ Medium in $35 \mathrm{~mm}$ Schalen ausgesät. Am darauffolgenden Tag erfolgte die Transfektion der Zellen. Dazu wurde das LipofectaminReagenz (GIBCO, BRL) verwendet. 10 $\mu 1$ Lipofectamin wurden in $100 \mu 1$ serumfreies Medium 
verdünnt, ebenfalls in $100 \mu \mathrm{l}$ wurden $1-2 \mu \mathrm{g}$ Plasmid-DNA verdünnt. Die DNA und das Transfektionsreagenz wurden miteinander vermischt und zur Bildung von Komplexen 30min bei RT inkubiert. Zellen wurden einmal mit PBS und einmal mit serumfreiem Medium gewaschen. Zu den DNA-Lipofectamin-Komplexen wurden 0,8ml serumfreies Medium gegeben und der Ansatz auf die Zellen aufgetropft. 5-6 Stunden nach der Transfektion wurde das Medium mit serumhaltigen Medium ersetzt.

\subsubsection{Immunfärbung von Säugerzellen}

Für Immunfluoreszenz-Applikationen wurden die Zellen in $35 \mathrm{~mm}$ Schalen auf sterilen Deckgläschen (Durchmesser, 13mm) kultiviert. Um eine effiziente Haftung der Zellen zu ermöglichen wurden die Deckgläschen zuvor für mindestens 2h mit Poly-L-Lysin Lösung mit einer EK von 0,1mg/ml behandelt. Anschließend wurde die Lösung entfernt, zweimal mit Wasser gewaschen und kurz luftgetrocknet. Die Transfektion der Zellen erfolgte wie in 4.6.3 beschrieben. 36-48h nach der Transfektion wurden die Zellen einmal mit PBS gewaschen und mit 4\% PFA/PBS für 10min bei RT fixiert. Anschließend wurden die Zellen 3x für 5min mit 0,05\% Tween-20 in PBS (PBST) gewaschen. Die Zellen wurden durch eine Inkubation mit 0,1\% Triton X-100 in PBS für 10min permeabilisiert. Die Deckgläschen mit den kultivierten Zellen wurden aus den Schalen entnommen und in einer feuchten Plastikschale auf Parafilm aufgelegt. Es folgte eine Inkubation mit Blockierungslösung für 30min-1h und anschließend die Inkubation mit den Primärantikörpern in der jeweils angegebenen Verdünnung in Blockierungslösung (s. 4.3.9) ÜN bei $4^{\circ} \mathrm{C}$. Am darauffolgenden Tag wurden die Zellen 3x für 5min mit PBST gewaschen und es folgte die Zugabe der Sekundärantikörpern. Nach einer 30minütiger Inkubation bei RT wurden die Deckgläschen wie zuvor 3x für 5min mit PBST gewaschen und in Mowiol eingebettet.

Bei der Verwendung des Mapl-1 polyklonalen Antiserums wurden die Zellen für 5min bei $20^{\circ} \mathrm{C}$ in $\mathrm{MeOH}$ fixiert. Es folgte anschließend die Inkubation mit der Blockierungslösung und die Zugabe des Primärantikörpers. Die Detektion des Mapl-1-Proteins in transfizierten Zellen erfolgte wie oben beschrieben. Für die Detektion des endogenen Mapl-1 wurde nach der Inkubation mit dem Primärantikörper zur Verstärkung des Signals ein Amplifizierungssystem verwendet. Dazu wurde ein biotinilierter anti-Kaninchen-Antikörper (Vektor) in Blockierungslösung zugegeben und für 30min Inkubiert. Es folgte die Zugabe von AvidinPeroxidase (Vectastain ABC-Kit, nach Angaben des Herstellers) und eine Inkubation für 
20min. Schließlich wurde das Substrat Tyramid gegeben, das durch die Aktivität der Peroxidase zu einem Fluoreszenz-emittierenden Produkt umgesetzt wird (TSA ${ }^{T M}$ Fluorescence Systems, NEN, nach Angaben des Herstellers). Zwischen den oben aufgeführten Inkubationen wurde jeweils für 5min bei RT mit PBST gewaschen. Eingebettet wurde in Mowiol.

Zur Färbung der Zellkerne wurde DAPI mit einer EK von $0,5 \mu \mathrm{g} / \mathrm{ml}$ in PBST mit dem ersten Waschschritt zugegeben.

Blockierungslösung
$5 \%(\mathrm{v} / \mathrm{v})$ Normales Ziegenserum
in PBST

Fluoreszenzaufnahmen wurden mit einem Olympus BX-60 Fluoreszenzmikroskop/digitalen Kamerasystem (Colorview 12) dokumentiert und mit dem Programm AnalySIS bearbeitet.

\subsubsection{Quantitative Messung von Enzymaktivitäten in transfizierten Zellen}

COS7-Zellen wurden mit 0,5 $\mathrm{gg}$ des Plasmids pGAL4(5X)-Luc und steigender Menge des Plasmids pSG424 bzw. pSG424(1528-1634) transfiziert. Eine konstante Menge von 0,2 $\mu \mathrm{g}$ des Plasmids pCMV-LacZ wurden bei allen Ansätzen transfiziert und diente als interne Kontrolle zur Berechnung der Transfektionseffizienz. Bei allen Ansätzen wurde die Gesamtmenge an transfizierte DNA mit pBSKSII ${ }^{+}$auf $2 \mu \mathrm{g}$ konstant gehalten. Die Transfektion erfolgte mit Lipofectamin wie in 4.6 .3 beschrieben.

48h nach der Transfektion wurden die Zellen einmal mit PBS gewaschen und mit $100 \mu \mathrm{l}$ Lysispuffer (Galacto-Light Plus ${ }^{T M}$, Tropix) versetzt. Inkubiert wurde auf Eis für 20min. Die Zellen wurden aus der Platte abgelöst und in Eppendorf-Gefäße überführt. Zur vollständigen Lyse der Zellen wurde 4-5mal mit der Pipette auf und ab pipettiert. Zelltrümer wurden durch Zentrifugation (5min, 3000rpm, $4^{\circ} \mathrm{C}$ ) entfernt und der Überstand aufbewahrt.

$20 \mu 1$ des Überstands wurden für die Bestimmung der Luciferase-Aktivität mit dem „Luciferase Assay System“ nach den Angaben des Herstellers (Promega) eingesetzt. Die quantitative Messung der $\beta$-Galaktosidase Aktivität erfolgte mit dem „,Galacto-Light Plus $^{T M ،-S y s t e m}$ nach den Angaben des Herstellers (Tropix). Dazu wurden $10 \mu \mathrm{d}$ des Zellextrakts eingesetzt. 


\subsubsection{Erzeugung transgener Mäuse (Hogan et al., 1986)}

Drei Wochen alte FVB-Weibchen wurden superovuliert durch intraperitoneale Injektion von 4u Gonadotropin (PMS) (Sigma) gefolgt von 4u humanes chorionisches Gonadotropin (HCG) nach 48h. Fertilisiert wurde durch Verpaarung mit FVB-Männchen. Am folgenden Tag wurden Einzell-Embryonen entnommen und mit Hyaluronidase $(300 \mathrm{mg} / \mathrm{ml})$ von CumulusZellen befreit. Der männliche Vorkern wurde mit ca. 2pl DNA/0,1xTE (2ng/ml) mikroinjiziert. Injizierte Oocyten wurden in scheinschwangere NMRI-Rezipientenmäuse retransferiert. Die Rezipientenmäuse wurden durch intraperitoneale Injektion von 3u PMS und nach $48 \mathrm{~h}$ von $2 \mathrm{u}$ HCG synchronisiert und mit vasektomierten NMRI-Männchen verpaart. Der Tag des Retransfers wurde als E0,5 definiert.

Die Identifizierung von transgenen Mäusen erfolgte durch Schwanzbiopsie und SouthernBlot-Analyse (s. 4.4.18). Mapl-1 ${ }^{\mathrm{gfp}+}-$ Embryonen konnten mit dem Leica MZ-FLIIIFluoreszenzbinokular identifiziert und mit dem Kappa-PS30C Digitalkamerasystem dokumentiert werden.

\subsubsection{In vivo-Elektroporation von Mausembryonen}

NMRI-Weibchen wurden durch zervikale Dislokation getötet und die Embryonen am Tag E8,0-8,5 in M2-Medium (Sigma), dem FCS mit einer EK von 10\% zugesetzt wurde aus den Uteri isoliert unter Beibehaltung der extraembryonalen Membranen und der Ektoplacenta. Die Embryonen wurden in einer Plastikschale zwischen zwei Platin-Elektroden und in einem Tropfen PBS mit konzentrierter DNA-Lösung ( $5 \mu \mathrm{g} / \mu \mathrm{l}$ in PBS) mit Hilfe einer Glaskapillare injiziert (Eppendorf Microinjector 5242). Injiziert wurde an verschiedenen Stelen des Embryos. Die Elektroporation erfolgte unter den folgenden Bedingungen: 3 Pulse, 34Volt, 50msec Pulslänge, (BTX, Electro square porator T820). Die elektroporierten Embryonen wurden in FCS mit $10 \mathrm{mM}$ Glukose bei $37^{\circ} \mathrm{C} / 5 \% \mathrm{CO}_{2}$ für $4 \mathrm{~h}$ kultiviert. Anschließend wurden die Embryonen in PBS aus den extraembryonalen Membranen befreit, für 40min in $4 \% \mathrm{PFA} / \mathrm{PBS}$ bei $4^{\circ} \mathrm{C}$ fixiert und zur Herstellung von Gefrierschnitten bearbeitet.

\subsubsection{Anfertigung von Gefrierschnitten und Immunfärbung}

Elektroporierte Embryonen wurden nach PFA-Fixierung 3x für jeweils 10 min in eiskaltem PBS gewaschen, in eiskalten $30 \%$ Sukrose/PBS überführt und ÜN bei $4^{\circ} \mathrm{C}$ inkubiert. Die 
Embryonen wurden in Kryomatrix (Shandon) überführt und positioniert. Die Blöcke wurden auf Trockeneis abgekühlt bis die Kryomatrix fest wurde. Gelagert wurden die Blöcke bei $20^{\circ} \mathrm{C}$.

Gefrierschnitte wurden mit Hilfe eines Kryostats (Leica) mit einer Dicke von $10 \mu \mathrm{m}$ angefertigt, auf Superfrost-Objektträgern (Menzel) gesammelt und bei RT für 1h getrocknet. Die angefertigten Schnitte wurden nach zweimaligem Waschen mit PBST direkt für die Immunfärbung eingesetzt wie in (4.6.4) beschrieben.

\subsection{9 mRNA in situ-Hybridisierung}

\subsubsection{In situ-Hybridisierung von Ganzpräparaten (,,whole-mount $\left.{ }^{6 *}\right)$}

Das Protokoll wurde nach den Vorgaben in (Wilkinson, 1992), durchgeführt.

Herstellung der RNA-Sonde

Präparation der Matrizen-DNA

Als DNA-Matrizen für die Herstellung von RNA-Sonden wurden Plasmide verwendet in denen cDNA Sequenzen flankiert von Bakteriophagen Promotoren (T3, T7 oder SP6) kloniert waren. Die Plasmide wurden jeweils stromabwärts des klonierten Inserts linearisiert und mit der entsprechenden RNA-Polymerase für die in vitro Transkription des klonierten Fragments inkubiert. Somit ist die Herstellung von zwei Sonden für eine bestimmte DNA-Matrize möglich. Je nachdem an welcher Stelle das Plasmid linearisiert wird und in welcher Orientierung die DNA-Matrize transkribiert wird, kann einerseits der „antisense”- und andererseits der ,sense”-RNA-Strang produziert werden. Der ,antisense”-Strang ist in der Lage mit den endogenen Transkripten zu hybridisieren, während der „sense”-Strang nicht hybridisierien sollte und als Kontrolle zur Einschätzung des unspezifischen Hintergrundes verwendet wurde.

\section{Linearisierung der DNA-Matrize}

$25 \mu \mathrm{g}$ Plasmid-DNA wurden mit ca. 60u eines geeigneten Restriktionsenzyms in einem Gesamtvolumen von $200 \mu$ l verdaut. Das Plasmid sollte komplett linearisiert werden. Aus diesem Grund erfolgte die Inkubation mit dem Enzym 4h bis ÜN. Ein Aliquot wurde auf kompletten Verdau hin überprüft; war das nicht der Fall wurde frisches Enzym und Puffer zugesetzt und das Volumen wurde auf $250 \mu$ l erhöht. Nach vollständiger Linearisierung

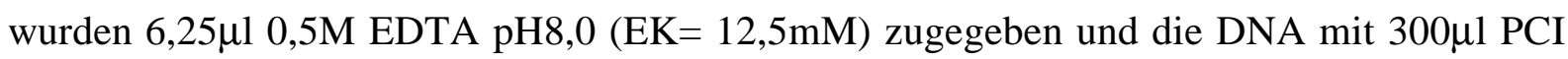
und $300 \mu \mathrm{l}$ CI extrahiert. Die DNA wurde aus der wässrigen Phase mit Natriumacetat $(\mathrm{EK}=$ 
0,3M) und 96\% (v/v) EtOH gefällt, durch Zentrifugation präzipitiert, mit $70 \%$ (v/v) EtOH gewaschen, luftgetrocknet und in $20 \mu \mathrm{l}$ Wasser resuspendiert. Für die in vitro Transkription wurde $1 \mu \mathrm{l}$ der somit präparierten Matrizen-DNA (entspricht ca. $1 \mu \mathrm{g}$ ) eingesetzt.

In vitro Transkription

Zur Herstellung von Digoxigenin markierten RNA-Sonden wurde der folgende Transkriptionsansatz auf Eis zusammenpipetiert und für $2 \mathrm{~h}$ bei $37^{\circ} \mathrm{C}$ inkubiert.

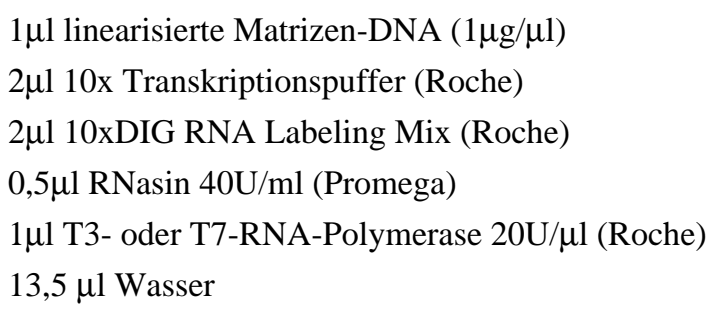

Verdau der DNA-Matrize und Aufreinigung der RNA-Sonden

Nach der in vitro Transkription wurde die DNA-Matrize mit $2 \mu 1$ RNase freier DNase $(20 \mathrm{u} / \mu \mathrm{l})$ (Promega) verdaut, für $15 \mathrm{~min}$ bei $37^{\circ} \mathrm{C}$. Anschließend wurde das Volumen mit Wasser auf $50 \mu 1$ erhöht und die synthetisierte Sonde über eine „ProbeQuant ${ }^{T M} G-50$ Microclumn“" (Pharmacia) nach den Angaben des Herstellers von nicht eingebauten Nukleotiden aufgereinigt. Die Synthese der RNA-Sonde wurde auf ein 1\%iges Agarosegel kontrolliert.

Präparation und Behandlung von Embryonen

NMRI Weibchen wurden ÜN verpaart und der Tag des Vaginalpropfes wurde als Tag 0,5 der Embryonalentwicklung angesehen. Embryonen wurden nach dem Töten der Weibchen durch zervikale Dislokation in kaltem PBS aus den Uteri präpariert und ÜN in $4 \%$ PFA/PBS-Lösung bei $4^{\circ} \mathrm{C}$ fixiert. Am nächsten Tag wurden die Embryonen gründlich (3x 10min) mit PBT bei $4^{\circ} \mathrm{C}$ gewaschen um die Fixierungslösung vollständig zu entfernen und wie folgt über eine aufsteigende $\mathrm{MeOH}$ Reihe dehydriert:

25\% MeOH/PBT, 50\% MeOH/PBT, 75\% MeOH/PBT, 3x100\% MeOH jeweils für 5min bei RT. Wenn nicht unmittelbar danach fortgefahren wurde wurden die Embryonen in 100\% $\mathrm{MeOH}$ bei $-20^{\circ} \mathrm{C}$ gelagert. Zuvor wurden bei E10,5 Embryonen mit einer Insektennadel Öffnungen in den Ventrikel des Telenzephalons und im vierten Ventrikel eingestochen. Dadurch wird verhindert, daß die RNA-Sonde oder die zu deren Nachweis verwendeten Antikörper in den Ventrikeln eingeschlossen bleiben. 
Die oben aufgeführte MeOH Reihe, jetzt in umgekehrter Reihenfolge, wurde im Anschluß zur Rehydrierung der Embryonen verwendet. Dabei wurden die gleichen Zeiten wie bei der Entwässerung eingehalten. Zum Schluß wurden die Embryonen 2x für 5min in PBT gewaschen.

Durch eine darauffolgende Behandlung mit 6\%igem $\mathrm{H}_{2} \mathrm{O}_{2}$ für 30min bei RT wurden die Embryonen gebleicht. Dabei erhöht sich die Transparenz des Gewebes, etwas das vorteilhaft ist bei die Dokumentation des Ergebnisses des Experiments. Außerdem werden durch $\mathrm{H}_{2} \mathrm{O}_{2}$ reaktive Gruppen zerstört die unspezifisch mit der RNA-Sonde hybridisieren könnten. Das $\mathrm{H}_{2} \mathrm{O}_{2}$ wurde im Anschluss 3x mit PBT für jeweils 10min bei RT ausgewaschen.

Um die Permeabilität des Gewebes für die RNA-Sonde zu erhöhen wurde mit Proteinase K-Lösung behandelt. Die Dauer der Behandlung hängte vom Alter der Embryonen ab. Sehr junge Embryonen, E8,5 wurden für 5min, ältere, E9,5-E10,5 für 10min behandelt. Der Proteinase K Verdau wurde durch eine Inkubation mit frisch angsetztem 0,2\% Glycin/PBT gestoppt. Dabei wurde kurz in PBT gewaschen und zweimal für 5min in der Glycin-Lösung inkubiert.

Glycin wurde durch dreimaliges Waschen in PBT für 5min entfernt. Da bei diesem Schritt das Gewebe nach der Proteinase K Behandlung sehr zerbrechlich ist, wurden die Embryonen für 20min in 4\%PFA/PBT, 0,2\% Glutaraldehyd refixiert. Gewaschen wurde im Anschluß 3x mit PBT für $5 \mathrm{~min}$.

\section{Prä-und Hybridisierung}

Zur Prähybridisierung wurden die Embryonen in auf $70^{\circ} \mathrm{C}$ vorgewärmte Prähybridisierungslösung überführt und für mindestens $1 \mathrm{~h} \mathrm{im} \mathrm{Wasserbad} \mathrm{bei} 70^{\circ} \mathrm{C}$ inkubiert. Zur Hybridisierung wurde die RNA-Sonde (s.o) bei $70^{\circ} \mathrm{C}$ für $10 \mathrm{~min}$ denaturiert in frische vorgewärmte Prähybridisierungslösung auf ca. $1 \mu \mathrm{g} / \mathrm{ml}$ verdünnt und mit den Embryonen bei $70^{\circ} \mathrm{C}$ ÜN inkubiert.

\section{Waschschritte}

Die unten aufgeführten Waschschritte dienten dem Ablösen von unspezifischen Hybriden mit der RNA-Sonde. Dabei wurden die Embryonen zuerst für 2x30min in Waschpuffer A bei $70^{\circ} \mathrm{C}$ inkubiert, und für $10 \mathrm{~min}$ bei $70^{\circ} \mathrm{C}$ in Waschpuffer $\mathrm{A} /$ Waschpuffer $\mathrm{B}(1: 1(\mathrm{v} / \mathrm{v}))$ gewaschen. Beide Lösungen wurden zuvor auf $70^{\circ} \mathrm{C}$ vorgewärmt. Nach zweimaligem Waschen in Waschpuffer B bei RT für 5min wurden die Embryonen bei $37^{\circ} \mathrm{C}$ für $30 \mathrm{~min}$ mit RnaseA $(100 \mu \mathrm{g} / \mathrm{ml})$ in Waschpuffer B inkubiert. Während dieses Waschschritts wird 
einzelsträngige RNA und dementsprechend nichthybridisierte RNA-Moleküle durch die Aktivität der RNaseA abgebaut. RNA-RNA-Hybride bleiben vor der Wirkung der Ribonuklease geschützt. RnaseA wurde durch Waschen in zuerst in Lösung B für $5 \mathrm{~min}$ bei $\mathrm{RT}$ und anschließend in Waschpuffer $\mathrm{C}$ für $30 \mathrm{~min}$ bei $65^{\circ} \mathrm{C}$ entfernt.

\section{Antikörper-Inkubation}

Die hybridisierte RNA-Sonde wurde mittels mit alkalischer Phosphatase gekoppelten anti-Digoxigenin Antikörpern sichtbar gemacht. Zuvor wurden unspezifische Bindungsstellen für die Antikörper abgeblockt. Dies erfolgte durch zweimaliges Waschen in MAB für 15min bei RT, Inkubation in 2\% BMB („Blocking Reagent“) von Roche in MAB für $1 \mathrm{~h}$ und schließlich in $2 \%$ BMB, 20\% FCS in MAB ebenfalls für 1 h. Die Inkubation mit den Antikörpern in einer Verdünnung von 1:2000 in 2\% BMB, 20\% FCS in MAB erfolgte ÜN bei $4^{\circ} \mathrm{C}$.

Auswaschen der nicht spezifisch gebundenen Antikörpern

$\mathrm{Zu}$ diesem Zweck wurden die Embryonen durch folgende Lösungen nacheinander überführt und bei RT unter leichtem Schütteln inkubiert.

$5 \mathrm{~min}$ in $\mathrm{MAB}$
$5 \mathrm{~min}$ in $\mathrm{MAB}$
$5 \mathrm{~min}$ in MAB
$1 \mathrm{~h}$ in MAB
$1 \mathrm{~h}$ in MAB
$1 \mathrm{~h}$ in MAB
$1 \mathrm{~h}$ in $\mathrm{MAB}$

Nach dem letzten Waschschritt wurden die Embryonen kurz mit NTMT gewaschen und ÜN in NTMT bei $4^{\circ} \mathrm{C}$ inkubiert. Während dieser Inkubation wird einerseites der $\mathrm{pH}-\mathrm{Wert}$ für die anschließende Färbereaktion eingestellt, andereseits werden durch die Wirkung von Levamisol endogene phosphatase Aktivitäten inhibiert.

Färben der Embryonen

Die Farbreaktion erfolgte durch Inkubation der Embryonen in NBT/BCIP Lösung (Roche) wobei durch die Aktivität der an die Antikörper gekoppelten alkalischen phospatase zur Bildung eines blauen Niederschlags kommt. Zuvor wurden die Embryonen dreimal für jeweils 10min in NTMT inkubiert und anschließend in die Färbelösung (NBT/BBCIP 1:50 verdünnt in NTMT) überführt. Die Färbereaktion erfolgte im Dunkeln und ihr Fortschreiten wurde nach regelmäßigen Zeitabständen kontrolliert. Sobald, sich die Expressionsdomänen des zu untersuchenden Gens im Embryo intensiv angefärbt wurden, wurde die Reaktion 
abgebrochen und die Embryonen in PBT überführt. Die Dauer der Färbereaktion war von der jeweils verwendeten Sonde abhängig und variierte zwischen 30min und 5h.

Fotographieren

Zur Fotographischen Dokumentation des Ergebnisses der in situ Hybridisierung wurden die Embryonen zuerst in 30\% Glycerin/PBT überführt für mehrere Stunden inkubiert und anschließend in 50\% Glycerin/PBT. Fotographiert wurde in $80 \%$ Glycerin/PBT mit einem SV11 Binokular von Zeiss.

\author{
$\underline{\text { PBT }}$ \\ in PBS \\ (Lösung wurde autoklaviert) \\ Prähybridisierungslösung \\ $50 \%(\mathrm{v} / \mathrm{v})$ deionisiertes Formamid \\ 5xSSC pH4,5 (aus 20x Stock) \\ $50 \mu \mathrm{g} / \mathrm{ml}$ Heparin (aus 50mg/ml Stock) \\ $1 \%(\mathrm{w} / \mathrm{v}) \mathrm{SDS}$ \\ $100 \mu \mathrm{g} / \mathrm{ml}$ Hefe tRNA (aus 10mg/mlStock) \\ $\underline{50 \mathrm{mg} / \mathrm{ml} \text { Heparin }}$ \\ in Wasser gelöst \\ (Lösung wurde in Aliquots \\ bei $-20^{\circ} \mathrm{C}$ gelagert)
}

Waschpuffer A

$50 \%(\mathrm{v} / \mathrm{v})$ Formamid

$5 \mathrm{xSSC} \mathrm{pH} 4,5$

$1 \%$ SDS

Waschpuffer C

$50 \%$ Formamid

2xSSC pH 4,5

$10 \%(\mathrm{w} / \mathrm{v})$,.Blocking Reagent“ (BMB)

BMB (Roche) mit EK von $10 \%(\mathrm{v} / \mathrm{v})$

in MAB gelöst. Zum vollständigen Lösen

wurde die Lösung autoklaviert. In Aliquots bei $-20^{\circ} \mathrm{C}$ gelagert.
Proteinase K-Lösung

aus Proteinase K Stock $(10 \mu \mathrm{g} / \mu \mathrm{l})$

mit EK von $10 \mu \mathrm{g} / \mathrm{ml}$ in PBT

$\underline{20 x S S C ~ p H ~ 4,5}$

$3 \mathrm{M} \mathrm{NaCl}$

$0,3 \mathrm{M} \mathrm{Na}_{3}$-Citrat

(pH wurde mit

Zitronensäure auf 4,5 eingestellt)

(Lösung wurde autoklaviert)

Hefe tRNA

Hefe tRNA (Roche)

mit EK von

$10 \mathrm{mg} / \mathrm{ml}$ in Wasser gelöst und

bei $-20^{\circ} \mathrm{C}$ gelagert

Waschpuffer B

$0,5 \mathrm{M} \mathrm{NaCl}$

10mM Tris/HCl, $\mathrm{pH} 7,5$

$0,1 \%(\mathrm{v} / \mathrm{v})$ Tween-20

$\underline{\mathrm{MAB}}$

100mM Maleinsäure

$150 \mathrm{mM} \mathrm{NaCl}$

$\mathrm{pH}$ wurde mit $\mathrm{NaOH}$

auf 7,0 eingestellt

Lösung wurde sterilfiltriert

NTMT

$100 \mathrm{mM} \mathrm{NaCl}$

100mM Tris/HCl, pH 9,5

$50 \mathrm{mM} \mathrm{MgCl}{ }_{2}$

$1 \%(\mathrm{v} / \mathrm{v})$ Tween-20

$2 \mathrm{mM}$ Levamisol (frisch zugesetzt) 


\subsubsection{In situ-Hybridisierung auf Paraffinschnitten (Hogan et al., 1986)}

Herstellung der RNA-Sonde

Die Präparation der Matrizen DNA für die in vitro-Transkription ist in Abscnitt 6.2.9.1 beschrieben.

$\underline{\text { In vitro Transkription }}$

Für die in situ-Hybridisierung auf Paraffinschnitten wurden RNA-Sonden hergestellt in denen $[\alpha]^{35}$ S-UTP eingebaut wurde. Der Reaktionsansatz wurde wie folgt auf Eis zusammenpipetiert und bei $37^{\circ} \mathrm{C}$ für $1 \mathrm{~h}$ inkubiert.

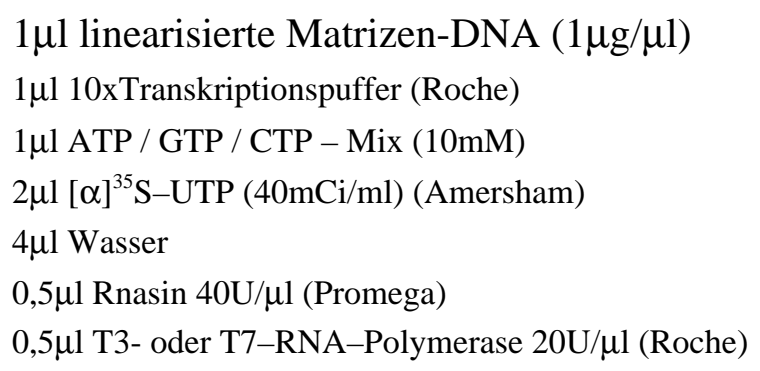

Verdau der DNA-Matrize und Aufreinigung der RNA - Sonden

Zum Verdau der DNA-Matrize nach Ablauf der Reaktion wurde zum Transkriptionsansatz $1 \mu 1$ Hefe-tRNA $(10 \mathrm{mg} / \mathrm{ml})$ und $3 \mu 1$ RNase freie DNase $(20 \mathrm{u} / \mu 1$, Promega) zugegeben und für 10 min bei $37^{\circ} \mathrm{C}$ inkubiert. Die Aufreinigung der Sonde erfolgte wie im Abschnitt 6.2.9.1 beschrieben über eine „ProbeQuant ${ }^{\mathrm{TM}} \mathrm{G}-50$ Microclumn“, (Pharmacia). Die aufgereinigte Sonde wurde zum Schluß in $100 \mu$ l Wasser verdünnt, dazu wurden $25 \mu 1$ deionisiertes

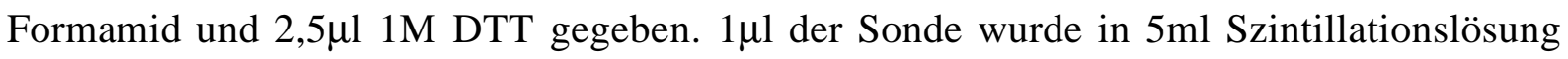
verdünnt und im Szintillationszähler (Beckman LS 1701) gemessen.

Präparation der Embryonen und Herstellung von Schnitten

Die Präparation der Embryonen erfolgte wie im Abschnitt 6.2.9.1 beschrieben. Sie wurden ÜN in 4\% PFA/PBS-Lösung fixiert. Am nächsten Tag wurden die Embryonen in einem Einbettautomat (Chandon) nach folgendem Programm dehydriert:

$\begin{array}{ll}\text { 1h } & \text { PBS } \\ \text { 1h } & 0,86 \% \mathrm{NaCl} \\ \text { 1h } & 70 \% \text { Ethanol } \\ \text { 1h } & 80 \% \text { Ethanol } \\ \text { 1h } & 90 \% \text { Ethanol } \\ \text { 1h } & 95 \% \text { Ethanol } \\ \text { 1h } & 100 \% \text { Ethanol } \\ \text { 2h } & 100 \% \text { Isopropanol } \\ 1 \mathrm{~h} & \text { Toluen }\end{array}$


Nach der Dehydrierung wurden die Embryonen in der gewünschten Orientierung in Paraffin (Paraplast Plus) eingebettet und bis zur Herstellung der Schnitte bei $4^{\circ} \mathrm{C}$ gelagert.

Zur Herstellung von Schnitten wurde der in Paraffin eingebettete Embryo in ein Mikrotom (Reichert-Jung, Biocut, 2035, Leica) eingespannt und geschnitten. Es wurden 8mm dicke Schnitte angefertigt die anschließend auf die Wasseroberfläche eines ca. $40^{\circ} \mathrm{C}$ warmen Wasserbads gelegt wurden und von dort auf einen Objektträger aufgenommen wurden. Bis zur Anfertigung aller Schnitten wurden die Schnitte-tragenden Objektträger auf eine $37^{\circ} \mathrm{C}$ Wärmeplatte gelegt. Die Schnitte wurden ÜN bei $37^{\circ} \mathrm{C}$ getrocknet, den darauffolgenden Tag bei RT und bis zur Verwendung bei $4^{\circ} \mathrm{C}$ gelagert.

Hybridisierung

Vor der Hybridisierung mußten die Objektträger mit den Parafinschnitten entparaffiniert und die Schnitte für die Hybridisierung vorbereitet werden. Dazu wurden die Schnitte auf den Objektträgern folgender Prozedur unterzogen:

$\begin{array}{ll}\text { Xylol } & 10 \mathrm{~min} \\ \text { Xylol } & 10 \mathrm{~min} \\ 100 \% \text { EtOH } & 2 \mathrm{~min} \\ 95 \% \text { EtOH } & 2 \mathrm{~min} \\ 90 \% \mathrm{EtOH} & 2 \mathrm{~min} \\ 80 \% \mathrm{EtOH} & 2 \mathrm{~min} \\ 70 \% \mathrm{EtOH} & 2 \mathrm{~min} \\ 50 \% \mathrm{EtOH} & 2 \mathrm{~min} \\ 30 \% \mathrm{EtOH} & 2 \mathrm{~min} \\ \text { Saline }(0,86 \% \mathrm{w} / \mathrm{v} \mathrm{NaCl}) & 5 \mathrm{~min} \\ \text { PFA/PBS } & 20 \mathrm{~min} \\ \text { PBS } & 2 \mathrm{~min} \\ \text { PBS } & 2 \mathrm{~min} \\ \text { Proteinase K-Mix } & 7 \mathrm{~min} \\ \text { PBS } & 5 \mathrm{~min} \\ \text { Acetylierungs-Mix } & 10 \mathrm{~min} \\ \text { PBS } & 5 \mathrm{~min} \\ \text { Saline }(0,86 \% \mathrm{w} / \mathrm{v} \mathrm{NaCl}) & 5 \mathrm{~min} \\ 30 \% \text { EtOH } & 2 \mathrm{~min} \\ 50 \% \text { EtOH } & 2 \mathrm{~min} \\ 70 \% \text { EtOH } & 2 \mathrm{~min} \\ 80 \% \text { EtOH } & 2 \mathrm{~min} \\ 90 \% \text { EtOH } & 2 \mathrm{~min} \\ 95 \% \text { EtOH } & 2 \mathrm{~min} \\ 100 \% \text { EtOH } & 2 \mathrm{~min}\end{array}$

Anschließend wurden die Schnitte für ca. 1h bei RT vor dem Auftragen der markierten RNASonde luftgetrocknet. 
Die RNA-Sonde wurde mit dem Hybridisierungspuffer auf $5 \times 104 \mathrm{cpm} / \mu 1$ verdünnt. Vor dem Auftragen wurde die verdünnte Sonde $2 \mathrm{~min}$ bei $80^{\circ} \mathrm{C}$ erhitzt. Auf jedem Schnitt wurden ca. $4 \mu 1$ der verdünnten Sonde aufgetragen und mit einem Deckgläschen $(15 \times 20 \mathrm{~mm})$ luftblasenfrei abgedeckt. Die Hybridisierung erfolgte ÜN bei $50^{\circ} \mathrm{C}$ in einem dicht abgeschlossen Plastikkasten, der durch zwei auf dem Boden des Kastens liegende Lagen Filterpapier feucht gehalten wurde. Das Filterpapier war zuvor mit einer Lösung aus 50\%(v/v) deionisiertem Formamid und 2xSSC getränkt worden.

$\begin{array}{ll}\text { 10xHybrisierungssalz } & \underline{\text { Hybridiserungspuffer }} \\ 0,2 \% \text { (w/v) PVP } & 1 \text { 1xHybridisierungssalz } \\ 0,2 \% \text { (w/v) Ficoll } & 50 \%(\mathrm{v} / \mathrm{v}) \text { Formamid } \\ 0,1 \mathrm{M} \mathrm{Tris} / \mathrm{HCl}, \mathrm{pH} 8,0 & 0,1 \mathrm{M} \text { DTT } \\ 50 \mathrm{mM} \mathrm{EDTA}, \mathrm{pH} 8,0 & 10 \% \text { Dextransulfat } \\ 0,1 \mathrm{M} \mathrm{Natrium}-\mathrm{Phosphatpuffer,} \mathrm{pH} 6,8 & \\ 3 \mathrm{M} \mathrm{NaCl} & \end{array}$

\section{Waschen}

Die Objektträger wurden in einem Halter einsortiert und zunächst in einer Lösung aus 5xSSC, $50 \%(\mathrm{v} / \mathrm{v})$ deionisiertem Formamid, 0,14\% (v/v) $\beta$-Mercaptoethanol bei $50^{\circ} \mathrm{C}$ für $20 \mathrm{~min}$ und dann in 2xSSC, $50 \%(\mathrm{v} / \mathrm{v})$ deionisiertes Formamid, 0,14\% (v/v) $\beta$-Mercaptoethanol bei $60^{\circ} \mathrm{C}$ für 20min unter leichtem Schütteln gewaschen.

Während dieser Waschschritte sollten die Deckgläschen abfallen. Anschließend wurden die Objektträger bei $37^{\circ} \mathrm{C}$ zuerst zweimal für 5min in NTE-Puffer, dann für 30min in NTE-Puffer dem zusätzlich RNaseA zu einer EK von $20 \mu \mathrm{g} / \mathrm{ml}$ zugesetzt wurde, und für 30min wieder in NTE-Puffer gewaschen.

Anschließend wurde erneut $20 \mathrm{~min}$ bei $60^{\circ} \mathrm{C}$ in $2 x \mathrm{xSC}, 50 \%$ (v/v) deionisiertem Formamid, 0,14\% (v/v) b-Mercaptoethanol gewaschen, dann 30min bei $60^{\circ} \mathrm{C}$ in $2 \mathrm{xSSC}$ und $30 \mathrm{~min}$ bei $60^{\circ} \mathrm{C}$ in $0,1 \mathrm{xSSC}$.

Während dieser stringenten Waschschritte werden einerseits durch die hohe Temperatur und andereseits durch die absinkende Salzkonzentration unspezifische Hybride abgelöst, so daß schließlich nur die spezifischen RNA-RNA-Hybride zwischen der Sonde und der endogenen mRNA erhalten bleiben.

Die Schnitte wurden anschließend in einer Reihe steigender EtOH-Konzentrationen (30\%, 50\%, 70\%, 80\%, 90\%, 95\%, 100\%) dehydriert. Um die Stärke des Signals und den Ausmaß des unspezifischen Hintergrunds beurteilen zu können, sowie um einen ersten Eindruck über 
das Expressionsmuster des untersuchten Gens zu bekommen, wurde ein Film auf die Schnitte aufgelegegt und ÜN exponiert.

Exponieren, Entwickeln und Färben

Die Objektträger wurden in völliger Dunkelheit nacheinander in 10ml einer 1:1 Lösung aus Kodak NTB-2 Flüssigfilm und Wasser getaucht, die zuvor in einem $42^{\circ} \mathrm{C}$-Wasserbad vorgewärmt und in einer ebenfalls vorgewärmten „dipping”-Küvette überführt wurden. Sie wurden dann in eine dunkle Kammer gestellt und getrocknet. Anschließend wurden sie wieder in völliger Dunkelheit aus der Kammer entnommen, in eine Plastikbox übertragen die mit Klebeband versiegelt und mit Alufolie eingehüllt wurde. Die Objektträger wurden so bei $4^{\circ} \mathrm{C}$ im Dunkeln ca.7-12, in der Regel 10 Tage exponiert.

Entwicklung

Die verwendeten Lösungen wurden zuvor auf eine Temperatur von $18^{\circ} \mathrm{C}$ abgekühlt und es wurde in völliger Dunkelheit gearbeitet. Die Objektträger wurden zunächst 3min in einer 16\%ige (w/v) Kodak D-19 Entwickler-Lösung entwickelt, in einer 1\%igen (v/v) Essigsäurelösung für 1min inkubiert, in einer 30\%igen (w/v) Natriumthiosulfat-Lösung für 3 min fixiert und mehrmals, nun bei Licht, mit $\mathrm{H} 2 \mathrm{O}$ gewaschen.

Färben

Um Gewebe- und Zellstrukturen auf dem Schnitt erkennbar zu machen, wurden die Objektträger im Anschluß 30min lang in Giemsa-Färbelösung inkubiert. Überflüssige Färbelösung wurde durch Spülen mit Leitungswasser entfernt. Die Objektträger wurden dann luftgetrocknet und mit einem, mit Einschlußmittel (Eukitt) beschichteten, Deckgläschen luftblasenfrei eingedekkelt. Photographien wurden mit einem Zeiss Axiophot im Hell- und Dunkelfeld gemacht.

\subsubsection{Chromosomale Kartierung mittels Fluoreszenz in situ-Hybridisierung (FISH) (Heng et al., 1992, Heng and Tsui, 1993)}

Die Methode der FISH wurde von der Firma „SeeDNA“ (Ontario) angewandt um die chromosomale Lokalisation des mapl-1-Gens zu ermitteln. Dazu, diente ein 14kb langes genomisches Fragment das das erste Exon des Gens umfasst als Sonde verwendet. Die Sonde wurde mit biotiniliertem dATP markiert und zur Hybridisierung mit Mauschromosomen inkubiert. Das Hybridisierungssignal wurde anhand von emitierter Fluoreszenz detektiert. Die 
Identifizierung der Chromosomen erfolgte anhand der Bänderung die nach der Färbung des Chromatins mit DAPI entsteht. Um das Gen genauer auf das Chromosom zu lokalisieren wurde das Mittel aus 10 Aufnahmen berücksichtigt. 


\section{Zusammenfassung}

Pax-Proteine spielen eine Schlüsselrolle bei der Spezifizierung und Differenzierung von Zelltypen während der Embryonalentwicklung. Trotz der ähnlichen Struktur und DNABindungsmodus der für alle Pax-Proteine charakteristische Paired-Domäne sind sie in der Lage, verschiedene genetische Programme während der Entwicklung zu steuern. Im Rahmen dieser Arbeit wurde ein neues Protein charakterisiert, ,MAP-like 1“ (Mapl-1), das als Interaktionspartner von Pax-6, dem „master control protein“ der Augenentwicklung, identifiziert wurde. Die Analyse des Expressionsmusters von mapl-1 ergab einen hohen Grad an Überlappung mit der Pax-6-Expression, insbesondere während der frühen Entwicklungsstadien. Ähnlich wie Pax-6 ist mapl-1 auch bei anderen Spezies konserviert und stellt das erste Mitglied einer neuen Protein-Familie dar. Bei der Wechselwirkung zwischen Pax-6 und Mapl-1 konnte zum ersten Mal die aminoterminale (PAI) Untereinheit der Pax-6-Paired-Domäne als Protein-Protein-Interaktionsmotiv identifiziert werden. Eine zweite in dieser Arbeit untersuchte Eigenschaft von Mapl-1 ist seine Fähigkeit spezifisch mit den zellulären Mikrotubuli zu interagieren und entscheidend ihren dynamischen Polymerisationszustand $\mathrm{zu}$ beeinflussen. Diese Fähigkeit von Mapl-1 sowie die Anwesenheit einer „bona fide“ Mikrotubuli-bindenden Domäne im Carboxyterminus des Proteins etablieren Mapl-1 als ein neues Mikrotubuli-assoziiertes Protein (MAP). Es konnte gezeigt werden, daß Mapl-1 in der Lage ist eine partielle Retention von Pax-6 außerhalb des Zellkerns an den Mikrotubuli hervorzurufen. Weiterhin kann Mapl-1 in den Zellkern transportiert werden und besitzt zusätzlich transkriptionsaktivierende Eigenschaften. Diese Eigenschften des Proteins in Verbindung mit seiner potentiellen Rolle als Pax-6-Inhibitor auf der Ebene der DNA-Sequenzerkennung durch die PairedDomäne, liefern neue Einblicke in der Regulation der Funktion oder/und der Dosis von Pax-Proteinen. Die vorliegende Arbeit stellt zum ersten Mal eine Verbindung zwischen dem Cytoskelett und der Regulation der Aktivität der Pax-Proteinen her. 


\section{Literaturverzeichnis}

Alber, T (1992). Structure of the Leucine zipper. Curr. Opin. Genet. Dev. 2, 205-210.

Altschul, S. F., Gish, W., Miller, W., Myers, E. W. and DJ., L. (1990). Basic local alignment search tool. J Mol Biol 215, 403-410.

Andersen, S. S., Buendia, B., Dominguez, J. E., Sawyer, A. and Karsenti, E. (1994).

Effect on microtubule dynamics of XMAP230, a microtubule-associated protein present in Xenopus laevis eggs and dividing cells. J. Cell Biol. 127, 1289-1299.

Ashery-Padan, R., Marquardt, T., Zhou, X. and Gruss, P. (2000). Pax6 activity in the lens primordium is required for lens formation and for correct placement of a single retina in the eye. Genes Dev. 14, 2701-2711.

Auerbach, R. (1954). Analysis of the developmental effects of a lethal mutation in the house mouse. J. Exp. Zool. 127, 305-329.

Ausubel, F. M., Brent, R., Kingston, R. E., Moore, D. D., Seidman, J. G., Smith, J. A. and Struhl, K. (1987). "Current protocolls in molecular biology." John Wiley \& Sons, New York.

Aza-Blanc, P., Ramirez-Weber, F. A, Laget, M. P., Schwartz, C. and Kornberg, T. B. (1997). Proteolysis that is inhibited by hedgehog targets Cubitus interruptus protein to the nucleus and converts it to a repressor. Cell 89, 1043-1053.

Baas, D., Bumsted, K. M., Martinez, J. A., Vaccarino, F. M., Wikler, K. C. and Barnstable, C. J. (2000). The subcellular localization of OTX2 is cell-type specific and developmentally regulated in the mouse retina. Mol. Brain Res. 78, 26-37.

Baldwin, C. T., Hoth, C. F., Amos, J. A., da-Silva, E. O. and Milunski, A. (1992). An exonic mutation in the HuP2 paired domain gene causes Waardenburg's syndrome. Nature 355, 637-638.

Balling, R., Deutsch, U. and Gruss P. (1988). Undulated, a mutation affecting the development of the mouse skeleton, has a point mutation in the paired box of Pax-1. Cell $\mathbf{5 5 , 5 3 1 - 5 3 5 . ~}$ 
Bateman, A., Birney, E., Durbin, R., Eddy, S. R., Howe, K. L. and Sonnhammer, E. L. (2000). The Pfam Protein Families Database. Nucl. Acids Res. 28, 263-266.

Baxevanis, A. D. and Vinson, C. R. (1993). Interactions of coiled coils in transcription factors: where is the specificity? Curr. Opin. Genet. Dev. 3, 278-285.

Belmont, L. D. and Mitchison, T. J. (1996). Identification of a protein that interacts with tubulin dimers abd increases the catastrophe rate of microtubules. Cell 84, 623-631.

Bertuccioli, C., Fasano, L., Jun, S., Wang, S., Sheng, G. and Desplan, C. (1996). In vivo requirement for the paired domain and homeodomain of the paired segmentation gene product. Development 122, 2673-2685.

Billeter, M., Quian, Y.-Q., Otting, G., Müller, M., Gehring, W. J. and Wüthrich, K. (1990). Determination of the three-dimensional structure of the Antennapedia homeodomain from Drosophila in solution by ${ }^{1} \mathrm{H}$ nuclear magnetic resonance spectroscopy. J. Mol. Biol. 214, 183-197.

Birnboim, H. C. and Doly, J. (1979). A rapid alkaline extraction procedure for screening recombinant plasmid DNA. Nucleic Acids Res. 7, 1512-1523.

Bishop, K. M., Goudreau, G.,and O'Leary, D. D. (2000). Regulation of area identity in the mammalian neocortex by Emx2 and Pax6. Science 288, 344-349.

Blake, M. S., Johnston, K. H., Russel-Jones, G. J. and Gotschlich, E. C. (1984). A rapid sensitive method for detection of alkaline phosphatase-conjugated anti-antibody on western blots. Anal. Biochem 136, 175-179.

Bopp, D., Burri, M., Baumgartner, S., Frigerio, G. and Noll, M. (1986). Conservation of a large protein domain in the segmentation gene paired and in functionally related genes of Drosophila. Cell 47, 1033-1040.

Bopp, D., Jamet, E., Baumgartner, S., Burri, M. and Noll, M. (1989). Isolation of two tissue-specific Drosophila paired box genes, Pox meso and Pox neuro. EMBO J. 8, 3447 3457.

Briscoe, J., Pierani, A., Jessel, T. M. and Ericson, J. (2000). A homeodomain protein code specifies progenitor cell identity and neuronal fate in the ventral neural tube. Cell 101, 435-445.

Bulinsky, J. C. and Gundersen, G. G. (1991). Stabilization and post-translational modification of microtubules during cellular morphogenesis. BioEssays 13, 285-293. 
Capecchi, M. R. (1989). Altering the mouse genome by homologous recombination. Science 244, 1288-1292.

Carninci, P. a. H., Y. (1999). High-efficiency full-length cDNA cloning. Methods in enzymology 303, 19-44.

Chalepakis, G., Fritsch, R., Fickenscher, H., Deutsch, U., Goulding, M. and Gruss, P. (1991). The molecular basis of the undulated/Pax-1 mutation. Cell 66, 873-884.

Chalepakis, G., Jones, F. S., Edelman, G. M. and Gruss, P. (1994). Pax-3 contains domains for transcription activation and transcription inhibition. Proc. Natl. Acad. Sci. USA 91, 12745-12749.

Chalepakis, G., Stoykova, A., Wijnholds, J., Tremblay, P. and Gruss, P. (1993). Pax: Gene regulators in the developing nervous system. J. Neurobiol. 24, 1367-1384.

Chapin, S. J., and Bulinsky J. C. (1992). Microtubule stabilization by assemblypromoting microtubule-associated proteins: a repeat performance. Cell Motil. Cytoskeleton 23, 236-243.

Chen, Y., Gallaher, N., Goodman, R. H. and Smolik, S. M. (1998). Protein kinase A directly regulates the activity and proteolysis of cubitus interruptus. Proc. Natl. Acad. Sci. USA 95, 2349-2354

Chow, R. L., Altmann, C. R., Lang, R. A. and Hemmati-Brivanlou, A. (1999). Pax6 induces ectopic eyes in a vertebrate. Development 126, 4213-4222.

Collinson, J. M., Quinn, J. C., Buchanan, M. A., Kaufman, M. H., Wedden, S. E., West, J. D., and Hill, R. E. (2001). Primary defects in the lens underlie complex anterior segment abnormalities of the Pax6 heterozygous eye. Proc. Natl. Acad. Sci. USA 98, 96889693.

Conway, S. J., Henderson, D. J. and Copp, A. J. (1997a). Pax3 is required for cardiac neural crest migration in the mouse: evidence from the splotch $(\mathrm{Sp} 2 \mathrm{H})$ mutant. Development 124, 505-514.

Conway, S. J., Henderson, D. J., Kirby, M. L., Anderson, R. H. and Copp, A. J. (1997b). Development of a lethal congenital heart defect in the splotch (Pax3) mutant mouse. Cardiovasc. Res. 36, 163-173.

Copeland, J. W. R., Nasiadka, A., Dietrich, B. H. and Krause, H. M. (1996). Patterning of the Drosophila embryo by a homeodomain deleted Ftz polypeptide. Nature 379, 162165. 
Cvekl, A., Kashanchi, F., Brady, J. N. and Piatigorsky, J. (1999). Pax-6 interactions with TATA-box-binding protein and retinoblastoma protein. Invest. Opthalmol. Vis. Sci. 40, 1343-1350.

Cvekl, A. and Piatigorsky, J. (1996). Lens development and crystallin gene expression: many roles for Pax-6. Bioessays 18, 621-630.

Czerny, T., Halder, G., Kloter, U., Souabni, A., Gehring, W. J. and Busslinger, M. (1999). Twin of eyeless, a second Pax-6 gene of Drosophila, acts upstream of eyeless in the control of eye development. Mol. Cell 3, 297-307.

Czerny, T., Schaffner, G. and Busslinger, M. (1993). DNA sequence recognition by Pax proteins: bipartite structure of the paired domain and its binding site. Genes Dev. 7, 20482061.

Czerny, T. and Busslinger, M. (1995). DNA- binding and transactivation properties of Pax-6: three amino acids in the paired domain are responsible for the different sequence recognition of Pax-6 and BSAP (Pax-5). Mol. Cell. Biol. 15, 2858-2871.

Dahl, E., Koseki, H. and Balling, R. (1997). Pax genes and organogenesis. BioEssays 19, 755-765.

Derynck, R., Zhang, Y. and Feng, X. H. (1998). Smads: transcriptional activators of TGF-beta responses. Cell 95, 737-740.

Dobyns, W. B., Reiner, O., Carozzo, R. and Ledbetter, D. H. (1993). Lissencephaly: a human brain malformation associated with deletion of the LIS1 gene located at chromosome 17p13. JAMA 23, 2838-2842.

Dong, C., Li, Z., Alvarez, R. Jr., Feng, X.-H. and Goldschmidt-Clermont, P. J. (2000). Microtubule Binding to Smads May Regulate TGF $\beta$ Activity. Mol. Cell 5, 27-34.

Dower, W. J., Miller, J. F. and Ragsdale, C. W. (1988). High efficiency transformation of E.coli by high voltage electroporation. Nucleic Acids Res. 16, 6127.

Duboule, D. (1994). "Guidebook to the Homeobox genes." Oxford University Press, Oxford.

Duncan, M. K., Haynes, J. I. 2nd., Cvekl, A., and Piatigorski, J. (1998). Dual roles for Pax-6: a transcriptional repressor of lens fiber cell-specific beta-crystallin genes. Mol. Cell. Biol. 18, 5579-5586.

Eberhard, D. and Busslinger, M. (1999). The partial homeodomain of the transcription factor Pax-5 (BSAP) is an interaction motif for the retinoblastoma and TATA-binding proteins. Cancer Res. 59(7Suppl), 1716S-1724S. 
Eberhard, D., Jimenez, G., Heavey, B. and Busslinger, M. (2000). Transcriptional repression by Pax5 (BSAP) through interaction with corepressors of the Goucho family. EMBO J. 19, 2292-2303.

Eccles, M. R. and Schimmenti, L. A. (1999). Renal-coloboma syndrome: a multi-system developmental disorder caused by PAX2 mutations. Clin. Genet. 56, 1-9.

Epstein, D. J., Vekemans, M. and Gros, P. (1991). splotch $\left(S p^{2 H}\right)$, a mutation affecting development of the mouse neural tube, shows a deletion within the paired homeodomain of Pax-3. Cell 67, 767-774.

Epstein, J. A., Glaser, T., Cai, J., Jepeal, L., Walton, D. S. and Maas, R. L. (1994a). Two independent and interactive DNA-binding subdomains of the Pax6 paired domain are regulated by alternative splicing. Genes Dev. 8, 2022-2034.

Epstein, J., Cai, J., Glaser, T., Jepeal, L. and Maas, R. (1994b). Identification of a Pax Paired Domain Recognition Sequence and Evidence for DNA-dependent Conformational Changes. J. Biol. Chem 269, 8355-8361.

Ericson, J., Rashbass, P., Schedl, A., Brenner-Morton, S., Kawakami, A., van Heyningen V., Jessel, T. M. and Briscoe, J. (1997). Pax6 controls progenitor cell identity and neuronal fate in response to graded Shh signaling. Cell 90, 169-180.

Favor, J., Sandulache, R., Neuhauser-Klaus, A., Pretsch, W., Chatterjee, B., Senft, E., Wurst, W., Blanquet, V., Grimes, P., Sporle, R. and Shughart, K. (1996). The mouse $\operatorname{Pax} 2(1 \mathrm{Neu})$ mutation is identical to a human Pax2 mutation in a family with renalcoloboma syndrome and results in developmental defects of the brain, ear, eye and kidney. Proc. Natl. Acad. Sci. USA 93, 13870-13875.

Feinberg, A. P. and Vogelstein, B. (1983). A technique for radiolabeling DNA restriction endonuclease fragments to high specific activity. Anal. Biochem. 132, 6-13.

Fitzsimmons, D., Hodsdon, W., Wheat, W., Maira, S.-M., Wasylyk, B. and Hagman, J. (1996). Pax-5 (BSAP) recruits Ets proto-oncogene family proteins to form functional ternary complexes on a B-cell-specific promoter. Genes \& Dev. 10, 2198-2211.

Franz, T., Kothary, R., Surani, M. A. H. and Grim, M. (1993). The Splotch mutation interferes with muscle development in the limbs. Anat. Embryol. 187, 153-160.

Fujiwara, M., Uchida, T., Osumi-Yamashita, N. and Eto, K. (1994). Uchida rat ( $r S e y)$ : a new mutant rat with craniofacial abnormalities resembling those of the mouse Sey mutant. Differentiation 57, 31-38. 
Fukuda, M., Asano, S., Nakamura, T., Adachi, M., Yoshida, M., Yanagida, M. and Nishida, E. (1997). CRM-1 is responsible for intracellular transport mediated by the nuclear export signal. Nature 390, 308-311.

Gard, D. and Kirschner, M. (1987). A microtubule-associated protein from Xenopus eggs that specifically promotes assembly at the plus end. J. Cell Biol. 105, 2203-2215.

Gehring, W. J. and Ikeo, K. (1999). Pax6: mastering eye morphogenesis and eye evolution. Trends Genet. 15, 371-377.

Glardon, S., Callaerts, P., Halder, G. and Gehring, W. J. (1997). Conservation of Pax-6 in a lower chordate, the ascidian Phallusia mammilata. Development 124, 817-825.

Glaser, T., Jepeal, L., Edwards, J. G., Young, S. R., Favor, J. and Maas, R. L. (1994). PAX6 gene dosage effect in a family with congenital cataracts, aniridia, anophthalamia and central nervous system defects. Nature Genet. 7, 463-471.

Glaser, T., Walton, D. S. and Maas, R. L. (1992). Genomic structure, evolutionary conservation and aniridia mutations in the human PAX6 gene. Nature Genet. 2, 232-239.

Gleeson, J. G., Lin, P. T., Flanagan, L. A. and Walsh, C. A. (1999). Doublecortin is a microtubule-assoiated protein and is expressed widely by migrating neurons. Neuron 23, 257-271.

Goldstein, S. B. L. and Yang, Z. (2000). Microtubule-based Transport systems in Neurons: The Roles of Kinesins and Dyneins. Annu. Rev. Neurosci. 23, 39-71.

Goulding, M. D., Lumsden, A.,and Gruss, P. (1993). Signals from the notochord and floor plate regulate the region-specific expression of two Pax genes in the developing spinal cord. Development 117, 1001-1016.

Groger, H., Callaerts, P., Gehring, W. J. and Schmid, V. (2000). Characterization and expression analysis of an ancestor-type Pax gene in the hydrozoan jellyfish Podocoryne carnea. Mech. Dev. 94, 157-169.

Halder, G., Callaerts, P. and Gehring, W. J. (1995). Induction of ectopic eyes by targeted expression of the eyeless gene in Drosophila. Science 267, 1788-1792.

Hanahan, D. (1983). Studies on transformation of Escherichia coli with plasmids. J. Mol. Biol. 166, 557.

Heldin, C. H., Miyazono, K. and ten Dijke, P. (1997). TGF-beta signaling from cell mambrane to nucleus through SMAD proteins. Nature 390, 465-471. 
Henderson, B. R. and Eleftheriou, A. (2000). A comparison of the activity, sequence specificity and CRM-1 dependence of different nuclear export signals. Exp. Cell Res. 256, 213-224.

Heng, H. H. Q., Squire, J. and Tsui, L. C. (1992). High resolution mapping of mammalian genes by in situ hybridisation to free chromatin. Proc. Natl. Acad. Sci. 89, 9509-9513.

Heng, H. Q. Q. and Tsui, L. C. (1993). Modes of DAPI banding and simultaneous in situ hybridisation. Chromosoma 102, 325-332

Hill, R. E., Favor, J., Hogan, B. L. M., Ton, C. C. T., Saunders, G. F., Hanson, I. M., Prosser, J., Jordan, T., Hastie, N. D. and van Heyningen, V. (1991). Mouse Small eye results from mutations in a paired-like homeobox-containing gene. Nature 354, 522-525.

Hirokawa, N. (1994). Microtubule organization and dynamics dependent on microtubuleassociated proteins. Curr. Opin. Cell Biol. 6, 74-81.

Hittner, H. M. (1989). Aniridia. In "The glaucomas" (R. Rich, M. B. Shields, and T. Krupin, Eds.), pp. 869-884. Mosby, St. Louis.

Hogan, B. L. M., Constantini, F. and Lacy, E. (1986). "Manipulating the mouse embryo: A laboratory manual.” Cold Spring Harbor Laboratory, New York.

Hollenbach, A. D., Sublett, J. E., McPherson, C. J. and Grosveld, G. (1999). The Pax3FKHR oncoprotein is unresponsive to the Pax3-associcated repressor hDaxx. EMBO J. 18, $3702-3711$.

Holmes, D. S. and Quigley, M. (1981). A rapid boiling method for the preparation of bacterial plasmids. Anal. Biochem. 114, 193.

Hoshiyama, D., Suga, H., Iwabe, N., Koyanagi, M., Nikoh, N., Kuma, K., Matsuda, F., Honjo, T. and Miyata, T. (1998). Sponge Pax cDNA related to Pax-2/5/8 and ancient gene duplication in the Pax family. J. Mol. Evol. 47, 640-648.

Hurst, H. C. (1995). Transcription factors 1: bZip proteins. Protein Profile 2, 101-168.

Hussain, M. A. and Habener, J. F. (1999). Glucagon gene transcription activation mediated by synergistic interactions of Pax-6 and cdx-2 with the p300 co-activator. J. Biol. Chem. 274, $28950-28957$.

Itasaki, N., Bel-Vialar, S. and Krumlauf, R. (1999). Shocking developments in chick embryology: Electroporation and in ovo gene expression. Nat. Cell Biol. 1, E203-E207. 
Jordan, T., Hanson, I., Zaletayev, D., Hodgson, S., Prosser, J., Seawright, A., Hastie, N. and van Heyningen, V. (1992). The human PAX6 gene is mutated in two patients with aniridia. Nature Genet. 1, 328-332.

Jun, S. and Desplan, C. (1996). Cooperative interactions between paired domain and homeodomain. Development 122, 2639-2650.

Jun, S., Wallen, V. R., Goriely, A., Kalionis, B. and Desplan, C. (1998). Lune/eye gone, a Pax-like protein, uses a partial paired domain and a homeodomain for DNA recognition. Proc. Natl. Acad. Sci. USA 95, 13720-13725.

Kamachi, Y., Uchikawa, M., Tanouchi, A., Sekido, R. and Kondoh, H. (2001). Pax6 and Sox 2 form a co-DNA-binding partner complex that regulates initiation of lens development. Genes Dev. 15, 1272-1286.

Kammandel, B., Chowdhury, K., Stoykova, A., Aparicio, S., Brenner, S. and Gruss, P. (1999). Distinct cis-essential modules direct the time-space pattern of the Pax6 gene activity. Dev. Biol. 205, 79-97.

Kaufman, T. C., Lewis, R. and Wakimoto, B. (1980). Cytogenetic analysis of chromosome 3 in Drosophila melanogaster: The homeotic gene complex in polytene chromosome interval 84A-B. Genetics 94, 115-133.

Khawaja, S., Gundersen, G. G. and Bulinsky, J. (1988). Enhanced stability of microtubules enriched in detyrosinated tubulin is not a direct function of of detyrosination level. J. Cell Biol. 106, 141-149.

Kirschner, M. and Mitchison, T. (1986). Beyond self-assembly: from microtubules to morphogenesis. Cell 45, 329-342.

Kissinger, C. R., Liu, B., Martin-Bianco, E., Kornberg, T. B. and Pabo, C. O. (1990). Crystal structure of an engrailed homeodomain-DNA complex at 2.8 A resolution: a framework for understanding homeodomain-DNA interactions. Cell 63, 579-590.

Klemm, J. D., Rould, M. A., Aurora, R., Herr, W. and Pabo, C. O. (1994). Crystal structure of the Oct-1 POU domain bound to an octamer Site: DNA recognition with tethered DNA-binding modules. Cell 77, 21-32.

Kozak, M. (1986). Bifunctional messenger RNAs in eucaryotes. Cell 44, 283-292.

Kozmik, Z., Czerny, T. and Busslinger, M. (1997). Alternatively spliced insertions in the paired domain restrict the DNA sequence specificity of Pax6 and Pax8. EMBO J. 16, 67936803. 
Kudo, N., Khochbin, S., Nishi, K., Kitano, K., Yanagida, M., Yoshida, M. and Horinouchi, S. (1997). Molecular cloning and cell cycle-dependent expression of mammalian CRM-1, a protein involved in nuclear export of proteins. J. Biol. Chem. 272, 29742-29751.

Laemmli, E. K. (1970). Cleavage of structural proteins during the assembly of the head of bacteriophage T4. Nature 227, 680-685.

Laughon, A. and Scott, M. P. (1984). Sequence of a Drosophila segmentation gene: Protein structure homology with DNA-binding proteins. Nature 310, 25-31.

Leventer, R. J., Cardoso, C., Ledbetter, D. H. and Dobyns, W. B. (2001). LIS1: from cortical malformation to essential protein of cellular dynamics. TINS 24, 489-492.

Lewis, E. B. (1978). A gene complex controlling segmentation in Drosophila. Nature 276, $565-570$.

Macchia, P. E., Lapi, P., Krude, H., Pirro, M. T., Missero, C., Chiovato, L., Souabni, A., Baserga, M., Tassi, V., Pinchera, A., Fenzi, G., Gruters, A., Busslinger, M. and Di Lauro, R. (1998). Pax 8 mutations associated with congenital hypothyroidism caused by thyroid dysgenesis. Nat. Genet. 19, 83-86.

Magnaghi, P., Roberts, C., Lorain, S., Lipinski, M. and Scambler, P. J. (1998). HIRA, a mammalian homologue of Saccharomyces cerevisiae transcriptional co-repressors, interacts with Pax3. Nat. Genet. 20, 74-77.

Mansouri, A., Chowdhury, K. and Gruss, P. (1998). Follicular cells of the thyroid gland require Pax8 gene function. Nat. Genet. 19, 87-90.

Mansouri, A., Goudreau, G. and Gruss, P. (1999). Pax genes and their role in organogenesis. Cancer Res. 59, 1707-1709.

Mansouri, A., Stoykova, A., Torres, M. and Gruss, P. (1996). Dysgenesis of cephalic neural crest derivatives in $\operatorname{Pax} 7^{-/-}$mutant mice. .

Matsunaga, E., Araki, I. and Nakamura, H. (2000). Pax6 defines the di- mesencephalic boundary by repressing En1 and Pax2. Development 127, 2357-2365.

Matsuo, T., Osumi-Yamashita, N., Noji, S., Ohuchi, H., Koyama, E., Myokai, F., Matsuo, N., Taniguchi, S., Doi, H., Ninomiya, Y., Fujiwara, M., Watanabe, T. and Eto, K. (1993). A mutation in the Pax-6 gene in rat small eye is associated with impaired migration of midbrain crest cells. Nature Genet. 3, 299-304. 
McGinnis, W., Levine, M. S., Hafen, E., Kuroiwa, A. and Gehring, W. J. (1984). A conserved DNA sequence in homoeotic genes of the Drosophila antennapedia and bithorax complexes. Nature 308, 428-433.

Mikkola, I., Bruun, J.-A., Bjorkoy, G., Holm, T. and Johansen, T. (1999). Phosphorylation of the Transactivation Domain of Pax6 by Extracellular Signal-regulated Kinase and p38 Mitogen-activated Protein Kinase. J. Biol. Chem. 274, 15115-15126.

Mikkola, I., Bruun, J.-A., Holm, T. and Johansen, T. (2001). Superactivation of Pax6mediated Transactivation from Paired Domin-binding Sites by DNA-independent Recruitment of Different Homeodomain Proteins. J. Biol. Chem. 276, 4109-4118.

Miller, D. J., Hayward, D. C., Reece-Hoyes, J. S., Scholten, I., Catmull, J., Gehring, W., Callaerts, P., Larsen, J. E. and Ball, E. E. (2000). Pax gene diversity in the basal cnidarian Acropora millepora (Cnidaria, Anthozoa): implications for the evolution of the Pax gene family. Proc. Natl. Acad. Sci. USA 97, 4475-4480.

Miskiewicz, P., Morissey, D., Lan, Y., Raj, L., Kessler, S., Fujoka, M., Goto, T. and Weir, M. (1996). Both the paired domain and homeodomain are required for in vivo function of Drosophila paired. Development 122, 2709-2718.

Mullis, K. B. and Faloona, F. A. (1987). Specific synthesis of DNA in vitro-a polymerase chain reaction. Meth.Enzymol, 335-350.

Muramatsu, T., Mitzutani, Y. and Okumura, J. (1996). Live detection of the firefly luciferase gene expression by bioluminescence in incubating chicken embryos. Ann. Sci. Technol. 67, 906-909.

Nagase, T., Ishikawa, K., Suyama, M., Kikuno, R., Hirosawa, M., Miyajima, N., Tanaka, A., Kotani, H., Nomura, N. and Ohara, O. (1998a). Prediction of the coding sequences of unidentified human genes. XII. The complete sequences of 100 new cDNA clones from brain which code for large proteins in vitro. DNA Res. 5, 355-364.

Nagase, T., Ishikawa, K., Suyama, M., Kikuno, R., Miyajima, N., Tanaka, A., Kotani, H., Nomura, N. and Ohara, O. (1998b). Prediction of the coding sequences of unidentified human genes. XI. The complete sequences of 100 new cDNA clones from brain which code for large proteins in vitro. DNA Res. 5, 277-286.

Nakai, K. and Kanehisa, M. (1992). A knowledge base for predicting protein localization sites in eukaryotic cells. Genomics $\mathbf{1 4}$, 897-911. 
Nelson, L. B., Spaeth, G. L., Nowinski, T. S., Margo, C. E. and Jackson, L. (1984). Aniridia. A review. Surv. Ophthalmol. 28, 621-642.

Nornes, S., Clarkson, M., Mikkola, I., Pedersen, M., Bardsley, A., Martinez, J. P., Krauss, S. and Johansen, T. (1998). Zebrafish contains two pax6 genes involved in eye development. Mech. Dev. 77, 185-196.

Norton, J. D. (2000). Id helix-loop-helix in cell growth, differentiation and tumourigenesis. J. Cell. Sci. 113(Pt.2), 3897-3905.

Norton, J. D., Deed, R. W., Craggs, G. and Sablitzky, F. (1998). Id helix-loop-helix proteins in cell growth and differentiation. Trends Cell Biol. 8, 58-65.

Nüsslein-Volhard, C. and Wieschaus, E. (1980). Mutations affecting segment number and polarity in Drosophila. Nature 287, 795-801.

Otting, G., Quian, Y. Q., Müller, M., Affolter, M., Gehring, W. and Wüthrich, K. (1988). Secondary structure determination of the Antennapedia homeodomain by nuclear magnetic resonance and evidence for a helix-turn-helix motif. EMBO J. 7, 4305-4309.

Pabo, C. O. and Sauer, R. T. (1984). Protein-DNA recognition. Ann. Rev. Biochem. 53, 293-321.

Peters, H., Neubüser, A., Kratochwil, K. and Balling, R. (1998). Pax9 deficient mice lack pharyngeal pouch derivatives and teeth and exhibit craniofacial and limb abnormalities. Genes Dev. 12, 2735-2747.

Petrou, P. (1997). Identifizierung von Proteinen die mit dem Maus-Pax6-Protein interagieren, mittels des Hefe-"Two-hybrid"-Systems. Diplomarbeit, Georg-AugustUniversität Göttingen.

Philips, C. L., Vershon, A. K., D., J. A. and Dahlquist, F. W. (1991). Secondary structure of the homeodomein of yeast $\alpha 2$ repressor determined by NMR spectroscopy. Genes Dev 5, 764-772.

Pineda, D., Gonzalez, J., Callerts, P., Ikeo, K., Gehring, W. J. and Salo, E. (2000). Searching for the prototypic eye genetic network: Sine oculis is essential for eye regeneration in planarians. Proc. Natl. Acad. Sci. USA 97, 4525-4529.

Planque, N., Leconte, L., Conquell, M. F., Martin, P. and Saule, S. (2001a). Specific Pax-6/Microphtalmia Transcription Factor Interactions Involve Their DNA-binding Domains and Inhibit Transcriptional Properties of Both Proteins. J. Biol. Chem. 276, 29330-29337. 
Planque, N., Leconte, L., Coquelle, M. F., Benkhelifa, S., Martin, P., FelderSchmittbuhl, M.-P. and Saule, S. (2001b). Interaction of Maf transcription factors with Pax-6 results in synrgistic activation of the glucagon promoter. J. Biol. Chem. , in press.

Plaza, S., Langlois, M.-C., Turque, N., LeCornet, S., Bailly, M., Bègue, A., Quatannens, B., Dozier, C. and Saule, S. (1997). The Homeobox-containing Engrailed-1 (En-1) Product Down-Regulates the Expression of Pax-6 through a DNA Bindingindependent Mechanism. Cell Growth Differ. 8, 1115-1125.

Proudfoot, N. and Brownlee, G. G. (1976). 3' non-coding region sequences in eukaryotic messenger RNA. Nature 263, 211-214.

Punzo, C., Kurata, S. and Gehring, W. (2001). The eyless homeodomain is dispensable for eye development in Drosophila. Genes Dev. 15, 1716-1723.

Qian, Y. Q., Billeter, M., Otting, G., Müller, M., Gehring, W. J., and Wüthrich, K. (1989). The structure of the Antennapedia homeodomain determined by NMR spectroscopy in solution: comparison with prokaryotic repressors. Cell 59, 573-580.

Qian, Y. Q., Furukubo-Tokunaga, K., Resendez-Perez, D., Müller, M., Gehring, W. J. and Wütrich, K. (1994). Nuclear magnetic resonance solution structure of the Fushi Tarazu homeodomain from Drosophila and comparison with the Antennapedia homeodomain. J Mol Biol 238, 333-345.

Qian, Y. Q., Otting, G., Billeter, M., Müller, M., Gehring, W. and Wütrich, K. (1993). Nuclear magnetic resonance spectroscopy of a DNA complex with the uniformly ${ }^{13} \mathrm{C}$ labeled Antennapedia homeodomain and structure determination of the DNA-bound homeodomain. J Mol Biol 234, 1070-1083.

Quiring, R., Walldorf, U., Kloter, U. and Gehring, W. J. (1994). Homology of the eyeless gene of Drosophila to the Small eye gene in mice and Aniridia in humans. Science 265, 785-789.

Raff, E. C. and Raff, R. A. (1985). Possible functions of the homeobox. Nature 313, 185. Raj, L., Vivekanand, P., Das, T. K., Badam, E., Fernandes, M., Finley, R. L. J., Brent, R., Appel, L. F., Hanes, S. D. and Weir, M. (2000). Targeted localized degradation of Paired protein in Drosophila development. Curr. Biol. 10, 1265-1272.

Read, A. P. and Newton, V. E. (1997). Waardenburg syndrome. J. Med. Genet. 34, 656665. 
Ritz-Laser, B., Estreicher, A., Gauthier, B. and Philippe, J. (2000). The paired homeodomain transcription factor Pax-2 is expressed in the endocrine pancreas and transactivates the glucagon gene promoter. J. Biol. Chem. 275, 32708-32715.

Ritz-Laser, B., Estreicher, A., Klages, N., Saule, S. and Philippe, J. (1999). Pax-6 and Cdx-2/3 Interact to activate Glucagon Gene Expression on the G1 Element. J. Bio. Chem. 274, 4124-4132.

Roberts, E. C., Deed, W. R., Inoue, T., Norton, J. D. and Sharrocks, A. (2001). Id Helix-Loop-Helix Proteins Antagonize Pax Transcription Factor Activity by Inhibiting DNA Binding. Mol. Cell. Biol. 21, 524-533.

Robbins, D. J., Nybakken, K. E., Kobayashi, R., Sisson, J. C. and Bishop, J. M. (1997). Hedgehog elicits signal transduction by means of a large complex containing the kinesin-related protein Costal2. Cell 90, 225-234.

Roth, M. B., Zahler, A. M. and Stolk, J. A. (1991). A coserved family of nuclear phosphoproteins localized to sites of polymerase II transcription. J. Cell Biol. 115, 587596.

Russel, W. L. (1947). Splotch, a new mutation in the house mouse, Mus musculus. Genetics 32, 102.

Russell, P., Carper, D. A. and Kinoshita, J. H. (1978). Synthesis of gamma crystallin by a cloned cell line from Nakano mouse lens. Invest. Opthalmol. Vis. Sci. 17, 568-570.

Sadowski, I. and Ptashne, M. (1990). A vector for expressing GAL4(1-147) fusions in mammalian cells. Nucleic Acids Res. 17, 7539.

Saiki, R.K., Gelfand, D. H., Stoffel, S., Scharf, S. J., Higuchi, R., Horn, G. T., Mullis, K. B. and Erlich, H. A. (1988). Primer directed enzymatic amplification of DNA with a thermostable DNA polymerase. Science. 239, 487-494.

Sánchez, C., Diaz-Nido, J. and Avila, J. (2000). Phophorylation of microtubuleassociated protein 2 (MAP2) and its relevance for the regulation of the neuronal cytoskeleton function. Progr. Neurobiol. 61, 133-168.

Sambroock, J., Fritsch, E. F. and Maniatis, T. (1989). "Molecular Cloning. A Laboratory Manual.” Cold Spring Harbor Laboratory, Cold Spring Harbor.

Sanyanusin, P., Schimmenti, L. A., McNoe, L. A., Ward, T. A., Pierpont, M. E. M., Sullivan, M. J., Dobyns, W. B. and Eccles, M. R. (1995). Mutation of the PAX2 gene in a family with optic nerve colobomas, renal anomalies and vesicoureteral reflux. Nature Genet. 9, 358-363. 
Sapir, T., Elbaum, M. and Reiner, O. (1997). Reduction of microtubule catastrophe events by LIS1, platelet-activating factor acetylhydrolase subunit. EMBO J. 16, 6977-6984. Saxton, W. M., Stemple, D. L., Leslie, R. J., Salmon, E. D., Zavortnik, M. and McIntosh, J. R. (1984). Tubulin dynamics in cultured mammalian cells. J. Cell. Biol. 99, 2175-2186.

Schedl, A., Ross, A., Lee, M., Engelkamp, D., Rashbass, P., van Heyningen, V. and Hastie, N. (1996). Influence of PAX6 Gene Dosage on Development: Overexpression Causes Severe Eye Abnormalities. Cell 86, 71-82.

Schultz, J., Copley, R. R., Doerks, T., Ponting, C. P. and Bork, P. (2000). SMART: a web-based tool for the study of genetically mobile domains. Nucl. Acids Res. 28, 231-234. Schultz, J., Milpetz, F., Bork, P. and Ponting, C. P. (1998). SMART, a simple modular architecture research tool: identification of signaling domains. Proc. Natl. Acad. Sci. USA 95, 5857-5864.

Schulze, E. and Kirschner, M. (1987). Dynamic and stable populations of microtubules in cells. J. Cell Biol. 104, 277-288.

Schwartz, M., Eberhart, J., Mastick, G. S. and Krull, C. E. (2001). Sparking New Frontiers: Using in Vivo Electroporation for Genetic Manipulations. Dev. Biol. 233, 13-21.

Scott, M. P. and Weiner, A. J. (1984). Structural relationships among genes that control development: Sequence homology between the antennapedia, ultrabithorax and fushi tarazu loci of Drosophila. Proc. Natl. Acad. Sci. USA 81, 4115-4119.

Shaw, M. W., Falls, H. F. and Neel, J. V. (1960). Congenital aniridia. Am J. Hum. Genet. $12,389-415$.

Sisson, J. C., Ho, K. S., Suyama, K. and Scott, M. P. (1997). Costal2, a novel kinesinrelated protein in the Hedgehog signaling pathway. Cell 90, 235-245.

Smith, D. B. and Johnson, K.S. (1988). Single-step purification of polypeptides expressed in Escherichia coli as fusions with glutathione S-transferase. Gene 67, 31.

Smith, S. B., Ee, H. C., Conners, J. R. and German, M. S. (1999). Paired-homeodomain transcription factor $\mathrm{Pax} 4$ acts as a transcriptional repressor in early pancreatic development. Mol. Cell. Biol. 19, 8272-8280.

Sosa-Pineda, B., Chowdhury, K., Torres, M., Oliver, G. and Gruss, P. (1997). The Pax4 Gene is essential for differentiation of Insulin-producing beta cells in the mammalian Pancreas. Nature 386, 399-402. 
St-Onge, L., Sosa-Pineda, B., Chowdhury, K., Mansouri, A. and Gruss, P. (1997). Pax6 is required for differentiation of glucagon-producing $\alpha$-cells in mouse pancreas. Nature 387, 406-409.

Stamataki, D., Kastrinaki, M.-C., Baljinder, M. S., Pachnis, V. and Karagogeos, D. (2001). Homeodomain proteins Mox 1 and Mox 2 associate with Pax1 and Pax3 transcription factors. FEBS Letters 499, 274-278.

Stein, S., Fritsch, R., Lemaire, L. and Kessel, M. (1996). Checklist: Vertebrate homeobox genes. Mech. Dev. 55, 91-108.

Stockton, D. W., Das, P., Goldenberg, M., D'Souza, R. N. and Patel, P. I. (2000). Mutation of $\operatorname{Pax} 9$ is associated with oligodontia. Nat. Genet. 24, 18-19.

Stoykova, A. and Gruss, P. (1994). Roles of Pax-genes in developing and adult brain as suggested by expression patterns. J. Neurosci. 14, 1395-1412.

Stuart, E. T., Haffner, R., Oren, M. and Gruss, P. (1995). Transcriptional regulation of p53 by PAX: implications for development and cancer. EMBO J. 14, 5638-5645.

Studier, F. W. and Moffatt, B. A. (1986). Use of bacteriophage T7 RNA polymerase to direct selective high-level expression of cloned genes. J. Mol. Biol. 189, 113-130.

Sun, H., Rodin, A., Zhou, Y., Dickinson, D. P., Harper, D. E., Hewett-Emmett, D. and Li, W. H. (1997). Evolution of paired domains: isolation and sequencing of jellyfish and hydra Pax genes related to Pax-5 and Pax-6. Proc. Natl. Acad. Sci. USA 94, 5156-5161.

Tassabehji, M., Read, A. P., Newton, V. E., Harris, R., Balling, R., Gruss, P. and Strachan, T. (1992). Waardenburg's syndrome patients have mutations in the human homologue of the Pax-3 paired box gene. Nature 355, 635-636.

Taylor, K. R., Holzer, A. K., Bazan, J. F., Walsh, C. A. and Gleeson, J. G. (2000). Patient mutations in doublecortin define a repeated tubulin-binding domain. J. Biol. Chem. 275, 34442-344450.

The $C$. elegans sequencing consortium (1998). Genome sequence of the nematode $C$. elegans: a platform for investigative biology. Science 282, 2012-2018.

Thompson, J. D., Higgins, D. G., and Gibson, T. J. (1994). CLUSTAL W: improving the sensitivity of progressive multiple sequence alignment through sequence weighting, position-specific gap penalties and weight matrix choice. Nucl. Acids Res. 22, 44673-4680. Tomarev, S. I., Callaerts, P., Kos, L., Zinovieva, R., Halder, G., Gehring, W. and Piatigorsky, J. (1997). Squid Pax-6 and eye development. Proc. Natl. Acad. Sci. USA 94, 2098-2100. 
Torres, M., Gomez-Pardo, E., Dressler, G. R. and Gruss, P. (1995). Pax-2 controls multiple steps of urogenital development. Development , 4057-4065.

Towbin, H., Staehelin, T., and Gordon, J. (1979). Electrophoretic transfer of proteins from polyacrylamide gels to nitrocellulose sheets: procedure and some applications. Proc. Natl. Acad. Sci. USA 76, 4350-4354.

Treisman, J., Harris, E. and Desplan, C. (1991). The paired box encodes a second DNAbinding domain in the Paired homeo domain protein. Genes Dev. 5, 594-604.

Tremblay, P., Kessel, M. and Gruss, P. (1995). A transgenic neuroanatomical marker identifies cranial neural crest deficiencies associated with the Pax3 mutant Splotch. Dev. Biol. 2, 130-136.

Underhill, A. D. (2000). Genetic and biochemical diversity in the Pax gene family. Biochem. Cell Biol. 78, 629-638.

Urbánek, P., Wang, Z.-Q., Fetka, I., Wagner, E. F. and Busslinger, M. (1994). Complete Block of Early B Cell Differentiation and Altered Patterning of the Posterior Midbrain in Mice Lacking Pax5/BSAP. Cell 79, 901-912.

van Raamsdonk, C. D. and Tilghman, S. M. (2000). Dosage requirement and allelic expression of Pax6 during lens placode formation. Development 127, 5439-5448.

Venter, G. et al., (2000). The sequence of the human genome. Science 291, 1304-1351.

Veraksa, A., Del Campo, M. and McGinnis, W. (2000). Developmental Patterning Genes and Their Conserved Functions: From Model Organisms to Humans. Mol. Genet. Metabolism 69, 85-100.

Verde, F., Dogterom, M., Stelzer, E., Karsenti, E. and Leibler, S. (1992). Control of microtubule dynamics and length by cyclin A- and cyclin B- dependent kinases in Xenopus egg extracts. J. Cell Biol. 118, 1097-1108.

Vogan, K. J. and Gros, P. (1997). The C-terminal subdomain makes an important contribution to the DNA binding activity of the Pax-3 paired domain. J. Biol. Chem. 272, 28289-28295.

Vogan, K. J., Underhill, D. A. and Gros, P. (1996). An alternative splicing event in the Pax-3 paired domain identifies the linker region as a key determinant of paired domain DNA-binding activity. Mol. Cell. Biol. 16, 6677-6686.

Vogelstein, B. and Gillespie, D. (1979). Preparative and analytical purification of DNA from agarose. Proc.Natl.Acad.Sci 76, 615-619. 
von Salvini-Plawen, L. and Mayr, E. (1977). On the evolution of photoreceptors and eyes. Evol. Biol. 10, 207-263.

Walker, R. A., O’Brien, E. T., Pryer, N. K., Sobeiro, M. F., Voter, W. A., Erickson, H. P. and Salmon, E. D. (1988). Dynamic instability of individual microtubules analyzed by video light microscopy: rate constants and transition frequencies. J. Cell Biol. 107, 14371448.

Walther, C. and Gruss, P. (1991a). Pax-6, a murine paired box gene, is expressed in the developing CNS. Development 113, 1435-1449.

Walther, C., Guénet, J.-L., Simon, D., Deutsch, U., Jostes, B., Goulding, M., Plachov, D., Balling, R. and Gruss, P. (1991b). Pax: a murine multigene family of paired box containing genes. Genomics 11, 424-434.

Webster, D. R., Wehland, J., Weber, K.,and Borisy, G. G. (1990). Detyrosination of alpha tubulin does not stabilize microtubules in vivo. J. Cell Biol. 111, 113-122.

Wheat, W., Fitzsimmons, D., Lennox, H., Krautkramer, S. R., Gentile, L. N., McIntosh, L. P. and Hagman, J. (1999). The highly conserved beta-hairpin of the paired DNA-binding domain is required for assembly of Pax-Ets ternary complexes. Mol. Cell. Biol. 19, 2231-2241.

Wiche, G. (1998). Role of plectin in cytoskeleton organization and dynamics. J. Cell Sci. 111, 2477-2486.

Wiggan, O., Taniguchi-Sidle, A. and Hamel, P. A. (1998). Interaction of the pRb-family proteins with factors containing paired-like homeodomains. Oncogene 16, 227-236.

Wilkinson, D. G. (1992). "In situ hybridisation; a practical approach.” Oxford University Press, London.

Wille, H., Mandelkow, E. M., Dingus, J., Valle, R. B., Binder, L. I. and Mandelkow, E. (1992a). Domain structure and antiparallel dimers of microtubule-associated protein 2 (MAP2). J. Struct. Biol. 108, 49-61.

Wille, H., Mandelkow, E. M. and Mandelkow, E. (1992b). The juvenile microtubuleassociated protein MAP2c is a rod-like molecule that forms antiparallel dimers. J. Biol. Chem. 267, 10737-10742.

Williams, S. C., Altmann, C. R., Chow, R. L., Hemmati-Brivanlou, A. and Lang, R. A. (1998). A highly conserved lens transcriptional control element from the Pax6 gene. Mech. Dev, 73, 225-229 
Willmer, P. (1990). "Invertebrate Relationships: Patterns in Animal Evolution." Cambridge, UK.

Wolberger, C., Vershon, A. K., Liu, B., Johnson, A. D. and Pabo, C. O. (1991). Crystal structure of a MAT $\alpha 2$ homeodomain-operator complex suggests a general model for homeodomain-DNA interactions. Cell 67, 517-528.

Xu, H. E., Rould, M. A., Xu, W., Epstein, J. A., Maas, R. L. and Pabo, C. O. (1999). Crystal structure of the human Pax6 paired domain-DNA complex reveals specific roles for the linker region and carboxy-terminal subdomain in DNA binding. Genes Dev. 13, 1263-1275.

Xu, W., Rould, M. A., Jun, S., Desplan, C. and Pabo, C. O. (1995). Crystal structure of a paired domain-DNA complex at $2.5 \AA$ resolution reveals structural basis for Pax developmental mutations. Cell 80, 639-650.

Yoneda, Y. (2000). Nucleocytoplasmic protein traffic and its significance to cell function. Genes to Cells 5, 777-787

Zákány, J., and Duboule, D. (1999). Hox genes in digit development and evolution. Cell Tissue Res. 296, 19-25. 


\section{Publikationen}

Voss, A. K, Thomas, T., Petrou, P., Anastassiadis, K., Schöler, H., Gruss, P. (2000). „Taube nuss“ is a novel gene essential for the survival of pluripotent cells of early mouse embryos. Development 127(24): 5449-5461

Thomas, T., Voss, A. K., Petrou, P., Gruss, P.(2000).The murine gene, traube, is essential for the growth of preimplantation embryos. Dev. Biol. 227(2): 324-342

Goudreau, G., Petrou, P., Reneker, L. W., Graw, J., Oliver, G, Gruss, P. Mutually regulated expression of Pax6 and Six3 during murine lens development: Implications for the Pax6 haploinsufficient lens phenotype. (In Vorbereitung).

Petrou, P., Gruss, P. Interaction between Pax6 and Mapl-1, a novel microtubule associated Protein and implications for Pax6-function. (In Vorbereitung). 


\section{Danksagung}

Mein besonderer Dank gilt Herrn Prof. Dr. Gruss für seine langjährige Unterstützung und für die Möglichkeit in seinem Labor promovieren zu dürfen.

Bei Dr. Sigrid Hoyer-Fender bedanke ich mich für die kurzfristige Übernahme der Begutachtung der Arbeit.

Ich bedanke mich bei Dr. Giorgos Chalepakis für die Bereitstellung von Protokollen, regelmäßige Diskussion und nicht zuletzt für Motivation während schwieriger Phasen dieser Arbeit.

Vielen Dank an Prof. Dr. Mary Osborn und Prof. Dr. Klaus Weber nicht nur für die Bereitstellung von Antikörpern sondern auch für die Einführung in die Welt des Cytoskeletts und für regelmäßige Diskussion und Ratschläge.

Für die Verfügungstellung von in dieser Arbeit verwendeten Materialien bedanke ich mich bei Dr. Meinrad Busslinger für das Pax6(5a) Plasmid, Dr. F. Vaccarino für den Otx-2 Antikörper und Dr. Ruth Ashery für den IRES-gfp Plasmid.

Im Labor habe ich Dr. Guy Goudreau zu danken für die Einführung in den Umgang mit Mäusen und für die Bereitstellung von Materialien, Ulli Franke für die Mikroinjektion, Marianne Schuster, Dr, Tanja Vogel und May-Britt Becker für Korrekturen des Textes.

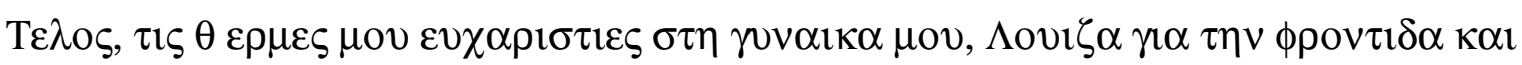

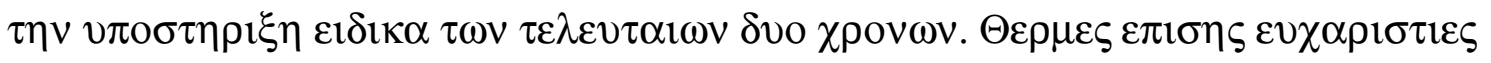

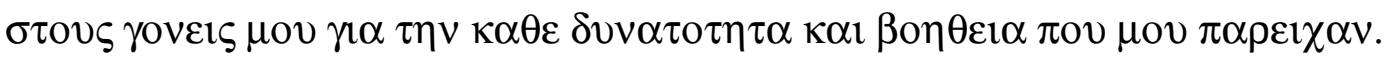




\section{Lebenslauf}

Name: Petrou

Vorname: Petros

Geboren: 02 Mai, 1971

Geburtsort: Famagusta/Zypern

Staatsangehörigkeit: zypriotisch

Familienstand: ledig

1976-1982

1982-1988

Jun. 1988

Jun. 1988-Sep1990

WS 1990/91

WS 1991/92

Okt. 1993

Feb. 1996

Apr. 1996

-Jun. 1997

Aug.1997
Besuch der Grundschule in Larnaka/Zypern

Besuch des Gymnasiums in Larnaka/Zypern

Abschluss des Gymnasiums/Apolyterion

Militärdienst in Zypern

Sprachkurs an der Georg-August-Universität Göttingen

Studium der Biologie an der Georg-August-Universität Göttingen

Vordiplom in den Fächern Molekulare Genetik, Zoologie,

Anorganische Chemie, Physikalische Chemie. Note: „Sehr gut“.

Mündliche Diplomprüfung in den Fächern Molekulare Genetik,

Biochemie, Organische Chemie.

Diplomarbeit am Max-Planck-Institut für Biophysikalische Chemie, in der Abteilung Molekulare Zellbiologie von Prof. Dr. Peter Gruss. Thema: „Identifizierung von Proteinen, die mit dem Maus-Pax6Protein interagieren, mittels des Hefe-,,Two-hybrid“-Systems“ Verleihung des Hochschulgrades „Diplom-Biologe“ an der GeorgAugust-Universität Göttingen. Note: „Sehr gut“. 
Seit Sep. 1997

Doktorarbeit am Max-Planck-Institut für Biophysikalische Chemie, in der Abteilung Molekulare Zellbiologie von Prof. Dr. Peter Gruss. Thema: „Charakterisierung eines neuen Proteins, Mapl-1 und seine Rolle in der Regulation der Pax6-Funktion". 